Nelson Castañeda Ortiz

Phosphorus efficiency of Arachis pintoi genotypes and possible mechanisms for tolerance to low soil $P$ supply

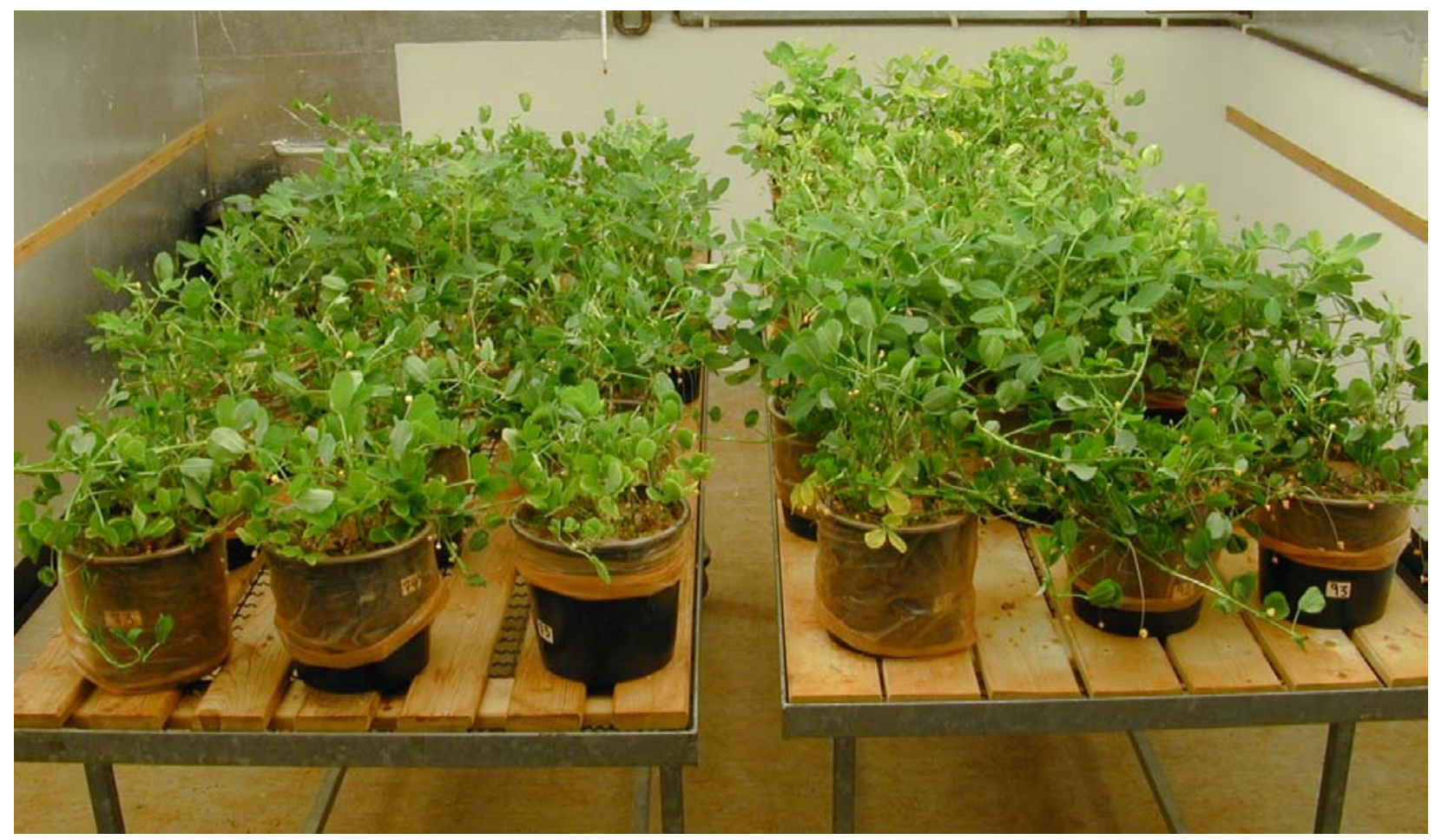




\title{
Phosphorus efficiency of Arachis pintoi genotypes and possible mechanisms for tolerance to low soil $P$ supply
}

\author{
Doctoral Dissertation \\ Submitted for the degree of Doctor of Agricultural Science \\ of the Faculty of Agricultural Science \\ Georg-August-University of Göttingen
}

by

Nelson Castañeda Ortiz

Göttingen, May 2006 
D 7

1st examiner:

Prof. Dr. N. Claassen

$2^{\text {nd }}$ examiner:

Prof. Dr. H. Becker

Day of oral examination:

13th of July 2006 
To my wife Viviane and my sons Daniel and Raphael for their patience, support and encouragement throughout this study 


\section{Table of contents}

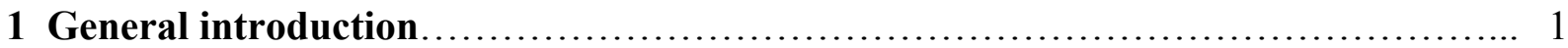

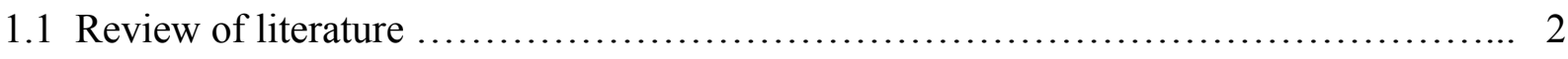

1.2 Objectives, hypothesis and outline of the thesis................................ 10

1.3 Statistical analysis....................................................... 11

2 Screening of promising Arachis pintoi genotypes for phosphorus efficiency in acidic

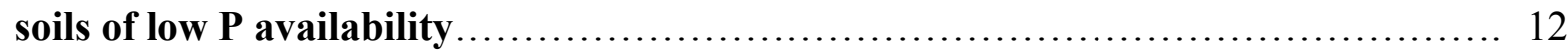

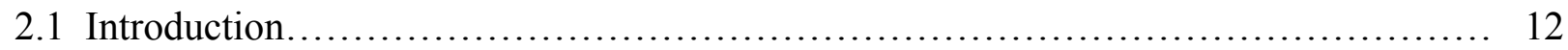

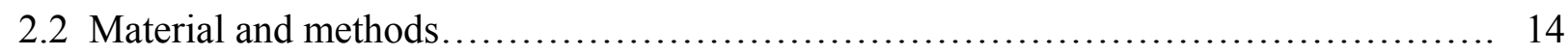

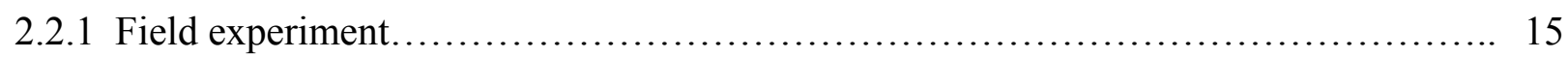

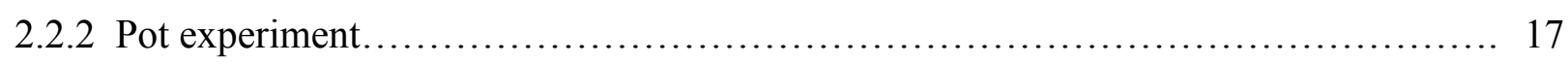

2.3 Results and Discussion................................................ 21

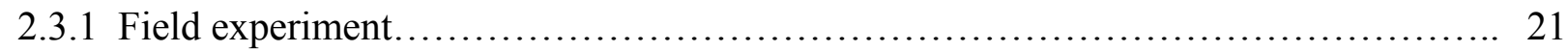

2.3.1.1 Shoot biomass production and the influence of the germination.................. 21

2.3.1.2 Shoot P concentration....................................................... 26

2.3.1.3 Extractable P-Bray II and $\mathrm{pH}$ of the soil samples after harvesting................. 27

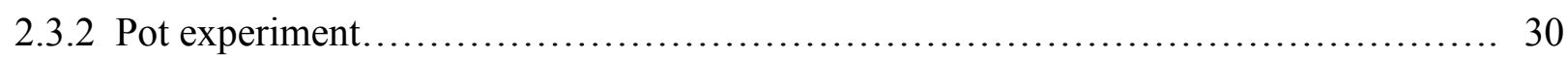

2.3.2.1 Shoot biomass production........................................... 30

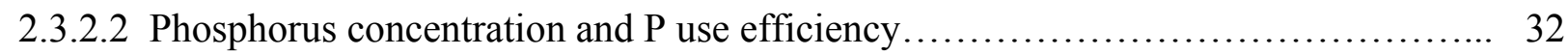

2.3.2.3 Phosphorus content and the root length-shoot ratio........................... 34

2.3.2.4 Phosphorus uptake per unit of root length and $\mathrm{P}$ concentration in the soil solution... 37

2.3.2.5 $\mathrm{pH}$ value in soil and soil solution and extractable $\mathrm{P}$ of soil samples after harvesting.. 41

2.4 Concluding discussions...................................................... 42

3 Influence of arbuscular mycorrhizae fungi (AMF) on morphological and physiological plant parameter related to $\mathrm{P}$ efficiency of Arachis pintoi genotypes

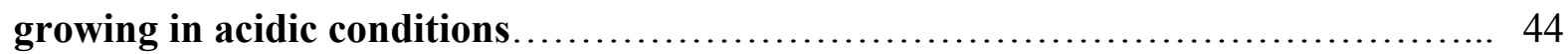

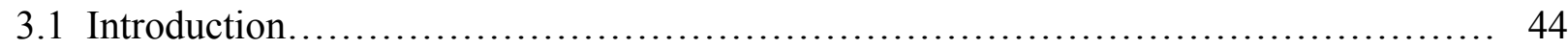

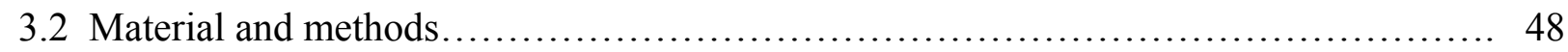

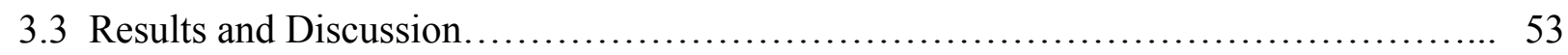

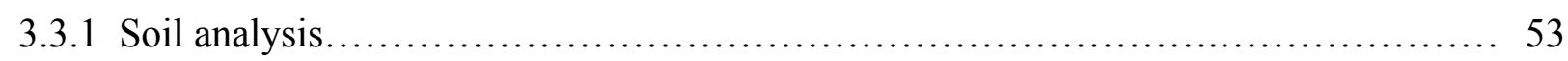

3.3.2 Root colonisation grade of the arbuscular mycorrhizae fungi (AMF).............. 54

3.3.3 Shoot biomass production............................................... 56 


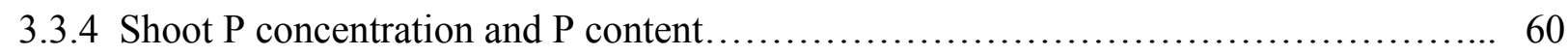

3.3.5 Phosphorus use efficiency and the acid phosphatase activity in the leaves and roots.... 64

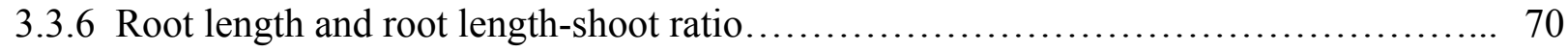

3.3.7 The $\mathrm{P}$ uptake per unit root length and the $\mathrm{P}$ inflow............................. 75

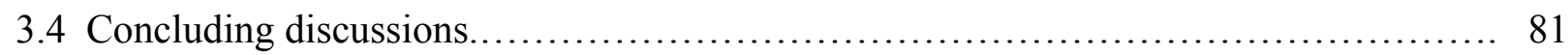

4 The development of $P$ efficiency mechanisms with plant age of perennial peanut (Arachis pintoi) genotypes and of one groundnut (Arachis hypogea) genotype........ 83

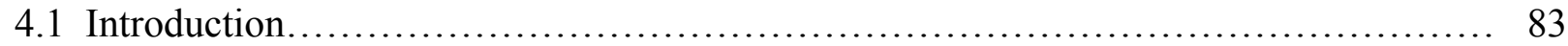

4.2 Material and methods......................................................... 85

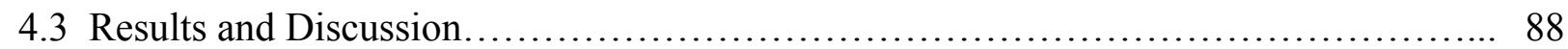

4.3.1 Shoot biomass production and shoot growth rate............................... 88

4.3.2 Shoot $\mathrm{P}$ concentration and $\mathrm{P}$ content......................................... 91

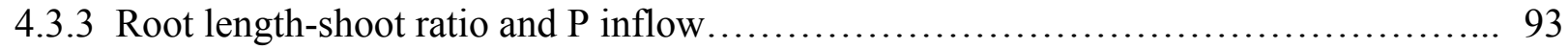

4.3.4 Phosphorus concentration and $\mathrm{pH}$ in the soil solution and the extractable $\mathrm{P}$ in the soil. 96

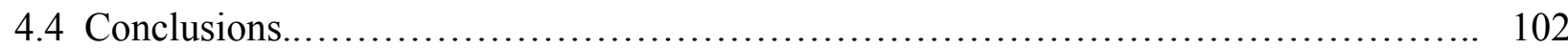

5 Root exudation of organic acids and acid phosphatase of two different $P$ efficient Arachis pintoi genotypes and their influence on $\mathbf{P}$ acquisition efficiency............... 103

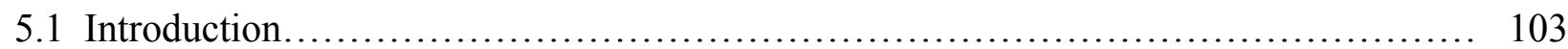

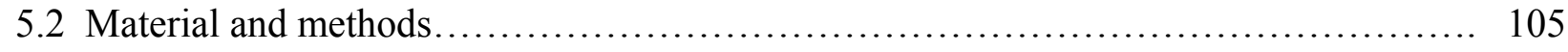

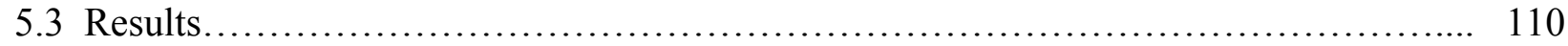

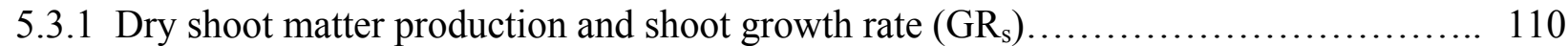

5.3.2 Shoot $\mathrm{P}$ concentration and $\mathrm{P}$ content........................................ 111

5.3.3 Root length shoot ratio and $\mathrm{P}$ inflow........................................ 113

5.3.4 Phosphorus concentration and $\mathrm{pH}$ in the soil solution and the extractable $\mathrm{P}$ in the soil. 115

5.3.5 Colonisation grade in roots of native arbuscular mycorrhizae fungi (AMF) ......... 118

5.3.6 Acid phosphatase activity (APase) and $\mathrm{pH}$ on the root surface $\ldots \ldots \ldots \ldots \ldots \ldots \ldots \ldots \ldots$

5.3.7 Root exudation of organic acids.............................................. 119

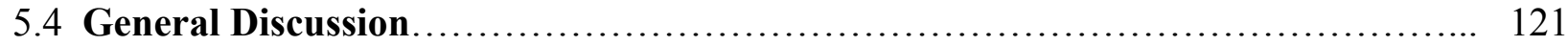

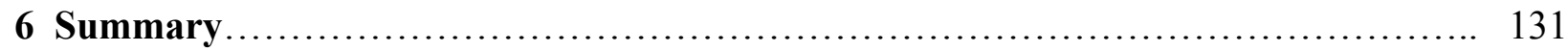

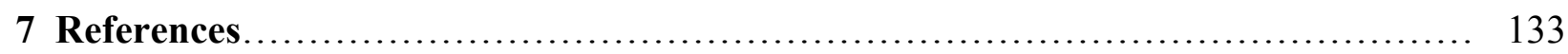

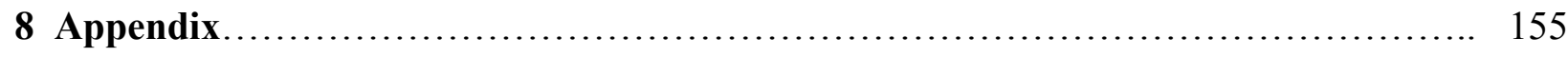

Acknowledgements

Curriculum vitae 


\section{List of abbreviations}

Ah

AMF

ANOVA

$A p$

APase

CAL

CIAT

DAE

DAS

DAT

HPLC

LOD

OA

PAE

$\mathrm{P}_{\mathrm{i}}$

PNP

$p$ NPP

$\mathrm{P}_{\mathrm{o}}$

PR

PUE

PURL

RL

RSR

SAS

TSP
Arachis hypogea

Arbuscular mycorrhizae fungi

Analysis of variance

Arachis pintoi

Acid phosphatase

Calcium acetate lactate extractant solution

International Center for Tropical Agriculture

Days after establishment

Days after sowing

Days after transplanting

High performance liquid chromatography

Limit of determination

Organic acids

Phosphorus acquisition efficiency

Inorganic phosphorus

p-Nitrophenol

p-Nitrophenyl Phosphate

Organic phosphorus

Phosphate rock

Phosphorus use efficiency

Phosphorus uptake per unit root length

Root length

Root length-shoot biomass ratio

Statistical analysis system

Triple superphosphate 


\section{General Introduction}

While in most countries of Western and Central Europe and North America the production of agricultural products per unit area takes place at high level, it is low in other parts of the world, particularly in developing countries of the tropics and subtropics (Vlek et al. 1992; Cakmak 2002).

Biotic and abiotic factors are the major causes of the low yields of the most important crops, when they are compared with the best yields obtained with best management practices. Biotic factors (insects, diseases and weeds) are an important source of these losses (less than $20 \%$ of the record yields) (Boyer, 1982; Zeigler, 1990; Krieg, 1994), but the abiotic factors (edaphic and climatic) account for the most important losses of yield and are, hence, a great source of agriculture research. Among the edaphic factors, low availability of phosphorus (P) is a major constraint to crop production in the tropics (World Bank, 1994; Batjes, 1997). Von Uexküll and Mutert (1995) estimate that $95 \%$ of the acid soils located in tropical areas are deficient in P.

The most evident way to improve the availability of $\mathrm{P}$ is to add phosphate fertilisers to Pdeficient acid soils, either as water soluble P fertiliser or as phosphate rock (Von Uexküll and Mutert, 1995; Sanchez et al., 1997). However, this option in tropical areas is very restricted by the low purchasing power of the small-scale farmers, by the lack of fertiliser availability, and by low fertiliser efficiency due to a high $\mathrm{P}$ sorption in acid soils. On the other hand, phosphate resources are limited and not renewable and their unlimited use leads to the environment pollution (soil, ground waters, rivers, etc). Other convenient alternatives are: i) to identify plant species that are efficient in term of $\mathrm{P}$ uptake under low $\mathrm{P}$ soil availability and to include them in crop rotation in combination with relatively low levels of $\mathrm{P}$ inputs, and ii) to improve $\mathrm{P}$ acquisition efficiency by identifying genes responsible for the adaptation of given plants to low$\mathrm{P}$ soils and to transfer them in agricultural crops that present a low $\mathrm{P}$ acquisition.

Such research strategies are highly promising to an increased food production in the tropics, because growing nutrient-efficient plants will enable to increase the output at a maintained low input. These allow a sustainable agriculture and conserve the environment. However, in order to achieve the maximum use of $\mathrm{P}$ in $\mathrm{P}$-limited native soil and strategic $\mathrm{P}$ inputs, it is necessary to focus the research on identifying genotypic differences and on understanding the specific mechanisms involved in the acquisition of P from different P sources (Rao et al., 1999b). 


\subsection{Review of literature}

\section{Phosphorus availability in tropical soils}

Poor soils dominate the tropical latitudes, hence most developing countries. The inherent infertility of many tropical soils is a consequence of their formation on geological parent materials that were low in essential mineral elements coupled with the intense rates of weathering they have experienced under warm humid tropical conditions that develop highly acidic solum (Richter and Babbar, 1991). Most of these tropical soils have limited available P (Oxisols, Ultisols and Andisols). Oxisols and Ultisols are constituted by clays, oxides of iron $(\mathrm{Fe})$ and Aluminium (Al) and weatherable minerals in which phosphorus in the form of calcium phosphate is hydrolyzed (Walker and Syers 1976; Van Wambeke, 1991). With weathering the clays lost silica and generated iron and aluminium hydrous oxides onto which phosphates adsorb or precipitate. Strong weathering is also correlated with an increase in the amount of sesquioxides, which exhibit high P-sorption properties (Frossard et al., 1995; Torrent, 1997). Oxisols and Ultisols require great amounts of applied $\mathrm{P}$ to attain the required equilibrium solution concentration to support adequate crop growth (Sánchez and Uehara, 1980).

On the other hand, Tiessen et al. (1992) suggested that in highly weathered soil, most of the plant-available $\mathrm{P}$ is derived from the mineralisation of organic $\mathrm{P}$ forms, in less weathered soils plant-available $\mathrm{P}$ is derived predominantly from inorganic $\mathrm{P}$ fractions. Soil solution $\mathrm{Pi}$ (Orthophosphate ions) is also replenished by mineralization of labile organic phosphorus forms (Po) in processes mediated largely by inter- and extracellular phosphatase enzymes (Helal and Sauerbeck, 1984; Tarafdar and Jungk, 1987). The availability and contribution of labile Po forms to plant $\mathrm{P}$ nutrition depends on microbial activity. Nevertheless, Pi released from organic sources is either adsorbed onto mineral surfaces or enters into the organic $\mathrm{P}$ cycle through plant or microbial absorption.

The use of $\mathrm{P}$ fertilisers, water soluble like triple superphosphate (TSP) or insoluble like phosphate rock (PR), represents frequently a poor improvement in $\mathrm{P}$ supply for the plant. Phosphorus from both fertilisers precipitate in different forms when it enters into adsorption reactions with soil mineral constituents and its recovery by plants, due to low availability, is small. Phosphorus rock dissolution rate of $\mathrm{Ca}$ and $\mathrm{P}$ ions is slow, because it depends on an acid reaction governed by external factors as $\mathrm{Ca}$ and $\mathrm{Pi}$ concentration in soil solution and soil $\mathrm{pH}$. However, it has been argued that P release from PR would be more in synchrony with plant demand enabling roots to capture a greater proportion of the Pi before sorption (Chien, 1992). 
On the other site, there is strong evidence that soluble P sources are less affected by increased sorption capacity than PR sources (Mokwunye and Hammond 1992).

The solubility of $\mathrm{Ca}, \mathrm{Al}$ and $\mathrm{Fe}$ phosphate minerals (and their amorphous precursors) depends on $\mathrm{pH}$. $\mathrm{Al}$ and $\mathrm{Fe}$ phosphate solubility increases with increasing $\mathrm{pH}$ while the solubility of $\mathrm{Ca}$ phosphates, including phosphate rocks decreases (Olsen and Khasawneh, 1980). Phosphate sorption on $\mathrm{Fe}$ and $\mathrm{Al}$ oxide surfaces depends on $\mathrm{pH}$ although the literature reports contradictory effects (Parfitt, 1978; Barrow, 1990). In the absence of cation interferences, increasing $\mathrm{pH}$ reduces Pi adsorption due to increased negative charge on the variable charge oxide surfaces (Barrow, 1990). Nevertheless, decreasing the $\mathrm{pH}$ in the rhizosphere soil results in increased desorption of labile Pi, influencing $\mathrm{P}$ availability. In this way plant adaptation to low $\mathrm{P}$ soils may depend on how the plant can influence the availability of $\mathrm{P}$ in the various soil $\mathrm{P}$ pools. Mineralization of $\mathrm{P}$ from organic pools may be stimulated by exudation of organic acids which become substrates for microbial and enzymatic processes in the rhizosphere (Helal and Sauerbeck, 1984; Tate, 1984).

\section{Importance of phosphorus supply to plant growth}

Phosphorus is needed most by young, fast growing tissues, and performs a number of functions related to growth, development, photosynthesis and use of carbohydrates (Clarkson and Hanson, 1980; Bieleski and Ferguson, 1983; Moorby and Besford, 1983, Marschner, 1995; Rao, 1996); hence, $\mathrm{P}$ deficient soils produce poor yield crops. Optimal plant growth requires $\mathrm{P}$ in the range of 0.3 to $0.5 \%$ of dry matter during the vegetative growth stage. The productive efficiency of $\mathrm{P}$ for grain or seed is higher at early growth stages than at later stages because $\mathrm{P}$ is needed for tillering or branching. If sufficient $\mathrm{P}$ is absorbed at early growth stages, it will be redistributed to other growing organs. On the other hand, P deficiency reduces leaf expansion, auxiliary bud growth and, therefore, shoot canopy reduces the plant's photosynthetic surface area and carbohydrate utilization (Marschner, 1995; Rao, 1996). Since cell and leaf expansion are more retarded than chloroplast and chlorophyll formation (Hecht-Bucholz, 1967), low P supply increases the soluble protein and chlorophyll content per unit leaf area, resulting in small and darker green leaves (Rao and Terry, 1989). An increase in root-to-shoot ratio is due to the $\mathrm{P}$ deficient plants decrease more shoot growth than root growth (Rao and Terry 1995; Marschner et al., 1996). This fact can be observed in the forage legume, Stylosanthes hamata, not only because most $\mathrm{P}$ is retained but also because there is additional net translocation of $\mathrm{P}$ from the shoot to the root (Smith et al., 1990). In addition to the afore mentioned effects on vegetative growth, low-P supply also limits the 
formation of reproductive organs. Premature leaf senescence, delayed flower initiation (Rossiter, 1978), decreased number of flowers (Bould and Parfitt, 1973) and restricted seed formation (Barry and Miller, 1989) all contribute to yield reductions under P limited conditions.

\section{Plant P efficiency}

Different species and cultivars within a species vary widely in their ability to thrive in nutrientdeficient environments, i.e. plants differ greatly in their nutrient efficiencies (Chen and Gabelman, 1995; Cakmak, et.al, 1997; Trehan and Claassen, 1998).

Genotypes that can acquire and use scarce P resources more efficiently from low-P soils could improve and stabilize agricultural production (Friesen et al., 1997; Rao et al., 1999c). Genotypical differences in nutrient efficiency are related to differences in efficiency of acquisition by the roots or in use by the plant, or both (Sattelmacher et al., 1994; Horst et al., 1996; Rao et al., 1999a). Phosphate acquisition efficiency (PAE) is defined in terms of total uptake per plant. It is related to morphological root characteristics such as root system size, fine roots which means an increased root surface per unit of root weight and root hairs which allows for efficient nutrient scavenging of a larger soil volume. The second component is the root physiological activity such as differing uptake kinetics i.e. $\mathrm{I}_{\max }, \mathrm{K}_{\mathrm{m}}$ and $\mathrm{C}_{\mathrm{Lmin}}$, which results in different nutrient uptake rates per unit root and time (Steingrobe and Claassen, 2000). Other mechanisms affecting the uptake efficiency include symbiosis with mycorrhizal fungi (Wilcox, 1991; Tarafdar and Marschner, 1994; Marschner, 1995) and chemical mobilization of nutrients by root exudates of protons, of complexing or chelating substance or of enzymes in the rhizosphere (Uren and Reisenauer, 1988; Raghothama, 1999; Jones and Farrar, 1999).

Plant P use efficiency (PUE) is the dry matter produced per unit P taken up. It depends on the available amount of nutrient into the plant (Godwin and Blair, 1991; Marschner, 1995). The PUE is equivalent to the reciprocal of the nutrient concentration in the entire plant, often termed as the nutrient efficiency ratio (Gourley et. al., 1994).

The plants' P efficiency could be also assessed by other terms like the "external" and "internal" $\mathrm{P}$ requirements for plant growth and yield under limited $\mathrm{P}$ availability in soil. Genetic variation in plant adaptation to low-P soils may be related to external and internal P requirements.

The internal requirement is the minimum uptake by a plant associated with a specific yield, usually near maximum growth (Fox, 1981). It is also defined as the critical concentration for optimal crop growth or yield i.e. the nutrient concentration in plants sufficient to produce a 
certain proportion, e.g. 90\%, of maximum dry matter yield (Föhse et al., 1988, Godwin and Blair, 1991). Therefore, plants growing under limited $\mathrm{P}$ conditions with a low internal $\mathrm{P}$ requirement may have a low external $\mathrm{P}$ requirement or may be inefficient acquiring $\mathrm{P}$, but they must be efficient in using the $\mathrm{P}$ taken up to produce dry matter.

The external $\mathrm{P}$ requirement of plants is the $\mathrm{P}$ concentration in soil solution associated with adequate nutrition or growth (Fox, 1981) and thus very close related to the plant P efficiency. Concentration of $\mathrm{P}$ in soil solution, which is in the order of $0.32-19.37 \mu \mathrm{mol} \mathrm{P} \mathrm{L}^{-1}$ (Wild, 1988; Kamprath and Watson, 1980), can be depleted rapidly by growing roots in soil. As solution Pi falls below its equilibrium concentration, it is replenished by labile $\mathrm{Pi}$ desorbed from clay mineral surfaces adjacent to the roots (Fox, 1981). Consequently, Pi moves from the adsorbed forms into solution and along a concentration gradient to the root where the concentration is low. However, in P-limited tropical soils, the quantity of labile P may be insufficient to maintain Pi solution concentration against depletion by plant root. Thus this specific soil condition influences the movement of $\mathrm{P}$ toward the root surface because gradient is the driving force of diffusive $\mathrm{P}$ flux. On the other hand, $\mathrm{P}$ inflow depends on the concentration at the root surface, for that $\mathrm{P}$ depletion may imply severe restriction of $\mathrm{P}$ inflow into plants.

It has been reported that the $\mathrm{P}$ concentration in soil solution (external P requirement) necessary to achieve maximum growth differs widely among crops. Using flowing solution cultures, Asher and Loneragan (1967) showed a 25-fold difference in external P requirements among eight plant species and Asher (1978) reported a 200-fold difference for 18 species ranging from Stylosanthes guianensis to cassava. Fox, (1981) showed that the external P requirements of a range of crops and vegetables estimated in the field on Hawaiian Oxisols using adsorption isotherms were equally variable. Kamprath and Watson (1980) summarized the external P requirements for several temperate and tropical crop species varies in the range of 2 to $22 \mu \mathrm{mol} \mathrm{L}^{-1}$.

Hence, at a low $\mathrm{P}$ concentration in soil solution, $\mathrm{P}$ efficient plants may be either those with a low external $\mathrm{P}$ requirement or those which are able to achieve their external requirement by developing of morphological and/or physiological root mechanisms (PAE), always in connection with the P use efficiency.

Since different concepts of nutrient efficiency have been developed, some giving emphasis to productivity and other to internal nutrient requirement (Gourley et, al., 1994), it is important to clarify the definition of $\mathrm{P}$ efficiency for this research. Buso and Bliss (1988) defined that efficiency with regard to a specific mineral nutrient, is the ability of a species or cultivar to produce a high yield in a soil limiting in this particular nutrient element compared to a standard 


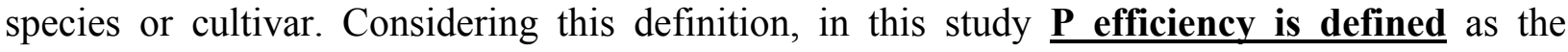
genotype's ability to produce shoot biomass under low P availability in soil in comparison with other genotypes.

\section{Plant factors for $P$ acquisition efficiency (PAE)}

The ability of plants to adapt their morphological and physiological root characteristics to variable nutrient availability is genetically determined (Batten, 1992; Egle et al., 1999; Fransen et al., 1999; Horst et al., 1993). The low mobility of P in soil makes $\mathrm{P}$ acquisition by the plant very dependent on soil exploration in time and space (Nye and Tinker, 1977; Barber, 1984; Koide, 1991; Marschner, 1991). Efficiency of P acquisition depends markedly on rooting density and root distribution in the soil profile, and these, in turn, on plant genotype, soil chemical and physical properties, and cropping system (e.g. rotation). The rooting depth of annual crops increases as the growing season progresses, but in comparison, perennial forage species, particularly grasses, develop more vigorous root systems as an adaptive feature to low P availability in tropical soils (Friesen et al., 1997; Rao et al. 1996). Field and greenhouse studies (Otani and Ae, 1996) indicated that $P$ uptake by crops is strongly related to root length in soils where $\mathrm{P}$ availability is high, but not in soils with low $\mathrm{P}$ availability or where soil volume is limited.

Since the uptake of nutrients occurs on the root surface, root diameter and root length defines the maximum volume of soil which can be exploited with a given amount of photosynthate. Root diameter varies between species and cultivars and changes with plant age (Welbank et al., 1973; Atkinson, 1985). Dicotyledonous species have greater root diameter than monocotyledonous (Atkinson, 1990; Fitter, 1991).

As the mobility of $\mathrm{P}$ in soil is low, the root cylinder may not be enough to feed the plant. Therefore, plants grow root hairs, which are tubular shaped growing cells arising from root epidermal cells known as trichoblasts (Ridge, 1996). Jungk and Claassen (1989) found the influx of $\mathrm{P}$ per unit root length greatly enhanced by root hairs. This can be explained by the enlargement of the root surface area and because root hairs penetrate the soil perpendicular to the root axis, giving access to a larger volume of soil per unit root length. Consequently, P depletion profiles are found to differ in their radial extension depending on root hair length (Hendriks et al., 1981). Assuming a frequency of $100 \mathrm{~mm}^{-1}$, a radius of $0.005 \mathrm{~mm}$ and a dry matter content of $5 \%$, Clarkson (1991) calculated a threefold increase in surface area could be achieved at an expense of less than $2 \%$ of root dry matter. Föhse et al. (1991) found that spinach had highest 
root hair density and length followed by bean, wheat and rape. Eticha and Schenk (2001) found that differences in $\mathrm{P}$ efficiency between two cabbages varieties could partly attributed to differences in root hair length.

Arbuscular mycorrhizae fungi (AMF) colonize the roots of most plants and serve as an extended link between plant roots and soil (Marschner and Dell, 1994). When root exploration of the soil is restricted by low $\mathrm{P}$ supply, up to $80 \%$ of the plant $\mathrm{P}$ can be delivered to the host plant by the external arbuscular-mycorrhizal (AM) hyphae, which explore soil to a distance of more than 10 $\mathrm{cm}$ from the root surface ( $\mathrm{Li}$ et al., 1991). The mycorrhizal efficiency of $\mathrm{P}$ acquisition probably varies markedly among crop species. Cassava has a higher AM dependence than Stylosanthes guianensis, cowpea, beans, Andropogon gayanus, maize, or rice (Howeler et al., 1987). Soil and crop management practices (crop sequence, tillage, fertilisers, and pesticides) can influence the total quantity of AMF development (Miller et al., 1994). Therefore, crop systems improving soil environment for high population of AMF species, could enhance P supply to plants, especially from strongly sorbed $\mathrm{P}$ pools in the soil, which the plant is unable to take up only through the enlargement of the root system (Dodd et al., 1987).

Phosphorus uptake by plants is also influenced by the uptake kinetics. These parameters include maximum net influx per centimetre of root length $\left(\mathrm{I}_{\max }\right)$, Michaelis- constant $\left(\mathrm{K}_{\mathrm{m}}\right)$ and minimum soil solution concentration $\left(\mathrm{C}_{\text {Lmin }}\right)$ (Nielsen, 1979). The absorption kinetics of the plant is controlled by these parameters. Under conditions in which the rate-determining step in $\mathrm{P}$ uptake is located in the root, $\mathrm{P}$ uptake will increase if root length per unit plant weight and $\mathrm{I}_{\max }$ increase, and $\mathrm{K}_{\mathrm{m}}$ and $\mathrm{C}_{\mathrm{Lmin}}$ decrease (Nielsen, 1979). These parameters vary with $\mathrm{P}$ concentration in the soil solution. Fontes et al. (1986) reported that $\mathrm{I}_{\max }$ values decrease with increase in $\mathrm{P}$ supply to the tomato plants. An average increase of 173 per cent in $I_{\max }$ was observed in plants grown at insufficient $P$ supply. Buhse (1992) reported that the $I_{\max }$ of rape and sugar beet increases remarkable not only when the P supply decrease from 50 to $0.2 \mu \mathrm{M} \mathrm{P}$ but also when the root temperature increase from 10 to $25^{\circ} \mathrm{C}$. On the other hand, $\mathrm{K}_{\mathrm{m}}$ and $\mathrm{C}_{\mathrm{Lmin}}$ values were not affected by $\mathrm{P}$ supply to the tomato plants. The assessment of the kinetic parameters $\left(I_{\max }, K_{m}\right.$ and $\left.C_{L m i n}\right)$ characterizing the uptake system of a genotype is complicated by at least 3 factors (Sattelmacher et al., 1994): (i) the plasticity of the system in response to the P status of the plant (Jungk and Claassen, 1989; Abdou, 1989); (ii) the differences in P uptake along roots (Kuhlmann and Barraclough, 1987; Henriksen et al., 1992); and (iii) the dependence of $P$ uptake on plant growth rate (Engels, 1993). Thus there is general agreement that the efficiency of the uptake system is of minor importance for $\mathrm{P}$ acquisition from 
soils because transport of $\mathrm{P}$ to the root surface rather than the uptake is the limiting step (Barber, 1984). Therefore it is less likely that selection for efficient $\mathrm{P}$ uptake kinetics will contribute to more efficient $\mathrm{P}$ acquisition from low-P soils.

The root release of organic acids (especially malic acid, citric acid and perhaps oxalic acid) is another key component in $\mathrm{P}$ acquisition. Organic acids differ markedly in their capacity to complex $\mathrm{Fe}$ and $\mathrm{Al}$ and thus solubilize the respective $\mathrm{P}$ compounds in soil bound by these ions. Different cultivars produce a specific acid that complexes a specific mineral ( $\mathrm{Fe}, \mathrm{Al}$, and $\mathrm{Ca}$ ), for example, pigeon pea releases piscidic acid that complexes Fe but not Ca (Ae et al., 1990). Ae et al. (1996) proposed that cell walls of plant roots are involved in P-solubility activity. Root exudation of acid phosphatases (ectoenzymes) is common in plants and is usually enhanced under P deficiency (Ozawa et al. 1995). Acid phosphatases deplete organic $P$ in the rhizosphere of lupin roots within about $2.5 \mathrm{~mm}$ of the root surface (Li et al., 1997). Secretion of phytase was highest in Brachiaria decumbens CIAT 606, Stylosanthes guianensis CIAT 184 and tomato. It is speculated that the secretion of phytase could provide an efficient mechanism for wide adaptation of the tropical forage grass $B$. decumbens CIAT 606 (planted on over 40 million ha) to the low P supplying tropical soils of Latin America.

\section{Plant factors for P use efficiency (PUE)}

Plant adaptation to $\mathrm{P}$ limited tropical soils can be partially attributed to inherent genotypic differences in P use efficiency (PUE). Phosphorus use efficiency describes the amount of $\mathrm{P}$ that is needed to build one unit of shoot biomass. Efficient use of $\mathrm{P}$ is dependent on a number of plant attributes (Clark, 1990; Caradus, 1990) including: 1) high dry-matter yield per unit of $\mathrm{P}$ acquired; 2) growth duration and plant type; 3) partitioning of $\mathrm{P}$ between different pools and its translocation within the plant; 4) leaf death rate; and 5) partitioning of a greater proportion of biomass to harvestable yield. The ability of crop plants to remobilize $\mathrm{P}$ from vegetative to reproductive organs, and forage plants from senescing to growing points may form an important mechanism that allows plants to improve the use of acquired P (Caradus, 1990). Several researchers found that species (like white clover) adapted to low $\mathrm{P}$ soils generate a lower proportion of dead leaf to total leaf material when under $\mathrm{P}$ stress than species from high $\mathrm{P}$ soils (Beadle, 1966; Specht and Groves, 1966; Grime and Hunt, 1975).

A number of tropical crop and forage species can grow normally with low tissue $\mathrm{P}$ concentrations due to efficient use of $\mathrm{P}$ among the major biochemical fractions (soluble-P, lipid$\mathrm{P}$, and residue-P). Lotus, which maintained relatively low tissue Pi concentrations, was found to 
be more tolerant to low $\mathrm{P}$ conditions than white clover, which exhibited high Pi concentrations in the tissues (Hart and Jessop, 1983). Pigeon pea is more tolerant to low P conditions compared to soybean because it maintains relatively low tissue concentration of $\mathrm{Pi}$ due to the efficient incorporation of the external Pi into residue-P (Adu-Gyamfi et al., 1990). Intracellular Pi compartmentation studies using ${ }^{31} \mathrm{P}-\mathrm{NMR}$ (nuclear magnetic resonance) indicate that, under Pi deficiency, the vacuole acts as a Pi reservoir to maintain a constant cytoplasmic Pi concentration (Rao, 1996; Foyer and Spencer, 1986; Ratcliffe, 1994).

\section{The perennial peanut (Arachis pintoi Krap. \& Grez.) and its habit to take up $\mathbf{P}$}

The forage legume Arachis pintoi $(A p)$ originates from the valleys of the Jequitinhonha, São Francisco and Tocantins rivers in central Brazil. It grows naturally in soils low in P with high Al saturation (red sandy-loam alluviums) under low forest with a fairly dense canopy with rainfalls ranging from 1800-2000 mm (Cook, 1992). It has since been distributed to Argentina, Australia, Colombia, the United States, and more recently to South East Asia, Central America and the Pacific, where it is used as a ornamental plant, a cover crop (e.g. in coffee, banana, oil palm, macadamia, and hearts of palm, etc.), a ground cover in tree plantations, in agroforestry system and specially in intensively managed grass/legume pastures (Cook, 1992; Clement and DeFrank, 1998).

One feature that makes $A p$ persistent compared to other tropical legumes, specially in associations with aggressive creeping grasses as Brachiarias, is its stoloniferous growth habit that allows it to readily invade any bare ground. The stolons root freely and contribute to greater acquisition of nutrients and water. Another plant attribute that improves persistence is its ability to propagate both vegetatively and from the underground produced seeds (geocarpic plant) (Cook, 1992; Kerridge and Hardy, 1994).

Earlier agronomic evaluation of $A p$ accessions "CIAT" (International Center for Tropical Agriculture) in different environmental conditions (Australia, Brazil, Colombia, Costa Rica, Philippines and Malaysia) indicated that the cultivars CIAT 18747, 18748, 18750 and 22160 are better adapted to acidic soil with scarce available phosphorus than the commercial cultivar CIAT 17434. Complementary to these field studies, Rao et al. $(1995,1996,1997)$ evaluated in greenhouse studies at CIAT the P efficiency of the genotype CIAT 17434 grown in clay loam Oxisols (2.1 mg kg-1 available P-Bray II) in monoculture and also in association with the grass Brachiaria dictyoneura (CIAT 6133). 
These researches showed that Arachis pintoi i) in both crop system (monoculture and association) was able to acquire greater amounts of $\mathrm{P}$ and $\mathrm{Ca}$ than that of the grass alone; ii) acquired more P from Ca-P source than from Al-P; iii) had a lower P use efficiency than the grass and iv) had a higher $\mathrm{P}$ acquisition efficiency than the grass. From these results it follows that understanding the mechanisms responsible for the differential abilities of $A p$ genotypes to grow at low or high $\mathrm{P}$ is a prerequisite to the identification, selection and breeding of forage germplasm for low-P soils.

\subsection{Objectives, hypothesis and outline of the thesis}

Through a joint research project between the Tropical Forage Program of the International Center for Tropical Agriculture (CIAT, Colombia) and the Institute of Agricultural Chemistry of the Georg-August University of Göttingen (Germany), the commercial cultivar (CIAT 17434) was compared with nine promising Arachis pintoi (Ap) genotypes, which showed a special ability to grow in soils with very low P availability.

The general objectives of this research were:

1. To assess the efficiency of $A p$ genotypes to acquire and/or use $\mathrm{P}$ at different growth stages under natural (field experiment) and controlled (pot experiment) conditions grown on two acid tropical soils low in plant available $\mathrm{P}$.

2. To assess the effect of the acid phosphatase (APase) activity in the leaf on the P use efficiency.

3. To investigate possible mechanisms of $\mathrm{P}$ efficiency in the rhizosphere, mainly to see whether arbuscular mycorrhiza fungae (AMF) colonisation, organic acid root exudates or acid phosphatase (APase) activity, could explain the differences in the $\mathrm{P}$ acquisition of Ap genotypes growing at a low concentration of $\mathrm{P}$ in soil solution.

We hypothesized that the ability of $\mathrm{P}$ efficient Arachis pintoi genotypes to grow under low soil $\mathrm{P}$ supply might be due to a high P-acquisition efficiency (PAE). Reasons for this could be symbiosis with AMF and/or physiological adaptation mechanisms like root exudation of organic acids and/or phosphatase enzymes. 
The structure of this work is as follows:

Chapter 2, 3 and 4 are addressed to assess the P efficiency of different $A p$ genotypes and the influence of age on P efficiency.

To evaluate $\mathrm{P}$ efficiency and identify genotypes with different $\mathrm{P}$ efficiencies for further studies, a field and a pot experiment with 10 genotypes were carried out (chapter 2). In the field the genotypes were grown on a clayey Ultisols and in the pot experiment on a clayey Oxisols under controlled conditions.

The effect of the symbiosis with mycorrhizae on the $\mathrm{P}$ efficiency of the genotypes used in chapter 2 was evaluated in a greenhouse pot experiment in chapter 3 , as well as the effect of $\mathrm{P}$ fertilisation on the phosphatase activity in leaves and root tissue.

In chapter 4, the P efficiency of 3 Ap genotypes and one of Arachis hypogea was studied in a pot experiment in a growth chamber. The effect of different $\mathrm{P}$ concentrations in the soil solution, ranging from deficient to optimum levels, as well as the influence of plant age on P efficiency were evaluated in this experiment.

Chapter 5 evaluates in detail whether the physiological changes in the rhizosphere are responsible for the different levels of $\mathrm{P}$ efficiency in the $A p$ genotypes. This was achieved using a split root system pot experiment to determine amount of root exudates and phosphatase activity at different growth stages. Two Ap genotypes, with different $\mathrm{P}$ efficiency were tested.

During the description of the results of chapters 2 to 4 only a brief discussion was done. A general and deeper discussion of the results from the chapters 2 to 5 is given in chapter 5 and finally general conclusions are drawn.

\subsection{Statistical Analysis}

Analysis of variance was calculated with the SAS computer program (release 8.2 for Windows, 2001). The specific differences among genotypes and among treatments were evaluated with the Tukey test, where a probability level of 0.05 was considered statistically significant. 


\section{Screening of Arachis pintoi genotypes for phosphorus efficiency in acidic soils of low $\mathbf{P}$ availability}

\subsection{Introduction}

In natural tropical ecosystems, $\mathrm{P}$ availability is seldom optimal for plant growth due to their high weathered soils, and due to chemical and biological reactions (Sample et al., 1980; Stevenson, 1986). This fact has induced plant species and cultivars to develop inter- and intra-specific differences in their ability to grow or yield well at suboptimal phosphorus supply (phosphorus efficiency) as compared to inefficient species (Clark and Duncan, 1991; Lynch and Beebe, 1995; Lynch, 1998).

Studies conducted in the last two decades have identified superior tropical crop and forage germplasm adapted to low P soils (Howeler et al., 1987; Ae et al., 1990; da Silva and Gabelman, 1992; Rao et al., 1993; Pellet and El-Sharkawy, 1993a; Pellet and El-Sharkawy, 1993b; Fageria and Baligar, 1997; de Datta et al., 1994; Lynch and Beebe, 1995; Johansen et al., 1995; Randall, 1995, Machado, 2000; Machado et al., 2001; Osborne and Rengel, 2002; Vance et al., 2003; Parra et al., 2004; Wang et al., 2005). Phosphorus efficient crops and forages, which are genetically adapted to low P-supplying tropical soils, are often characterized by low $\mathrm{P}$ requirements and/or increased efficiency in absorbing $\mathrm{P}$ from soils of low $\mathrm{P}$ status (P acquisition efficiency), and in using $\mathrm{P}$ for plant growth ( $\mathrm{P}$ use efficiency or low internal $\mathrm{P}$ requirement). For example, several tropical crop species (maize, sorghum, pearl millet, pigeon pea, groundnut and soybean) may differ in their ability to use different sources of mineral $\mathrm{P}$, possibly by chelating $\mathrm{Fe}^{3+}$ (Ae et al., 1990), which may bind phosphate ions very strongly.

Rao et al. (1995) showed substantial inter-specific differences in adaptive attributes among tropical forage grasses and legumes to infertile acid soil. Jungk and Claassen (1989) showed that plant species with long root hairs like wheat, ryegrass and oilseed rape exhibit a higher P uptake per unit root than plant species with short root hairs like onion. Caradus (1983) indicated that the high P efficiency in white clover genotypes is based on a high development of root hairs, while in bush beans it is due to an above-mean root-shoot ratio, as well as, to a good root growth (Whiteaker, et al. 1976; Gabelman, et al. 1986). In tomatoes, P efficient genotypes result from high root length, high $\mathrm{P}$ uptake per unit root or a high internal $\mathrm{P}$ use efficiency (Coltman et al. 1985; Gabelman et al. 1986). In contrast, Dinkelaker (1990) found that P efficiency differences among nine chickpea genotypes were not attributed to specific adaptation mechanisms to low $\mathrm{P}$ availability, but rely to unspecific differences in growth potential. 
From the results mentioned above it follows that for the $\mathrm{P}$ acquisition efficiency of plant species or cultivars not only morphological plant parameters like root architecture, root length and root hairs can be important, but also physiological features like root exudation, which are able to produce changes in the soil chemism increasing the $\mathrm{P}$ solubility. Another possibility can be that the $\mathrm{P}$ use efficiency varies. Several studies have been conducted to determine the factors governing the $\mathrm{P}$ efficiency of groundnut (Arachis hypogea), but this is not the case for Arachis pintoi (Ap). For this reason, it is necessary to obtain more information about possible differences in the $\mathrm{P}$ efficiency among $A p$ genotypes and to investigate the possible mechanisms improving the acquisition and/or use of phosphate under low P soil conditions.

Genotypical differences in P efficiency can be examined in field experiments as well as in pot experiments with soil or with nutrient solution (Gabelman and Gerloff, 1983; Graham, 1984; Gerloff, 1987). However, contradictory results may be obtained when a plant species or genotypes are evaluated using these three experimental systems due to different growth conditions. On the one hand, results from pot trials with soil and especially from field trials can be not easily repeatable due to soil heterogeneity and complexity (Gerloff and Gabelman, 1983; Graham, 1984; Gerloff, 1987). Even using the same soil in pot experiments, the results are often not repeatable because the availability of nutrient can change during the soil storage (Graham, 1984; Gerloff, 1987). However, pot trials compared to field trials have the advantage that uniform growth conditions can be set regarding fertilization and soil homogeneity and also, that weather effects can be largely controlled. On the other hand, although nutrient solution experiments can normally be easily repeated, this can cover only a part of factors, which can be responsible for genotypical differences in nutrient efficiency by plants growing in soil. For instance, the root growth conditions and $\mathrm{P}$ uptake are substantially different between nutrient solution experiments and pot soil trials. Additionally, the relevance of different plant and non plant factors in P uptake would be different according to the experimental methodology used. Bhadoria et al., 2001 reported that in early growth stages under field conditions, groundnut was not limited by low P soil (1.9 $\mu \mathrm{M}$ P), whereas maize only yielded $15-35 \%$ of its maximum yield. In contrast, Bhadoria et al., 2004, growing the same plant material under flowing solution culture, reported that maize was more $\mathrm{P}$ efficient since it was able to produce up to $90 \%$ of its maximum yield at only $1 \mu \mathrm{M} \mathrm{P}$ concentration in the nutrient solution, whereas groundnut was inefficient, producing only $20 \%$ of its maximum yield at this P concentration.

Tropical field growth conditions (e.g. light intensity, soil humidity and soil layers compactation, temperature, evapotranspiration, etc.) and their variations during the day are very difficult to reproduce in greenhouse or growth chamber, despite of the use of accurate technology. 
Consequently, different genotypical variation among the genotypes could be observed as affected by the growth conditions.

Taking into consideration these experimental limitations, the ability of ten Arachis pintoi genotypes to grow under low $\mathrm{P}$ conditions was tested in natural tropical conditions in an Ultisols (field trial in Colombia) and in controlled conditions in an Oxisol (pot trial in Germany) by evaluation of plant and soil parameters affecting $\mathrm{P}$ efficiency.

\section{Hypotheses}

The following hypotheses were tested:

1. Arachis pintoi genotypes differ in their ability to grow under low $\mathrm{P}$ soil conditions.

2. The growth differences among the genotypes are more related to differences in their ability to acquire $\mathrm{P}$ from the soil than to use the $\mathrm{P}$ taken up.

3. The P efficiency of the genotypes is affected by the growth conditions (Field and growth chamber).

\subsection{Materials and Methods}

To evaluate differences in phosphorus efficiency among ten selected Arachis pintoi (Ap) genotypes under different growth conditions and acidic soils, a field trial (Ultisol) and a growth chamber pot experiment (Oxisol) were carried out.

\section{Plant material}

Earlier agronomic evaluation work of $A p$ genotypes in different environmental conditions (Australia, Brazil, Costa Rica, Philippines and Malaysia) and a multi-locational agronomic evaluation with 30 genotypes of $A p$ conducted in Colombia (Annual report CIAT, 1997), indicated that the genotypes CIAT 18747, CIAT 18748, CIAT 18751 and CIAT 22160 have a higher adaptability to low fertility soils than the genotypes CIAT 17434 and CIAT 18744.

Based on the results of persistence obtained from the genotypes grown under clayey soil conditions only, nine promising genotypes were selected and compared with the commercial 
genotype CIAT 17434. Table 2.1 shows the genetic plant material used in this study, which was renamed from 1 to 10 according to its ascendant accession number as given by CIAT.

Table 2.1 Genetic plant material of Arachis pintoi used in the experiments

\begin{tabular}{clll}
\hline Genotype & Rename as & Genotype & Rename as \\
\hline CIAT 17434 & $=1$ (Commercial) & CIAT 18751 & $=6$ \\
CIAT 18744 & $=2$ & CIAT 22155 & $=7$ \\
CIAT 18745 & $=3$ & CIAT 22159 & $=8$ \\
CIAT 18747 & $=4$ & CIAT 22160 & $=9$ \\
CIAT 18748 & $=5$ & CIAT 22172 & $=10$ \\
\hline
\end{tabular}

\subsubsection{Field experiment}

\section{Location}

A field study was established in a humid tropical lowland site located at latitude $1^{\circ} 25^{\prime} \mathrm{N}$, longitude $75^{\circ} 27^{\prime} \mathrm{W}$ and 180 m.a.s.l. (Montañita - Caquetá Department, Colombia). The weather conditions of this region, which has a good rainfall distribution during the year, were in average per year: rainfall $3500 \mathrm{~mm}$, temperature $25^{\circ} \mathrm{C}$ and relative humidity $80 \%$.

\section{Growth conditions}

The field was under native pasture and fertilisers had never been applied. After hoeing and removing the native pasture for the establishment of the experiment, the soil had the following physical and chemical characteristics (0-20 cm depth): $12 \%$ sand; $70 \%$ clay $18 \%$ silt; $4.5 \mathrm{pH}$ (soil to water, 1:1); $3.6 \%$ organic matter; $8.5 \mathrm{cmol}_{\mathrm{c}} \mathrm{kg}^{-1} \mathrm{Al} ; 0.27 \mathrm{cmol}_{\mathrm{c}} \mathrm{kg}^{-1} \mathrm{Ca} ; 0.14 \mathrm{cmol}_{\mathrm{c}} \mathrm{kg}^{-1}$ $\mathrm{Mg} ; 0.15 \mathrm{cmol}_{\mathrm{c}} \mathrm{kg}^{-1} \mathrm{~K}$; $93 \% \mathrm{Al}$ saturation; and $4.1 \mathrm{mg} \mathrm{kg}^{-1}$ extractable P (Bray II).

According the classification used at CIAT for tropical forages, P Bray-II values lower than $2 \mathrm{mg}$ $\mathrm{kg}^{-1}$ are low, between 2 and 5 are medium, between 5 and 10 are high and $>10$ are very high. However, the critical level in a mineral soil for crops is much higher, e.g. $11 \mathrm{mg} \mathrm{kg}^{-1}$ Bray II is the critical level for beans. The analytical methods used to determine the soil characteristics were as described in Salinas and Saif (1990). The soil was classified as a clayey Ultisols (Malagón et al. 1995).

The experiment was laid down in a split plot randomized complete block design with three $\mathrm{P}$ treatments as main plots, ten genotypes as subplots and three blocks as replications. Phosphorus treatments were native soil phosphate $(0 \mathrm{P}), 50 \mathrm{~kg} \mathrm{P}^{-1}$ as phosphate rock (50PR) and $20 \mathrm{~kg} \mathrm{P}$ 
$\mathrm{ha}^{-1}$ as triple superphosphate (20TSP). According to the methodology developed for the Tropical Forage Program by CIAT to establish pasture in acid soils, the effect of 50PR and 20TSP on the $\mathrm{P}$ availability to the plant is similar.

The chemical composition of the phosphate rock from Huila, Colombia, (commercial fertiliser "Calfomag") was 5.2\% P, 25\% Ca, 6\% Mg and 1\% S. A basal fertiliser was applied ( $\left.\mathrm{kg} \mathrm{ha}^{-1}\right)$ at $20 \mathrm{~K}(\mathrm{KCl}), 50 \mathrm{Ca}$ (agricultural lime plus dolomitic lime), $14 \mathrm{Mg}$ (dolomitic lime) and $10 \mathrm{~S}$ (elemental sulfur). Assuming that a legume as Arachis pintoi can fix nitrogen from the atmosphere by symbiosis with native Rhizobium strains, the trial was not fertilised with nitrogen.

The calculated fertiliser amounts for each subplot were thoroughly mixed in a plastic bag and then separately applied to each subplot to have a homogeneous distribution on the whole area. The subplots $(4 \mathrm{~m} \times 3 \mathrm{~m}$ ), which consisted of 8 rows spaced $40 \mathrm{~cm}$ apart, were sown in June 1999. The establishment of the different wild genotypes was not homogeneous due to a low germination percentage caused by a natural high seed dormancy and high rainfall during and after sowing. Therefore, a second sowing 15 days later was necessary in order to achieve a more homogenous establishment. Plant density of 30 plants $\mathrm{m}^{-2}(10 \mathrm{~cm}$ between plants and $40 \mathrm{~cm}$ between rows) in each subplot was reached by thinning. However, the plants' ages were heterogeneous. Weed control was done by hoeing between rows and by hand in the rows. Harvests were carried out 45 and 90 days after thinning.

\section{Measurements and Analysis}

\section{Shoot sampling}

At harvest, $1 \mathrm{~m}^{2}$ area of plants was cut at soil surface from each subplot and its shoot fresh weight was determined. The shoot biomass was blended and a sample was taken and weighed. Leaf lamina were separated from other shoot material and after determining the leaf area (LI 3100; LI-COR Inc., Lincoln-NE) leaves and stems were then separately oven-dried at $70^{\circ} \mathrm{C}$ for 2 days, weighed and ground to pass a $1 \mathrm{~mm}$ stainless steel sieve.

\section{Chemical analysis}

\section{Plant material}

Subsamples of the ground plant material were wet digested in a concentrated di-acid mixture $\left(\mathrm{HNO}_{3}\right.$ and $\mathrm{HClO}_{4}$ in a volumetric ratio of $2: 1$, respectively). Phosphorus content was measured 
by the method of Murphy and Riley (1962). All analyses were performed twice and the results presented are the average of both measurements of three replications.

\section{Soil analysis}

To characterize readily available phosphorus and a part of the active reserve of phosphorus in acid soil, the Bray II extraction method of Bray and Kurtz (1965) was used. Briefly, an amount of $2.85 \mathrm{~g}$ of air dried soil (2 mm sieved) was mixed $(300 \mathrm{rpm})$ for $40 \mathrm{sec}$ with $20 \mathrm{~mL}$ of extractant solution $\left(0.03 \mathrm{M} \mathrm{NH}_{4} \mathrm{~F}+0.1 \mathrm{M} \mathrm{HCl}\right)$ and later filtered. Inorganic $\mathrm{P}$ in soil extractions was analysed colorimetrically after Murphy and Riley (1962). The $\mathrm{pH}$ value was measured in a soil-water ratio of 1:1.

\subsubsection{Pot experiment}

The plants were grown in a growth chamber, at $16 / 8$ hours light/dark regime, $30 / 20^{\circ} \mathrm{C}$ and a constant relative humidity of $75 \%$. The photosynthetic photon flux density during daylight was $250 \mu \mathrm{E} \mathrm{m}^{-2} \mathrm{~s}^{-1}$.

\section{Growth conditions}

After sterilizing the seeds with $30 \% \mathrm{H}_{2} \mathrm{O}_{2}$ (hydrogen peroxide) for 10 minutes and washing them in distilled water, the seeds were germinated in sand culture. Eight pre-germinated seeds were placed directly into each pot and after thinning, only four plants were grown per pot. Plastic pots (3 liter) were filled with $3.5 \mathrm{~kg}$ of air dry clay fossil Oxisol from Lich in the Vogelsberg area (Hessen - Germany). Soil analysis before fertiliser application showed the following characteristics: $5.1 \mathrm{pH}\left(0.01 \mathrm{M} \mathrm{CaCl}_{2}\right.$ 1:2.5); $3.0 \mathrm{mg} \mathrm{P} \mathrm{kg}^{-1}$ (CAL) and $12.9 \mathrm{mg} \mathrm{P} \mathrm{kg}^{-1}$ (Bray II). Tarafdar and Claassen (2003) reported additional characteristics for this fossil Oxisol as follows: $20 \%$ sand, $41 \%$ clay, $39 \%$ silt, $0.3 \%$ organic matter, $\mathrm{Fe}_{\mathrm{ox}} 2925 \mathrm{mg} \mathrm{kg}{ }^{-1}, \mathrm{Al}_{\mathrm{ox}} 3544 \mathrm{mg} \mathrm{kg} \mathrm{kg}^{-1}$, Fe/Al-P $788 \mathrm{mg} \mathrm{kg}^{-1}$ and Ca-P $330 \mathrm{mg} \mathrm{kg}^{-1}$. The rates of P used as treatment were 0,10 and 400 mg $\mathrm{P} \mathrm{kg}^{-1}$ of soil supplied as $\mathrm{Ca}\left(\mathrm{H}_{2} \mathrm{PO}_{4}\right)_{2} \cdot \mathrm{H}_{2} \mathrm{O}$. These rates were incorporated by thoroughly mixing them with the soil. Before sowing, the fertilisation gave soil solution P concentrations of $0.11 \mu \mathrm{M}(0 \mathrm{P}), 0.15 \mu \mathrm{M}(10 \mathrm{P})$, and $1.75 \mu \mathrm{M}$ (400P). Other added nutrients ( $\mathrm{mg} \mathrm{kg}^{-1}$ soil) were 50 $\mathrm{K}$ as $\mathrm{K}_{2} \mathrm{SO}_{4}, 40 \mathrm{Mg}$ as $\mathrm{MgSO}_{4}, 0.2 \mathrm{~B}$ as $\mathrm{H}_{3} \mathrm{BO}_{3}$, and $0.1 \mathrm{Mo}$ as $\left(\mathrm{NH}_{4}\right)_{6} \mathrm{Mo}_{7} \mathrm{O}_{24}$. 
Agricultural legumes are commonly inoculated with selected strains of rhizobia to cover the $\mathrm{N}$ demand in the expectation that the inoculation will fix the nitrogen more effectively than the native strains. However, the success or failure of inoculant strains and the symbiotic effectiveness vary between species and within cultivars due to the different affecting factors in the environment (Vincent, 1982). In order to have solely the effect of different $\mathrm{P}$ availabilities in the soil on the $\mathrm{P}$ efficiency of the genotypes, $200 \mathrm{mg} \mathrm{N} \mathrm{kg}{ }^{-1}$ soil as $\mathrm{Ca}\left(\mathrm{NO}_{3}\right)_{2}$ split in two applications ( 0 and 35 days) was added.

The moisture content of the soil was adjusted to $65 \%$ of the maximum water holding capacity and monitored daily by weighing. One pot was left unplanted to measure soil moisture evaporation losses and also as control of $\mathrm{P}$ dynamic in unplanted soil.

The trial was arranged in a completely randomized design with three replications. Pots were relocated weekly to minimize any effect of uneven environmental factors within the growth chamber. Plants were harvested 70 days after transplanting.

\section{Measurements and Analysis}

\section{Shoots sampling}

Plants were harvested by cutting at soil surface and the shoots were oven-dried at $65^{\circ} \mathrm{C}$ for 1 day and then at $105^{\circ} \mathrm{C}$ to determine dry weight. After grinding, the plant material was used for determining the phosphorus concentration.

\section{Root sampling and root length}

The roots were carefully separated by washing off the soil in a sieve with a $200 \mu \mathrm{m}$ wide mesh. Roots were cleaned of any foreign materials and then spread on paper towels. The surface moisture on the roots was removed manually by applying uniform pressure using paper towels and finally the root fresh weight was determined. Afterwards, a representative fresh root material of different parts of the root system (upper, middle and apical) was cut in small pieces (0.5-1 $\mathrm{cm})$. After blending these root portions, two sub-samples were taken and preserved in $20 \%$ ethanol for later measurements of the root length, using the line intersection method of Tennant (1975). The fresh weight of the rest of the roots was recorded and then oven-dried and ground as described above for the shoots. 
The sub-sample was dispersed in a known volume of water and an aliquot was taken and poured in a plastic dish with a grid bottom with lines $1.25 \mathrm{~cm}$ apart. The total number of root intercepts with the vertical and horizontal grid lines was counted by means of hand tally counter. The root length in the aliquot of the sub-sample was calculated using the following equation:

$$
\mathrm{RL}=\frac{11}{14} \cdot \mathrm{GD} \cdot \mathrm{N}
$$

where, $\quad \mathrm{RL}=$ Root length of the sample in the plastic dish in $\mathrm{cm}$

$\mathrm{GD}=$ Grid dimension $(1.25 \mathrm{~cm}$ grid squares $)$

$\mathrm{N}=$ Number of intercepts

The root length in the fresh weight subsample was calculated from a volumetric relation between the aliquot and the subsample. The total root length of the plants was obtained from the weight relation between the subsample and the total weight.

\section{Chemical analysis}

\section{Plant material}

Roots and shoots dry ground material $(0.2 \mathrm{~g})$ was digested in $4 \mathrm{~mL} \mathrm{HNO}_{3}(65 \%)$ by using a teflon container under pressure at $175^{\circ} \mathrm{C}$ for 11 hours. Phosphorus was measured using the molybdate-vanadium method of Kitson and Mellon (1944).

\section{Soil Analysis}

\section{Available phosphorus}

Available P was characterized using i) the soil extraction methods of Bray II and the standard German method CAL (Ca-acetate-lactate extraction) (Schüller, 1969) and ii) the soil solution P concentration (Adams, 1974). Inorganic P in soil extracts and in soil solutions were analysed colorimetrically after Murphy and Riley (1962).

Since extremely low Pi concentration in the soil solution $(0.06 \mu \mathrm{M})$ have been reported for the used fossil Oxisols (Tarafdar and Claassen, 2003), the reliability of the measurements in the spectrophotometer using a cuvette with a path length of $5 \mathrm{~cm}$ was assessed by the calculation of the confidence interval for a specified limit of determination (LOD) according the methodology of Eurochem (Kromidas, 1999). The LOD is the concentration level at which a quantitative 
measurement can be performed with a stated relative uncertainty i.e. the lowest concentration that can be measured using routine analysis. Therefore, for a confidence interval of $25 \%$, the consequential limit of determination is: $\mathrm{LOD}=0.065 \mu \mathrm{M} \pm 0.016 \mu \mathrm{M}$.

\section{P-CAL extract}

Into a plastic flask, $5 \mathrm{~g}$ of air dried soil (2 mm sieved), $100 \mathrm{~mL}$ of CAL solution (0.1 M Calactate; 0.1 M Calcium acetate, 0.3 M Acetic acid adjusted to $\mathrm{pH} 4.1$ ) and a small amount of $\mathrm{P}$ free charcoal were mixed and horizontally shaken for $90 \mathrm{~min}$ and finally filtered. Values of CAL $\mathrm{P}<20 \mathrm{mg} \mathrm{P} \mathrm{kg}^{-1}$ are ranged as very low soil content class (Landwirtschaftskammer Weser Ems, 2003). The $\mathrm{pH}$ value was measured in a soil- $0.01 \mathrm{M} \mathrm{CaCl}_{2}$ solution ratio of 1:2.5.

\section{Soil solution}

Soil solution of planted and unplanted pots was obtained by a modified column displacement technique (Adams, 1974). Taking into account the evapotranspiration, one day before harvesting water was added to have the soil with moisture around $60 \%$ of its water holding capacity. After cutting the shoot, the soil was separated from the roots, sieved with a $4 \mathrm{~mm}$ wide mesh and then plastic graduated cylinders of $250 \mathrm{~mL}$ with filter paper covering the drain hole at the bottom were filled. A similar soil density as it had in the pot was reached hitting the cylinder softly at the bottom during the filling up. Using a peristaltic pump, water was allowed to drop slowly onto the soil surface. The water displaced the soil solution downwards, where it was collected in acidwashed glass beakers. In order to have a good water distribution as well as to avoid surface sealing due to water dropping, coarse sand was placed at the top.

To collect only the soil solution without dilution by the added water, $4 \%$ potassium thiocyianate was added to the water as a marker. The collected soil solution was then tested with $5 \% \mathrm{FeCl}_{3}$. A red colouration in the solution would indicate the presence of the marker. In the measurements, the marker was never detected in the first $20 \mathrm{~mL}$ and hence only the first $15 \mathrm{~mL}$ of the displaced soil solution were collected for measurements of phosphorus concentrations. The $\mathrm{pH}$ in the soil solution was also determined by potentiometry. 


\subsection{Results and Discussion}

\subsubsection{Field experiment}

\subsubsection{Shoot biomass production and influence of the germination}

Figures 2.1 and 2.2 show the dry weight shoot production in each $\mathrm{P}$ treatment for all the genotypes at 45 and 90 days after establishment (DAE). The genotypes' growth for the first as well as for the second harvest, as measured by shoot per unit soil surface area ( $\left.\mathrm{t} \mathrm{ha}^{-1}\right)$, varied greatly, but in a similar proportion at the same P levels. Moreover, the yield pattern among the genotypes tended to be similar at each $\mathrm{P}$ treatment at both harvest. For example, at $90 \mathrm{DAE}$ (Figure 2.2) the variation between the maximum and minimum yields among the genotypes at each P level was around $70 \%$.

Genotype 4 had the maximum yield at $0 \mathrm{P}\left(2.2 \mathrm{t} \mathrm{ha}^{-1}\right)$ and at 50PR $\left(2.9 \mathrm{t} \mathrm{ha}^{-1}\right)$ and genotype 6 at 20TSP $\left(2.2 \mathrm{tha}^{-1}\right)$, whereas genotype 10 had the minimum yield at each P level $(0.7,0.9$ and 0.7 $\mathrm{t} \mathrm{ha}^{-1}$, respectively). The same pattern was already recorded at 45 DAE for OP and 50PR (Figure 2.1). Here, it is important to highlight that at 90 DAE the maximum and minimum yields at 20TSP did not differ from the yields at 0P (Figure 2.2).

Rao et al. (1993), who evaluated the adaptation to low P supply of genotype 1 (Arachis pintoi CIAT 17434) when grown in a clay loam Oxisol (2.1 $\mathrm{mg} \mathrm{P} \mathrm{kg}^{-1}$ Bray II) at four P treatments (0, 10,20 and $50 \mathrm{~kg} \mathrm{P} \mathrm{ha}^{-1}$ as triple superphosphate) in a greenhouse using a big container, reported similar yields at $\mathrm{OP}\left(0.8 \mathrm{tha}^{-1}\right)$ as those found in the field. However, contrary to that recorded in the field, the addition of 20TSP increased clearly the yield $\left(3.7 \mathrm{t} \mathrm{ha}^{-1}\right)$ in the greenhouse and it was even 1.2 times higher that the maximum yield found at 50PR in the field. Although different soils were used, the different effects of the fertiliser (20TSP) on the yields can be related to: i) the growth conditions (field and greenhouse), and ii) the way to add the fertiliser to the soil (in a greenhouse trial it is mixed with the soil and in a field trial it is spread on the soil surface) as reported by Gerloff, (1987). Furthermore, in the above mentioned experiment Rao et al., (1993) reported that the maximal $\mathrm{P}$ application (50TSP) was not high enough to reach an asymptote.

The yield of the genotypes at 90 DAE, in comparison to the overall mean, showed also a similar pattern at each $\mathrm{P}$ level (Figure 2.2). For instance, at $0 \mathrm{P}$ there were 4 genotypes $(1,2,4,6)$ above the overall mean $\left(1.24 \mathrm{tha}^{-1}\right)$, while the rest of the genotypes had a similar yield which did not differ statistically among them. Taking into consideration that for this study $\mathrm{P}$ efficient genotypes are those capable of producing a high yield under low $\mathrm{P}$ conditions at $90 \mathrm{DAE}$, two $\mathrm{P}$ efficient groups were identified. Genotypes 4, 6, 1 and 2, in decreasing order, were rated as $\mathrm{P}$ efficient, while the rest were considered as P inefficient. 


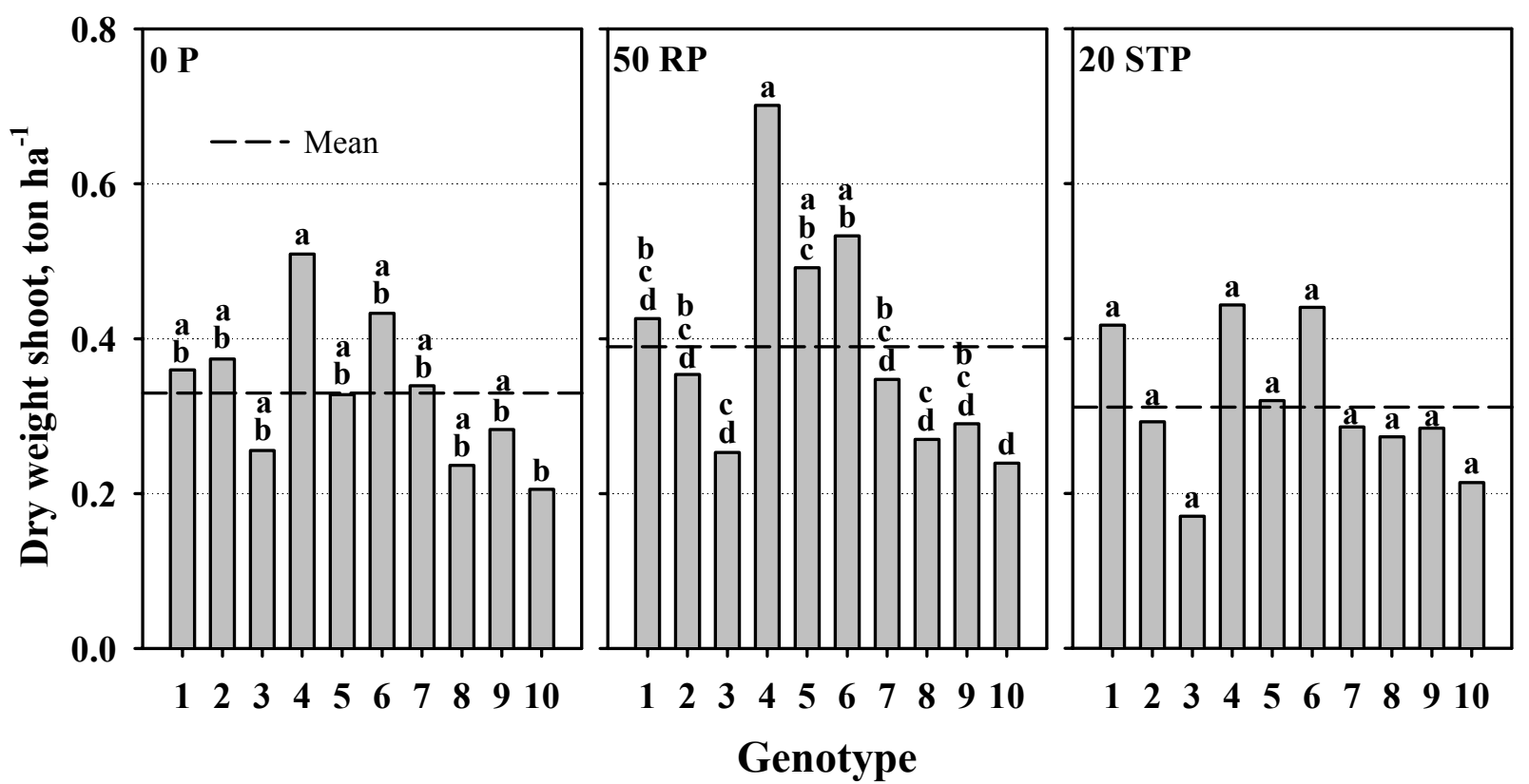

Figure 2.1 Influence of $\mathrm{P}$ fertilisation $\left(0 \mathrm{P}=\right.$ native phosphorus; $50 \mathrm{PR}=50 \mathrm{~kg} \mathrm{P} \mathrm{ha}^{-1}$ as phosphate rocks; 20TSP $=20 \mathrm{~kg} \mathrm{P} \mathrm{ha}^{-1}$ as triple superphosphate) on shoot dry matter production $\left(\mathrm{t} \mathrm{ha}{ }^{-1}\right)$ of ten Arachis pintoi genotypes 45 days after establishment. Within a $\mathrm{P}$ treatment, bars marked with the same letters are not statistically different according to the Tukey mean test $(\mathrm{p}<0.05)$.
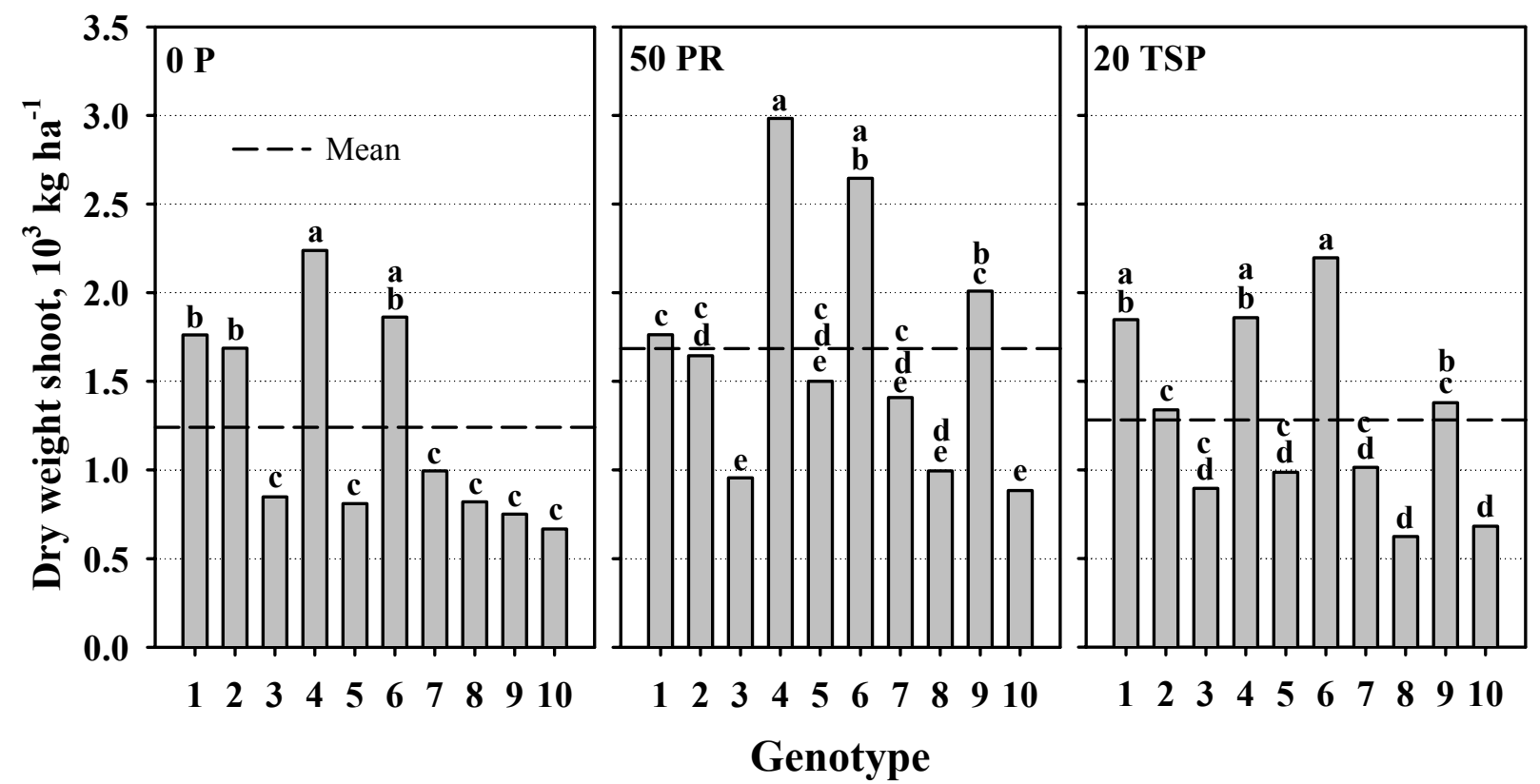

Figure 2.2 Influence of $\mathrm{P}$ fertilisation $\left(0 \mathrm{P}=\right.$ native phosphorus; $50 \mathrm{PR}=50 \mathrm{~kg} \mathrm{P} \mathrm{ha}^{-1}$ as

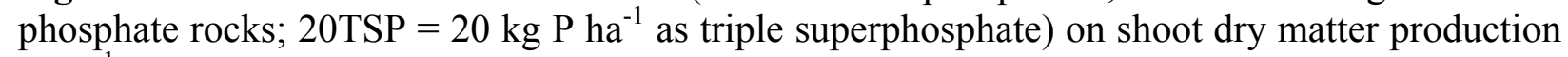
$\left(\mathrm{t} \mathrm{ha}{ }^{-1}\right)$ of ten Arachis pintoi genotypes 90 days after establishment. Within a $\mathrm{P}$ treatment, bars marked with the same letters are not statistically different according to the Tukey mean test $(\mathrm{p}<0.05)$. 
The absolute yield values, instead of the relative yield, were used as selection criterion in this present study because the comparing of $\mathrm{P}$ efficiency is among genotypes within the same specie (Arachis pintoi). The use of relative yield is more sense for comparison $\mathrm{P}$ efficiency among species due to its different ontogenesis.

When $\mathrm{P}$ was added, the overall mean of the genotypes at 50PR was $26 \%$ higher than at $0 \mathrm{P}$, but unexpectedly at 20TSP it did not differ from the overall mean at 0P (Figure 2.2). Furthermore, the genotypes rated as $\mathrm{P}$ efficient were also above the overall mean, except for genotype 2 at 50PR. However, when the effect of the fertilisation on the genotypes' yields were compared with the yields at 0P, an increase was recorded only for genotypes $4(33 \%)$ and $6(42 \%)$ at 50PR and for genotypes $1(5 \%)$ and $6(18 \%)$ at 20TSP.

With regards to the genotypes rated as $\mathrm{P}$ inefficient, all increased their yield much more at 50PR than at 20TSP in comparison to OP. From them, genotypes 9 and 5 showed the highest $\mathrm{P}$ dependence and increased its yield 2.7-fold and 1.9-fold at 50PR and 1.8-fold and 1.2-fold at 20TSP compared to 0P, respectively. However, only the increase of genotype 9 achieved a yield above the overall mean at 50PR and at 20TSP.

A plausible explanation for this low biomass production at 20TSP could be that the soil solution $\mathrm{P}$ concentration was not increased when $20 \mathrm{~kg} \mathrm{P} \mathrm{ha}^{-1}$ as TSP was added. The Ultisols, characterized by having clayey topsoils with more than $20 \%$ iron or aluminium oxides in their clay particles, "fix" or sorb rapidly large quantities of added phosphorus, transforming them into slowly soluble iron and aluminium phosphates that are not available to the plants (Sanchez et al., 2003). Moreover, Sanchez and Uehara 1980 reported that soils with a high P sorption capacity like Ultisols or Oxisols are able to absorb up to $5600 \mathrm{~kg} \mathrm{ha}^{-1} \mathrm{P}$ until they are able to provide satisfactory crop growth. On the other hand, it is well known that diffusion i.e. phosphorus flux through the soil to the plant's roots, is in many soils the mechanism governing 90 to $98 \%$ of the P supply to the roots (Barber, 1980). The diffusion depends strongly on the initial solution $\mathrm{P}$ concentration and because of the high $\mathrm{P}$ buffer power of this soil, the addition of $20 \mathrm{~kg}$ of TSP ha ${ }^{-1}$ might not have been enough to alter the P concentration in the soil solution and the values were similar as at $0 \mathrm{P}$. In contrast, the biomass production at 50PR led to conclude that the soil solution $\mathrm{P}$ concentration was increased. Characteristics for good effectiveness from a direct application of PR as described by Bolan et al., (1990) are: particle size of PR (finely ground), soil conditions (acidic soil $<\mathrm{pH} 5.5$ in $\mathrm{CaCl}_{2}$ and preferably $<\mathrm{pH} 4.9$ ), the crop grown (perennial rather than annual) and the rainfall ( $>500 \mathrm{~mm}$ and preferably $>800 \mathrm{~mm}$ ). These conditions were present in this field trial. Moreover, phosphate rocks have generally proved to be 
more effective in supplying $\mathrm{P}$ to perennial crops and permanent pastures in New Zealand than for cereal crops and pastures based on annual legumes in Australia (Bolan et al., 1990).

The above described results of shoot biomass production were besides $\mathrm{P}$ efficiency also affected by the different germination of the different genotypes. Since wild genotypes of Arachis pintoi $(A p)$ were used, their natural dormancy affected the germination making it low and irregular. Moreover, high rainfall, during and after the sowing, was also a negative contributing factor to the homogeneous establishment of the field trial. These facts influenced the growth potential of the different genotypes among $\mathrm{P}$ treatments and replications.

Figure 2.3 shows that the biomass production at 90 DAE was effected by germination. That means for instance, that the good growth performance of genotype 4 was rather due to a good germination than P efficiency.

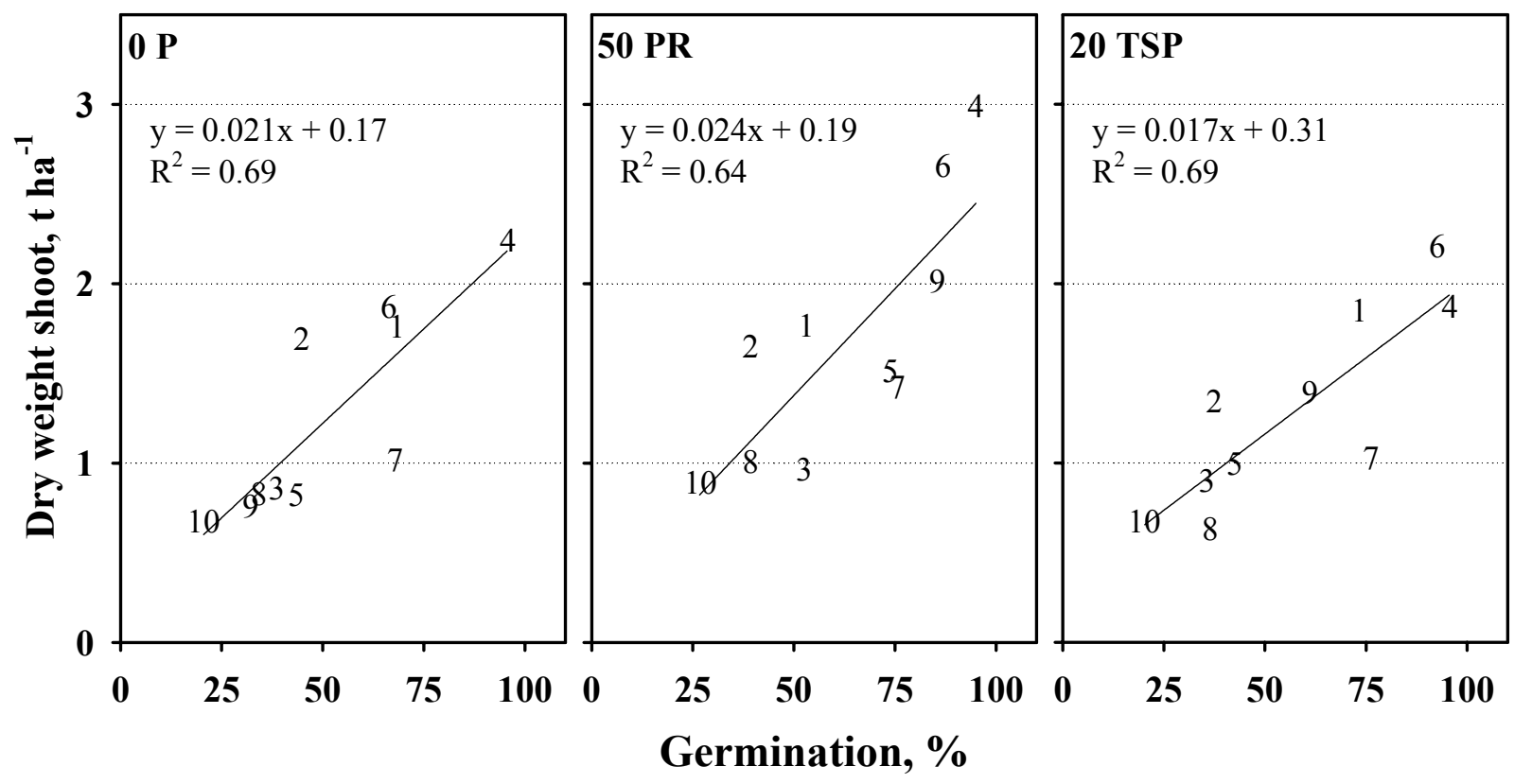

Figure 2.3 Influence of genotype germination at each $\mathrm{P}$ fertilisation $(\mathrm{P}=$ native phosphorus; $50 \mathrm{PR}=50 \mathrm{~kg} \mathrm{P} \mathrm{ha}{ }^{-1}$ as phosphate rocks; 20TSP $=20 \mathrm{~kg} \mathrm{P} \mathrm{ha}^{-1}$ as triple superphosphate) on shoot biomass production 90 days after establishment.

However, there were a few genotypes $(2,6,1)$ that obtained high yields that cannot be explained by germination, specially in the treatments with low P availability (0P and 20TSP). On the other hand, some genotypes $(5,7)$ were always below the regression line. These results show that the $\mathrm{P}$ efficiency in the experiment cannot be deduced solely by the dry matter yield, because this is mainly influenced by germination. Taking this into account, the residue between measured values and the regression lines (Figure 2.3) was considered to describe the P efficiency of the genotypes. Additionally, it was necessary to redefine the selection criterion in order to identify 
the actual P efficient genotypes under these conditions. Since the objective of the present study is to select Arachis pintoi genotypes according their $\mathrm{P}$ efficiency i.e. ability to yield under low $\mathrm{P}$ supply, as new selection criterion was used the absolute residual difference (ARD) at OP i.e. $\underline{\mathrm{P}}$ efficient genotypes would be those with a high ARD of shoot biomass production under low $\mathrm{P}$ supply at 90 DAE. Table 2.2 shows the calculation of the absolute residual differences i.e. measured dry shoot biomass at 90 DAE, minus calculated dry shoot biomass through the correlation found in the $0 \mathrm{P}$ treatment.

Table 2.2 Calculation of the absolute residual difference (ARD) between the dry shoot biomass values and the calculated by the correlation formula $y=21.1 x+168.3$ for the second harvest $(90$ $\mathrm{DAE})$ at $0 \mathrm{P}$.

\begin{tabular}{cccccc}
\hline \multirow{2}{*}{ Genotype } & Germination & \multicolumn{3}{c}{ Shoot biomass, kg ha ${ }^{-1}$} & \multirow{2}{*}{\begin{tabular}{c} 
Difference \\
\cline { 3 - 4 }
\end{tabular}} \\
\cline { 3 - 4 } & $\%$ & Measured & Calculated & ARD & $\%$ \\
\hline 2 & 44 & 1687 & 1106 & 581 & 52 \\
6 & 66 & 1863 & 1569 & 294 & 17 \\
1 & 68 & 1762 & 1598 & 164 & 10 \\
10 & 21 & 667 & 602 & 65 & 7 \\
4 & 96 & 2239 & 2185 & 54 & 2 \\
8 & 34 & 820 & 883 & -63 & -8 \\
9 & 32 & 751 & 848 & -97 & -12 \\
3 & 38 & 848 & 977 & -129 & -16 \\
5 & 43 & 810 & 1077 & -266 & -25 \\
7 & 68 & 995 & 1610 & -615 & -38 \\
\hline
\end{tabular}

These results show a very high discrepancy in the absolute residual difference among the genotypes, but especially among those above the regression line. For instance, genotype 2 had the maximal residual difference (52\%) followed by genotype $6(17 \%)$, and genotype 7 had the minimal absolute residual difference (-38\%). Other genotypes, whose absolute residual difference was close above and below the regression line, seemed to have an average yield. Consequently, taking into consideration the new classification criterion, genotypes 2,6 , and 1 were rated as P efficient, genotypes 3, 5 and 7 as P inefficient and genotypes 10, 4, 8 and 9 as genotypes with an average $\mathrm{P}$ efficiency. Table 2.2 presents the new $\mathrm{P}$ efficient order ranked from highest to lowest, which from now on will be used as the standard to present the result of this study. 


\subsubsection{Shoot $P$ concentration}

The nutritional status of the plant can be characterised by the P concentration in the dry matter. Table 2.3 shows the influence of $\mathrm{P}$ fertilisation on the $\mathrm{P}$ concentration of the shoot at 45 and 90 DAE. It is important to note that all the genotypes showed no statistically significant differences at the different $\mathrm{P}$ treatments and harvest times. However at both harvests the fertilised treatments (20TSP and 50PR) had in general a higher P shoot concentration than in the 0P treatment.

Table 2.3 Influence of $\mathrm{P}$ fertilisation ( $0 \mathrm{P}=$ native phosphorus; $50 \mathrm{PR}=50 \mathrm{~kg} \mathrm{P} \mathrm{ha}^{-1}$ as phosphate rocks; 20TSP $=20 \mathrm{~kg} \mathrm{P} \mathrm{ha}^{-1}$ as triple superphosphate) on shoot $\mathrm{P}$ concentration ( $\mathrm{g}$ $\mathrm{kg}^{-1}$ ) of ten Arachis pintoi genotypes 45 and 90 days after establishment.

\begin{tabular}{|c|c|c|c|c|c|c|}
\hline \multirow{3}{*}{ Genotype } & \multicolumn{6}{|c|}{ Shoot $\mathrm{P}$ concentration, $\mathrm{g} \mathrm{kg}^{-1}$} \\
\hline & \multicolumn{3}{|c|}{$45 \mathrm{DAE}$} & \multicolumn{3}{|c|}{$90 \mathrm{DAE}$} \\
\hline & OP & 50PR & 20TSP & OP & 50PR & 20TSP \\
\hline 2 & $2.7 \mathrm{a}$ & $3.2 \mathrm{a}$ & $3.4 \mathrm{a}$ & $2.3 \mathrm{a}$ & $2.5 \mathrm{a}$ & $2.6 \mathrm{a}$ \\
\hline 6 & $2.5 \mathrm{a}$ & $2.6 \mathrm{a}$ & $2.9 \mathrm{a}$ & $1.9 \mathrm{a}$ & $2.0 \mathrm{a}$ & $2.2 \mathrm{a}$ \\
\hline 1 & $2.7 \mathrm{a}$ & $3.3 \mathrm{a}$ & $3.0 \mathrm{a}$ & $2.0 \mathrm{a}$ & $2.2 \mathrm{a}$ & $2.3 \mathrm{a}$ \\
\hline 10 & $2.9 \mathrm{a}$ & $2.8 \mathrm{a}$ & $3.2 \mathrm{a}$ & $2.1 \mathrm{a}$ & $2.5 \mathrm{a}$ & $2.8 \mathrm{a}$ \\
\hline 4 & $2.4 \mathrm{a}$ & $3.2 \mathrm{a}$ & $3.0 \mathrm{a}$ & $1.9 \mathrm{a}$ & $2.4 \mathrm{a}$ & $2.8 \mathrm{a}$ \\
\hline 8 & $2.5 \mathrm{a}$ & $2.8 \mathrm{a}$ & $3.1 \mathrm{a}$ & $2.0 \mathrm{a}$ & $2.6 \mathrm{a}$ & $2.5 \mathrm{a}$ \\
\hline 9 & $2.3 \mathrm{a}$ & $2.6 \mathrm{a}$ & $2.9 \mathrm{a}$ & $1.9 \mathrm{a}$ & $2.0 \mathrm{a}$ & $2.3 \mathrm{a}$ \\
\hline 3 & $2.7 \mathrm{a}$ & $3.2 \mathrm{a}$ & $3.0 \mathrm{a}$ & $1.8 \mathrm{a}$ & $2.4 \mathrm{a}$ & $2.1 \mathrm{a}$ \\
\hline 5 & $2.7 \mathrm{a}$ & $2.9 \mathrm{a}$ & $3.2 \mathrm{a}$ & $2.2 \mathrm{a}$ & $2.3 \mathrm{a}$ & $2.5 \mathrm{a}$ \\
\hline 7 & $2.3 \mathrm{a}$ & $2.3 \mathrm{a}$ & $2.4 \mathrm{a}$ & $2.2 \mathrm{a}$ & $2.1 \mathrm{a}$ & $2.3 \mathrm{a}$ \\
\hline $\bar{X}$ & 2.6 & 2.9 & 3.0 & 2.0 & 2.3 & 2.4 \\
\hline
\end{tabular}

Within a $\mathrm{P}$ treatment, values followed with the same letters are not statistically different according to the Tukey mean test $(\mathrm{p}<0.05)$.

With age (90 DAE), the concentration decreased. Furthermore, although at 0P genotype 2 had the highest $\mathrm{P}$ concentration and genotype 3 the lowest, there was no visible trend that the $\mathrm{P}$ concentration decreased with decreasing $\mathrm{P}$ efficiency. The addition of fertilisers produced an increase in the $\mathrm{P}$ concentration. From the $\mathrm{P}$ efficient, genotype 2 had the highest increase (9\%), but the genotypes with average $\mathrm{P}$ efficiency $(10,4,5)$ had the highest increase overall with respect to $0 \mathrm{P}$. It is noteworthy that although in average the genotypes had the highest shoot $\mathrm{P}$ concentration at 20TSP, the highest yield was at 50PR and low yield differences were found between 20TSP and 0P (Figure 2.3). 
Rao and Kerridge (1994) reported $2.0 \mathrm{~g} \mathrm{~kg}^{-1}$ as sufficient P concentration in leaves of genotype 1 (CIAT 17434) after an establishment of 70 days. Taking this result into consideration, both the efficient and inefficient genotypes grown at $0 \mathrm{P}$ and at 90 DAT had a sufficient $\mathrm{P}$ nutritional status. Nevertheless, there were yield differences between 0P and 50PR i.e. the P was not limited but also not sufficient. Hence, under the given growth conditions a $\mathrm{P}$ concentration of $2.0 \mathrm{~g} \mathrm{~kg}^{-1}$ might be too low. On the other hand, the fact that the addition of 20TSP increased the shoot P concentration clearly above the sufficient $\mathrm{P}$ concentration but the yield was similar to $0 \mathrm{P}$, it may indicated that the high yield at 50PR was not a response to the $\mathrm{P}$ fertilisation but may be to the $\mathrm{Ca}$ and $\mathrm{Mg}$ of PR.

Taking into account that the $\mathrm{P}$ use efficiency is equivalent to the inverse of the $\mathrm{P}$ concentration, these results suggest that differences in the $\mathrm{P}$ efficiency among the genotypes under low $\mathrm{P}$ availability tend to be more related to their ability to acquire $P$.

\subsubsection{Extractable P-Bray II and pH of the soil samples after harvesting}

Beside the relationship between $\mathrm{P}$ concentration and growth of plants, extractable $\mathrm{P}$ in the soil can be a measure of its availability. To describe the availability of $\mathrm{P}$ to the plant through desorption and/or dissolution processes in the soil, the $\mathrm{NH}_{4} \mathrm{~F}$-exchangable $\mathrm{P}$ Bray II was determined at each harvest. According the classification used at CIAT for tropical forages, $\mathrm{P}$ Bray-II values $<2 \mathrm{mg} \mathrm{kg}^{-1}$ are low, between 2 and 5 are medium, between 5 and 10 are high and $>10$ are very high. However, the scale used at CIAT for crops is much higher, e.g. $11 \mathrm{mg} \mathrm{kg}^{-1}$ Bray II is the critical level for a legume like bean.

The extractable $\mathrm{P}$ varied depending on the $\mathrm{P}$ application on the plots and the soil layer at both harvest (Table 2.4). As expected, at 45 and 90 DAE the highest amount of extractable $P$ was measured at 50PR in the first layer $(0-5 \mathrm{~cm})$, followed by 20TSP and 0P. For example, at 50PR the extractable $\mathrm{P}$ was 3-fold and 2.3-fold higher than that of $0 \mathrm{P}$ at $45 \mathrm{DAE}$ and $90 \mathrm{DAE}$ respectively, whereas at 20TSP it was 1.4 -fold at both harvests. Differences on the extractable P among the $\mathrm{P}$ treatments were statistically confirmed. As the depth increased in $5 \mathrm{~cm}$, the extractable $\mathrm{P}$ decreased remarkable, especially where $\mathrm{P}$ was added (by $70 \%$ at $50 \mathrm{PR}$ and by $50 \%$ at TSP) and statistical differences were found only up to the $10 \mathrm{~cm}$ layer for 50PR at 45 DAE. Although some differences in the extractable $\mathrm{P}$ were found in the lower layers, these are very small (around $1 \mathrm{mg} \mathrm{kg}^{-1}$ ). 
Table 2.4 Extractable $\mathrm{P}$ (Bray II) and $\mathrm{pH}_{(\mathrm{H} 2 \mathrm{O})}$ value for planted and unplanted soil at different soil layer under different $\mathrm{P}$ fertilisation treatments $\left(0 \mathrm{P}=\right.$ native phosphorus; $50 \mathrm{PR}=50 \mathrm{~kg} \mathrm{P}^{-1}$ as phosphate rocks; 20TSP $=20 \mathrm{~kg} \mathrm{P} \mathrm{ha}^{-1}$ as triple superphosphate) at 45 and 90 days after establishment.

\begin{tabular}{|c|c|c|c|c|c|c|c|c|c|}
\hline \multirow[b]{3}{*}{$\begin{array}{c}\text { Depth } \\
\mathrm{cm}\end{array}$} & \multirow[b]{3}{*}{$\begin{array}{c}\text { Treatment } \\
\mathrm{kg} \mathrm{ha}^{-1}\end{array}$} & \multicolumn{4}{|c|}{ Planted soil } & \multicolumn{4}{|c|}{ unplanted soil } \\
\hline & & \multicolumn{2}{|c|}{$45 \mathrm{DAE}$} & \multicolumn{2}{|c|}{$90 \mathrm{DAE}$} & \multicolumn{2}{|c|}{$45 \mathrm{DAE}$} & \multicolumn{2}{|c|}{$90 \mathrm{DAE}$} \\
\hline & & $\mathrm{pH}$ & $\begin{array}{l}\text { P-Bray II } \\
\mathrm{mg} \mathrm{kg}^{-1}\end{array}$ & $\mathrm{pH}$ & $\begin{array}{l}\text { P-Bray II } \\
\mathrm{mg} \mathrm{kg}^{-1}\end{array}$ & $\mathrm{pH}$ & $\begin{array}{c}\text { P-Bray II } \\
\mathrm{mg} \mathrm{kg}^{-1}\end{array}$ & $\mathrm{pH}$ & $\begin{array}{c}\text { P-Bray II } \\
\mathrm{mg} \mathrm{kg}^{-1}\end{array}$ \\
\hline \multirow[t]{3}{*}{$0-5$} & OP & $4.6 b$ & $5.1 \mathrm{c}$ & $4.5 \mathrm{ab}$ & $4.9 \mathrm{~b}$ & $4.3 \mathrm{a}$ & $7.6 \mathrm{~b}$ & $4.4 \mathrm{a}$ & $6.4 b$ \\
\hline & 50PR & $4.7 \mathrm{a}$ & $15.6 \mathrm{a}$ & $4.6 \mathrm{a}$ & $10.2 \mathrm{a}$ & $4.3 \mathrm{a}$ & $12.7 \mathrm{a}$ & $4.3 \mathrm{a}$ & $10.8 \mathrm{a}$ \\
\hline & 20TSP & $4.6 b$ & $7.5 b$ & $4.4 \mathrm{ba}$ & $6.5 b$ & $4.3 \mathrm{a}$ & $10.1 \mathrm{a}$ & $4.4 \mathrm{a}$ & $8.6 \mathrm{a}$ \\
\hline \multirow[t]{3}{*}{$5-10$} & OP & $4.5 \mathrm{a}$ & $3.3 b$ & $4.3 \mathrm{ba}$ & $3.1 \mathrm{a}$ & $4.2 \mathrm{a}$ & $4.1 \mathrm{~b}$ & $4.3 \mathrm{a}$ & $3.9 b$ \\
\hline & 50PR & $4.6 \mathrm{a}$ & $4.5 \mathrm{a}$ & $4.5 \mathrm{a}$ & $3.5 \mathrm{a}$ & $4.2 \mathrm{a}$ & $7.0 \mathrm{a}$ & $4.3 \mathrm{a}$ & $6.4 \mathrm{a}$ \\
\hline & 20TSP & $4.6 \mathrm{a}$ & $3.8 \mathrm{ab}$ & $4.4 \mathrm{ba}$ & $3.3 \mathrm{a}$ & $4.2 \mathrm{a}$ & $3.1 b$ & $4.2 \mathrm{a}$ & $3.0 \mathrm{~b}$ \\
\hline \multirow[t]{3}{*}{$10-20$} & OP & $4.5 \mathrm{a}$ & $2.2 \mathrm{a}$ & $4.3 \mathrm{ba}$ & $2.6 \mathrm{a}$ & $4.2 \mathrm{a}$ & $2.2 \mathrm{a}$ & $4.2 \mathrm{a}$ & $2.1 \mathrm{a}$ \\
\hline & $50 \mathrm{PR}$ & $4.5 \mathrm{a}$ & $2.6 a$ & $4.4 \mathrm{a}$ & $2.3 \mathrm{a}$ & $4.1 \mathrm{a}$ & $3.7 \mathrm{a}$ & $4.2 \mathrm{a}$ & $3.5 \mathrm{a}$ \\
\hline & 20TSP & $4.5 \mathrm{a}$ & $2.2 \mathrm{a}$ & $4.3 \mathrm{ba}$ & $2.6 \mathrm{a}$ & $4.2 \mathrm{a}$ & $2.5 \mathrm{a}$ & $4.3 \mathrm{a}$ & $2.4 \mathrm{a}$ \\
\hline \multirow[t]{3}{*}{$20-40$} & OP & $4.5 \mathrm{a}$ & $1.7 \mathrm{a}$ & $4.3 \mathrm{a}$ & $2.0 \mathrm{a}$ & $4.3 \mathrm{a}$ & $1.1 \mathrm{a}$ & $4.3 \mathrm{a}$ & $1.0 \mathrm{a}$ \\
\hline & $50 \mathrm{PR}$ & $4.5 \mathrm{a}$ & $2.0 \mathrm{a}$ & $4.4 \mathrm{a}$ & $1.9 \mathrm{a}$ & $4.2 \mathrm{a}$ & $1.7 \mathrm{a}$ & $4.4 \mathrm{a}$ & $1.6 \mathrm{a}$ \\
\hline & 20TSP & $4.5 \mathrm{a}$ & $1.7 \mathrm{a}$ & $4.3 \mathrm{a}$ & $2.1 \mathrm{a}$ & $4.3 \mathrm{a}$ & $1.2 \mathrm{a}$ & $4.4 \mathrm{a}$ & $1.1 \mathrm{a}$ \\
\hline
\end{tabular}

Treatment followed by the same letters are not statistically different according to the Tukey mean test $(\mathrm{p}<0.05)$.

The fact that the extractable P-Bray II increased only in the $0-5 \mathrm{~cm}$ depth, especially at 50PR, point out that probably a large fraction of the P added as PR (2.5-fold more than that as TSP) was still not solubilized at 90 DAE. Taking into account the CIAT classification, it seems to be that the extractable P-Bray II found at each P treatment were at least with a medium level i.e. the genotypes were grown above the critical level $\left(<2 \mathrm{mg} \mathrm{kg}^{-1}\right)$.

The $\mathrm{pH}_{(\mathrm{H} 2 \mathrm{O})}$ was in general scarcely affected by the $\mathrm{P}$ application. As expected, in the first layer 50PR increased the $\mathrm{pH}$ in both samplings. For the deeper layers, statistical significant differences 
were not found. Under unplanted conditions, the application of fertiliser did not produce any affect on the $\mathrm{pH}$ value. Similar results were found by Jadin and Truong (1987) in an incubation trial, where the single effect of $100 \mathrm{mg} \mathrm{kg}^{-1}$ of fertiliser (PR and TSP) on the $\mathrm{pH}$ of an Oxisol $\left(\mathrm{pH}_{(\mathrm{H} 2 \mathrm{O})} 4.3\right)$ with a relative low $\mathrm{P}$ sorption capacity $\left(234 \mathrm{mg} \mathrm{kg}^{-1}\right)$ was measured. They found that the addition of TSP increased the $\mathrm{pH}$ in the soil only by $7.5 \%$ compared with the control (without fertilisation), whereas the addition of PR increased it by $12.5 \%$. Consequently, the low amount of $\mathrm{P}$ supplied (50PR and 20TSP) to this Ultisols was not sufficient to produce changes in the $\mathrm{pH}$ in the soil.

Both chemical and physical characteristics of Ultisols may be related to this results. Among others, the high acidity and relatively low quantities of plant-available $\mathrm{Ca}, \mathrm{Mg}$, and $\mathrm{K}$ leached by intense weathering and by ii) a high dense sub-surface due to the accumulation of clays with a high content of Fe oxides (Sanchez, 1976), which normally limits root growth and thus root penetration (Unger and Kaspar, 1994). Taking into account this natural soil characteristics and the strong reduction of the $\mathrm{P}$ availability with depth found in the present study (Table 2.4), it is probable that the main $\mathrm{P}$ source for the roots was in the first $10 \mathrm{~cm}$ of depth. In this case, the high extractable $\mathrm{P}$ at 50PR found in the first $10 \mathrm{~cm}$ of depth (Table 2.4) may be related to the increase of the shoot $\mathrm{P}$ concentration (Table 2.3) at 50PR and hence to the higher yield on average of all the genotypes at both harvest (Figure 2.1 and 2.2). However, since in average the shoot $\mathrm{P}$ concentration of the genotypes at 20TSP was higher than that at 50PR (Table 2.3) suggests that a high per cent of the extractable P-Bray II at 50PR resulted from the dissolution of the PR by the acidic extractant solution of Bray II and hence it was not actually available for the plant. The Bray II method is characterized by the extremely acidic extractant solution ( $\mathrm{pH} 1.35$ ), which remove easily acid soluble reaction $\mathrm{P}$ forms (Fe-Al-P), and by the $\mathrm{F}$ ions form complexes with $\mathrm{Al}$ and $\mathrm{Ca}$, which lead to extensive dissolution of $\mathrm{P}$ compounds and also suppresses the readsorption of solubilized $\mathrm{P}$ by soil colloids. Assuming this point of view and that the values of P-Bray II found are above the values used as critical by CIAT, the high yield found at 50PR might be related to the $\mathrm{Ca}$ and $\mathrm{Mg}$ content of the phosphate rocks.

However, that was not the case if 20TSP and 0P are compared. Despite the fact that between 0-5 $\mathrm{cm}$ depth the extractable P Bray II value at 20TSP was already $40 \%$ higher than that of 0P (Table $2.4)$, the $\mathrm{P}$ efficient genotypes $(2,6,1,10)$ at $\mathrm{OP}$ had a higher absolute residual difference than that at 20TSP (data no shown). That may indicate, that i) due to the absorb process in the soil the addition of 20TSP was not able to increase the $\mathrm{P}$ soil solution concentration in comparison to $\mathrm{PP}$ or ii) the $\mathrm{P}$ efficient genotypes were able to increase their $\mathrm{P}$ acquisition efficiency. 
Since the availability of sparingly accumulated soluble $\mathrm{P}$ in the soil to the root is low, genotypes with a $\mathrm{P}$ acquisition efficiency, as were considered genotypes 2, 6, 1 and 10, must be able to enhance either i) the morphological abilities to exploit a larger soil volume through a larger and finer root system (e.g. root hairs, mycorrhizal hyphae) in addition to it's ability to root from stolons and/or ii) their physiological abilities to increase the $\mathrm{P}$ concentration on the root surface (e.g. root exudates, acid phosphatase activity) to a similar level as when 20TSP was added and thus acquire native $\mathrm{P}$ and/or recover $\mathrm{P}$ from less available $\mathrm{P}$ pools in the soil.

\subsubsection{Pot experiment in growth chamber}

In order to validate the results obtained in the field and to identify clearly responsible mechanisms, a growth chamber pot experiment with the same genotypes was conducted.

\subsubsection{Shoot biomass production}

The objectives of this pot trial were to assess whether the genotypes grown under other soil and P supply conditions than in the field, showed a similar P efficiency as that found in the field; as well as the relationship between $\mathrm{P}$ acquisition efficiency and the root system. Furthermore, a high P treatment (400 P) was included as control for the genotypes $(2,1,10,4)$, which in the field had an absolute residual difference above the regression line. The genotypes were plotted in a decreasing order, according to the absolute residual difference calculated at the $0 \mathrm{P}$ treatment in the field at 90 DAE (Table 2.2).

Figure 2.4 shows the shoot yields 70 days after establishment (DAE), as affected by $\mathrm{P}$ fertilisation. After a homogeneous establishment in a fossil Oxisols under controlled growth conditions, most of the genotypes growing under scarce $\mathrm{P}$ conditions showed a different ability to produce shoot biomass compared with the P efficiency found under field conditions (Table 2.2).

At the same P levels, shoot biomass production varied among the genotypes, but the variation decreased when the added $\mathrm{P}$ was increased and it was lower than that in the field. For example, the variation between the maximum and the minimum yields among all genotypes was $62.4 \%$ at $0 \mathrm{P}, 38.2 \%$ at $10 \mathrm{P}$ and $15 \%$ at $400 \mathrm{P}$. Nevertheless, the shoot biomass production on average for all genotypes at $0 \mathrm{P}$ was the same as that at 10P (Figure 2.4). But the average yield of genotypes 2, 1, 10 and 4 at $0 \mathrm{P}$ and $10 \mathrm{P}$ was 1.3-fold lower than that at a high $\mathrm{P}$ supply (400P), which was 8 
times higher than the maximal $\mathrm{P}$ application in the field (50PR). That indicates that the genotypes grown at $0 \mathrm{P}$ and 10P suffered from $\mathrm{P}$ deficiency.

Under unfertilised conditions, the yield of genotypes rated as P efficient in the field did not come clearly forward in comparison to the $\mathrm{P}$ inefficient ones and therefore, the differences were not statistically confirmed. However, from the rated P efficient genotypes in the field (Table 2.2), genotype 2 and 6 yielded above the overall mean of all genotypes, whereas genotype 1 had the lowest yield. It is interesting to note that some genotypes with a low P efficiency in the field were $\mathrm{P}$ efficient in this pot experiment. For example, genotype 10, which had an average $\mathrm{P}$ efficiency in the field (Table 2.2), achieved a yield similar to genotype 2, and specially notable was that the rated $\mathrm{P}$ inefficient genotype 3 in the field had the highest yield among all the genotypes (Figure 2.4).

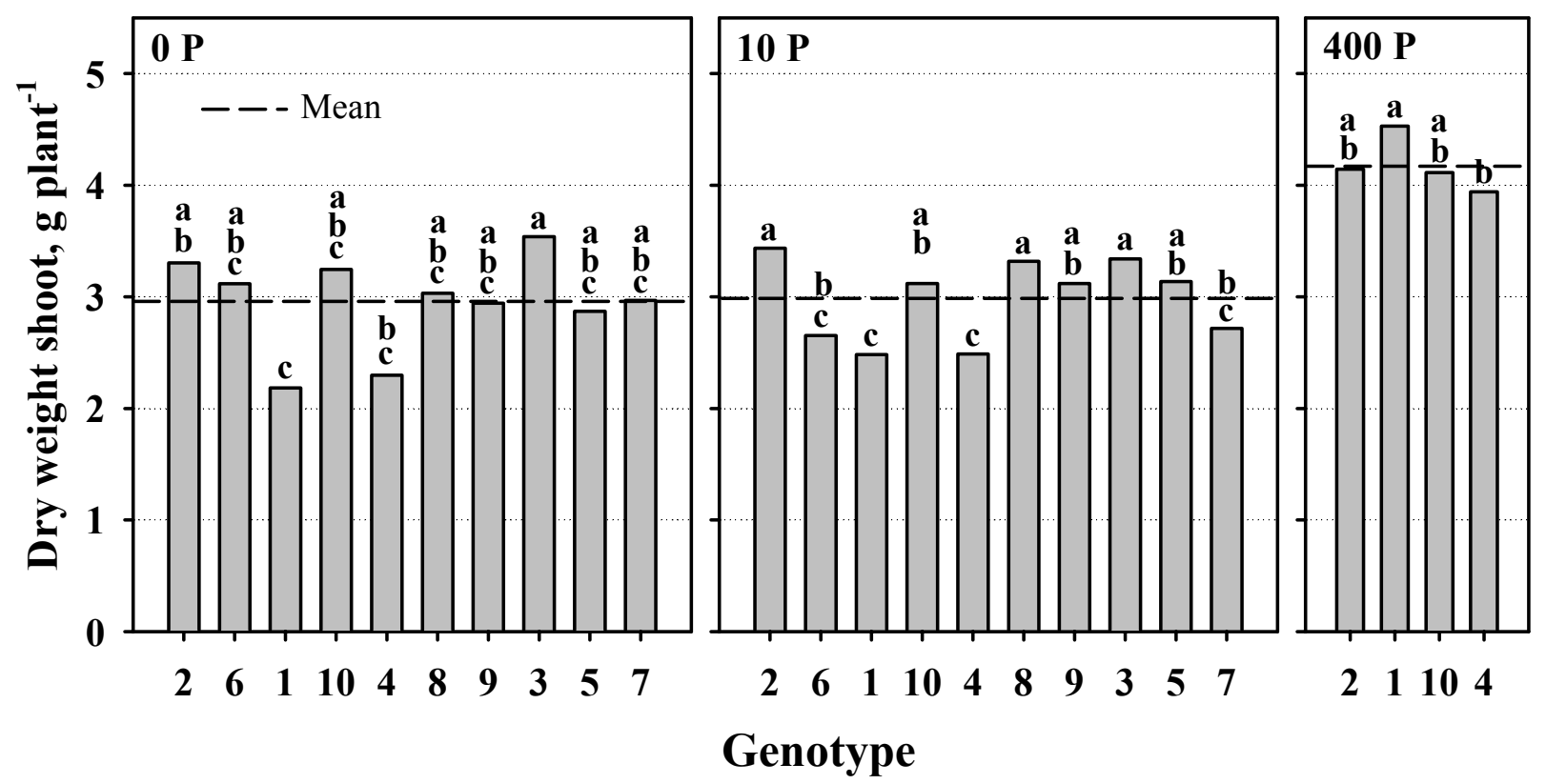

Figure 2.4 Influence of varying phosphorus supply $(0 \mathrm{P}=$ native phosphorus; $10 \mathrm{P}$ and $400 \mathrm{P}=10$ and $400 \mathrm{mg} \mathrm{P} \mathrm{kg}^{-1}$ as $\left.\mathrm{Ca}\left(\mathrm{H}_{2} \mathrm{PO}_{4}\right)_{2} \cdot \mathrm{H}_{2} \mathrm{O}\right)$ on shoot dry matter at 70 days after establishment (DAE). Within a $\mathrm{P}$ treatment, bars marked with the same letters are not statistically different according to the Tukey mean test $(\mathrm{p}<0.05)$.

The addition of $10 \mathrm{mg} \mathrm{P} \mathrm{kg}^{-1}(10 \mathrm{P})$ as $\mathrm{Ca}\left(\mathrm{H}_{2} \mathrm{PO}_{4}\right)_{2}$, which was just about the amount applied in the field (20 kg P ha ${ }^{-1}$ with a bulk density of $1.25 \mathrm{~g} \mathrm{~cm}^{-3}$ results on $\left.8 \mathrm{mg} \mathrm{P} \mathrm{kg}^{-1}\right)$, produced also no effect on the average of the shoot biomass production. As probably also occurred in the field, the available $\mathrm{P}$ in the soil solution $\mathrm{P}$ concentration was not positively affected (Table 2.5 ), due to the high P fixation capacity of this Oxisol. Tarafdar and Claassen (2003) reported a high amount of $\mathrm{Al}$ and $\mathrm{Fe}$ oxide in this fossil Oxisol. The statistical analysis showed that the rated inefficient genotypes, except for genotype 7, were similar to the efficient genotype 2 . When $400 \mathrm{mg} \mathrm{P} \mathrm{kg}^{-1}$ 
(400P) were added, genotype 1 showed the highest response at high $\mathrm{P}$ supply but it was only different to genotype 4 statistically.

It may furthermore be noted that the yield potential, i.e. yield at high P supply, was similar for all genotypes so that differences of growth at low P supply (0P) were due to different ability to cope with low P supply and not to differences of growth potential. This is especially true for genotype 1 with the highest yield potential (400P) but lowest yield at $0 \mathrm{P}$.

\subsubsection{Shoot $P$ concentration and $P$ use efficiency}

As it was already shown in Figure 2.4, the genotypes yielded in average at 10P the same as at $0 \mathrm{P}$. Moreover, at 400P there were no significant differences obtained between the rated $\mathrm{P}$ efficient genotypes 2 and 1 in the field (Figure 2.4). Consequently, P concentration and $\mathrm{P}$ content will be described only at $0 \mathrm{P}$. The data at $10 \mathrm{P}$ and $400 \mathrm{P}$ is given in the appendix.

The shoot $\mathrm{P}$ concentration can reflect the nutritional status of the plant. Under $\mathrm{P}$ deficient conditions (0P), the efficient genotype 2 showed the highest shoot $\mathrm{P}$ concentration (Figure 2.5). However, it was statistically similar to the others, except for genotype 6, which among the rated $\mathrm{P}$ efficient in the field (Table 2.2) had also the lowest shoot $\mathrm{P}$ concentration at each P level at 90 DAE (Table 2.3), and the inefficient genotype 7.

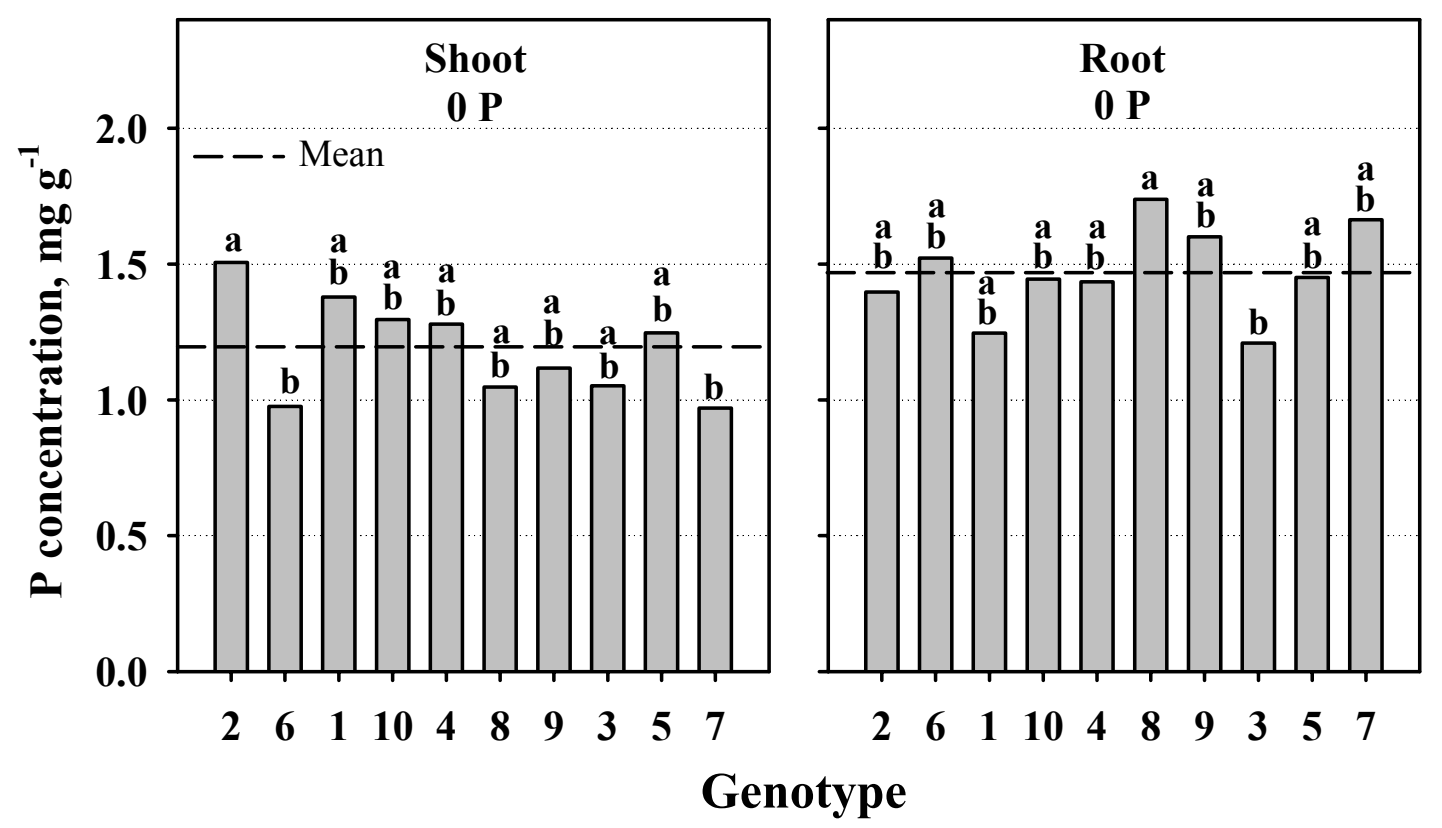

Figure 2.5 Phosphorus concentration in shoots and roots under unfertilised condition at 70 days after establishment. Within a $P$ treatment, bars marked with the same letters are not statistically different according to the Tukey mean test $(\mathrm{p}<0.05)$. 
The root $\mathrm{P}$ concentration of the efficient genotypes was not statistically different from the inefficient. Significant differences were found only between the inefficient genotypes 8 and 3 . Comparing the shoot $\mathrm{P}$ concentration on average $\left(2.1 \mathrm{mg} \mathrm{g}^{-1}\right)$ at $400 \mathrm{P}$ (see appendix) with the average of the genotypes 2, 1, 10 and $4\left(1.4 \mathrm{mg} \mathrm{g}^{-1}\right)$ at $0 \mathrm{P}$, the average at 400P was 1.5-fold higher than that at 0P. Rao and Kerridge (1994) reported $2 \mathrm{mg} \mathrm{g}^{-1}$ as sufficient for leaves of Arachis pintoi (genotype 1 "CIAT 17434") after 70 days of establishment. In spite of the fact that $\mathrm{P}$ concentration in leaves is higher than in the shoots, the nutritional status of the genotypes grown at $0 \mathrm{P}$ seems to be at a lower level.

Phosphorus use efficiency (PUE), which is equivalent to the inverse of the P concentration, represents the capacity of the plant to produce dry matter per each unit of $\mathrm{P}$ absorbed. For the calculation of the PUE the total $\mathrm{P}$ concentration was considered, i.e. shoot and root $\mathrm{P}$ concentration.

As Figure 2.6 shows, although no significant differences were found among the genotypes at 0P, the PUE of the genotypes seemed to be related to the P efficient classification in the field (Table 2.2). For instance, the P efficient genotypes 2, 1 and 10 had the lowest PUE and its P efficiency seemed not to be related to the PUE. In contrast, the also P efficient genotype 6 had the highest PUE, followed by the rated P inefficient genotypes $(3,7,5)$ and genotype 9 , whose PUE was above the overall mean.

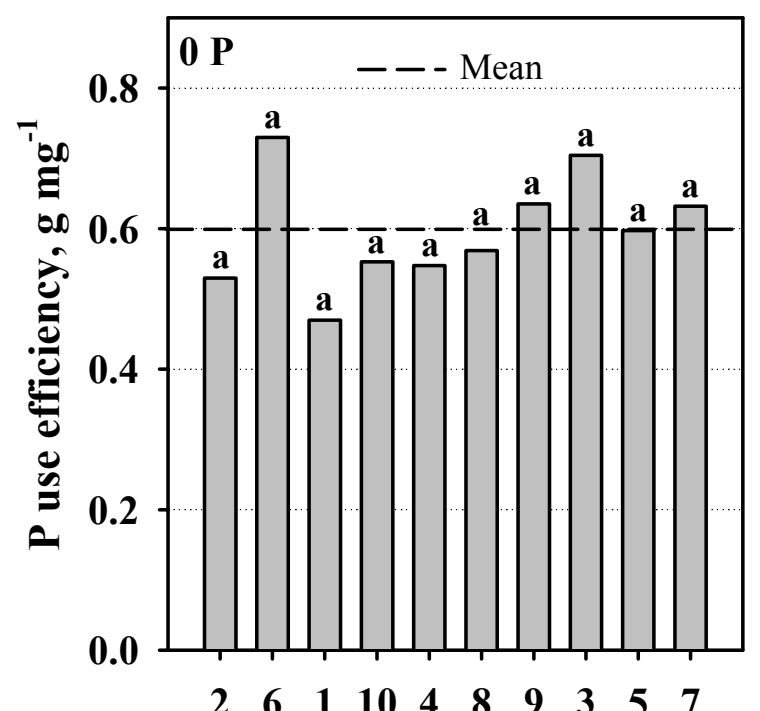

$\begin{array}{lllllllllll}2 & 6 & 1 & 10 & 4 & 8 & 9 & 3 & 5 & 7\end{array}$

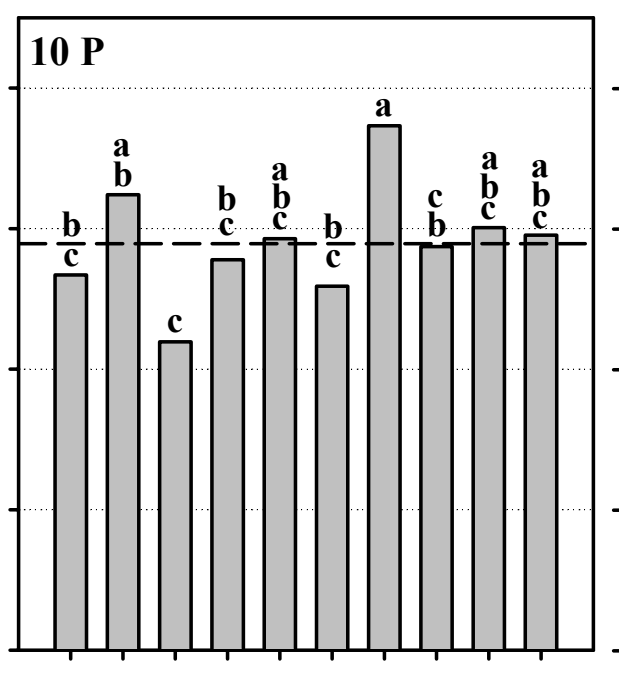

$\begin{array}{llllllllll}2 & 6 & 1 & 10 & 4 & 8 & 9 & 3 & 5 & 7\end{array}$

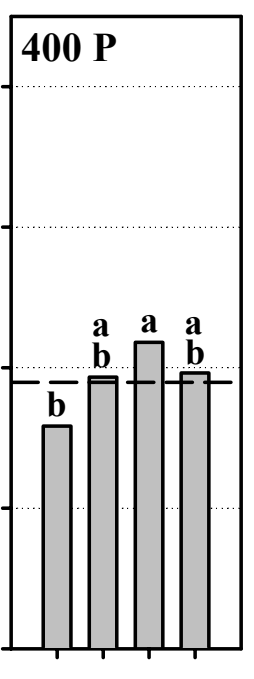

21104

Genotype

Figure 2.6 Influence of varying phosphorus supply ( $0 \mathrm{P}=$ native phosphorus; $10 \mathrm{P}$ and $400 \mathrm{P}=10$ and $400 \mathrm{mg} \mathrm{P} \mathrm{kg}^{-1}$ as $\left.\mathrm{Ca}\left(\mathrm{H}_{2} \mathrm{PO}_{4}\right)_{2} \cdot \mathrm{H}_{2} \mathrm{O}\right)$ on $\mathrm{P}$ use efficiency at 70 days after establishment (DAE). Within a $\mathrm{P}$ treatment, bars marked with the same letters are not statistically different according to the Tukey mean test $(\mathrm{p}<0.05)$. 
Noteworthy is that a similar pattern was also observed in the field at OP and at 90 DAE (Table 2.3), where genotypes 3, 6 and 9 had the lowest $P$ concentration i.e. the highest PUE, and the lowest shoot $\mathrm{P}$ content, except for genotype 6.

With the application of $10 \mathrm{P}$, the pattern observed at $0 \mathrm{P}$ did not change, but significant differences were found only between genotype 1 and 9 (Figure 2.6). At high P supply (400P), the average PUE of the genotypes decreased by $30 \%$ with respect to the average of the same genotypes at $0 \mathrm{P}$ and 10P. Genotype 2 had the lowest PUE and it differed statistically from genotype 10, whose PUE was the highest.

Consequently, the P efficiency of genotypes 6, 3 and 9 seems to be mainly due to a PUE while of genotypes 2, 1 and 10 could be another efficiency mechanism as P acquisition efficiency.

\subsubsection{Phosphorus content and the root length-shoot ratio}

The amount of $\mathrm{P}$ in the plant points to the ability of the root system to absorb P. Figure 2.7 shows the $\mathrm{P}$ content in the shoots and roots under low $\mathrm{P}$ availability (0P). From the rated $\mathrm{P}$ efficient genotypes in the field $(2,6,1)$, genotype 2 had the highest shoot $\mathrm{P}$ content and it differed statistically from genotypes 6 and 1. This results tend to point out clearly genotypical differences in the $\mathrm{P}$ efficiency, e.g. genotype 2 was efficient in taking up P, whereas genotype 6 in using the up taken P (Figure 2.6).

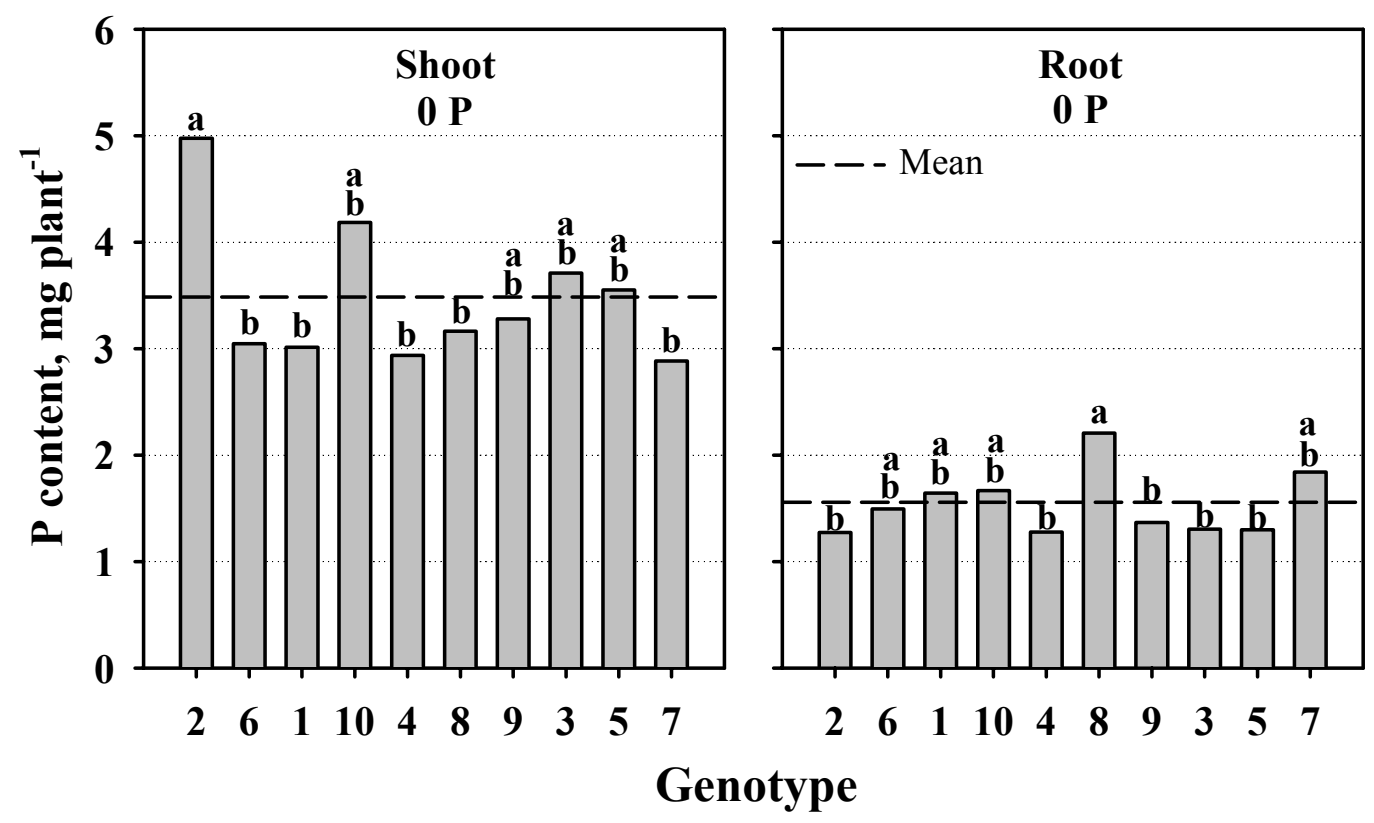

Figure 2.7 Phosphorus content in shoots and roots under unfertilised condition at 70 days after establishment. Within a $\mathrm{P}$ treatment, bars marked with the same letters are not statistically different according to the Tukey mean test $(\mathrm{p}<0.05)$. 
Contrary to that observed in the field, genotype 1 seemed to be unable to uptake $\mathrm{P}$ and/or use it. It could be that genotype 1 is more sensitive to the reduction of light intensity than the others when grown in the growth chamber. Gerloff (1997) reported that contradictory results may be obtained when a plant species or genotypes are evaluated by different soil experiment systems (field and pot in greenhouse), due to different growth conditions especially for the root growth. On the other hand, it is also possible that genotype 1 had a slow shoot growth rate and thus needs more time to develop adaptation mechanisms under these artificial conditions.

The relative high yield of genotype 10 (Figure 2.4) seems to be related to its relative high shoot $\mathrm{P}$ content, in contrast to that observed in the field, where it had the second lowest shoot P content (data no shown). From the rated $\mathrm{P}$ inefficient genotypes $(3,5,7)$, genotype 7 had the lowest shoot $\mathrm{P}$ content, but genotypes 5 and specially 3 had shoot $\mathrm{P}$ contents above the overall mean. Taking into account that the relative high PUE of genotype 3 was confirmed in this pot trial, its high yield was due to an improved ability to uptake P.

With regards to the root $\mathrm{P}$ content, the genotypes did not differ statistically among them. The exception was genotype 8 , which had the highest root P content. Since genotype 8 showed at both trials a low ability to uptake and/or use the phosphorus, the ability to accumulate $\mathrm{P}$ in the root in relation with an efficient re-translocation of $\mathrm{P}$ to the shoot, could be the mechanisms allowing the plant to achieve a yield close to the overall mean.

It is well known that plants grown under low P supply can modify their root system (length, fineness, density of their root hairs i.e. greater absorbing surface) to exploit larger volume of soil and/or increase the root length-shoot ratio (Garcia and Ascencio 1992; Ciereszko et al. 2002; Foehse and Jungk 1983; Kirk et al. 1998), which could be the case of genotype 2, 10 and 8.

The root system is responsible for feeding the plant, and the amount of $\mathrm{P}$ absorbed can depend on the size of the root surface developed to explore larger volumes of soil (see appendix). However, the root length available to feed the shoot biomass (root-shoot ratio) can reflect in a better way the $\mathrm{P}$ acquisition ability of the plants (Figure 2.8). The increase of the root-shoot ratio (RSR) has been identified as an adaptation mechanism of plants grown under low $\mathrm{P}$ condition (Trolove et al., 2003). However, that was not the case in the current trial. Two genotypes rated as average P efficient $(4,8)$ had the highest RSR followed by two P inefficient genotypes $(3,7)$ and the efficient genotype 6. It seems to be that the genotypes with a low yield in the field experiment, when grown in pots the root system is able to grow better, thus producing a higher RSR. In contrast, the P efficient genotype 2 had the lowest RSR followed by the average genotype 10 . 
When the effect of the P availability in the soil (scarce P vs. ample P supply) on the average RSR of the genotypes $(2,1,10,4)$ is compared, no difference occurred. For instance, genotypes 2 and 10 did not increase the RSR and genotypes 1 and 4 only slightly under low P conditions (0P).

At high P supply (400P) genotypes 4 and 1 had the highest RSR. This could be the reason for the different $\mathrm{P}$ efficiency of these genotypes when grown in pots (Figure 2.8) and in the field (Table 2.2). In contrast to field conditions, where the ability of $A p$ to root from stolons increase even more the spatial root distribution specially in the top soil layers $(0-10 \mathrm{~cm}$ depth), the root system of plants grown in pots has a limited soil volume to explore, which can cause a higher root length density $\left(R L_{v}\right)$.
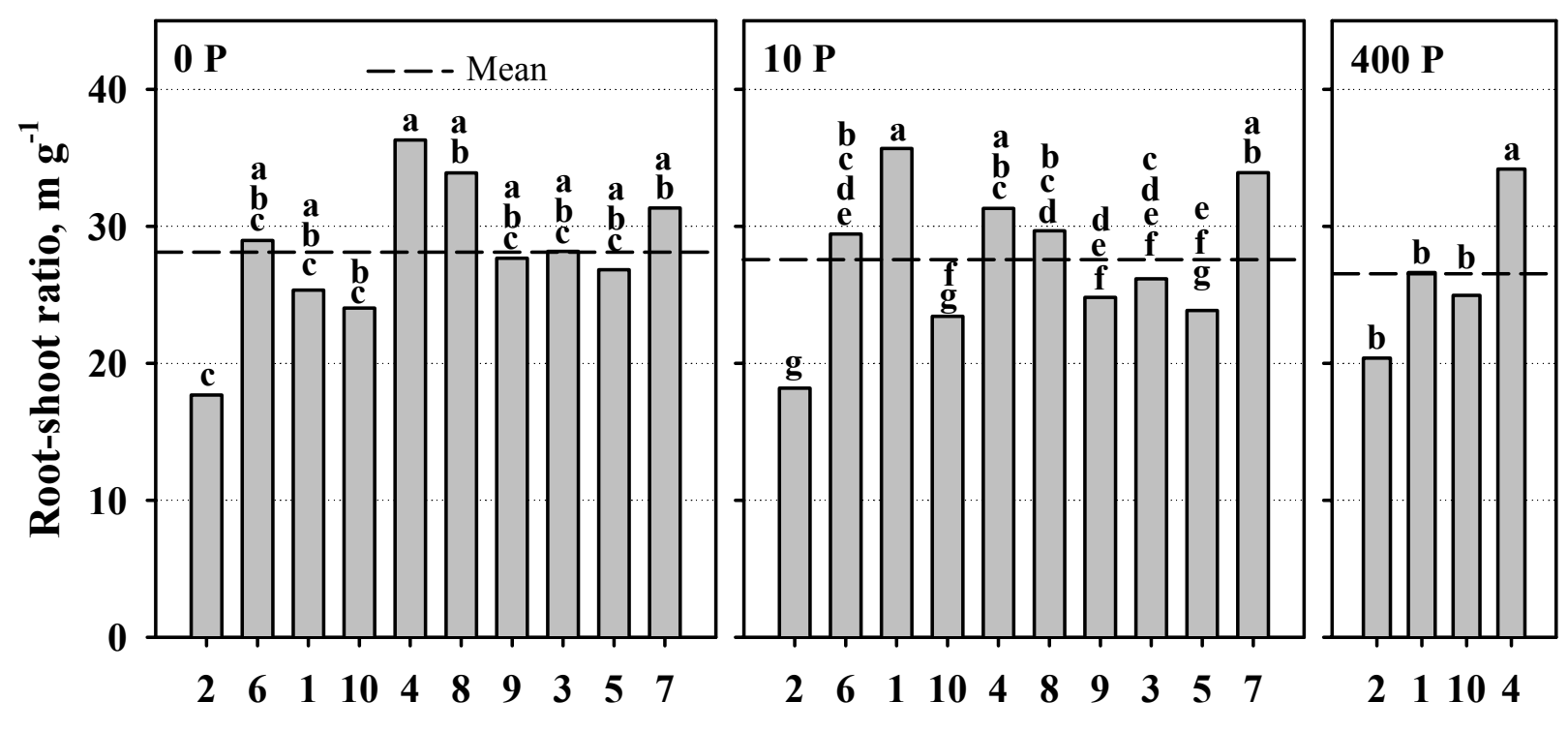

Genotype

Figure 2.8 Influence of varying phosphorus supply $(0 \mathrm{P}=$ native phosphorus; $10 \mathrm{P}$ and $400 \mathrm{P}=10$ and $400 \mathrm{mg} \mathrm{P} \mathrm{kg}{ }^{-1}$ as $\left.\mathrm{Ca}\left(\mathrm{H}_{2} \mathrm{PO}_{4}\right)_{2} \cdot \mathrm{H}_{2} \mathrm{O}\right)$ on root length-shoot biomass ratio at 70 days after establishment (DAE). Within a $\mathrm{P}$ treatment, bars marked with the same letters are not statistically different according to the Tukey mean test $(\mathrm{p}<0.05)$.

Moreover, due to an uneven root distribution in the whole pot, a root density on the border zones of the pots higher than the average can be expected. Taking into account that a higher $\mathrm{RL}_{\mathrm{v}}$ results in a smaller average half distance between neighbouring roots $\left(r_{1}\right)$, if $r_{1}$ is smaller than the depletion zone then inter-root competition for P can occur. Assuming that the roots are regularly distributed, in this pot study the $r_{1}\left(r_{1}=\sqrt{ }(S V / \pi R L)\right.$, where $S V=$ soil volume of $3000 \mathrm{~cm}^{3} ; \mathrm{RL}=$ root length "see appendix") of the genotypes 1 and 4 was $1.4 \mathrm{~mm}$ and $1.3 \mathrm{~mm}$ at $400 \mathrm{P}$ and 1.9 $\mathrm{mm}$ and $1.6 \mathrm{~mm}$ at $0 \mathrm{P}$ respectively, and the extension of the depletion zones $\left(\Delta \mathrm{x}=\sqrt{ }\left(\pi \mathrm{D}_{\mathrm{e}} \mathrm{t}\right)\right.$, where $\mathrm{t}=6480000 \mathrm{~s}$ and $\mathrm{D}_{\mathrm{e}}=$ effective diffusion coefficient was calculated using a buffer " $\mathrm{b}$ " = 978 , volumetric soil water content " $\theta$ " $=0.442 \mathrm{~cm}^{3} \mathrm{H}_{2} \mathrm{O} \mathrm{cm}{ }^{-3}$ soil, a impedance factor " $\mathrm{f}$ " $=0.27$ 
and a diffusion coefficient of $\mathrm{H}_{2} \mathrm{PO}_{4}^{-}$" $\mathrm{D}_{\mathrm{L}} "=8.9 \times 10^{-6} \mathrm{~cm}^{2} \mathrm{~s}^{-1}$ ) was $1.4 \mathrm{~mm}$ i.e. inter-root competition for $\mathrm{P}$ cannot be excluded. Consequently, a plausible explanation for the better $\mathrm{P}$ efficiency of genotypes 1 and 4 in the field than that in the pot trial could be due to a good root distribution in the field and a low $\mathrm{RL}_{\mathrm{v}}$, which allowed a better root performance to acquire $\mathrm{P}$.

Since the root-shoot ratio cannot neither explain the efficiency of genotypes 2 and 10 to produce shoot biomass (Figure 2.4) nor their high P content (Figure 2.7) under low P supply, this results point to two options: i) the genotypes were capable of acquiring more $\mathrm{P}$ because AM hyphae enlarged the root system when in symbiosis with the native mycorrhizae fungae, and/or ii) the root system of these genotypes was efficient in acquiring more $\mathrm{P}$ per unit root (P inflow). The root-induced changes in soil chemical conditions increase the soil solution P concentration on the root surface, by the release of root exudates or the enzymatic hydrolysis (acid phosphatase) of organic P.

\subsubsection{Phosphorus uptake per unit of root length and $P$ concentration in the soil solution}

The $\mathrm{P}$ acquisition efficiency of a plant depends not only on root length but also on P inflow i.e. the net amount of a nutrient taken up per unit root and time. For the calculation two harvests are necessary. However, in this experiment only one harvest was conducted, and thus the P inflow could not be calculated. In order to assess the P uptake in shoot biomass per unit root length, the P uptake per unit root length (PURL) was calculated (Figure 2.9) i.e. the total P content (shoot + root) was divided by the root length at 70 days after establishment (DAE).

Although on average the PURL of the genotypes at 10P was similar to at $0 \mathrm{P}$, statistically significant differences were found among the genotypes at each $\mathrm{P}$ treatment. Moreover, the PURL pattern at $0 \mathrm{P}$ and $10 \mathrm{P}$ was also similar.

Under P unfertilised conditions, the efficient genotype 2 had the highest PURL, followed by genotypes 1 and 10. As it was observed in the field, the P efficiency of genotypes 1, 10 and specially 2 are clearly related to a high $\mathrm{P}$ uptake per unit root. The rest of the genotypes, which had a relative high PUE, had a remarkable low PUR and it differed statistically from genotype 2. The P uptake per unit root length of these genotypes on average was $17 \%$ below the overall mean.

The high P supply (400P) produced an increase in P uptake per unit root length (PURL), but only significant differences were found between genotype 2 and the others. The relative low $\mathrm{P}$ acquisition per unit root of genotypes 1,10 and 4, could be related to a low demand of $\mathrm{P}$ due to 
the well nutritional status achieved by the genotypes. Genotype 4, with the highest shoot $\mathrm{P}$ concentration (see appendix) presented a luxurious P uptake.

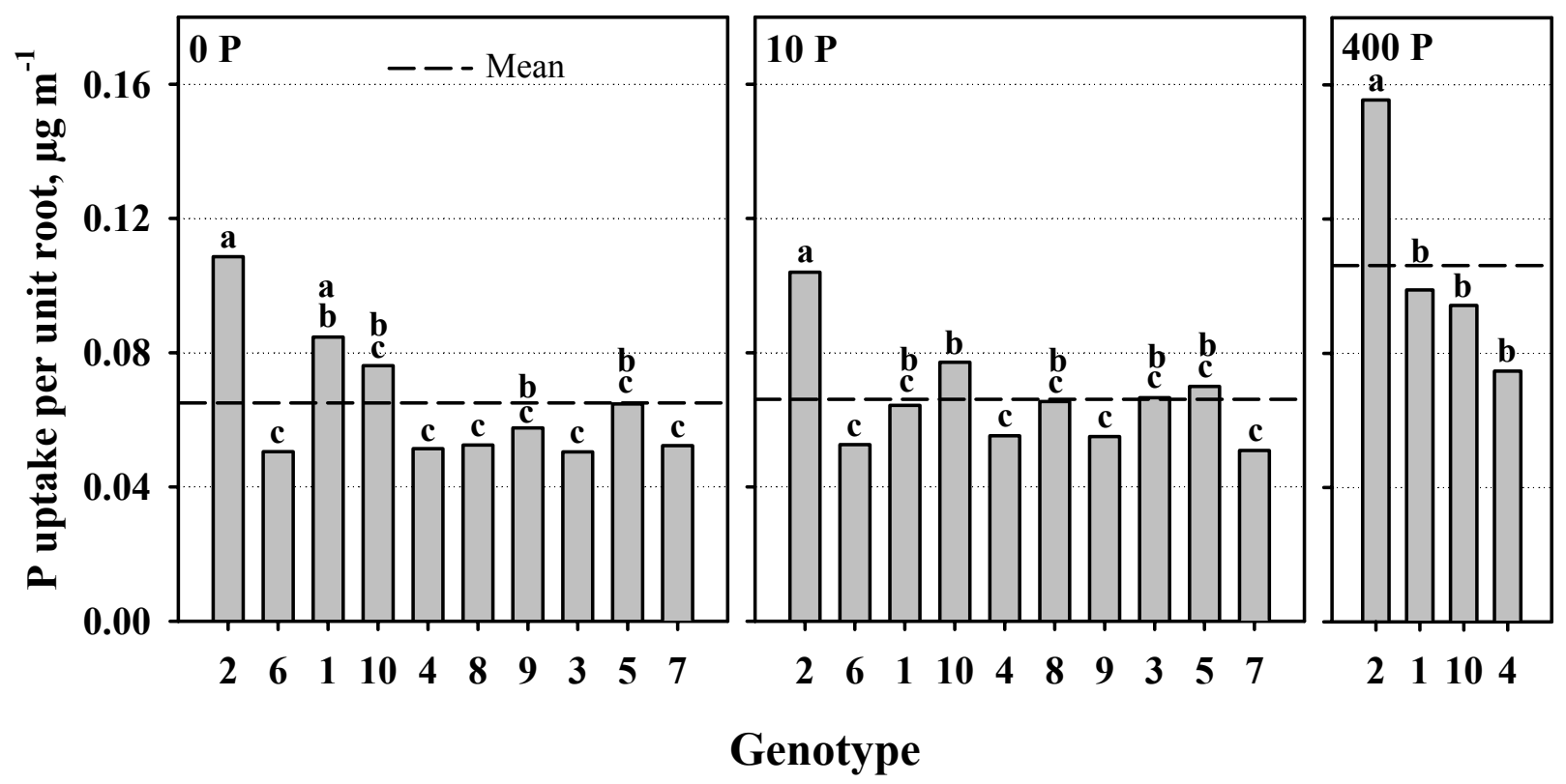

Figure 2.9 Influence of varying phosphorus supply ( $0 \mathrm{P}=$ native phosphorus; $10 \mathrm{P}$ and $400 \mathrm{P}=10$ and $400 \mathrm{mg} \mathrm{P} \mathrm{kg}{ }^{-1}$ as $\left.\mathrm{Ca}\left(\mathrm{H}_{2} \mathrm{PO}_{4}\right)_{2} \cdot \mathrm{H}_{2} \mathrm{O}\right)$ on $\mathrm{P}$ uptake per unit of root at 70 days after establishment (DAE). Within a $\mathrm{P}$ treatment, bars marked with the same letters are not statistically different according to the Tukey mean test $(\mathrm{p}<0.05)$.

It is interesting to note that the yield of genotypes 2,1 and 10 seemed to be directly related to the $\mathrm{P}$ uptake per unit root length, and that the yield and PURL differences between high $\mathrm{P}$ supply and low $\mathrm{P}$ condition were not high. For example, the yield on average of genotypes 2 and 10 at OP was 20\% lower than that at 400P and the PURL on average of genotypes 2, 1 and 10 was also $20 \%$ lower. That could suggest that these genotypes at $0 \mathrm{P}$ yielded $80 \%$ of the maximum $\mathrm{P}$ acquisition per unit root (400P). If this is the case, one would expect a high P availability (soil solution and soil P concentration) for genotypes 2, 1 and 10.

Since the plant roots can only take up P from the soil solution, the P concentration at the root surface determines its rate of uptake per unit of root, and the transport of $\mathrm{P}$ to the root surface is also in solution, the concentration of $\mathrm{P}$ in the soil solution $\left(\mathbf{C}_{\mathbf{L i}}\right)$ is a very important parameter, which can explain differences in P acquisition efficiency among genotypes. Figure 2.10 shows the shoot $\mathrm{P}$ content (upper) and the inorganic $\mathrm{P}$ concentration of the soil solution (lower) at harvest for genotypes 2, 1 and 10 with a high $\mathrm{P}$ uptake per unit root length and genotype 4 with a low one. Soil solutions of unplanted soil were included as control.

It is important to highlight that soil solution $\mathrm{P}$ concentration $\left(\mathrm{C}_{\mathrm{Li}}\right)$ of non-planted soil at $0 \mathrm{P}$ and 10P (Figure 2.10) was lower than $\mathrm{C}_{\mathrm{Lmin}}(0.2 \mu \mathrm{M})$ as found in a flowing nutrient solution culture 
for Arachis hypogea (Bhadoria et al., 2004), which is closely related to Arachis pintoi. This would mean, that the plants had to increase the $\mathrm{P}$ concentration in soil solution, i.e. to mobilise $\mathrm{P}$, in order to get a positive net influx.
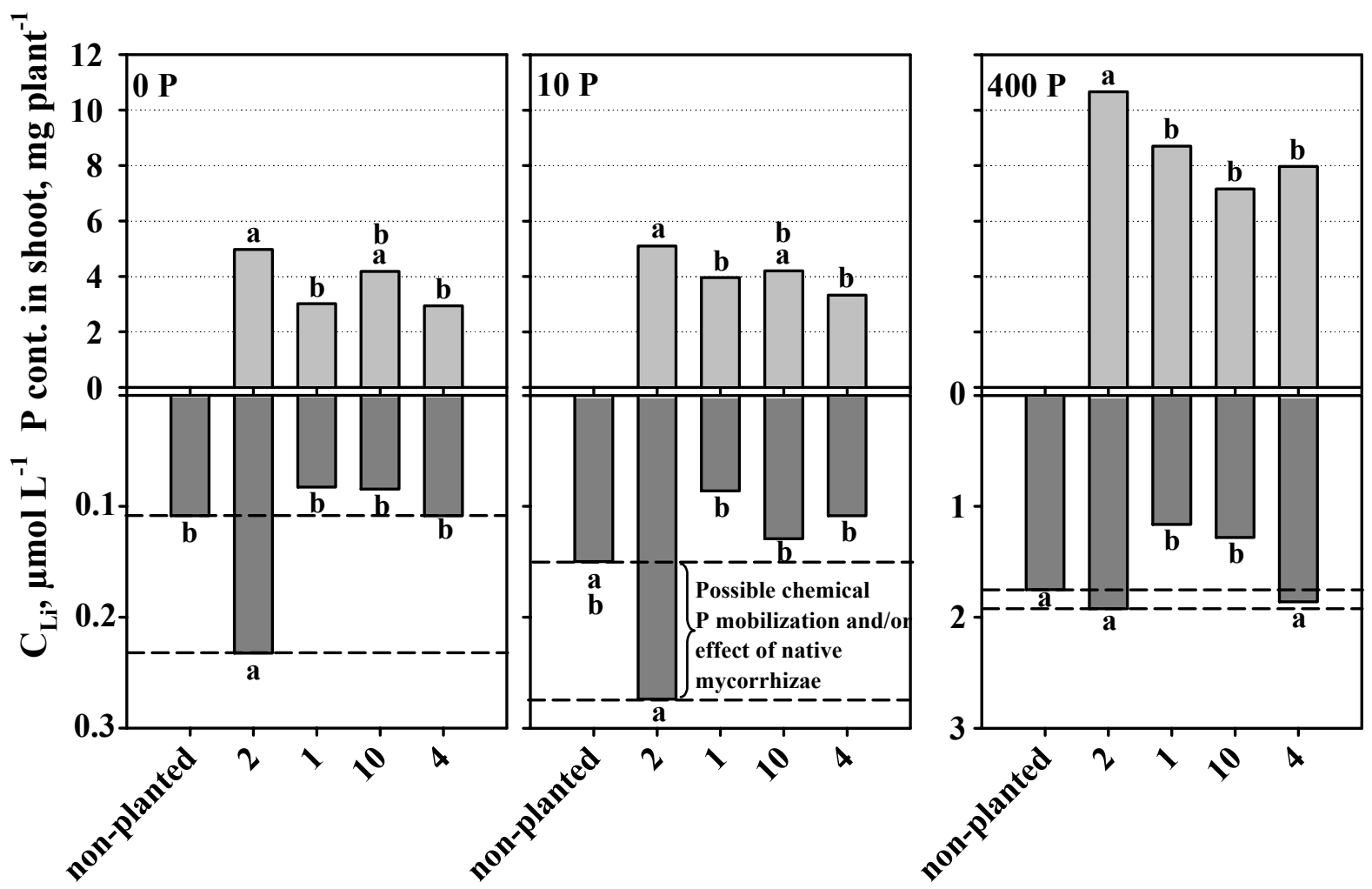

\section{Genotype}

Figure 2.10 Influence of varying phosphorus supply $(0 \mathrm{P}=$ native phosphorus; $10 \mathrm{P}$ and $400 \mathrm{P}=$ 10 and $400 \mathrm{mg} \mathrm{P} \mathrm{kg}^{-1}$ as $\left.\mathrm{Ca}\left(\mathrm{H}_{2} \mathrm{PO}_{4}\right)_{2} \cdot \mathrm{H}_{2} \mathrm{O}\right)$ on shoot $\mathrm{P}$ content (upper) and the inorganic $\mathrm{P}$ concentration of the soil solution (lower) of genotypes 1, 2, 4 and 10. Within a P treatment, bars marked with the same letters are not statistically different according to the Tukey mean test $(\mathrm{p}<0.05)$. The determination limit of $\mathrm{CLi}=0.065 \mu \mathrm{M} \pm 0.016 \mu \mathrm{M}$ (after Eurachem methodology).

As Figure 2.10 shows, genotypes 1, 10 and 4 had a similar soil solution P concentration at low $\mathrm{P}$ supply (0P and 10P), which was slightly lower than the control (unplanted) caused by the $\mathrm{P}$ uptake. But statistically these differences were not significant. Moreover, as it was mentioned above, genotypes 1 and 4 had a high root length density, which seemed to lead to inter-root competition for P. However, it is important to remark that the $\mathrm{P}$ concentration in soil solution was obtained from a mix of bulk and rhizosphere soil, which can cause a dilution effect on the $\mathrm{P}$ soil solution concentration of the rhizosphere soil.

Surprisingly, the $\mathrm{P}$ soil solution concentration of genotype 2 increased on average 2.5 -fold in comparison to the $\mathrm{P}$ soil solution concentration of unplanted soil and the other genotypes. This 
points to a mobilisation of $\mathrm{P}$ in the rhizosphere, which could explain the high $\mathrm{P}$ acquisition efficiency of genotype 2 (Figure 2.9).

In several plant species and cultivars with high $\mathrm{P}$ acquisition efficiency, the solubilizing ability has been related to the production of root exudates, with which P-sorbed minerals react in the rhizosphere inducing the release of orthophosphate to the soil solution, and consequently enhances the $\mathrm{P}$ acquisition by the plants (Hinsinger, 2001). Another solubilizing ability of sorbed P may be related to the root cell walls. Ae et al. (1996) reported that the crude root cell walls of a $\mathrm{P}$ efficient groundnut solubilized more $\mathrm{P}$ than those of sorghum and soybean.

Root exudates relevant for plant $\mathrm{P}$ nutrition under low $\mathrm{P}$ availability include phosphatase enzymes, $\mathrm{H}^{+}$and organic acids (OA). Phosphatases produced by soil microbes and/or roots can increase the hydrolysis of soil organic P (Tarafdar and Jungk, 1987) and thus solubilise organic P (Tarafdar and Claassen, 1988; Helal and Dressler, 1989; Tadano and Sasaki, 1991) that is not associated with $\mathrm{Al}$ or Fe, as the enzymes do not act on organic Al-P and Fe-P. Protons released from roots can solubilise inorganic P (Grinsted et al., 1982; Hedley et al., 1982; Moorby et al., 1988). Some organic acids (OA) are known to be able to remove inorganic $P$ from metal cations through processes such as i) acidification which can dissolve Ca-P by citric, malic and 2ketogluconic acids (Ohwaki and Hirata, 1992; Gardner et al., 1983; Moghimi et al., 1978), ii) reduction of $\mathrm{Fe}^{3+}$ to $\mathrm{Fe}^{2+}$ by formate which can solubilise Fe-P (Tanaka et al., 1995), and iii) chelating with $\mathrm{Al}^{3+}$ and $\mathrm{Fe}^{3+}$ by citric, malonic and piscidic acids (Ae et al., 1990; Otani and Ae 1997).

However, there are at least three critical points which question the effectiveness of root exudates to increase the $\mathrm{P}$ soil solution concentration. First, high concentrations of OA $(>100 \mu \mathrm{M}$ for citrate, $>1 \mathrm{mM}$ for oxalate, malate and tartrate) are required to mobilize significant amounts of $\mathrm{P}$ into the soil due to the fact that desorption of $\mathrm{P}$ is extremely soil-dependent (Earl et al., 1979; Lopez-Hernandez et al., 1986; Jones and Darrah, 1994, Lan et al., 1995). Secondly, soil microbes degrade exudates to some extent. Whilst the effect of OA might be relevant for specific situations, e.g. in the proteoid rhizosphere of white lupine, where the soil-solution concentrations of OA are high, their importance in most other situations remain speculative (Jones et al., 1996). Thirdly, the root exudates act not only upon P-fixed minerals, but also on other ion components having no P. Organic acid anions, such as citrate, tartrate and formate, have been shown to extract metallic ions from mineral surfaces creating new P sorption sites (Traina et al., 1986). Furthermore, organic anions may solubilise phosphate independently of any $\mathrm{pH}$ change (Staunton and Leprince, 1996). According Jones and Darrah, (1994), OA are dissociated in the 
root cells under the $\mathrm{pH}$ condition of the cytoplasm i.e. the OA should be released as organic anions and should not contribute per se to the acidification of the rhizosphere.

Nevertheless, root exudates are comprised not only of organic acids and ectoenzymes (e.g. phosphatase) but also of sugars, phenolics, amino acids and mucilage. Some of these substances could probably enhance directly or indirectly the complex process of releasing $\mathrm{P}$ into the rhizosphere.

\subsubsection{5 $\mathrm{pH}$ value in soil and soil solution and extractable $P$ of soil samples after harvesting}

Beside the soil solution $\mathrm{P}$ concentration, extractable soil $\mathrm{P}$ can also be a measure for $\mathrm{P}$ availability. Moreover, the $\mathrm{pH}$ of the soil has a major influence on $\mathrm{P}$ solubility. Table 2.5 shows the $\mathrm{pH}$ in soil solution as well as the extractable $\mathrm{P}$ (CAL and Bray II) and $\mathrm{pH}$ of the soil as affected by $\mathrm{P}$ supply in planted and unplanted soils.

The P fertilisation effect was reflected in the extractable P-CAL and P-Bray II. The genotypes decreased slightly the values due to the plant's P uptake. However, a correlation was not found between the decrease of the extractable $\mathrm{P}$ and the $\mathrm{P}$ content in the genotypes.

Taking into account the high $\mathrm{P}$ buffer capacity of this soil, the changes in the $\mathrm{P}$ balance of PCAL and P-Bray II tend to show that the genotypes used other P sources. For example, the extractable P-Bray II of genotype 2 at OP compared to the unplanted soil decreased $1 \mathrm{mg} \mathrm{kg}^{-1}$, which in a pot of $3.5 \mathrm{~kg}$ soil is equal to a reduction of $3.5 \mathrm{mg} \mathrm{P}^{-1}$. If the total $\mathrm{P}$ content (shoot + root) of genotype 2 at $0 \mathrm{P}$ was $6.2 \mathrm{~g} \mathrm{plant}^{-1}$ and per pot there were 4 plants, the total plant $\mathrm{P}$ content was $24.8 \mathrm{mg} \mathrm{P}^{-1}$, which results in a discrepancy of $21.3 \mathrm{mg} \mathrm{P}^{-1}$.

Phosphorus mobilisation observed in genotype 2 under low P supply (Figure 2.10) was not confirmed by P-CAL and P-Bray II. The $\mathrm{pH}$ varied slightly within the $\mathrm{P}$ treatment, but no relation to phosphorus mobilisation was found. 
Table $2.5 \mathrm{pH}$ in soil solution, extractable $\mathrm{P}$ (CAL and Bray II) and $\mathrm{pH}$ in soil as affected by $\mathrm{P}$ supply in planted and unplanted soil.

\begin{tabular}{|c|c|c|c|c|c|}
\hline \multirow[t]{2}{*}{ Treatment } & \multirow[t]{2}{*}{ Genotype } & \multicolumn{2}{|c|}{ pH-value } & \multicolumn{2}{|c|}{ Extractable $\mathrm{P}, \mathrm{mg} \mathrm{kg}^{-1}$} \\
\hline & & Soil solution & Soil $_{(\mathrm{CaCl} 2)}$ & CAL & Bray II \\
\hline \multirow[t]{5}{*}{$0 \mathrm{P}$} & 2 & $5.0 \mathrm{a}$ & $5.0 \mathrm{c}$ & $3.2 \mathrm{a}$ & $5.9 \mathrm{c}$ \\
\hline & 1 & $4.9 \mathrm{a}$ & $5.2 \mathrm{ab}$ & $3.2 \mathrm{a}$ & $6.1 \mathrm{bc}$ \\
\hline & 10 & $5.1 \mathrm{a}$ & $5.0 \mathrm{c}$ & $3.2 \mathrm{a}$ & $6.4 \mathrm{~b}$ \\
\hline & 4 & $5.3 \mathrm{a}$ & $5.3 \mathrm{a}$ & $3.2 \mathrm{a}$ & $5.8 \mathrm{c}$ \\
\hline & unplanted* & $4.9 \mathrm{a}$ & $5.1 \mathrm{bc}$ & $3.0 \mathrm{a}$ & $6.9 \mathrm{a}$ \\
\hline \multirow[t]{5}{*}{$10 \mathrm{P}$} & 2 & $5.0 \mathrm{a}$ & $5.2 \mathrm{a}$ & $3.4 \mathrm{a}$ & $7.2 \mathrm{ab}$ \\
\hline & 1 & $5.0 \mathrm{a}$ & $5.2 \mathrm{a}$ & $3.4 \mathrm{a}$ & $6.8 \mathrm{~b}$ \\
\hline & 10 & $5.2 \mathrm{a}$ & $5.0 \mathrm{a}$ & $3.4 \mathrm{a}$ & $7.6 \mathrm{ab}$ \\
\hline & 4 & $5.1 \mathrm{a}$ & $5.2 \mathrm{a}$ & $3.5 \mathrm{a}$ & $7.5 \mathrm{ab}$ \\
\hline & unplanted & $4.9 \mathrm{a}$ & $5.2 \mathrm{a}$ & $3.4 \mathrm{a}$ & $7.8 \mathrm{a}$ \\
\hline \multirow[t]{5}{*}{$400 \mathrm{P}$} & 2 & $5.0 \mathrm{a}$ & $4.9 \mathrm{bc}$ & $22.7 \mathrm{ab}$ & $59.1 \mathrm{a}$ \\
\hline & 1 & $4.9 \mathrm{a}$ & $4.8 \mathrm{c}$ & $23.4 \mathrm{a}$ & $61.0 \mathrm{a}$ \\
\hline & 10 & $5.1 \mathrm{a}$ & $4.8 \mathrm{c}$ & $20.5 \mathrm{~b}$ & $57.7 \mathrm{a}$ \\
\hline & 4 & $5.0 \mathrm{a}$ & $5.0 \mathrm{~b}$ & $22.0 \mathrm{ab}$ & $57.1 \mathrm{a}$ \\
\hline & unplanted & $4.9 \mathrm{a}$ & $5.2 \mathrm{a}$ & $24.3 \mathrm{a}$ & $56.5 \mathrm{a}$ \\
\hline
\end{tabular}

Within a $\mathrm{P}$ treatments, values followed by the same letters are not statistically different according to the Tukey mean test $(\mathrm{p}<0.05)$.

$*=$ soil without plant used as control.

\subsection{Concluding discussions}

The Arachis pintoi (Ap) genotypes differ statistically from each other in their ability to produce dry shoot biomass, when grown with and without $\mathrm{P}$ fertiliser application under different growth conditions (field on an Ultisol and pot on an Oxisol). These results could be used for the screening and identification of germplasm differing in their P efficiency under low $\mathrm{P}$ supply, which could help to provide superior genetic material in breeding programs.

When grown in the field, the yield differences observed were more clearly defined in the genotypes' ability to acquire P. The pot experiment confirmed this, and also indicated possible 
mechanisms which could explain their efficiency in absorbing P. Moreover, it also brought to light differences in their ability to use P.

The $\mathrm{P}$ efficiency of the genotypes, classified as efficient $(2,6,1)$, average $(10,4,8,9)$ and inefficient $(3,5,7)$, were caused by:

1. A high ability to use the P taken up for producing shoot biomass. Genotypes 6 and 9 can be highlighted by their high $\mathrm{P}$ use efficiency and is complemented by an average $\mathrm{P}$ uptake per unit root length and an average root-shoot ratio. The activity of enzymes able to hydrolyse organic $\mathrm{P}$ in the leaves such as phosphatase could be a mechanism affecting the $\mathrm{P}$ use efficiency.

2. A high ability to increase their root system more than their shoots biomass. Although the $P$ efficiency of genotypes 4 and 8 was considered as representative of the average, their high root length-shoot weight ratio seem to be the adaptation mechanism responsible for their growth under scarce P availability in the soil.

3. A high ability to acquire $\mathrm{P}$ under low $\mathrm{P}$ availability because an increase of $\mathrm{P}$ concentration in the soil solution. This can be confirmed by the high $\mathrm{P}$ acquisition efficiency per unit root length of genotypes 2 and 1, related to a increase of the soil solution $\mathrm{P}$ concentration (genotype 2) and their low root length-shoot weight ratio. Although the $\mathrm{P}$ efficiency of genotype 10 was classified as average, it showed a similar pattern as genotypes 2 and 1 . Taking into account the extreme low $\mathrm{C}_{\mathrm{Li}}$ value of un-planted soil, theses genotypes must have increased the concentration of $\mathrm{P}$ at the root surface. One strategy of the genotypes could be the solubilization of unavailable inorganic and/or organic P forms (Al-Fe-P) by root exudates such as organic acids, phenols, sugars, mucilages and/or ectoenzymes (e.g. phosphatase), to increase the soil solution P concentration and thus enhance the acquisition of P per unit root.

In contrast, the rest of the genotypes $(3,5,7)$ showed no particular mechanisms in relation to the $\mathrm{P}$ efficiency. 


\section{Influence of arbuscular mycorrhizae fungi (AMF) on morphological and physiological parameters related to $\mathrm{P}$ efficiency of Arachis pintoi genotypes}

\subsection{Introduction}

Arachis pintoi genotypes growing under low $\mathrm{P}$ availability differed in their $\mathrm{P}$ efficiency under field and controlled conditions, as it was observed in chapter 2. The P efficiency under both conditions was attributed to i) a high P use efficiency (genotypes 6 and 9), i.e. greater ability to produce more dry matter per unit of $\mathrm{P}$, ii) a high root length-shoot weight ratio (RSR) (genotypes 4 and 8) i.e. a larger root system exploiting a larger volume of soil to feed the plant and iii) a high P uptake per unit of root (genotypes 2, 1 and 10). However, it is not clear the mechanisms responsible for the $\mathrm{P}$ uptake efficiency of some genotypes with a low RSR.

It is well known that for diffusion-limited ions such as phosphate, short transport distances favour P-uptake. This implies that in P-limited soils, high root densities are important for plant P-uptake. However, as production of roots costs assimilates (carbon compounds), a high P acquisition ability of a root system depends on the mean diameter of the root. Therefore, the development of fine roots enables a plant to adjust to low available $\mathrm{P}$ conditions by strategies that maximize uptake-surface area per unit of carbon input. This occurs by enhancing the contact of the root surfaces to the soil through changes in the root architecture such as: extensivelybranched root systems (Lynch and Beebe, 1995; Mollier and Pellerin, 1999) and lateral root development (Lynch and Brown, 1998), reduced root diameter (Föhse et al., 1991) or formation of root hair with radii around $5 \mu \mathrm{m}$ and length larger than $1 \mathrm{~mm}$ (Gahoonia et al., 1997). Furthermore, changes in root physiology allow the uptake of $\mathrm{P}$ at lower concentrations in the soil solution, and/or to take up P from insoluble inorganic or organic forms (Marschner, 1995).

However, all these attributes may be significantly affected by symbiosis with arbuscular mycorrhizal fungi (AMF) (Redhead, 1979; Koide, 1991). Mycorrhizal hyphae, which are about 10 times thinner than fine roots and therefore have more surface per unit of assimilation, act as extensions of the root to take up P (Marschner and Dell, 1994). In exchange the AMF receives carbohydrates from its host plant (Harrison, 1997; Smith and Read, 1997).

Numerous reports have clearly demonstrated the beneficial effects of this symbiotic association especially when soils deficient in available P limit plant growth (Bolan 1991; Faber et al., 1990; Abott and Robson, 1982; Tinker, 1975). Various mechanisms have been suggested for the increase in the uptake of $\mathrm{P}$ by mycorrhizal plants: i) exploration of a larger soil volume by 
mycorrhizal plants by increasing the surface area of absorption through the external hyphae network (Sanders and Tinker, 1973; Tinker, 1978), ii) faster movement of $\mathrm{P}$ into mycorrhizal hyphae by increasing the affinity for P ions (Cress et al., 1979; Howeler et al., 1982), iii) solubilization of soil $\mathrm{P}$ achieved by the release of organic acids and phosphatases. (Gianinazzi Pearson and Gianinazzi, 1978; Parfitt, 1979; Moawad, 1986; Vielhauer, 1992).

The length of the extraradical network of hyphae forms in the soil and the small radius of the hyphae (approx. $2 \mu \mathrm{m}$ ) are responsible for the enlargement of the absorption surface area of colonised plants. Therefore, the hyphae may acquire and translocate $\mathrm{P}$ to the host plant from unavailable zones to the root system i.e. soil outside of the root depletion zone by diminishing the distance of $\mathrm{P}$ diffusion to the root surface (Tinker et al., 1992; Tinker, 1978). Mycorrhizal hyphae of Glomus sp. and Acaulospora sp. can transport P from distances of up to several centimetres from host plant roots (George et al., 1995; Jakobsen et al., 1992a; Jakobsen et al., 1992b; Li et al., 1991; Marschner and Dell, 1994), while root hairs exploit P usually in a range of up to one millimetres (Gahoonia and Nielsen, 1998).

Additionally, the efficiency of P uptake by AMF has been also related to the capacity of $\mathrm{P}$ uptake per unit length of the hyphae (Harrison, 1997; Jakobsen et al., 1992b, Schweiger and Jakobsen, 2000; Smith et al., 2000). The high efficiency of AMF hyphae in P uptake is attributed to the storage of polyphosphates in their vacuoles, which may be hydrolysed in the arbuscules and transported as inorganic P into the host plant across the plasma membrane of cells (Smith and Gianninazzi-Pearson, 1988). Moreover, it has been suggested that an enhancement of $P$ uptake of the roots could be an indirect effect of the P uptake of AMF hyphae. The faster P uptake rate of AMF hyphae affects the $\mathrm{P}$ concentration equilibrium between the solution and solid phase, which results in an increase of the desorption of adsorbed phosphate into the soil solution (Nye and Tinker, 1977). Another attribute of hyphae is their capability of storing larger amounts of absorbed $\mathrm{P}$ than plant roots, thus facilitating the continued movement of $\mathrm{P}$ into the host plant (Bolan, 1991). To what extent one or the other of these mechanisms prevails is still a subject of intensive scientific debate and, the possibility exists that all mechanisms act simultaneously and are dependent on the root morphology. For instance, Baon et al. (1994) working with rye genotypes, and Caradus (1995) with white clover genotypes, found that genotypes with short root hairs were more dependent on root-mycorrhizal association for growth in a P-deficient soil than genotypes with long root hairs.

The root colonization by AMF, which is also very common in crop plants of agrosystems (Smith and Read, 1997), may be stimulated by $\mathrm{P}$ deficiency in the soil, but is constrained by high $\mathrm{P}$ 
supply (Jones et al., 1990). A low AMF colonization percentage at high P supply is attributed to increased phospholipid levels, which decrease membrane permeability and reduce exudations of organic acids, amino acids, and sugars, which are the source of food for growth and development of germinating mycorrhizal spores (Ratnayake et al., 1978). Further of the attribute related to $\mathrm{P}$ nutrition, AM fungi can influence the growth and survival of plants by reducing stresses connected to nutrient deficits, unfavourable water conditions, soil structure, $\mathrm{pH}$, toxic metals, soil organic matter deficits and biotic factors such as soil pathogens which attack the roots of plants (Sylvia and Williams 1992).

Besides the effect of AMF on the P efficiency, the production and release of acid phosphatases by many higher plants in response to scarce P availability (Duff et al., 1994) seem to play an important role in many physiological processes including regulation of $\mathrm{P}$ efficiency (Bieleski, 1973) by solubilizing P from organic materials (Goldstein, 1992). Plant species such as maize, tomato, wheat and clover lupin, rice and soybean increased the acid phosphatase (APase) secretion to the rhizosphere in response to low $\mathrm{P}$ availability to hydrolyze soil organic $\mathrm{P}$ compounds at the root surface (Clark, 1975; Goldstein et al., 1988a and 1988b; Tarafdar and Jungk, 1987; Tadano et al., 1993).

Nevertheless, as acid phosphatase takes part in many of the metabolic processes in plant cells and can hydrolyze orthophosphate monoesters into more mobile orthophosphate anions (Pi) (Vincent et al., 1992), when P availability is low, phosphatase increases in the leaves to facilitate the availability of bound $\mathrm{P}$ in the cytoplasm. This internal APase activity in the leaves seems to be related to the P use efficiency (PUE). Mechanisms for enhanced PUE include reduced tissue P requirement (Fawole et al., 1982; Halsted and Lynch, 1996) and efficient P remobilization from senescent or non productive tissues to grow or produce tissues (Smith et al., 1990; Snapp and Lynch, 1996; Adu-Gyamfi et al., 1989; Barber et al., 1967; Bieleski, 1973; Loneraga, 1978). Under low P conditions, plants are able to relocate P from old leaves and vacuoles, which are metabolically less active, to more needed sites (Schachtman et al., 1998). Additionally, taking into account that leaf senescence is often accelerated when P is scarce (Snapp and Lynch, 1996), it can be safely deduced that an increase in APase activity in the leaves may be involved with the relocation of $\mathrm{P}$ from old leaves to young tissue.

However, it has been also observed that an increase in APase in the leaves is generally linked to the extent of the P deficiency symptoms in the plant (McLachlan et al., 1987). Since the relationship between leaf APase and P concentration in some plants is generally inverse, it has been proposed that leaf APase could be used as a diagnostic criterion for P deficiency (Besford, 
1980; McLachlan et al., 1987). Acid phosphatase found in the leaves was related to visual $\mathrm{P}$ deficiencies in maize (Elliott and Lauchli, 1986), tomato (Kaya et al., 2000) and wheat (Guthrie et al., 1991). Therefore, it is not clear, whether an increase in APase activity in the leaves is a mechanism of $\mathrm{P}$ efficiency or simply an indicator of $\mathrm{P}$ deficiency.

The reaction of plants on biotic and abiotic stress is affected essentially by the concur of so named phytohormone (plant growth regulators). The establishment and function of a mycorrhizae is a complex process, in which a molecular dialogue is inevitable between both symbiosis partners. Therefore, amongst others morphological and physiological changes in the plant could be affected by plant and fungal phytohormone (Gogala, 1991). These plant growth regulators, which are produced in different parts of the plant (leaves, root tips, meristem, embryos, etc) as well as by AM fungi, are responsible among other things for i) the induction and release of the dormancy or of passive growth state (abscisic acid), ii) the enlargement of shoot and root as well as the formation of lateral roots and the root development of plant cuttings (auxins), and iii) the inhibition of root growth and the acceleration of the senescence (jasmonates) (Grunwald, 2004). Glomus sp. colonized maize plants (Zea mays L.) show an increased concentration in abscisic acid in shoot and root and this increase was related to the improved phosphate supply of the plant (Bothe et al., 1994; Danneberg et al., 1993). In contrast the abscisic acid concentration decreased in leaves of AMF colonized Bouteloua gracilis (Allen et al., 1980). An increase of the concentration of the auxins's derivative Indol 3 butyric acid (IBA) was observed in $G$. intraradices colonized maize roots, although the endogenous IBA's content was not correlated with the mycorrhizae infection degree (Kaldorf and Ludwig-Müller, 2000; Ludwig-Müller et al., 1997). However, the content in Indol 3 acetic acid (IAA), another derivative of the auxins, remained constant.

The aim of the present study was to determine differences in $\mathrm{P}$ acquisition and $\mathrm{P}$ use among Arachis pintoi genotypes when grown with and without AMF associations at different levels of soil phosphate in clayed Ultisols.

\section{Hypotheses}

The following hypotheses were tested:

1. Genotypes differ in ability to associate with arbuscular mycorrhizae fungi (AMF) and thereby to adapt to low P availability.

2. Genotypes adapted to low P conditions (efficient in P uptake and/or use) present high leaf APase activity as a sign of the ability to hydrolyze and remobilize $\mathrm{P}$ within the plant. 


\subsection{Materials and Methods}

\section{Location}

A greenhouse study was conducted at CIAT, Palmira, Valle del Cauca Department, Colombia at latitude $3^{\circ} 30^{\prime} \mathrm{N}$, longitude $76^{\circ} 21^{\prime} \mathrm{W}$ and $965 \mathrm{~m}$ elevation. Plants were grown in pots in the greenhouse with temperature fluctuating from $20^{\circ} \mathrm{C}$ to $37^{\circ} \mathrm{C}$ in synchrony with photoperiod, and relative humidity ranging from 40 to $90 \%$. The maximum photosynthetic photon flux density during the day was $1100 \mu \mathrm{E} \mathrm{m}^{-2} \mathrm{~s}^{-1}$.

\section{Plant material}

The same ten Arachis pintoi (Ap) genotypes selected to study differences in P efficiency under natural and controlled growth condition (see chapter 2) were used.

\section{Growth conditions}

Plastic pots (3 liter) were filled with $3.5 \mathrm{~kg}$ dry Ultisols collected in the $0-20 \mathrm{~cm}$ depth layer from a field trials established at Montañita, Caquetá Department, Colombia $\left(1^{\circ} \mathrm{N}, 75^{\circ} \mathrm{W}, 180 \mathrm{~m}\right.$ elevation, $3500 \mathrm{~mm}$ mean annual rainfall). The soil's physical and chemical characteristic were equal to those described in chapter 2 , except for the higher value of organic matter $(3.8 \%)$ and available $\mathrm{P}$ (6.5 $\mathrm{mg} \mathrm{kg}^{-1}$ Bray II). The analytical methods used to determine the soil characteristics were as described in Salinas and Saif (1990).

Soil was sterilized with steam for 4 hours at $80^{\circ} \mathrm{C}$ to make soil free of native arbuscular mycorrhizae fungi (AMF). In order to restore the microflora in the sterilized soil, non-sterilized soil was mixed with water, agitated and the solution filtered (Whatman grade 2: filtration in the 8 $\mu \mathrm{m}$ particle size range) to eliminate spore or hyphae of native mycorrhizae from the extract. Three weeks before transplanting the seedlings into the pots, the microflora was reinoculated adding $100 \mathrm{~mL}$ of this extract per pot and watered up to $65 \%$ of its water holding capacity to improve the microflora incubation.

The amount of fertilised $\mathrm{P}$ was the same as in the field experiment (see chapter 2), except of TSP, which was only applied in the half amount in order to evaluate the effect of the mycorrhizae on the yield. Calculation was done considering the bulk density of the Ultisols (1.26 $\mathrm{g} \mathrm{cm}^{-3}$ ) and a soil depth of $20 \mathrm{~cm}$. A detailed description is presented in the Table 3.1. 
Table 3.1 Description of different treatment setup for the experiment in greenhouse.

\begin{tabular}{ccc}
\hline \multirow{2}{*}{ P treatments } & -AMF & +AMF \\
\cline { 2 - 3 } & \multicolumn{2}{c}{$\mathrm{mg} \mathrm{P} \mathrm{kg}^{-1}$} \\
\hline OP & 0 & 0 \\
PR & 20 & 20 \\
TSP & 4 & 4 \\
\hline
\end{tabular}

$\mathrm{AMF}=$ Arbuscular mycorrhizae fungi $\quad \mathrm{PR}=$ Phosphate rock $\quad \mathrm{TSP}=$ Triple superphosphate

The chemical composition of the phosphate rock from Huila, Colombia, (commercial fertilizer "Calfomag") was 5.2\% P, 25\% Ca, 6\% Mg and 1\% S. A basal fertilizer was applied (mg kg $\left.{ }^{-1}\right)$ at $8 \mathrm{~K}(\mathrm{KCl}), 20 \mathrm{Ca}$ (agricultural lime plus dolomitic lime), 5.6 Mg (dolomitic lime) and $4 \mathrm{~S}$ (elemental sulfur), which are equivalent to the basal fertilisation applied on the field (see Chapter 2). The soil was thoroughly mixed with the fertilizers, and then transfered to plastic pots. Nitrogen was not added to the treatments because plants were inoculated with Rhizobium.

Before seedling transplanting, the application $\left(\mathrm{mg} \mathrm{kg}^{-1}\right)$ of $20 \mathrm{PR}$ and 4 TSP resulted in available $\mathrm{P}$ (Bray II) of 14.9 and $10.4 \mathrm{mg} \mathrm{P} \mathrm{kg}^{-1}$ soil. According the classification used at CIAT for tropical forages (see Chapter 2), this P Bray-II values ranged between high and very high. However, it is worthy to mention that for a legume like bean the critical level in a mineral soil is $11 \mathrm{mg} \mathrm{kg}^{-1}$ of extractable Bray II.

The seeds were pre-germinated in sand using the same method described in chapter 2. Four seedlings were transplanted to each plastic pot and inoculated with a suspension of the recommended Rhizobium strain (CIAT 3101). Pots belonging to the treatment with AMF were inoculated with 30 spores of Glomus fasciculatum per plant. During the trial, soil moisture content was maintained at $65 \%$ of the maximum water holding capacity by daily monitoring the weight.

Two weeks after the transplanting, the thinning of the plants was done and 2 seedlings were remained in each pot. One pot from each $\mathrm{P}$ treatment was left unplanted to measure soil moisture evaporation losses and as control of $\mathrm{P}$ dynamic under unplanted conditions.

The trial was arranged in a completely randomized block design with three replicates. The total number of pots was 360 (10 genotypes x 3 P treatments x 2 mycorrhizae inoculation level x 3 replicates x 2 harvest). 


\section{Measurements and analysis}

To determine the average $\mathrm{P}$ inflow ( $\mu \mathrm{mol} \mathrm{P} \mathrm{cm}^{-1} \mathrm{~s}^{-1}$ ), plants were grown in two batches, one harvested at 45 days and the other at 90 days after transplanting.

\section{Shoot sampling}

Before each harvesting, four leaf discs (total area $\left.=1.54 \mathrm{~cm}^{2}\right)$ were punched with a cork borer $(\varnothing=0.7$ $\mathrm{cm}$ ) from the third young petiole of a stolon to determine inorganic P. Since the Arachis pintoi have 4 oval leaflets on each petiole, one disc per leaflet was collected. From the same leaflets and using a smaller cork borer $(\varnothing=0.5 \mathrm{~cm})$, five leaf discs (total area $=0.98 \mathrm{~cm}^{2}$ ) were punched to determine acid phosphatase activity (APase). Immediately after each procedure, the leaf discs were put in a tub, frozen with liquid nitrogen and stored at $-20^{\circ} \mathrm{C}$. At harvest, the plants were cut at the base and leaf lamina were separated from other shoot material, scanned for area and finally the material was oven-dried and ground as described for the field trial in chapter 2.

\section{Root sampling and root length}

After each harvesting, to determine inorganic $\mathrm{P}$, phosphatase activity and root colonization by AMF, the soil was carefully separated from the root manually by shaking. Root segments from different parts of the root system were taken and immediately washed with distilled water and put into tubes. Root samples for inorganic P and APase were immediately frozen with liquid nitrogen and stored at $-20^{\circ} \mathrm{C}$ and for $\mathrm{AMF}$ were stored at $5^{\circ} \mathrm{C}$. The rest of the roots were carefully separated from the soil by washing the soil in a $1 \mathrm{~mm}$ mesh wide sieve. After cleaning the roots of any foreign materials, they were scanned for length on a root-length scanner (Commonwealth Aircraft Corp., Melbourne, Australia) using the line-interception method of Newman (1966). The remaining water on the root samples was removed by applying uniform pressure using paper towels and then the fresh root weight was determined. The fresh root material used for inorganic $\mathrm{P}$, APase, AMF determination, and the rests of the root were weighed in order to calculate the total root length. Roots were oven-dried, for 2 days at $70^{\circ} \mathrm{C}$ to a constant weight and then ground for chemical analysis. 


\section{Chemical analysis of plant material}

Phosphorus content in the dry ground plant material was measured by the method of Murphy and Riley (1962) as described for the field trial in chapter 2.

\section{Determination of inorganic phosphorus $\left(\mathrm{P}_{\mathrm{i}}\right)$ in leaves and roots}

The tubes containing the frozen tissue material (4 leaf discs or $0.1 \mathrm{~g}$ roots) were kept in ice and pre-ground with a pestle in a pre-chilled mortar. After adding $5 \mathrm{~mL}$ of $2 \%$ acetic acid solution, it was again ground and the extract transferred to reagent tubes. After centrifugation $(1957 \mathrm{~g}, 5 \mathrm{~min}$ and $8^{\circ} \mathrm{C}$ ) an aliquot of $0.2 \mathrm{~mL}$ of the supernatant was taken out. Inorganic $\mathrm{P}$ in the tissue extract was measured colorimetrically with the ascorbic acid method (Murphy and Riley, 1962) but the absorbance was measured at $660 \mathrm{~nm}$.

\section{Determination of internal acid phosphatase (APase) activity in leaves and roots}

The principle of this determination consists of the hydrolysis of an artificial substrate pNitrophenyl Phosphate ( $p$ NPP) by the APase of the plants cells. Under alkaline conditions, the dephosphorylated reaction product p-Nitrophenol (PNP) turns yellow and exhibits an absorption at $405 \mathrm{~nm}$, which can be quantified photometrically using an alkaline solution of PNP as a standard. The tubes containing the frozen tissue material (leaf discs and roots) were kept in ice and pre-ground with a pestle in a pre-chilled mortar. After adding $5 \mathrm{~mL}$ of $0.1 \mathrm{M} \mathrm{Na}$-Ac (sodium acetate) buffer, it was again ground and the extract transferred to reagent tubes. After centrifugation $\left(906 \mathrm{~g}, 10 \mathrm{~min}, 2^{\circ} \mathrm{C}\right.$ ) an aliquot of $0.2 \mathrm{~mL}$ of the supernatant was taken out, and $0.5 \mathrm{~mL}$ of $0.1 \mathrm{M} \mathrm{Na}-\mathrm{Ac}$ buffer and $1 \mathrm{~mL}$ of $20 \mathrm{mM}$ of $p \mathrm{NPP}$ substrate were added. After a reaction time of $15 \mathrm{~min}$ at $25-30^{\circ} \mathrm{C} 1.5 \mathrm{~mL}$ of $1 \mathrm{M} \mathrm{NaOH}$ was added to terminate the reaction. The absorption of reaction solution was measured at $405 \mathrm{~nm}$ (Besford, 1980).

\section{Determination of arbuscular mycorrhizae fungi (AMF) colonization}

Roots were prepared by the clearing and staining procedure of Sieverding (1983), in which internal hyphae, arbuscules, and vesicles may be seen in the microscope in sharp contrast to the almost transparent root tissue. Briefly, a solution of $10 \% \mathrm{KOH}$ was added to each tube until the root sample was covered and put in a bain-marie at $60-70^{\circ} \mathrm{C}$ for $15 \mathrm{~min}$. After letting the root samples cool down, the $\mathrm{KOH}$ solution was discarded. When the root tissue was dark, a solution 
of $\mathrm{H}_{2} \mathrm{O}_{2}$ was added until the root was covered in order to clear it and then the samples were well washed with water. After that the root sample was covered with a solution of $10 \% \mathrm{HCl}$ and kept at room temperature for $15 \mathrm{~min}$. After discarding the $\mathrm{HCl}$, a solution of 5\% trypan blue was added and the samples were again put in a bain-marie for $15 \mathrm{~min}$. Finally, the trypan blue was discarded and the samples were again washed with water. The stained root samples were kept in the tubes covered with water and stored at $5^{\circ} \mathrm{C}$. Root colonization by the AMF was determined using the infection percentage in a glass slide method of Allen and Allen (1980).

\section{$P \operatorname{Inflow}\left(I_{n}\right)$}

The inflow is the net amount of a nutrient element taken up per unit root (weight, length or root surface area) and the unit time from the soil or nutrient solution (Claassen, 1994). To calculate the average inflow, at least two harvests are needed in which the nutrient content and root length of the plants are known. Assuming that after 45 days of transplanting the plants have a lineal root growth, the average $\mathrm{P}$ inflow was calculated using the following formula:

$$
I_{n}=\frac{\left(U_{2}-U_{1}\right)}{\left(t_{2}-t_{1}\right)} \times \frac{2}{\left(R L_{2}+R L_{1}\right)}
$$

where, $\quad \mathrm{U}=$ nutrient element content in the shoot in mol

$$
\mathrm{RL}=\text { root length in } \mathrm{cm}
$$

$\mathrm{t}=$ time in $\mathrm{s}$

indices 1 and 2 means $1^{\text {st }}$ and $2^{\text {nd }}$ harvest

\section{Soil Analysis}

\section{Extractable $\mathrm{P}$ and $\mathrm{pH}_{(\mathrm{H} 2 \mathrm{O})}$ in soil samples after harvesting}

To characterize readily available $\mathrm{P}$ plus a part of the active reserve $\mathrm{P}$ in acid soil, the Bray II extraction of Bray and Kurtz (1945) method was used. Inorganic P in soil extractions and in soil solutions were analysed colorimetrically as reported by Murphy and Riley (1962). The pH value was measured in 1:1 soil:water ratio. For more details see chapter 2. 


\section{Extractable $P$ in the soil and $P$ concentration in the soil solution from incubated soil}

Incubation study was conducted in Germany using Ultisols from greenhouse experiment in Colombia. The objectives were to determine the fertilization effect on $\mathrm{P}$ availability in the soil solution and to compare the $\mathrm{NH}_{4} \mathrm{~F}$-exchangeable $\mathrm{P}$ (Bray II) with the Ca-acetate-lactateexchangeable P (CAL-method). Air dried soil (1 kg) ground to pass a $2 \mathrm{~mm}$ mesh without steam sterilization was thoroughly mixed with the same amount of fertilizers applied for the greenhouse trial and then put into the plastic pots. The soil was kept in an oven during 30 days at $35^{\circ} \mathrm{C}$ and at $65 \%$ of maximum water holding capacity. The soil moisture was controlled daily by weight.

\section{Statistical Analysis}

Analysis of variance was calculated with the SAS computer program (release 8.2 for Windows, 2001). Significant differences among genotypes for each treatment were calculated with the Tukey test and differences between with and without AMF for each genotype were calculated with the Pdiff test. Correlations were calculated through the SAS procedure CORR, calculating the Pearson's correlations coefficients. The probability level of 0.05 was considered statistically significant.

\subsection{Results and Discussion}

\subsubsection{Soil analysis}

As it was described in chapter 2, the Ultisol used in this study had low $\mathrm{pH}_{(\mathrm{H} 2 \mathrm{O})}$ and was high in Al saturation and low in available nutrients. The addition of both P fertilisers (20PR and 4TSP) and the arbuscular mycorrhizae fungi (AMF) did not influence the overall mean $\mathrm{pH}_{(\mathrm{H} 2 \mathrm{O})}$ of planted soils, which at 45 and 90 days after transplanting (DAT) was around 3.9 and 4.2 respectively (see Appendix). However, a statistical significant increase of the $\mathrm{pH}_{(\mathrm{H} 2 \mathrm{O})}$ of the unplanted soil at 20PR was determined at 45 DAT in comparison to the planted soil. That could be an effect of the high Ca content of the PR per unit of P added, which in the case of the planted soil could have be affected by the complex biotic and abiotic processes in the rhizosphere.

Statistically significant differences were found among the overall means of extractable P (Bray II) of planted soil as effect of P fertilisation at both harvests (see Appendix). The extractable P (Bray II) at 4TSP and 20PR was 1.4 times and 2 times higher than at $0 \mathrm{P}\left(7.5 \mathrm{mg} \mathrm{P} \mathrm{kg}{ }^{-1}\right)$ at the first harvest, respectively. With time (at 90 DAT) the $\mathrm{P}$ uptake by the genotypes and the $\mathrm{P}$ 
adsorbed by $\mathrm{Al}$ and $\mathrm{Fe}$ oxide decreased the extractable $\mathrm{P}$ in the soil which was stronger at $20 \mathrm{PR}$ and 4TSP when the genotypes were inoculated with AMF.

When the soil with the same $\mathrm{P}$ treatments was incubated for 30 days at $30^{\circ} \mathrm{C}$ (Table 3.2 ), the $\mathrm{pH}$ in the soil solution of each $\mathrm{P}$ treatment was similar as those above described for the soil, but statistically did not differ. Although the soil solution $\mathrm{P}_{\mathrm{i}}$ and $\mathrm{P}_{\mathrm{o}}$ concentration was slightly higher when $\mathrm{P}$ was added, statistical significant difference were not confirmed. Noteworthy is that the $\mathrm{P}_{\mathrm{o}}$ concentration in the soil solution at each $\mathrm{P}$ treatment was at least 5 times higher than that of the $\mathrm{P}_{\mathrm{i}}$ concentration, which are close to the $\mathrm{C}_{\mathrm{Lmin}}(0.2 \mu \mathrm{M})$ reported for Arachis hypogea (Bhadoria et al., 2004).

Table 3.2 Influence of varying $P$ supply of phosphate rock (PR) and triple superphosphate (TSP) on the concentration of inorganic $\mathrm{P}\left(\mathrm{P}_{\mathrm{i}}\right)$ and organic $\mathrm{P}\left(\mathrm{P}_{\mathrm{o}}\right)$ and $\mathrm{pH}$ in the soil solution and the extractable $\mathrm{P}\left(\mathrm{CAL}\right.$ and Bray II) after 30 days of incubation at $30^{\circ} \mathrm{C}$.

\begin{tabular}{|c|c|c|c|c|c|}
\hline \multirow{3}{*}{$\begin{array}{l}\text { P level } \\
\mathrm{mg} \mathrm{kg}^{-1}\end{array}$} & \multicolumn{3}{|c|}{ Soil solution } & \multicolumn{2}{|c|}{ Soil } \\
\hline & \multirow[t]{2}{*}{$\mathrm{pH}$} & $\mathrm{P}_{\mathrm{i}}$ & $\mathrm{P}_{\mathrm{o}}$ & P-CAL & P-BrayII \\
\hline & & \multicolumn{2}{|c|}{$\mu \mathrm{M}$} & \multicolumn{2}{|c|}{$\mathrm{mg} \mathrm{kg}^{-1}$} \\
\hline $0 \mathrm{P}$ & $4.0 \mathrm{ab}$ & $0.15 \mathrm{a}$ & $0.96 \mathrm{a}$ & $1.7 b$ & $6.2 \mathrm{c}$ \\
\hline $20 \mathrm{PR}$ & $4.2 \mathrm{a}$ & $0.17 \mathrm{a}$ & $1.51 \mathrm{a}$ & $1.9 \mathrm{~b}$ & $9.9 \mathrm{a}$ \\
\hline 4 TSP & $3.9 \mathrm{~b}$ & $0.20 \mathrm{a}$ & $1.13 \mathrm{a}$ & $2.2 \mathrm{a}$ & $8.7 \mathrm{~b}$ \\
\hline
\end{tabular}

Among $\mathrm{P}$ treatments, values followed by the same letter are not significantly different after pdiff-test $(\mathrm{p}<0.05)$.

\subsubsection{Root colonisation grade of the arbuscular mycorrhizae fungi (AMF)}

Since the aim of this experiment was to assess the influence of AMF on the P efficiency of Arachis pintoi ( $A p$ ) genotypes, the starting point was to determine the AMF colonisation grade of the root system of each genotype produced by the inoculation with AMF at both harvests. Table 3.3 shows only the colonisation grade of the AMF inoculated genotypes, because no AM fungi were observed colonising roots of uninoculated genotypes at any harvest. Although at both harvests statistical differences were found among the genotypes within the treatments (Table 3.3), the percentage of AMF colonisation of roots was very low in all the genotypes at each treatment in the earlier growth stage (45 DAT). At this age, the lowest value was 7\% (at 4TSP) and the highest was $16 \%$ (at $0 \mathrm{P})$. The $\mathrm{P}$ fertilisation decreased slightly (10\%) the overall mean of the colonisation grade compared to the overall mean at $0 \mathrm{P}$. 
An increase on the overall mean of AMF colonisation was observed from the first to the second harvest (90 DAT), e.g. 2.4-fold at 0P, 2.2-fold at 20PR and 1.8-fold at 4TSP. Moreover, the application of $\mathrm{P}$ fertiliser decreased the overall mean of the colonisation grade at 20PR and 4TSP by $10 \%$ and $30 \%$ respectively, compared to the overall mean at $0 \mathrm{P}$. Similar results reported Rao et al., (1997) from the commercial A. pintoi genotype (genotype $1=$ CIAT 17434). After 80 days of growth, the AMF infection of roots in a clay Oxisol decreased from 10 to $1 \%$ with the increase of the $\mathrm{P}$ supply from $0 \mathrm{P}$ to $50 \mathrm{~kg} \mathrm{P} \mathrm{ha}^{-1}$ as TSP respectively.

Table 3.3 Influence of varying P supply of phosphate rock (PR) and triple superphosphate (TSP) on AMF (Glomus fasciculatum) colonisation in roots of Arachis pintoi genotypes after 45 and 90 days of transplanting (DAT).

\begin{tabular}{|c|c|c|c|c|c|c|}
\hline \multirow[t]{3}{*}{ Genotype } & \multicolumn{6}{|c|}{ Colonisation grade of AMF, $\%$} \\
\hline & \multicolumn{3}{|c|}{$45 \mathrm{DAT}$} & \multicolumn{3}{|c|}{$90 \mathrm{DAT}$} \\
\hline & $0 \mathrm{P}$ & $20 \mathrm{PR}$ & 4TSP & OP & 20PR & 4TSP \\
\hline 1 & $10 \mathrm{ab}$ & $9 \mathrm{c}$ & $10 \mathrm{bc}$ & $18 \mathrm{c}$ & $17 \mathrm{bc}$ & $17 \mathrm{~b}$ \\
\hline 2 & $12 \mathrm{ab}$ & $13 \mathrm{ab}$ & $8 \mathrm{c}$ & $22 b$ & $21 b$ & $16 b$ \\
\hline 3 & $13 \mathrm{a}$ & $15 \mathrm{a}$ & $14 \mathrm{a}$ & $38 \mathrm{a}$ & $31 \mathrm{ab}$ & $27 \mathrm{a}$ \\
\hline 4 & $16 \mathrm{a}$ & $13 a$ & $14 a$ & $41 \mathrm{a}$ & $38 \mathrm{a}$ & $25 \mathrm{a}$ \\
\hline 5 & $12 \mathrm{ab}$ & $11 b c$ & $9 c$ & $35 a b$ & $41 \mathrm{a}$ & $25 \mathrm{a}$ \\
\hline 6 & $9 b$ & $11 \mathrm{ab}$ & $11 b c$ & $21 b c$ & $15 \mathrm{c}$ & $15 \mathrm{bc}$ \\
\hline 7 & $9 b$ & $8 \mathrm{c}$ & $10 \mathrm{bc}$ & $20 b c$ & $15 \mathrm{c}$ & $15 \mathrm{bc}$ \\
\hline 8 & $15 \mathrm{a}$ & $14 \mathrm{a}$ & $15 \mathrm{a}$ & $36 a$ & $27 \mathrm{ab}$ & $22 \mathrm{ab}$ \\
\hline 9 & $8 b$ & $9 c$ & $9 c$ & $25 b$ & $21 b$ & $19 \mathrm{ab}$ \\
\hline 10 & $13 \mathrm{a}$ & $10 \mathrm{ab}$ & $7 c$ & $19 \mathrm{c}$ & $19 b$ & $11 \mathrm{c}$ \\
\hline $\bar{X}$ & $12 \mathrm{~A}$ & $11 \mathrm{~A}$ & $11 \mathrm{~A}$ & $28 A$ & $25 A B$ & $19 B$ \\
\hline
\end{tabular}

Within a $\mathrm{P}$ treatment, the values that are followed by the same letter, are not significantly different according to the pdiff-test $(\mathrm{p}<0.05)$. Means values $(\bar{X})$ marked with the same capital letter are not significantly different after Tukey-test $(\mathrm{p}<0.05)$.

It is well known that the formation and development of AMF is strongly influenced by the nutrient levels in the soil (Kamminga van-Wijk, 1991; Wallander 1992). Very high or very low $P$ levels may reduce AMF colonization of the roots (Koide, 1991). It is well established that infection by mycorrhizal fungi is significantly reduced at high soil P levels (Amijee et al., 1989; Koide and Li, 1990; Tones et al., 1990; MacFall et al., 1991). It has also been shown that the level of $\mathrm{P}$ in the plant influences the AMF colonisation grade, where high levels tend to inhibit it (Menge, et al. 1978; Graham et al., 1981; de Miranda et al., 1989; Asimi et al., 1989). 
It is important to remark the large difference in the AMF colonisation grade among the genotypes e.g. at 0P, 90 DAT, it varied from 18 to 41\%. At both harvests, genotypes 8, 3 and 4 had percentages of colonisation above the overall mean and statistically they were within the highest group. On the contrary, the remaining genotypes presented a colonisation grade below the overall mean at each treatment at 45 and 90 DAT.

\subsubsection{Shoot biomass production}

Figure 3.1 and 3.2 show the effect of the $\mathrm{P}$ supply and of the arbuscular mycorrhizae fungi (AMF) on the shoot yield of the genotypes at 45 DAT and 90 DAT respectively. On the right side of each $\mathrm{P}$ treatment a bar was added with the overall mean yield of -AMF and +AMF. Moreover, the results were sorted in a decreasing order on the basis of the genotype's ability to produce shoot biomass at 90 days after transplanting (DAT), under low P availability in the soil (0P) and without the effect of AMF. This P efficient order will be used as the standard to present the results of this study.

All genotypes without AMF infection responded to added $\mathrm{P}$ at both harvest, indicating that the low $\mathrm{P}$ treatments had provided P-limiting conditions. It is interesting to see that the P efficiency order of the genotypes obtained in this greenhouse pot trial (Figure 3.2) was very similar to the order established in the field trial (see Table 2.1 in chapter 2). The exception was genotype 4, which fell behind, as it was also observed in the pot trial in chapter 2. Nevertheless, the shoot biomass production of the genotypes at 45 DAT (Figure 3.1) did not match the $\mathrm{P}$ efficiency found at 90 DAT. That means that some genotypes $(1,10,8)$ manage to develop their efficiency only later.

Considering the overall mean yield of the P treatments without AMF, at 45 DAT the effect of the 20PR supply on the yield was clearly higher than that of 4TSP. Taking into account the fact that neither the application of 20PR (5-fold higher than that of TSP) nor of 4TSP increased the $\mathrm{P}_{\mathrm{i}}$ and $\mathrm{P}_{\mathrm{o}}$ concentration in the soil solution in comparison to 0P (Table 3.2), the yield differences among the $\mathrm{P}$ treatments are more likely related to the high $\mathrm{Ca}$ and $\mathrm{Mg}$ provide for the genotypes by the PR as it was also observed in the chapter 2 . Moreover, the genotypes responded differently to the fertilizers, but there was no relation to the P efficiency order.

At the second harvest (90 DAT), the fertilization effect on the yield of the genotypes changed. On average, the shoot biomass production of the genotypes grown at 20PR fell behind in comparison with TSP. However, different genotypes varied in their response to different fertilizers. For example, genotypes 2 and 1 had a higher yield at 20PR than that at 4TSP. 


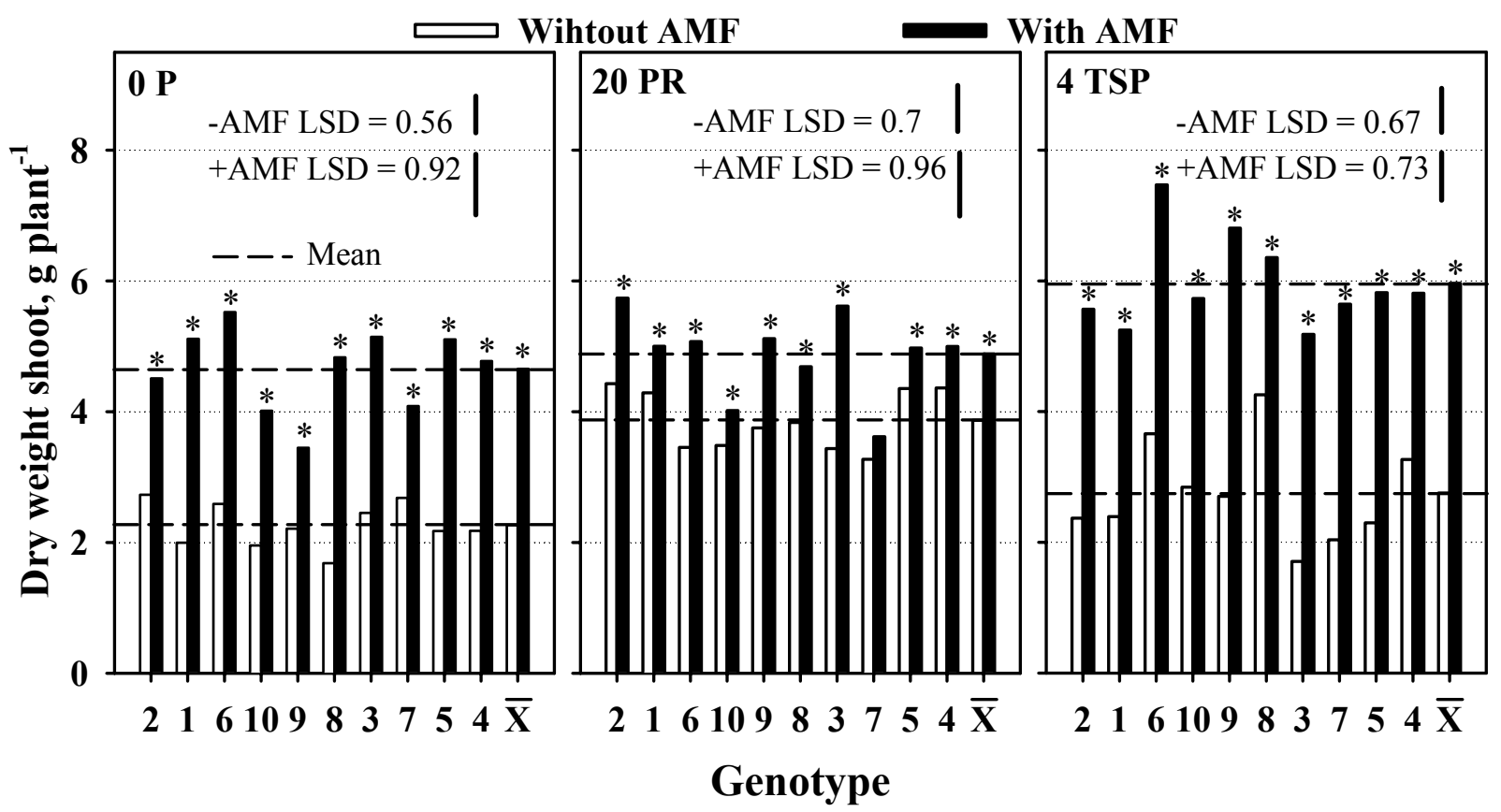

Figure 3.1 Influence of varying $P$ supply of phosphate rock (PR) and triple superphosphate (TSP) and AMF on shoot biomass production after 45 days of transplanting (DAT). LSD values are at the 0.05 probability level after Tukey-test. For each genotype and mean value $(\bar{X})$, bar with AMF having asterisk differs statistically from the bar without AMF at the $p<0.05(*)$ after pdiff-test.

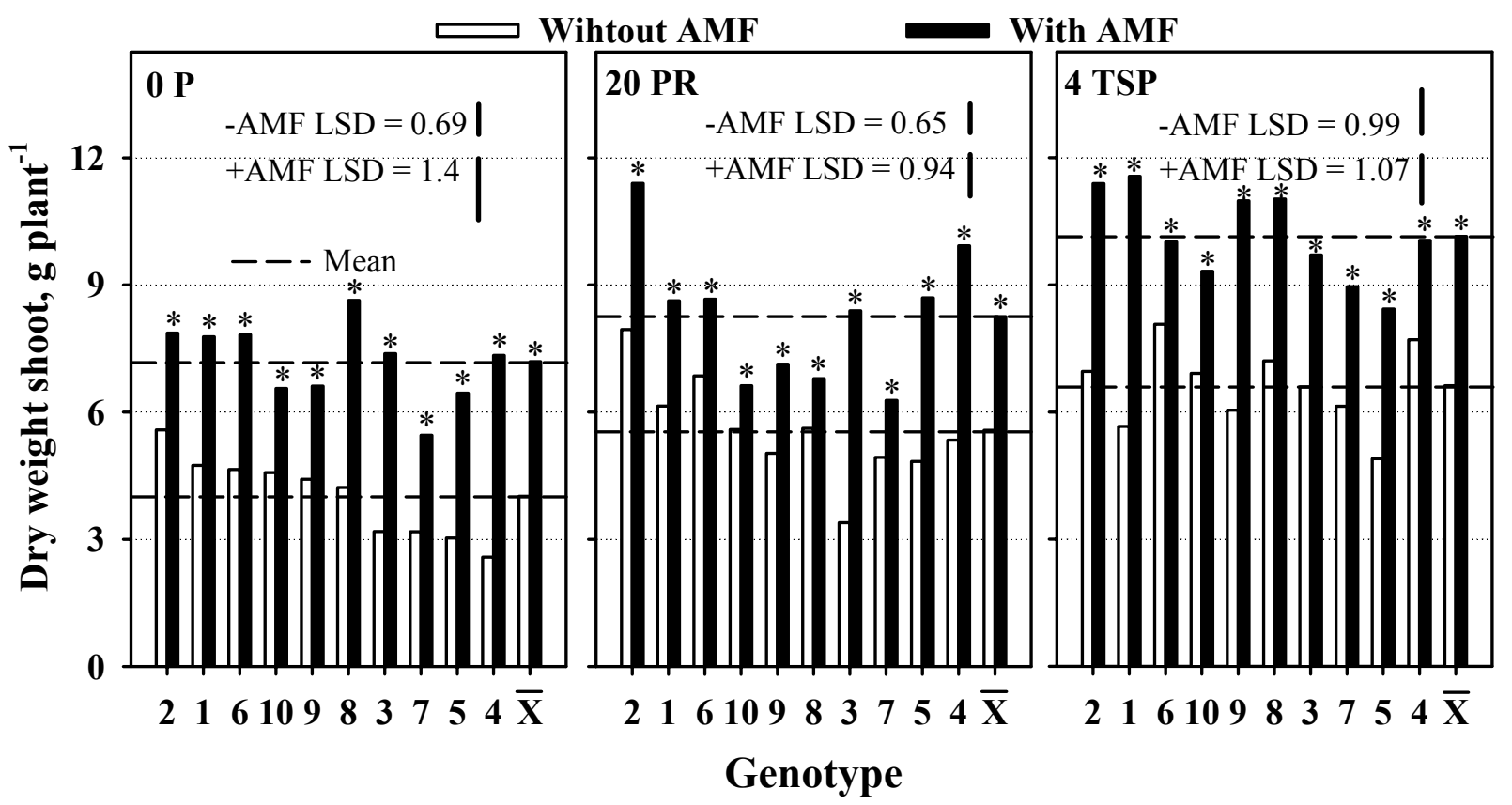

Figure 3.2 Influence of varying $P$ supply of phosphate rock (PR) and triple superphosphate (TSP) and AMF on shoot biomass production after 90 days of transplanting (DAT). LSD values are at the 0.05 probability level after Tukey-test. For each genotype and mean value $(\bar{X})$, bar with AMF having asterisk differs statistically from the bar without AMF at the $p<0.05(*)$ after pdiff-test. 
Nevertheless, although it was not possible to establish a relationship to the P efficiency order, the inefficient genotypes $(3,7,5,4)$ seemed to be more capable of using the TSP than the P efficient ones.

The previously general observations changed with the presence of AMF. All genotypes under all conditions profited from the AMF. At OP and 90 DAT, the effect of the AMF resulted in a adjustment of the biomass production among the genotypes (Figure 3.2). However, although the P efficient genotypes $(2,1,6)$ maintained still a slightly higher yield, from the percentage point of view, the inefficient genotypes $(3,7,5,4)$ profited more from the AMF. For instance, the $\mathrm{P}$ efficient genotypes increased their shoot biomass with AMF in a range of 1.4-1.7-fold, while the increase of the inefficient ones ranged between 1.7 and 2.8-fold. Several studies have predicted that plants with inherent mechanisms for acquiring $\mathrm{P}$ tend to benefit less from AMF colonisation (Koide, 1991; Koide 1993). For example, mycorrhizal benefit has been shown to be inversely related to absolute root allocation, root density, root fineness, root-shoot ratio, or root hairiness (Hayman, 1983; Graham and Syvertsen, 1985; Schawab, 1987; Hetrick et al., 1988; Koide et al., 1988).

A positive effect on the biomass production was already recorded at 45 DAT also when $\mathrm{P}$ was added (Figure 3.1), although the genotypes had a low AMF colonisation grade (Table 3.2). However, this positive effect of AMF was on average lower at 20PR (1.3-fold) than at 4TSP (2.2-fold). If the addition of 20PR was not enough to increase the P concentration in the soil solution of this Ultisol (Table 3.2), the fact that the genotypes without AMF at 20PR outyielded 4TSP and OP could be only explained due to i) a high availability of $\mathrm{Ca}$ and $\mathrm{Mg}$ for the genotypes or ii) the genotypes were able to increase the $\mathrm{P}$ concentration at the root surface in order to cover the $\mathrm{P}$ demand at this time, which could also have constrained the effectiveness of the AMF acquiring P. In contrast, if it is assumed that the genotypes have not still developed morphological and/or physiological root mechanisms to grow under low P availability (4TSP), it seems to be that the added $\mathrm{P}$ was apparently only available for the AMF hyphae, and was exploited efficiently to cover the $\mathrm{P}$ demand at this growth stage.

With time (90 DAT) the difference between the fertilizers on the AMF effectiveness to increase the yield was less, even though it was still possible to recognise slight differences. Furthermore, it is interesting to remark that on average the AMF effect on the biomass production at $0 \mathrm{P}$ was similar or higher than the effect of the fertilisers. Duponnois et al., (2005) reported that the AMF Glomus intraradices significantly increased the plant biomass (by 1.78-fold and 2.23-fold for 
shoot and root respectively) of Acacia holosericea, while mineral phosphate amendment had no effect in a sterilised soil after 4 month of growth.

In concordance with these results, Viebrock (1988) with Capsicum annuum and two P levels (0P and 10P) found already 4 weeks after transplanting an increase on the biomass production at both $\mathrm{P}$ treatments as effect of AMF Glomus macrocarpus. With time, at $\mathrm{OP}$ the effect of mycorrhizal relative to non-mycorrhizal plants on the biomass production was 10-fold. However, this positive effect of AMF on the yield was not achieved when the plants grown at 10P (Viebrock, 1988). This result, amongst others, could be related to different growth conditions between a greenhouse trial and a growth chamber trial. Studies have shown that growth conditions as light intensity and root zone temperature influence the formation and development of arbuscular mycorrhizae (AM) and thus plant growth and P acquisition performance (Reinhards et al., 1994; Lui et al., 2004). Moreover, it has been also hypothesized that mycorrhizal dependence is largely controlled by root architecture system (Baylis, 1975) and nutrient requirement (Ortas et al., 2001).

There was no clear relationship between total colonisation grade and growth or $\mathrm{P}$ response in this study. Similar results have shown that high AMF colonisation in plant species such as Onion, medic and tomato (Smith et al., 2004) and in maize (Jansa et al., 2003) were not associated with positive growth or P responses at the whole plant level. Conversely low AMF colonisation levels in flax were associated with positive growth and $\mathrm{P}$ responses and that there was generally lower colonisation in this plant than wheat or cucumber, which are relatively unresponsive (Ravnskov and Jakobsen, 1995). These results emphasise that low colonisation is not necessarily an indication of a small growth increase, as sometimes suggested. This large variability in host plant responsiveness to mycorrhizal colonization does occur. For example, wide variation in the effect of these fungi on promoting growth has not only been reported between different plant species (Mosse, 1978; Owusu-Bennoah and Mosse, 1979; Lambert and Cole, 1980; Plenchette, Fortin and Furlan, 1983a, b), but between genotypes of the same species including citrus (Menge, Johnson, and Platt, 1978; Graham and Syvertsen, 1985; Graham, Duncan and Eissenstat, 1997), corn (Toth et al., 1990), cowpea (Rajapakse and Miller, 1988; Mercy, Shivanshankar and Bagyarai, 1990), palm (Clement and Habte, 1997), pea (Estaun, Calvet and Hayman, 1987) and wheat (Azcon and Ocampo, 1981; Hetrick, Wilson and Todd, 1996).

Furthermore, the method used to determine the AMF colonisation grad may not be showing the actual AMF effectiveness. By the use of trypan blue to stain the AMF is not possible to distinguish between living and dead fungal structures. Although the percentage (or fraction) of 
the root length colonised by the fungus, without determination of the quality of the infection, is the most commonly used parameter for quantification of infection, this may lead to inconsistent results relative to plant growth and uptake of P (Smith and Dikson, 1991). On the other hand, it is well established that among plant species, and indeed genotypes within species vary in their responsiveness to AM colonisation on the basis of whole plant $\mathrm{P}$ uptake and/or growth and that many plant and environmental factors influence the magnitude of the responses (Smith and Gianinazzi- Pearson, 1988; Smith and Read, 1997; Jakobsen et al., 2002). Sometimes there is no positive response and where nonnutritional effects can be discounted, as in controlled experiments, it then appears that the plants receive insignificant amounts of $\mathrm{P}$ via the fungal symbiont.

Summarizing, the ability of the genotypes to grow under low $\mathrm{P}$ availability as well as to use the $\mathrm{P}$ added is clearly improved by the AMF. The inefficient genotypes tended to profit more from the presence of AMF, which evened out the yield differences to the $\mathrm{P}$ efficient ones. The next question to answer would be which morphological and/or physiological mechanisms were responsible for the $\mathrm{P}$ efficiency of the genotypes and the way of action of the AMF.

\subsubsection{Shoot $P$ concentration and $P$ content}

The nutritional $\mathrm{P}$ status of the genotypes did not differ strongly among the genotypes at each treatment at both harvests (Table 3.4). Therefore, in most treatments no statistical significant differences were found between the genotypes rated as $\mathrm{P}$ efficient $(2,1,6,10)$ and $\mathrm{P}$ inefficient $(3,7,5,4)$. With time (at 90 DAT) the shoot P concentration decreased at each treatment but this effect was clear (21\%) between the overall mean at 4TSP without AMF (Table 3.4).

The $\mathrm{P}$ fertilisation increased slightly the overall mean of the shoot $\mathrm{P}$ concentration, where with time (at 90 DAT) the PR effect tended to be higher (15\%) than that of TSP. However, the nutritional status achieved in average by the genotypes at each treatment in this study was clearly lower than those in the field (Chapter 2). For instance, the maximal shoot $\mathrm{P}$ concentration on average in this study was $1.4 \mathrm{mg} \mathrm{g}^{-1}$ (PR and TSP at $45 \mathrm{DAT}$ ), while in the field at $0 \mathrm{P}$ and 90 DAE was $2.0 \mathrm{mg} \mathrm{g}^{-1}$ (see Table 2.3 in chapter 2).

The AMF decreased the P concentration at each $\mathrm{P}$ level, being this effect higher in the first growth period (e.g. at 0P and 4TSP) than that in the second one (Table 3.4). It is well know that AMF increase the P uptake (Harrison, 1997; Jakobsen et al., 1992b, Schweiger and Jakobsen, 2000; Smith et al., 2000) i.e. the shoot P concentration of the genotypes with AMF should be equal or higher than that without AMF but not lower. 
Table 3.4 Influence of varying P supply of phosphate rock (PR) and triple superphosphate (TSP) and AMF on $\mathrm{P}$ concentration in shoot at 45 and 90 days after transplanting (DAT).

\begin{tabular}{|c|c|c|c|c|c|c|}
\hline \multirow[t]{3}{*}{ Genotype } & \multicolumn{6}{|c|}{ Shoot $\mathrm{P}$ concentration, $\mathrm{mg} \mathrm{g}^{-1}$} \\
\hline & \multicolumn{2}{|c|}{ OP } & \multicolumn{2}{|c|}{ 20PR } & \multicolumn{2}{|c|}{ 4TSP } \\
\hline & $-\mathrm{AMF}$ & $+\mathrm{AMF}$ & $-\mathrm{AMF}$ & $+\mathrm{AMF}$ & $-\mathrm{AMF}$ & $+\mathrm{AMF}$ \\
\hline & & & \multicolumn{2}{|c|}{$45 \mathrm{DAT}$} & & \\
\hline 2 & $1.4 \mathrm{ab}$ & $* 1.1 \mathrm{a}$ & $1.4 \mathrm{bc}$ & $1.4 \mathrm{a}$ & $1.0 \mathrm{c}$ & $* * 1.3 \mathrm{a}$ \\
\hline 1 & $1.4 \mathrm{a}$ & $* 1.1 \mathrm{a}$ & $1.3 \mathrm{~cd}$ & $1.4 \mathrm{a}$ & $1.3 \mathrm{~b}$ & $1.2 \mathrm{ab}$ \\
\hline 6 & $1.2 \mathrm{bc}$ & $1.0 \mathrm{a}$ & $1.3 \mathrm{~cd}$ & $1.3 \mathrm{a}$ & $1.4 \mathrm{ab}$ & $* * 1.1 \mathrm{c}$ \\
\hline 10 & $1.1 \mathrm{~cd}$ & $1.2 \mathrm{a}$ & $1.6 \mathrm{~b}$ & $* 1.4 \mathrm{a}$ & $1.5 \mathrm{ab}$ & $* * 1.3 \mathrm{a}$ \\
\hline 9 & $1.4 \mathrm{a}$ & $* 1.1 \mathrm{a}$ & $1.3 \mathrm{~cd}$ & $1.3 \mathrm{a}$ & $1.4 \mathrm{ab}$ & $* 1.2 \mathrm{ab}$ \\
\hline 8 & $0.9 \mathrm{~d}$ & $* * 1.2 \mathrm{a}$ & $1.1 \mathrm{~d}$ & $* 1.3 \mathrm{a}$ & $1.4 \mathrm{ab}$ & $* 1.2 \mathrm{ab}$ \\
\hline 3 & $1.4 \mathrm{a}$ & $* 1.2 \mathrm{a}$ & $1.8 \mathrm{a}$ & $* * 1.4 \mathrm{a}$ & $1.5 \mathrm{ab}$ & $* 1.3 \mathrm{a}$ \\
\hline 7 & $1.4 \mathrm{ab}$ & $* * 1.0 \mathrm{a}$ & $1.4 \mathrm{bc}$ & $1.3 \mathrm{a}$ & $1.6 \mathrm{a}$ & $* * 1.2 \mathrm{abc}$ \\
\hline 5 & $1.3 \mathrm{abc}$ & $* 1.1 \mathrm{a}$ & $1.4 \mathrm{c}$ & $1.3 \mathrm{a}$ & $1.6 \mathrm{a}$ & $* * 1.1 \mathrm{bc}$ \\
\hline 4 & $1.2 \mathrm{abc}$ & $* 1.0 \mathrm{a}$ & $1.3 \mathrm{c}$ & $1.4 \mathrm{a}$ & $1.4 \mathrm{ab}$ & $* * 1.1 \mathrm{bc}$ \\
\hline \multirow[t]{2}{*}{$\bar{X}$} & $1.3 A B C$ & $1.1 C$ & $1.4 A$ & $1.3 A B$ & $1.4 \mathrm{~A}$ & $1.2 B C$ \\
\hline & & & \multicolumn{2}{|c|}{90 DAT } & & \\
\hline 2 & $1.2 \mathrm{abc}$ & $* 1.1 \mathrm{a}$ & $1.2 \mathrm{~d}$ & $* 1.1 \mathrm{bc}$ & $1.0 \mathrm{bc}$ & $1.0 \mathrm{~cd}$ \\
\hline 1 & $0.9 \mathrm{f}$ & $* 1.1 \mathrm{a}$ & $1.3 \mathrm{~cd}$ & $* 1.1 \mathrm{~b}$ & $1.1 \mathrm{~b}$ & $* 1.0 \mathrm{bc}$ \\
\hline 6 & $1.0 \mathrm{ef}$ & $1.0 \mathrm{a}$ & $1.0 \mathrm{e}$ & $1.0 \mathrm{c}$ & $1.1 \mathrm{~b}$ & $1.1 \mathrm{ab}$ \\
\hline 10 & $1.1 \mathrm{cdef}$ & $1.0 \mathrm{a}$ & $1.2 \mathrm{~d}$ & $1.1 \mathrm{~b}$ & $1.2 \mathrm{~b}$ & $1.1 \mathrm{ab}$ \\
\hline 9 & $1.1 \mathrm{abcd}$ & $1.1 \mathrm{a}$ & $1.3 \mathrm{~cd}$ & $1.3 \mathrm{a}$ & $1.3 \mathrm{a}$ & $* 1.2 \mathrm{a}$ \\
\hline 8 & $1.0 \mathrm{def}$ & $0.9 \mathrm{a}$ & $1.1 \mathrm{~d}$ & $1.2 \mathrm{~b}$ & $1.1 \mathrm{~b}$ & $1.1 \mathrm{abc}$ \\
\hline 3 & $1.3 \mathrm{a}$ & $* 1.1 \mathrm{a}$ & $1.8 \mathrm{a}$ & $* * 1.1 \mathrm{~b}$ & $1.0 \mathrm{bc}$ & $* 1.2 \mathrm{a}$ \\
\hline 7 & $1.2 \mathrm{abc}$ & $* 1.0 \mathrm{a}$ & $1.1 \mathrm{~d}$ & $1.1 \mathrm{bc}$ & $1.1 \mathrm{~b}$ & $1.1 \mathrm{a}$ \\
\hline 5 & $1.1 \mathrm{bcde}$ & $1.1 \mathrm{a}$ & $1.5 b$ & $* * 1.0 \mathrm{bc}$ & $1.0 \mathrm{c}$ & $0.9 \mathrm{~d}$ \\
\hline 4 & $1.2 \mathrm{ab}$ & $* 1.1 \mathrm{a}$ & $1.4 \mathrm{bc}$ & $* 1.5 \mathrm{a}$ & $1.1 \mathrm{~b}$ & $1.1 \mathrm{abc}$ \\
\hline $\bar{X}$ & $1.1 A B$ & $1.0 B$ & $1.3 \mathrm{~A}$ & $1.2 A B$ & $1.1 A B$ & $1.1 B$ \\
\hline
\end{tabular}

Within a treatment, values that are followed by the same letter are not significantly different according the pdiff-test $(\mathrm{p}<0.05)$. For each genotype at each $\mathrm{P}$ treatment and harvest, the value with AMF having asterisk differ statistically from the value without AMF at the $p<0.05\left(^{*}\right)$ and $p<0.01(* *)$ level after pdiff-test. Mean values $(\bar{X})$ marked with the same capital letter are not significantly different after Tukey-test $(\mathrm{p}<0.05)$. 
As was shown in Figure 3.1 and 3.2, the growth of the genotypes was increased more strongly by the AMF than by the $\mathrm{P}$ supply but not because AMF improved the $\mathrm{P}$ status of the genotypes (Table 3.4). Similar results reported Duponnois et al., (2005), who assessing the effect of Glomus intraradices on the growth of Acacia holosericea found that the AMF significantly stimulated plant growth, which was significantly higher than that measured in the mineral phosphate treatment.

The $\mathrm{P}$ content in the shoots is the product of the dry matter yield and its $\mathrm{P}$ concentration. The shoot $\mathrm{P}$ content had in general a similar pattern to growth in response to $\mathrm{P}$ supply and AM colonisation (Figure 3.1 and 3.2), with minor variations accounted for by small differences in shoot P concentrations (Table 3.4).

When the P fertiliser was supplied, the overall mean of the shoot $\mathrm{P}$ content increased at both harvest, but at 90 DAT the shoot $\mathrm{P}$ content of both fertilisers differed statistically from $0 \mathrm{P}$. The inefficient genotypes $(3,5,4)$ increased the shoot $\mathrm{P}$ content due to the positive effect caused by the fertilizers on their shoot $\mathrm{P}$ concentration at both growth stages (45 and 90 DAT). On the contrary, at 20PR and at 90 DAT the P efficient genotypes 6 and 10 had shoot P content below the overall mean, because their shoot $P$ concentration decreased with age from 1.3 to $1.0 \mathrm{mg} \mathrm{g}^{-1}$ and from 1.6 to $1.2 \mathrm{mg} \mathrm{g}^{-1}$ respectively (Table 3.4 ).

With AMF, the genotypes at each $\mathrm{P}$ treatment and at both harvest had a higher absorption of $\mathrm{P}$, reflected in a statistically superior shoot $\mathrm{P}$ content than that without AMF (Table 3.5), even though the dilution of $\mathrm{P}$ observed in the shoot (Table 3.4). At 20PR +AMF, contrary to the behaviour of most genotypes, the inefficient genotype 4 increased its shoot $\mathrm{P}$ concentration from 1.4 to $1.5 \mathrm{mg} \mathrm{g}^{-1}$ with age (Table 3.4), producing the highest shoot $\mathrm{P}$ content among the genotypes at all P levels; thus, showing the highest dependence on AMF. The effect of the water soluble P (4TSP) on the shoot P content observed was closely related to the pattern found for shoot biomass production, as the changes on the shoot $\mathrm{P}$ concentration were proportional in all the genotypes at each treatment and harvest.

Summarizing, the remarkable positive effect of AMF on the yield which was not due to the improvement of the $\mathrm{P}$ status ( $\mathrm{mg} \mathrm{P} \mathrm{g}^{-1}$ ) but to $\mathrm{P}$ uptake, indicates that beside of the positive effect on the $\mathrm{P}$ absorption (Table 3.5), the AMF had other effects which stimulated plant growth. The AMF, beside its effects on $\mathrm{P}$ nutrition, may also be responsible for other nutritional processes as well as for abiotic and biotic factor and processes, which influence and likely stimulate the overall growth of the plant (Sylvia and Williams 1992). 
Table 3.5 Influence of varying P supply of phosphate rock (PR) and triple superphosphate (TSP) and AMF on $\mathrm{P}$ content in shoot after 45 and 90 days of transplanting (DAT).

\begin{tabular}{|c|c|c|c|c|c|c|}
\hline \multirow[t]{3}{*}{ Genotype } & \multicolumn{6}{|c|}{ Shoot $\mathrm{P}$ content, mg plant ${ }^{-1}$} \\
\hline & \multicolumn{2}{|c|}{ OP } & \multicolumn{2}{|c|}{ 20PR } & \multicolumn{2}{|c|}{ 4TSP } \\
\hline & -AMF & $+\mathrm{AMF}$ & -AMF & $+\mathrm{AMF}$ & $-\mathrm{AMF}$ & $+\mathrm{AMF}$ \\
\hline & & & \multicolumn{2}{|c|}{$45 \mathrm{DAT}$} & & \\
\hline 2 & $3.7 \mathrm{a}$ & $* * 5.0 \mathrm{bc}$ & $6.4 \mathrm{a}$ & $* * 7.8 \mathrm{a}$ & $2.5 \mathrm{~g}$ & $* * 7.2 \mathrm{bc}$ \\
\hline 1 & $2.8 \mathrm{cde}$ & $* * 5.9 \mathrm{a}$ & $5.6 \mathrm{~cd}$ & $* * 7.1 \mathrm{~b}$ & $3.1 \mathrm{f}$ & $* * 6.5 \mathrm{~d}$ \\
\hline 6 & $3.0 \mathrm{bcd}$ & $* * 5.8 \mathrm{a}$ & $4.4 \mathrm{ef}$ & $* * 6.4 \mathrm{~cd}$ & $5.0 \mathrm{~b}$ & $* * 8.0 \mathrm{a}$ \\
\hline 10 & $2.2 \mathrm{ef}$ & $* * 4.7 \mathrm{~cd}$ & $5.5 \mathrm{~d}$ & $5.6 \mathrm{e}$ & $4.3 \mathrm{~cd}$ & $* * 7.2 \mathrm{bc}$ \\
\hline 9 & $3.1 \mathrm{abcd}$ & $* 4.0 \mathrm{~d}$ & $4.8 \mathrm{e}$ & $* * 6.7 \mathrm{bc}$ & $3.9 \mathrm{de}$ & $* * 8.4 \mathrm{a}$ \\
\hline 8 & $1.6 \mathrm{f}$ & $* * 5.8 \mathrm{a}$ & $4.3 \mathrm{f}$ & $* * 6.1 \mathrm{~d}$ & $6.1 \mathrm{a}$ & $* * 7.7 \mathrm{ab}$ \\
\hline 3 & $3.5 \mathrm{abc}$ & $* * 6.2 \mathrm{a}$ & $6.2 \mathrm{ab}$ & $* * 7.7 \mathrm{a}$ & $2.5 \mathrm{~g}$ & $* * 6.6 \mathrm{~cd}$ \\
\hline 7 & $3.7 \mathrm{ab}$ & $* 4.2 \mathrm{~d}$ & $4.6 \mathrm{ef}$ & $4.7 \mathrm{f}$ & $3.2 \mathrm{f}$ & $* * 6.7 \mathrm{~cd}$ \\
\hline 5 & $2.9 \mathrm{~cd}$ & $* * 5.6 \mathrm{ab}$ & $5.9 b c$ & $* * 6.5 \mathrm{~cd}$ & $3.7 \mathrm{ef}$ & $* * 6.6 \mathrm{~cd}$ \\
\hline 4 & $2.6 \mathrm{de}$ & $* * 5.0 \mathrm{bc}$ & $5.9 \mathrm{bcd}$ & $* * 6.9 \mathrm{bc}$ & $4.6 b c$ & $* * 6.6 \mathrm{~cd}$ \\
\hline \multirow[t]{2}{*}{$\bar{X}$} & $2.9 C$ & $5.2 B$ & $5.4 B$ & $6.5 \mathrm{~A}$ & $3.9 C$ & $7.2 \mathrm{~A}$ \\
\hline & & & \multicolumn{2}{|c|}{$90 \mathrm{DAT}$} & & \\
\hline 2 & $6.8 \mathrm{a}$ & $* * 8.3 \mathrm{a}$ & $9.4 \mathrm{a}$ & $* * 12.2 \mathrm{~b}$ & $7.2 \mathrm{~cd}$ & $* * 11.2 \mathrm{bc}$ \\
\hline 1 & $4.4 \mathrm{~d}$ & $* * 8.3 \mathrm{a}$ & $7.7 b$ & $* * 9.9 \mathrm{c}$ & $6.3 \mathrm{e}$ & $* * 11.9 \mathrm{ab}$ \\
\hline 6 & $4.4 \mathrm{~cd}$ & $* * 7.7 \mathrm{a}$ & $6.6 \mathrm{ef}$ & $* * 8.4 \mathrm{def}$ & $9.2 \mathrm{a}$ & $* * 11.0 \mathrm{bcd}$ \\
\hline 10 & $4.9 \mathrm{bc}$ & $* * 6.9 \mathrm{ab}$ & $6.7 \mathrm{de}$ & $* 7.5 \mathrm{gf}$ & $8.0 \mathrm{~b}$ & $* * 10.4 \mathrm{~cd}$ \\
\hline 9 & $4.9 b$ & $* * 7.3 \mathrm{a}$ & $6.5 \mathrm{ef}$ & $* * 9.6 \mathrm{~cd}$ & $8.0 \mathrm{bc}$ & $* * 12.7 \mathrm{a}$ \\
\hline 8 & $4.3 \mathrm{~d}$ & $* * 8.1 \mathrm{a}$ & $6.4 \mathrm{ef}$ & $* * 8.0 \mathrm{efg}$ & $8.2 \mathrm{~b}$ & $* * 11.9 \mathrm{ab}$ \\
\hline 3 & $4.0 \mathrm{de}$ & $* * 8.0 \mathrm{a}$ & $6.2 \mathrm{f}$ & $* * 9.5 \mathrm{~cd}$ & $6.9 \mathrm{de}$ & $* * 11.2 \mathrm{bc}$ \\
\hline 7 & $3.8 \mathrm{e}$ & $* * 5.6 \mathrm{~b}$ & $5.7 \mathrm{~g}$ & $* * 6.9 \mathrm{~g}$ & $7.0 \mathrm{de}$ & $* * 10.2 \mathrm{~d}$ \\
\hline 5 & $3.3 \mathrm{f}$ & $* * 7.1 \mathrm{ab}$ & $7.1 \mathrm{~cd}$ & $* * 9.0 \mathrm{cde}$ & $4.7 f$ & $* * 7.7 \mathrm{e}$ \\
\hline 4 & $3.2 \mathrm{f}$ & $* * 7.8 \mathrm{a}$ & $7.4 \mathrm{bc}$ & $* * 14.6 \mathrm{a}$ & $8.6 \mathrm{ab}$ & $* * 10.7 \mathrm{~cd}$ \\
\hline $\bar{X}$ & $4.4 C$ & $7.5 B$ & $7.0 B$ & $9.6 \mathrm{~A}$ & $7.4 B$ & $10.9 \mathrm{~A}$ \\
\hline
\end{tabular}

Within a treatment, values that are followed by the same letter are not significantly different according the pdiff-test $(\mathrm{p}<0.05)$. For each genotype at each $\mathrm{P}$ treatment and harvest, the value with AMF having asterisk differ statistically from the value without AMF at the $p<0.05\left(^{*}\right)$ and $p<0.01(* *)$ level after pdiff-test. Mean values $(\bar{X})$ marked with the same capital letter are not significantly different after Tukey-test $(\mathrm{p}<0.05)$. 
These results could be related to the AMF hyphae ability to enhance the availability and uptake of other nutrients such as $\mathrm{Zn}$ as well as other factors such as enhancement of microbial activity and production of phytohormones (plant growth regulator), which in this study were not assessed. Moreover, the shoot $\mathrm{P}$ content of nearly all genotypes was influenced more by their different genotypical ability to produce biomass than by their shoot $\mathrm{P}$ concentration. Since the $\mathrm{P}$ use efficiency is equivalent to the inverse of the $\mathrm{P}$ concentration, differences in $\mathrm{P}$ efficiency among the genotypes at $\mathrm{OP}-\mathrm{AMF}$ (Figure 3.2) seemed to be more related to the ability of the genotypes to take up P under limited P conditions than to P use efficiency. Jansa et al., 2003 found that $\mathrm{P}$ content in maize was significantly higher in the mycorrhizal plants than in their non-mycorrhizal counterparts.

\subsubsection{Phosphorus use efficiency and the acid phosphatase activity in the leaves and roots}

In this study, the P use efficiency describes the amount of $\mathrm{P}$ (shoot and root) that is needed to build one unit of shoot biomass. At 90 DAT, the P use efficiency of the P efficient genotypes (2, 1, 6) was statistically higher than that of the inefficient ones $(3,7,5,4)$ when grown at $0 \mathrm{P}$ without AMF (Table 3.6). Nevertheless, this behaviour was not statistically confirmed at 45 DAT. Taking into account that the $\mathrm{P}$ use efficiency is equivalent to the inverse of the $\mathrm{P}$ concentration, the genotypes in the field trial (see chapter 2 Table 2.2) tended to have an opposite $\mathrm{P}$ use efficiency pattern as the afore mentioned. However, it is worth to mention that the shoot $\mathrm{P}$ concentrations of the rated $\mathrm{P}$ efficient genotypes in the field did not differ statistically from the P inefficient ones (see chapter 2 Table 2.2).

The application of fertilisers did not alter the $\mathrm{P}$ use efficiency pattern within the genotypes (Table 3.6). However, although statistical differences were not found among the overall mean of the $\mathrm{P}$ treatments, the $\mathrm{P}$ use efficiency on average at 20PR was lower $(10 \%)$ than that at $0 \mathrm{P}$ (Table 3.6). A similar behaviour of the genotypes, on average, was also observed in the field trial when P was added (see chapter 2 Table 2.2). However, when the genotypes were grown at 400TSP in the growth chamber trial, their shoot $\mathrm{P}$ concentration increased considerably (see appendix chapter 2) due to the ample $\mathrm{P}$ soil conditions available and therefore their $\mathrm{P}$ use efficiency decreased (see chapter 2 Table 2.6).

On average, the AMF tended to increase the $\mathrm{P}$ use efficiency of the genotypes at each $\mathrm{P}$ treatment and the addition of $\mathrm{P}$ fertilisers tended to decrease slightly the $\mathrm{P}$ use efficiency in comparison to the treatment without AMF at both harvests (Table 3.6). 
Table 3.6 Influence of varying P supply of phosphate rock (PR) and triple superphosphate (TSP) and AMF on P use efficiency (PUE) after 45 and 90 days of transplanting (DAT).

\begin{tabular}{|c|c|c|c|c|c|c|}
\hline \multirow[t]{3}{*}{ Genotype } & \multicolumn{6}{|c|}{ P use efficiency, $\mathrm{g} \mathrm{mg}^{-1}$} \\
\hline & \multicolumn{2}{|c|}{$0 \mathrm{P}$} & \multicolumn{2}{|c|}{ 20PR } & \multicolumn{2}{|c|}{ 4TSP } \\
\hline & $-\mathrm{AMF}$ & $+\mathrm{AMF}$ & $-\mathrm{AMF}$ & $+\mathrm{AMF}$ & $-\mathrm{AMF}$ & $+\mathrm{AMF}$ \\
\hline & & & 45 & DAT & & \\
\hline 2 & $0.69 b c$ & $* 0.81 \mathrm{ab}$ & $0.60 \mathrm{bcde}$ & $0.66 \mathrm{a}$ & $0.79 \mathrm{a}$ & $* * 0.68 \mathrm{~cd}$ \\
\hline 1 & $0.59 \mathrm{c}$ & $* 0.76 \mathrm{ab}$ & $0.67 \mathrm{ab}$ & $0.62 \mathrm{a}$ & $0.61 \mathrm{bcd}$ & $* 0.67 \mathrm{~cd}$ \\
\hline 6 & $0.78 \mathrm{ab}$ & $0.86 a$ & $0.63 \mathrm{bcd}$ & $0.68 \mathrm{a}$ & $0.63 b$ & $* * 0.85 \mathrm{a}$ \\
\hline 10 & $0.84 \mathrm{a}$ & $0.76 \mathrm{ab}$ & $0.54 \mathrm{de}$ & $* 0.62 \mathrm{a}$ & $0.57 \mathrm{bcd}$ & $* * 0.68 \mathrm{~cd}$ \\
\hline 9 & $0.66 b c$ & $0.73 \mathrm{ab}$ & $0.65 \mathrm{abc}$ & $0.65 a$ & $0.58 \mathrm{bcd}$ & $* * 0.72 b c$ \\
\hline 8 & $0.88 \mathrm{a}$ & $* * 0.68 b$ & $0.74 \mathrm{a}$ & $* 0.67 \mathrm{a}$ & $0.63 b$ & $* 0.72 b c$ \\
\hline 3 & $0.65 b c$ & $* 0.77 \mathrm{ab}$ & $0.52 \mathrm{e}$ & $* * 0.68 \mathrm{a}$ & $0.55 \mathrm{bcd}$ & $* * 0.69 \mathrm{bcd}$ \\
\hline 7 & $0.67 \mathrm{bc}$ & $* 0.78 \mathrm{ab}$ & $0.56 \mathrm{cde}$ & $0.60 \mathrm{a}$ & $0.51 \mathrm{~d}$ & $* * 0.65 \mathrm{~d}$ \\
\hline 5 & $0.67 b c$ & $* 0.80 \mathrm{ab}$ & $0.63 \mathrm{bcd}$ & $0.61 \mathrm{a}$ & $0.53 \mathrm{~cd}$ & $* * 0.72 b c$ \\
\hline 4 & $0.78 \mathrm{ab}$ & $0.83 \mathrm{a}$ & $0.66 \mathrm{ab}$ & $0.63 a$ & $0.62 b c$ & $* * 0.76 b$ \\
\hline $\bar{X}$ & $0.72 A B$ & $0.78 \mathrm{~A}$ & $0.62 C$ & $0.64 B C$ & $0.60 C$ & $0.72 A B$ \\
\hline
\end{tabular}
90 DAT

\begin{tabular}{lllllll}
2 & $0.70 \mathrm{ab}$ & $0.72 \mathrm{ab}$ & $0.62 \mathrm{bc}$ & $* * 0.73 \mathrm{ab}$ & $0.79 \mathrm{ab}$ & $0.77 \mathrm{a}$ \\
1 & $0.76 \mathrm{a}$ & $* 0.66 \mathrm{bcd}$ & $0.60 \mathrm{c}$ & $0.63 \mathrm{~cd}$ & $0.66 \mathrm{dc}$ & $* * 0.76 \mathrm{ab}$ \\
6 & $0.74 \mathrm{a}$ & $0.75 \mathrm{ab}$ & $0.84 \mathrm{a}$ & $* 0.79 \mathrm{a}$ & $0.72 \mathrm{bc}$ & $0.69 \mathrm{bcd}$ \\
10 & $0.69 \mathrm{abc}$ & $0.66 \mathrm{bcd}$ & $0.62 \mathrm{bc}$ & $* 0.56 \mathrm{def}$ & $0.67 \mathrm{~cd}$ & $0.63 \mathrm{def}$ \\
9 & $0.70 \mathrm{ab}$ & $0.68 \mathrm{bc}$ & $0.57 \mathrm{~cd}$ & $* 0.51 \mathrm{f}$ & $0.59 \mathrm{~d}$ & $* 0.68 \mathrm{cde}$ \\
8 & $0.64 \mathrm{bcd}$ & $* * 0.78 \mathrm{a}$ & $0.68 \mathrm{~b}$ & $* 0.59 \mathrm{def}$ & $0.69 \mathrm{c}$ & $* 0.74 \mathrm{abc}$ \\
3 & $0.59 \mathrm{de}$ & $* * 0.75 \mathrm{ab}$ & $0.40 \mathrm{e}$ & $* * 0.69 \mathrm{bc}$ & $0.81 \mathrm{a}$ & $* 0.72 \mathrm{abc}$ \\
7 & $0.60 \mathrm{de}$ & $0.57 \mathrm{~d}$ & $0.59 \mathrm{c}$ & $* 0.52 \mathrm{ef}$ & $0.65 \mathrm{~cd}$ & $* 0.59 \mathrm{f}$ \\
5 & $0.54 \mathrm{e}$ & $0.58 \mathrm{~cd}$ & $0.52 \mathrm{~d}$ & $* 0.61 \mathrm{cde}$ & $0.67 \mathrm{~cd}$ & $* 0.61 \mathrm{ef}$ \\
4 & $0.61 \mathrm{cde}$ & $* * 0.74 \mathrm{ab}$ & $0.58 \mathrm{c}$ & $0.54 \mathrm{def}$ & $0.69 \mathrm{c}$ & $0.73 \mathrm{abc}$ \\
$\bar{X}$ & $0.66 \mathrm{~A}$ & $0.69 \mathrm{~A}$ & $0.60 \mathrm{~A}$ & $0.62 \mathrm{~A}$ & $0.69 \mathrm{~A}$ & $0.69 \mathrm{~A}$ \\
\hline
\end{tabular}

Within a $\mathrm{P}$ treatment, values that are followed by the same letter are not significantly different according the pdiff-test $(\mathrm{p}<0.05)$. For each genotype at each $\mathrm{P}$ treatment and harvest, the value with AMF having asterisk differ statistically from the value without AMF at the $p<0.05\left(^{*}\right)$ and $p<0.01(* *)$ level after pdiff-test. Mean values $(\bar{X})$ marked with the same capital letter are not significantly different after Tukey-test $(\mathrm{p}<0.05)$. 
However, statistical differences between the overall mean of the genotypes were only confirmed at 4TSP at 45 DAT (Table 3.6). The positive effect of the AMF on the P supply for the genotypes and their direct influence on the plant growth could explain the decrease of the shoot $\mathrm{P}$ concentration at each $\mathrm{P}$ treatment in the presence of AMF i.e., the increase of the $\mathrm{P}$ use efficiency. As shown in Figure 3.2, the AMF increased the biomass production as a response to the improved P supply to the genotypes. However, if the P demand imposed by the shoot growth of the genotypes was only partially covered and other physiological adaptation process enhanced the growth, a dilution effect on the shoot $\mathrm{P}$ concentration at each $\mathrm{P}$ treatment with AMF could have occurred (Table 3.4).

Furthermore, morphological and physiological changes in the plants could probably be influenced by plant and fungi originated phytohormones, and their concentrations may be influenced by the P supply of the plant as well as the symbiosis with the AMF (Gogala, 1991). For instance, a concentration increase of the auxin derivate Indol 3 butyric acid (IBA) was confirmed in maize roots colonised by G. intraradices, and related to the improved phosphate supply of the plant, whereas the endogenous IBA content was not correlated to the degree of AMF colonisation (Kaldorf and Ludwig-Müller, 2000; Ludwig-Müller et al., 1997). Moreover, other studies showed a positive effect on colonisation and development of the AMF by exogenously applied auxin and jasmonat (Gunze and Hennessy, 1980; Regvar et al., 1996). Taking into consideration the effect of the auxins on the growth of shoot and root, an increase of the concentration of this phytohormone might also be playing a role in the $\mathrm{P}$ use efficiency in presence of AMF.

On the other hand, the PUE is enhanced by P remobilization from senescent or non productive tissues (Smith et al., 1990; Snapp and Lynch, 1996; Adu-Gyamfi et al., 1989; Barber et al., 1967; Bieleski, 1973; Loneraga, 1978). Taking into account that the leaf senescence could be accelerate not only under $\mathrm{P}$ stress condition but also as effect of jasmonates phytohormone, and that the acid phosphatase in the leaves can hydrolyze orthophosphate monoesters into more mobile anions (Pi) (Vincent et al., 1992), it could be likely that the high PUE is related to an increase in APase activity in the leaves i.e. low shoot $\mathrm{P}$ concentration due to the relocation of $\mathrm{P}$ from old leaves to young tissue.

The internal acid phosphatase activity, which takes part in many of the metabolic processes in the leaf (APase-1) and root (APase-r) cells, has been related to the $\mathrm{P}$ use efficiency of genotypes of maize, tomato, soybean especially under P deficient conditions (Clark and Brown 1974; Besford, 1980; McLachlan et al., 1987). However, inconsistent results with inverse and even no 
relationships have been also found in other plant species (Furlani et al., 1984; Dracup et al., 1984; Helal, 1990 Mc Lachlan and De Marco, 1982).

As Table 3.7 shows, both at 45 and 90 DAT there were significant differences in the acid phosphatase activity in the leaves (APase-1) among the genotypes within the treatments without AMF. The APase-1 varied among the genotypes between 4.2 and $14.4 \mu \mathrm{mol} \mathrm{m}^{-2} \mathrm{~s}^{-1}$ without AMF and between 2.8 and $15 \mu \mathrm{mol} \mathrm{m} \mathrm{m}^{-2} \mathrm{~s}^{-1}$ with AMF. Leaf APase variation has been reported among other genotypes. For example, the APase-1 activity among soybean genotypes varied between $4.13 \mu \mathrm{mol} \mathrm{g}{ }^{-1} \mathrm{~h}^{-1}$ (early genotype M-SOY 8001) and $12.74 \mu \mathrm{mol} \mathrm{g}^{-1} \mathrm{~h}^{-1}$ (Semi-late genotype IAC-19) when grown under limited P availability (Raposo et al., 2004), although the enzyme activity was expressed in different bases.

However, the P efficient genotypes $(2,1,6)$ having the highest $\mathrm{P}$ use efficiency at 90 DAT under scarce P condition (Table 3.6) had an APase-1 activity between intermediary and low as those displayed for some of the genotypes $(7,4)$ with a low P use efficiency (Table 3.7). The inefficient genotype 5, which had the lowest $\mathrm{P}$ use efficiency, displayed the second highest APase activity. When $\mathrm{P}$ was supplied (20PR and 4TSP), at 90 DAT the APase-1 activity in average decreased slightly but statistically was not significant lower (Table 3.7). However, although the effect of the P supply on APase-1 activity was inconsistent in some genotypes, the relationship pattern between $\mathrm{P}$ use efficiency and the APase-1 activity observed at OP was maintained.

The AMF effect on the APase-1 activity varied strongly among the treatments at 90 DAT, although statistically differences were not confirmed. For example, in average the AMF decreased the APase-1 activity at $0 \mathrm{P}$, but when $\mathrm{P}$ was added, it increased it, especially at PR.

Rao et al., (1997) reported an APase-1 activity of $5 \mu \mathrm{mol} \mathrm{m} \mathrm{m}^{-2} \mathrm{~s}^{-1}$ in Arachis pintoi (commercial genotype) and Stylosanthes capitata grown under scarce P soil conditions but inoculated with AMF Glomus manihotis, which stayed almost constant as 20 TSP was supplied. In contrast, the also legume Centrosema acutifolium and the grass Brachiaria dictyoneura had at 0P an APase-1 activity around $30 \mu \mathrm{mol} \mathrm{m} \mathrm{m}^{-1}$, which decreased strongly as 20TSP was supplied. 
Table 3.7 Influence of the P supply of phosphate rock (PR) and triple superphosphate (TSP) and AMF on the internal APase activity in leaf after 45 and 90 days of transplanting (DAT).

\begin{tabular}{|c|c|c|c|c|c|c|}
\hline \multirow[t]{3}{*}{ Genotype } & \multicolumn{6}{|c|}{ Acid phosphatase in leaf, $\mu \mathrm{mol} \mathrm{m} \mathrm{m}^{-2} \mathrm{~s}^{-1}$} \\
\hline & \multicolumn{2}{|c|}{ OP } & \multicolumn{2}{|c|}{ 20PR } & \multicolumn{2}{|c|}{ 4TSP } \\
\hline & -AMF & $+\mathrm{AMF}$ & -AMF & $+\mathrm{AMF}$ & -AMF & $+\mathrm{AMF}$ \\
\hline & & & 45 & DAT & & \\
\hline 2 & $8.3 \mathrm{c}$ & $7.8 \mathrm{ab}$ & $6.9 \mathrm{bcd}$ & $* * 10.7 \mathrm{a}$ & $20.3 \mathrm{a}$ & $* * 13.7 \mathrm{a}$ \\
\hline 1 & $4.7 \mathrm{de}$ & $3.9 \mathrm{c}$ & $3.4 \mathrm{~d}$ & $2.7 \mathrm{e}$ & $4.6 \mathrm{~d}$ & $4.2 \mathrm{~d}$ \\
\hline 6 & $6.0 \mathrm{~cd}$ & $* 10.0 \mathrm{a}$ & $5.1 \mathrm{~cd}$ & $6.2 \mathrm{~cd}$ & $5.5 \mathrm{~cd}$ & $* 9.4 \mathrm{bc}$ \\
\hline 10 & $12.1 \mathrm{ab}$ & $11.2 \mathrm{a}$ & $10.3 \mathrm{ab}$ & $* 7.9 \mathrm{bcd}$ & $9.1 \mathrm{c}$ & $10.0 \mathrm{~b}$ \\
\hline 9 & $8.9 b c$ & $* 5.9 \mathrm{bc}$ & $7.6 \mathrm{bc}$ & $* 5.6 \mathrm{~d}$ & $18.1 \mathrm{ab}$ & $* * 8.4 b c$ \\
\hline 8 & $7.5 \mathrm{~cd}$ & $* 9.7 \mathrm{a}$ & $7.2 \mathrm{bc}$ & $7.5 \mathrm{bcd}$ & $8.0 \mathrm{~cd}$ & $9.7 b$ \\
\hline 3 & $2.6 \mathrm{e}$ & $4.1 \mathrm{c}$ & $3.3 \mathrm{~d}$ & $2.9 \mathrm{e}$ & $8.4 \mathrm{~cd}$ & $* * 3.9 \mathrm{~d}$ \\
\hline 7 & $5.8 \mathrm{cde}$ & $5.4 b c$ & $3.5 \mathrm{~d}$ & $* 6.8 \mathrm{~cd}$ & $15.0 \mathrm{~b}$ & $* * 7.0 \mathrm{c}$ \\
\hline 5 & $7.1 \mathrm{~cd}$ & $8.8 \mathrm{ab}$ & $12.0 \mathrm{a}$ & $* 9.4 \mathrm{ab}$ & $15.5 b$ & $1 * 3.4 \mathrm{a}$ \\
\hline 4 & $12.8 \mathrm{a}$ & $* * 3.9 \mathrm{c}$ & $8.2 \mathrm{bc}$ & $8.0 \mathrm{bc}$ & $6.7 \mathrm{~cd}$ & $* 9.3 \mathrm{bc}$ \\
\hline $\bar{X}$ & $7.6 A$ & $7.1 A$ & $6.7 A$ & $6.8 \mathrm{~A}$ & $11.1 \mathrm{~A}$ & $8.9 A$ \\
\hline 2 & $5.4 \mathrm{~cd}$ & $* 9.8 b$ & $4.9 \mathrm{dc}$ & $* * 10.5 \mathrm{ab}$ & $4.3 \mathrm{bc}$ & $2.6 \mathrm{~cd}$ \\
\hline 1 & $4.7 \mathrm{~cd}$ & $3.8 \mathrm{c}$ & $1.7 \mathrm{e}$ & $1.9 \mathrm{e}$ & $2.1 \mathrm{c}$ & $2.1 \mathrm{~d}$ \\
\hline 6 & $8.5 b$ & $* * 3.1 \mathrm{c}$ & $7.4 \mathrm{bc}$ & $* 5.6 \mathrm{~d}$ & $6.7 \mathrm{abc}$ & $* 2.1 \mathrm{~d}$ \\
\hline 10 & $6.7 b c$ & $6.9 b c$ & $18.6 \mathrm{a}$ & $* * 9.1 \mathrm{bc}$ & $9.3 \mathrm{ab}$ & $8.8 b$ \\
\hline 9 & $5.2 \mathrm{~cd}$ & $4.2 \mathrm{c}$ & $5.9 \mathrm{dc}$ & $7.2 \mathrm{~cd}$ & $4.8 \mathrm{bc}$ & $* * 13.5 \mathrm{a}$ \\
\hline 8 & $14.4 \mathrm{a}$ & $15.0 \mathrm{a}$ & $6.6 \mathrm{bc}$ & $* * 13.0 \mathrm{a}$ & $3.5 \mathrm{c}$ & $3.4 \mathrm{~cd}$ \\
\hline 3 & $7.0 \mathrm{bc}$ & $6.6 \mathrm{bc}$ & $5.4 \mathrm{dc}$ & $5.7 \mathrm{~d}$ & $5.2 \mathrm{bc}$ & $5.0 \mathrm{c}$ \\
\hline 7 & $4.2 \mathrm{~d}$ & $4.3 \mathrm{c}$ & $3.4 \mathrm{de}$ & $* * 10.7 \mathrm{ab}$ & $4.8 \mathrm{bc}$ & $* 9.9 b$ \\
\hline 5 & $12.6 \mathrm{a}$ & $* 9.6 b$ & $8.8 \mathrm{~b}$ & $* * 4.8 \mathrm{de}$ & $3.0 \mathrm{c}$ & $5.2 \mathrm{c}$ \\
\hline 4 & $5.3 \mathrm{~cd}$ & $* 2.8 \mathrm{c}$ & $3.4 \mathrm{de}$ & $2.2 \mathrm{e}$ & $11.0 \mathrm{a}$ & $* * 3.0 \mathrm{~cd}$ \\
\hline $\bar{X}$ & $7.4 A$ & $6.6 \mathrm{~A}$ & $6.6 \mathrm{~A}$ & $7.1 \mathrm{~A}$ & $5.5 \mathrm{~A}$ & $5.6 \mathrm{~A}$ \\
\hline
\end{tabular}

Within a $\mathrm{P}$ treatment, values that are followed by the same letter are not significantly different according the pdiff-test $(\mathrm{p}<0.05)$. For each genotype at each $\mathrm{P}$ treatment and harvest, the value with AMF having asterisk differ statistically from the value without AMF at the $p<0.05\left(^{*}\right)$ and $p<0.01(* *)$ level after pdiff-test. Mean values $(\bar{X})$ marked with the same capital letter are not significantly different after Tukey-test $(\mathrm{p}<0.05)$. 
The acid phosphatase activity in the roots (APase-r), did not show statistical differences between efficient and inefficient genotypes within each treatment with or without AMF at 90 DAT (see Appendix). However, the APase-r activity of the efficient genotypes tended to be higher than the inefficient ones at each treatment, and was similar as those reported by Rao et al., (1997). Values of APase-r activity at OP for Arachis pintoi (commercial genotype) and Stylosanthes capitata were around $2 \mu \mathrm{mol} \mathrm{g}{ }^{-1} \mathrm{~min}^{-1}$, which were also not influenced by the supply of 20TPS.

Linear correlation coefficients were calculated between the leaf and root APase activity and the $\mathrm{P}$ use efficiency or other plant parameters related to $\mathrm{P}$ efficiency such as dry weight, $\mathrm{P}$ concentration and $\mathrm{P}$ content in the shoots and the roots, shoot-root ratio, leaf area index, $\mathrm{P}$ inorganic in the leaves (data not shown), root length, root length-shoot ratio, $\mathrm{P}$ inorganic in the roots (data not shown). For both, the $\mathrm{P}$ efficient and inefficient genotypes, there was no clear correlation between the enzyme activity and the variables related to plant $\mathrm{P}$ uptake and use efficiency.

Consequently, the results obtained in the present study led to reject the proposed hypothesis that $\mathrm{P}$ efficient genotypes present high internal leaves or root APase activity as a sign of the ability to hydrolyze and remobilize $\mathrm{P}$, by root secretion and/or leaf synthesis, making P more available to the plant, from soil or other older plant parts.

On the other hand, it has also been suggested that plants adapted to low P conditions would present a lower $\mathrm{P}$ demand and, consequently, a lower leaf or root APase activity under stress $\mathrm{P}$ conditions as compared to the non-adapted or higher P demanding plants. APase activity would then be a chemical indicator of the plant $\mathrm{P}$ deficiency severity degree, and the more the plant is stressed in relation to $\mathrm{P}$, the higher the APase activity and the less adapted the plant would be (Mc Lachlan 1980a; 1980b; Silberbush et al., 1981; Furlani et al., 1984; Elliot and Läuchli, 1986; Helal, 1990; Tadano et al., 1993). That could be the case in the present study for the average efficient genotype 8 and the inefficient genotype 5, which at 90 DAT had the highest APase-1 activity at $0 \mathrm{P}$ with and without AMF. However, the other P inefficient genotypes (3, 7, 4) had an intermediary or lower APase-1 activity.

However, positive as well as negative correlations have been demonstrated between leaf or root enzyme activity and P content in plants (Besford, 1978; 1979; 1980; Mc Lachlan and De Marco, 1982; Dracup et al., 1984; Elliot and Läuchli, 1986), or between APase activity and tolerance or susceptibility to P deficiency (Mc Lachlan 1980b; Silberbush et al., 1981; Furlani et al., 1984; Helal, 1990; Tadano et al., 1993). Nevertheless, the comparison of results is difficult because of the lack of systematization and standardization of methods and criteria for the plant APase 
activity determination, in such way that, data of the literature are inconsistent or contradictory in relation to different species, different laboratory techniques and different plant part samples.

Nevertheless, for other plant species, the results are also quite inconsistent, and inverse relationships between APase activity and root $\mathrm{P}$ concentrations or contents have been found for sorghum (Furlani et al., 1984), white clover (Dracup et al., 1984), and common beans (Helal, 1990); between leaf and root APase activity and P deficiency in wheat plants (Mc Lachlan and De Marco, 1982). On the other hand, no relationship was found between leaf or root APase activity and P deficiency in bean, cowpea, pigeon pea, cotton plants (Ascencio, 1994; Fernandez and Ascencio, 1994) and among maize genotypes (Machado and Furlani, 2004).

Consequently, such results are of difficult interpretation and comparison because APase activity data are derived from plants growing under different external P concentrations, or from different plant parts and/or from different genotypes, factors which might influence the gene expression of the acid phosphatase activity under a specific external $\mathrm{P}$ availability.

Besides, the root ability to secrete acid phosphatases can only be evaluated when intact roots are used for the APase activity determination. Moreover, since the hydrolysis of organic $\mathrm{P}$ occurs in the root surface, its effect on the P uptake could be better assessed if the root APase activity is measured directly on the surface of intact roots. Another complicating factor to be considered is that the gene control of acid APase synthesis and activation seems to be independent from the one that confers to the root the ability of enzyme secretion, which is usually activated under low P levels (Fukuda et al., 2001).

Although the P efficient genotypes showed a higher P use efficiency than the inefficient ones, their ability to grown at low $\mathrm{P}$ condition, specially in presence of AMF, seems to be more related with their ability to acquire $\mathrm{P}$.

\subsubsection{Root length and root length-shoot ratio}

The enlargement of the root system, i.e. larger root surface to exploit the $\mathrm{P}$ of larger volumes of soil, had been identified as an adaptive attribute of genotypes when grown under P deficient conditions (Marschner, 1995). In the present study, the root length developed by the genotypes (Table 3.8) cannot explain their $\mathrm{P}$ efficiency. For instance, although statistical significant differences were found among the genotypes within the treatments and at both harvest, both $\mathrm{P}$ efficient and inefficient genotypes had similar root length. 
Table 3.8 Influence of varying P supply of phosphate rock (PR) and triple superphosphate (TSP) and AMF on root length after 45 and 90 days of transplanting (DAT).

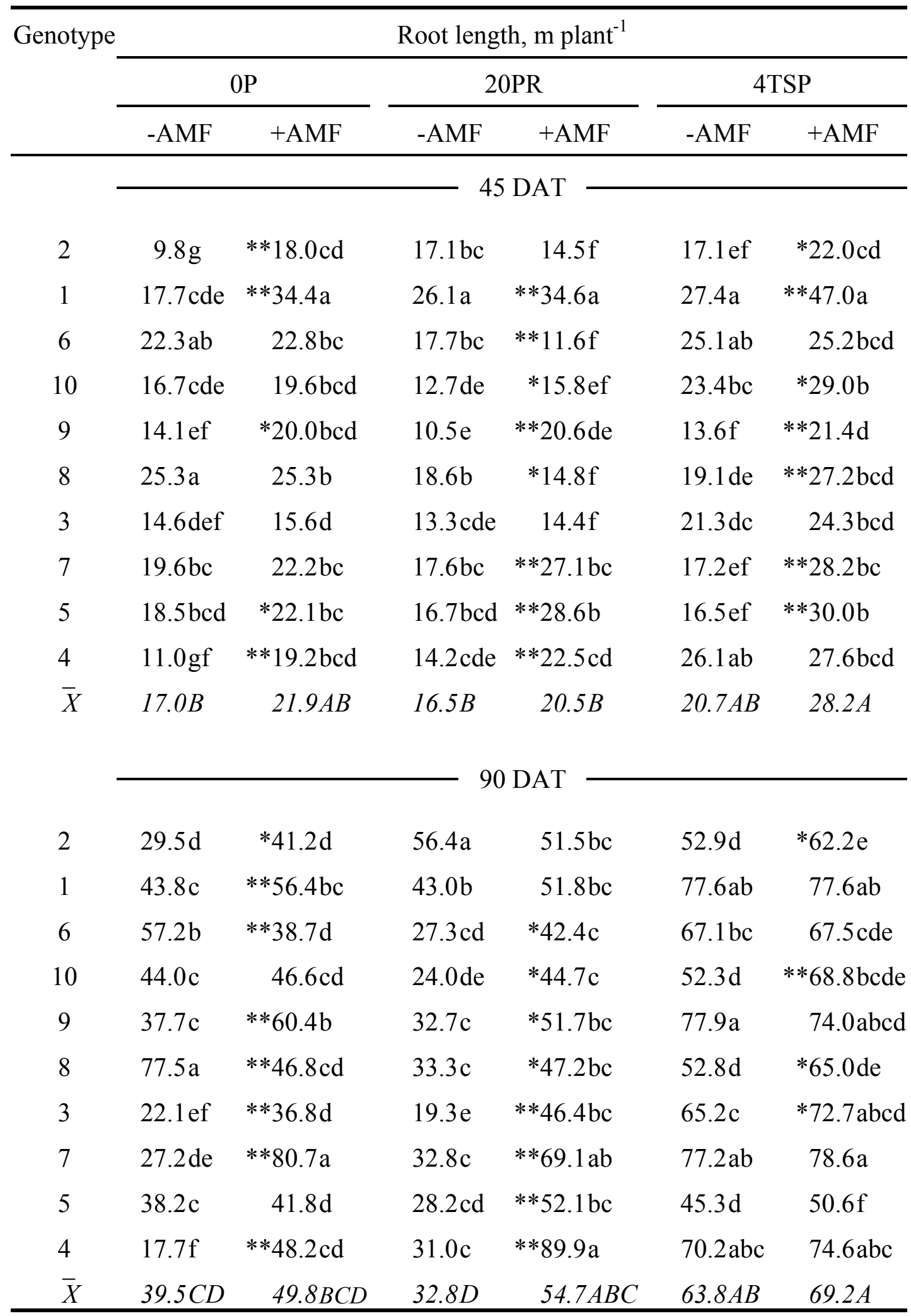

Within a treatment, values that are followed by the same letter are not significantly different according the pdiff-test $(\mathrm{p}<0.05)$. For each genotype at each $\mathrm{P}$ treatment and harvest, the value with AMF having asterisk differ statistically from the value without AMF at the $p<0.05\left(^{*}\right)$ and $p<0.01(* *)$ level after pdiff-test. Mean values $(\bar{X})$ marked with the same capital letter are not significantly different after Tukey-test $(\mathrm{p}<0.05)$. 
That means that the high shoot $\mathrm{P}$ content of the genotypes rated as efficient at $0 \mathrm{P}$ and 90 DAT was not because of an enlargement of the root system for exploring larger soil volume. Moreover, only the addition of 4TSP and at 90 DAT had a statistical significant positive effect on the root length (Table 3.8).

The AMF evened out the differences among the genotypes at each $\mathrm{P}$ treatment and harvest (Table 3.8). Noteworthy was the positive effect of AMF on the overall mean of root length at each $\mathrm{P}$ treatment and at both harvests compared with -AMF, even though statistical significant differences were confirmed only at 20PR at 90 DAT (Table 3.8). Moreover, at 90 DAT the overall mean of the root length at 20PR and 4TSP was higher than that at 0P. That means, that AMF would enhance the root length growth of the genotypes in order to cover the P demand imposed by the shoot growth or the enlargement of the root system may be solely the effect of AMF by improving the overall plant growth and thereby the root growth.

In order to elucidate whether the AMF effect on the root length is related to the ability of the genotypes to take up P under low P conditions, the root length-shoot ratio (RSR) i.e. the root length developed to feed the shoot biomass was considered at 45 and 90 DAT. A high root-shoot ratio (RSR) has been considered as an adaptation mechanism of plants grown under scarce $\mathrm{P}$ availability (Trolove et al., 2003).

At $0 \mathrm{P}$ and -AMF, the genotypes had not only a similar RSR at both harvest (Table 3.9), but also the RSR pattern was also similar as those observed in the pot trial of chapter 2 (Figure 2.6). The efficient genotypes $(2,1,6)$ varied in their RSR at 90 DAT (Table 3.9). The most P efficient genotype 2 (Figure 3.2) had the lowest RSR among all genotypes and it differed statistically from the efficient genotypes 1 and 6 . That means that the $\mathrm{P}$ efficiency of genotypes seem to develop two strategies under low P conditions: the genotypes 1 and 6 enlarged the root system to exploit the $\mathrm{P}$ of larger volume soil, while genotype 2 should be efficient taking up more $\mathrm{P}$ per unit root length. The inefficient genotypes $(7,5,4)$ showed variation in their RSR, but in general their RSR were higher than that of genotype 2 .

Only the addition of 20PR decreased statistically significant the overall mean of RSR at both harvests (Table 3.9). Moreover, at 90 DAT the RSR differences among the genotypes were lower than that at $0 \mathrm{P}$. The shoot $\mathrm{P}$ content (Table 3.5) of the $\mathrm{P}$ efficient genotypes $(2,1,6,10)$ can be explained by their RSR. For example, genotypes 2 and 1 had RSR higher than genotypes 6 and 10 and thus higher shoot $\mathrm{P}$ content. In contrast, at 4TSP the $\mathrm{P}$ efficient genotypes with a higher RSR than that at 20PR had lower shoot P content. 
Table 3.9 Influence of varying $P$ supply of phosphate rock (PR) and triple superphosphate (TSP) and AMF on root length-shoot ratio after 45 and 90 days of transplanting (DAT).

\begin{tabular}{|c|c|c|c|c|c|c|}
\hline \multirow[t]{3}{*}{ Genotype } & \multicolumn{6}{|c|}{ Root length-shoot ratio, $\mathrm{m} \mathrm{g}^{-1}$} \\
\hline & \multicolumn{2}{|c|}{ OP } & \multicolumn{2}{|c|}{ 20PR } & \multicolumn{2}{|c|}{ 4TSP } \\
\hline & $-\mathrm{AMF}$ & $+\mathrm{AMF}$ & -AMF & $+\mathrm{AMF}$ & $-\mathrm{AMF}$ & $+\mathrm{AMF}$ \\
\hline & & & 45 & DAT & & \\
\hline 2 & $3.6 \mathrm{e}$ & $4.0 \mathrm{~cd}$ & $3.8 \mathrm{bcd}$ & $* 2.5 \mathrm{ef}$ & $7.2 \mathrm{bc}$ & $* * 4.0 \mathrm{bc}$ \\
\hline 1 & $9.0 \mathrm{~b}$ & $* 6.7 \mathrm{a}$ & $6.1 \mathrm{a}$ & $* 6.9 \mathrm{ab}$ & $11.5 \mathrm{a}$ & $* * 9.0 \mathrm{a}$ \\
\hline 6 & $8.7 b c$ & $* * 4.1 \mathrm{~cd}$ & $5.1 \mathrm{ab}$ & $* * 2.3 \mathrm{f}$ & $6.9 \mathrm{bcd}$ & $* * 3.4 \mathrm{c}$ \\
\hline 10 & $8.6 b c$ & $* * 4.9 \mathrm{bc}$ & $3.6 \mathrm{~cd}$ & $3.9 \mathrm{de}$ & $8.3 b$ & $* * 5.1 \mathrm{~b}$ \\
\hline 9 & $6.4 \mathrm{~cd}$ & $5.8 \mathrm{ab}$ & $2.8 \mathrm{~d}$ & $* 4.0 \mathrm{de}$ & $5.0 \mathrm{~cd}$ & $* 3.1 \mathrm{c}$ \\
\hline 8 & $15.0 \mathrm{a}$ & $* * 5.3 \mathrm{abc}$ & $4.9 \mathrm{abc}$ & $* 3.2 \mathrm{def}$ & $4.5 \mathrm{~d}$ & $4.3 b c$ \\
\hline 3 & $6.0 \mathrm{de}$ & $* * 3.0 \mathrm{~d}$ & $3.9 \mathrm{bcd}$ & $* 2.6 \mathrm{ef}$ & $12.6 \mathrm{a}$ & $* * 4.7 b$ \\
\hline 7 & $7.3 \mathrm{bcd}$ & $* 5.4 \mathrm{abc}$ & $5.4 \mathrm{a}$ & $* * 7.5 \mathrm{a}$ & $8.4 b$ & $* * 5.0 \mathrm{~b}$ \\
\hline 5 & $8.5 b c$ & $* * 4.4 \mathrm{bcd}$ & $3.8 \mathrm{bcd}$ & $* * 5.8 \mathrm{bc}$ & $7.3 \mathrm{bc}$ & $* 5.2 \mathrm{~b}$ \\
\hline 4 & $5.0 \mathrm{de}$ & $4.0 \mathrm{~cd}$ & $3.3 \mathrm{~d}$ & $* 4.5 \mathrm{~cd}$ & $8.0 \mathrm{~b}$ & $* * 4.8 \mathrm{~b}$ \\
\hline \multirow[t]{2}{*}{$\bar{X}$} & $7.8 A$ & $4.8 B$ & $4.3 B$ & $4.3 B$ & $8.0 \mathrm{~A}$ & $4.8 B$ \\
\hline & & & \multicolumn{2}{|c|}{$90 \mathrm{DAT}$} & & \\
\hline 2 & $5.3 \mathrm{f}$ & $5.2 \mathrm{e}$ & $7.1 \mathrm{a}$ & $* 4.5 \mathrm{c}$ & $7.6 \mathrm{bc}$ & $* 5.5 \mathrm{~d}$ \\
\hline 1 & $9.2 \mathrm{~cd}$ & $* 7.3 \mathrm{c}$ & $7.0 \mathrm{ab}$ & $6.0 \mathrm{bc}$ & $13.7 \mathrm{a}$ & $* * 6.7 \mathrm{bc}$ \\
\hline 6 & $12.3 \mathrm{~b}$ & $* * 4.9 \mathrm{e}$ & $4.0 \mathrm{~d}$ & $4.9 \mathrm{c}$ & $8.3 b c$ & $* 6.7 \mathrm{bc}$ \\
\hline 10 & $9.7 \mathrm{c}$ & $* * 7.1 \mathrm{~cd}$ & $4.3 \mathrm{~d}$ & $* 6.8 \mathrm{bc}$ & $7.6 \mathrm{c}$ & $7.4 b$ \\
\hline 9 & $8.5 \mathrm{cde}$ & $9.2 b$ & $6.5 \mathrm{abc}$ & $7.3 \mathrm{bc}$ & $12.9 \mathrm{a}$ & $* * 6.7 b c$ \\
\hline 8 & $18.4 \mathrm{a}$ & $* * 5.4 \mathrm{de}$ & $5.9 \mathrm{abc}$ & $7.0 \mathrm{bc}$ & $7.3 \mathrm{c}$ & $* 5.9 \mathrm{~cd}$ \\
\hline 3 & $7.0 \mathrm{def}$ & $* 5.0 \mathrm{e}$ & $5.7 \mathrm{c}$ & $5.6 \mathrm{c}$ & $9.9 b$ & $* * 7.5 b$ \\
\hline 7 & $8.5 \mathrm{cde}$ & $* * 14.9 \mathrm{a}$ & $6.7 \mathrm{abc}$ & $* * 11.0 \mathrm{a}$ & $12.6 \mathrm{a}$ & $* * 8.8 \mathrm{a}$ \\
\hline 5 & $12.6 \mathrm{~b}$ & $* * 6.5 \mathrm{cde}$ & $5.8 \mathrm{bc}$ & $6.0 \mathrm{bc}$ & $9.3 b c$ & $* * 6.0 \mathrm{~cd}$ \\
\hline 4 & $6.8 \mathrm{ef}$ & $6.6 \mathrm{cde}$ & $5.8 \mathrm{c}$ & $* * 9.0 \mathrm{ab}$ & $9.2 \mathrm{bc}$ & $* 7.4 \mathrm{~b}$ \\
\hline $\bar{X}$ & $9.8 \mathrm{~A}$ & $7.2 A B$ & $5.9 B$ & $6.8 A B$ & $9.8 \mathrm{~A}$ & $6.9 A B$ \\
\hline
\end{tabular}

Within a $\mathrm{P}$ treatment, values that are followed by the same letter are not significantly different according the pdiff-test $(\mathrm{p}<0.05)$. For each genotype at each $\mathrm{P}$ treatment and harvest, the value with AMF having asterisk differ statistically from the value without AMF at the $p<0.05\left(^{*}\right)$ and $p<0.01(* *)$ level after pdiff-test. Mean values $(\bar{X})$ marked with the same capital letter are not significantly different after Tukey-test $(\mathrm{p}<0.05)$. 
Taking into account that no statistically significant differences were found between the $\mathrm{P}$ concentration in the soil solution at 20PR and 4TSP (Table 3.2), this effect could be related to the provide of $\mathrm{Ca}$ and $\mathrm{Mg}$ per unit of $\mathrm{P}$ added to the genotypes as 20PR.

Inoculation of plants with AMF has shown to decrease the root-shoot ratio (Cui and Caldwell, 1996; Smith and Read, 1997). In agreement to this finding, most of the genotypes at OP and 4TSP had a lower RSR in presence of AMF at both harvest than that at -AMF. A low RSR in presence of AMF could be related to the effectiveness of the AMF hyphae acquiring $\mathrm{P}$ under limited $\mathrm{P}$ conditions, which increases the $\mathrm{P}$ uptake efficiency per unit root length and thus the plant does not need to increase the root system in order to cover its $\mathrm{P}$ demand. Consequently, if the genotypes did not need to increase their root density to cover the P demand, the genotypes may provide large amount of carbon compounds to increase the AMF mycelium network and thereby the shoot biomass.

Wilson and Hartnett, (1998) found that grasses adapted to limited P conditions reflected two alternative strategies in $\mathrm{P}$ effectiveness: one $\mathrm{P}$ efficient group uses $\mathrm{C}$ to develop finely branched root system with high root hair density, the other allocates $\mathrm{C}$ to support well-developed mycorrhizas.

However, the root length at each $\mathrm{P}$ treatment and both harvest increased in presence of AMF (Table 3.8). A plausible explanation is that AMF had no preferential effect on root growth, but stimulated overall growth and thereby increased also the root length and explained the reduction of the shoot $\mathrm{P}$ concentration in comparison to -AMF (Table 3.4). Besides the attribute related to $\mathrm{P}$ nutrition, AMF together with specific bacteria, classified as plant growth promoting rhizobacteria (PGPR), may create a more indirect synergism that supports plant growth (Barea, 1997), including nutrient acquisition (Barea et al., 2002), inhibition of plant pathogenic fungi (Budi et al., 1999), and enhancement of root branching (Gamalero et al., 2004). Jansa et al., (2003) reported that maize plants inoculated with Glomus intraradices took up more P and Zn than non-mycorrhizal plants and the uptake of both ${ }^{33} \mathrm{P}$ and ${ }^{65} \mathrm{Zn}$ was significantly correlated to the mycelium length density. However, although the Glomus intraradices increased largely the total $\mathrm{P}$ and $\mathrm{Zn}$ content of the maize plants, it had little effect on the plant biomass production. Furthermore, morphological and physiological changes in the plant could be affected by plant and AMF fungal phytohormone (plant growth regulators) (Gogala, 1991), which may also affect the RSR. Glomus sp. colonized maize plants (Zea mays L.) have shown an increase of the concentration of abscisic acid in shoot and root in relationship to the improved $\mathrm{P}$ supply for the plant by the AMF (Bothe et al., 1994; Danneberg et al., 1993) and of the auxins's derivative 
Indol 3 butyric acid (IBA) in roots, even though the endogenous IBA's content was not correlated with the mycorrhizae infection degree (Kaldorf and Ludwig-Müller, 2000; LudwigMüller et al., 1997).

On the other hand, the AMF at 20PR produced in average an increase of the RSR (Table 3.9). However, this effect was not recorded in the P efficient genotypes $(2,1)$, which had even a RSR lower than that at 0P and 4TSP. In contrast, the inefficient genotypes $(7,4)$ had RSR 2-fold higher than that of genotype 2. This high RSR might be related to a less AMF effectiveness improving the $\mathrm{P}$ uptake. A similar relationship was observed between two ecotypes of Adropogon gerardii, which appeared to have adapted to contrasting soil P regimes (Schultz et al. 2001); the ecotype growing naturally in the high $\mathrm{P}$ soil was much less responsive to AMF, but had a more highly branched root system. The results confirm observation that crop plants adapted to highly fertilized environments have low dependence on AMF, even though their root remain infected by these fungi (Hentrick, et al., 1992; Graham and Eissenstat, 1994). Since the high $\mathrm{P}$ content of the $\mathrm{P}$ efficient genotype 2 cannot be explained by the RSR, its high $\mathrm{P}$ efficiency can be based on its ability to acquire higher amount of $\mathrm{P}$ per unit root length and time than the other P efficient genotypes.

\subsubsection{The $P$ uptake per unit root length and the $P$ inflow}

The $\mathrm{P}$ acquisition efficiency of a plant depends not only on root length but also on $\mathrm{P}$ inflow, i.e. the net amount of $\mathrm{P}$ taken up per unit root and time, which can be calculated between two harvests. As large differences between $-\mathrm{AMF}$ and $+\mathrm{AMF}$ were found in shoot biomass production (Figure 3.1) and shoot $\mathrm{P}$ content (Table 3.5) in the first growth stage (0 - 45 DAT), the P uptake per unit root length (PURL) was also calculated (Table 3.10) i.e. the total P content (shoot + root) was divided by the root length at 45 days after transplanting (DAT).

The ability of the genotypes taking up $\mathrm{P}$ per unit root length (PURL) at $\mathrm{OP}-\mathrm{AMF}$ would explain their yield and shoot $\mathrm{P}$ content. The high yield and shoot $\mathrm{P}$ content of genotypes 2, 3 and 7 were due to a high PURL, which was remarkable high in the case of genotype 2 (at least 1.6-fold higher than the other genotypes). In contrast, the low PURL of the genotypes 8 and 10 explain their low yield and shoot P content. The PURL cannot explain the yield of genotype 6 and 4, which could be due to a high P use efficiency.

The overall mean of PURL was not increased at 4TSP, whereas at 20PR was 2 times higher than that at $0 \mathrm{P}$ (Table 3.10). The ability of some genotypes taking up $\mathrm{P}$ per unit root varied at each $\mathrm{P}$ 
fertilisers. However, in most of the genotypes the PURL would explain the shoot biomass and shoot $\mathrm{P}$ content.

The AMF increased the overall mean of PURL at OP and 4TSP but not at 20PR (Table 3.10), although the colonisation grade of AMF was similar (Table 3.3). However, the PURL of some genotypes was not increased in presence of AMF, despite of the fact that their yield increased. Consequently, the higher yield recorded at $\mathrm{OP}+\mathrm{AMF}$ of the genotypes 2, 1, 9, 7 and 4 at $0 \mathrm{P}$ was not because the AMF enhanced the P uptake per unit root length. Taking into account, that shoot $\mathrm{P}$ concentration decreased in presence of the AMF, an increase on the $\mathrm{P}$ use efficiency could explain the high yield. Moreover, AMF could have influenced other factors which enhanced plant growth and that were not considered in this study.

Table 3.10 Influence of varying $P$ supply of phosphate rock (PR) and triple superphosphate (TSP) and AMF on P uptake per unit root length (PURL) at 45 days after transplanting (DAT).

\begin{tabular}{|c|c|c|c|c|c|c|}
\hline \multirow[t]{3}{*}{ Genotype } & \multicolumn{6}{|c|}{$\mathrm{P}$ uptake per unit root length, $\mathrm{mg} \mathrm{m}^{-1}$} \\
\hline & \multicolumn{2}{|c|}{ OP } & \multicolumn{2}{|c|}{ 20PR } & \multicolumn{2}{|c|}{ 4TSP } \\
\hline & -AMF & $+\mathrm{AMF}$ & $-\mathrm{AMF}$ & $+\mathrm{AMF}$ & -AMF & $+\mathrm{AMF}$ \\
\hline 2 & $0.41 \mathrm{a}$ & $* 0.31 \mathrm{~b}$ & $0.44 \mathrm{abc}$ & $* 0.60 \mathrm{a}$ & $0.18 \mathrm{de}$ & $* * 0.38 \mathrm{ab}$ \\
\hline 1 & $0.19 \mathrm{bcd}$ & $0.20 \mathrm{c}$ & $0.25 \mathrm{~d}$ & $0.23 \mathrm{~cd}$ & $0.14 \mathrm{e}$ & $0.17 \mathrm{~d}$ \\
\hline 6 & $0.15 \mathrm{de}$ & $* * 0.28 \mathrm{bc}$ & $0.31 \mathrm{~cd}$ & $* * 0.65 \mathrm{a}$ & $0.23 b c$ & $* * 0.35 \mathrm{abc}$ \\
\hline 10 & $0.14 \mathrm{de}$ & $* * 0.27 \mathrm{bc}$ & $0.50 \mathrm{ab}$ & $* 0.41 \mathrm{bc}$ & $0.22 \mathrm{~cd}$ & $* 0.29 b c$ \\
\hline 9 & $0.24 b c$ & $0.24 b c$ & $0.56 \mathrm{a}$ & $* 0.38 \mathrm{bcd}$ & $0.35 \mathrm{a}$ & $* * 0.44 \mathrm{a}$ \\
\hline 8 & $0.08 \mathrm{e}$ & $* * 0.28 \mathrm{bc}$ & $0.28 \mathrm{~d}$ & $* * 0.48 \mathrm{ab}$ & $0.35 \mathrm{a}$ & $0.33 b c$ \\
\hline 3 & $0.27 b$ & $* * 0.43 \mathrm{a}$ & $0.50 \mathrm{ab}$ & $* 0.60 \mathrm{a}$ & $0.14 \mathrm{e}$ & $* * 0.31 \mathrm{bc}$ \\
\hline 7 & $0.21 \mathrm{bcd}$ & $0.24 b c$ & $0.33 \mathrm{~cd}$ & $* 0.22 \mathrm{~d}$ & $0.23 b c$ & $* 0.31 \mathrm{bc}$ \\
\hline 5 & $0.18 \mathrm{~cd}$ & $* * 0.29 b$ & $0.42 b c$ & $* 0.28 \mathrm{~cd}$ & $0.27 b$ & $0.27 \mathrm{c}$ \\
\hline 4 & $0.26 \mathrm{bc}$ & $0.30 \mathrm{~b}$ & $0.47 \mathrm{ab}$ & $* 0.36 \mathrm{bcd}$ & $0.20 \mathrm{~cd}$ & $* 0.28 \mathrm{c}$ \\
\hline $\bar{X}$ & $0.21 C$ & $0.28 B C$ & $0.40 A B$ & $0.42 A$ & $0.23 C$ & $0.31 A B C$ \\
\hline
\end{tabular}

Within a $\mathrm{P}$ treatment, values that are followed by the same letter are not significantly different according the pdiff-test $(\mathrm{p}<0.05)$. For each genotype at each $\mathrm{P}$ treatment and harvest, the value with AMF having asterisk differ statistically from the value without AMF at the $p<0.05(*)$ and $p<0.01(* *)$ level after pdiff-test. Mean values $(\bar{X})$ marked with the same capital letter are not significantly different after Tukey-test $(\mathrm{p}<0.05)$.

As figure 3.5 shows, the ability of single roots to absorb $\mathrm{P}$ per unit of time (P inflow), varied greatly among the genotypes when grown at $0 \mathrm{P}$ without the presence of AMF. Some P efficient genotypes $(2,10)$ had a high $\mathrm{P}$ inflow, which could be the basis for the $\mathrm{P}$ efficiency under this 
low $\mathrm{P}$ conditions. However, the $\mathrm{P}$ efficient genotypes did not have always a high $\mathrm{P}$ inflow. For instance, the P efficient genotypes 1 and 6 had a lower average P inflow, which was similar to that of the $\mathrm{P}$ inefficient ones.

The addition of fertilisers (20PR and 4TSP) increased the P inflow for all genotypes, but not for the $\mathrm{P}$ efficient 2 and 10, which achieved their maximum $\mathrm{P}$ inflow at $0 \mathrm{P}$. That means that although these genotypes $(2,10)$ had also the highest $\mathrm{P}$ inflow, this was reduced by the P supply. Consequently, if the $\mathrm{P}$ inflow decreases when the $\mathrm{P}$ supply is increased, that may indicate that $\mathrm{P}$ was not limiting at $0 \mathrm{P}$.

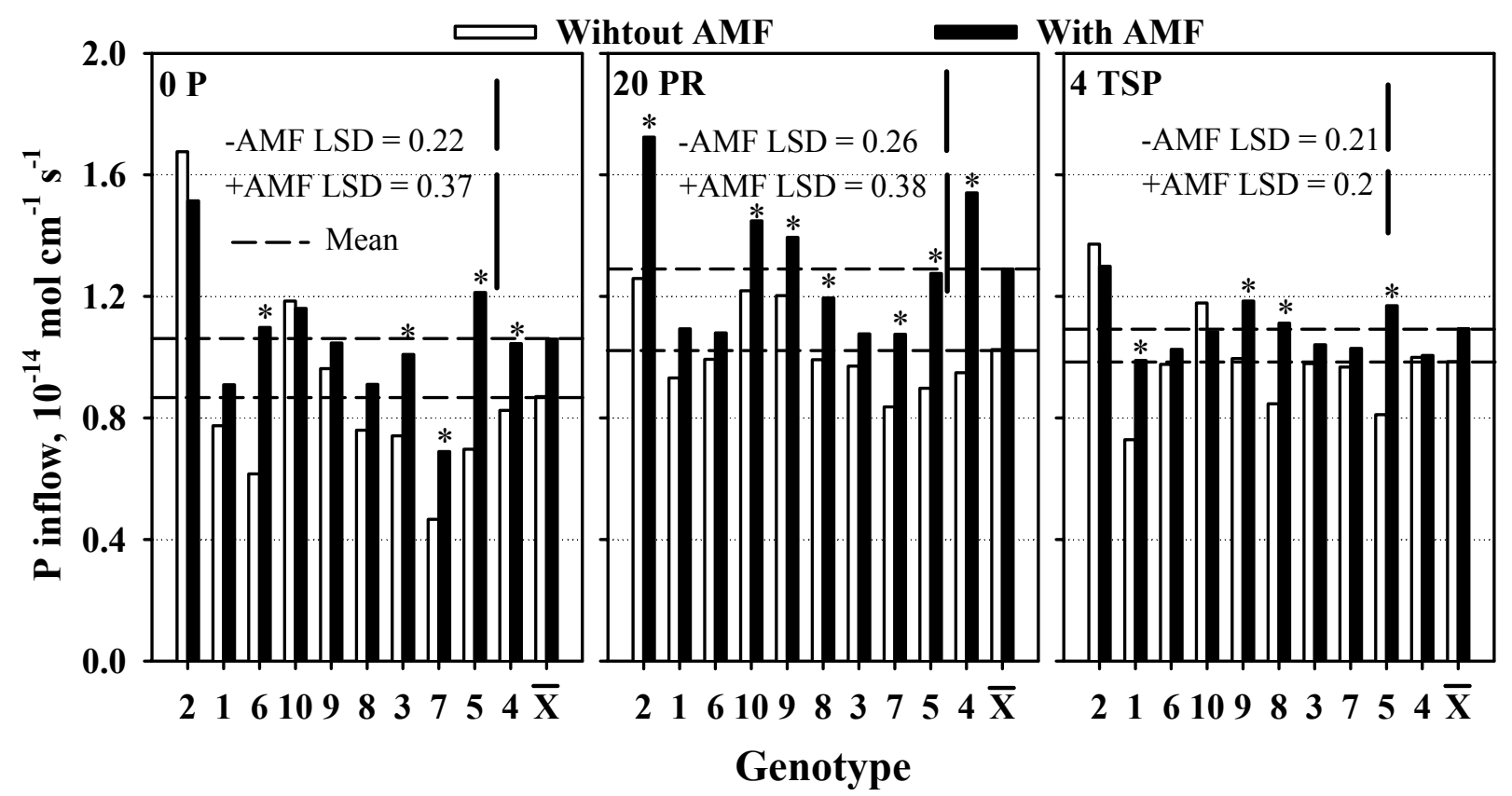

Figure 3.3 Influence of varying $P$ supply of phosphate rock (PR) and triple superphosphate (TSP) and AMF on P inflow between 45 and 90 days of transplanting (DAT). LSD values are at the 0.05 probability level after Tukey-test. For each genotype and mean value $(\bar{X})$, bar with AMF having asterisk differs statistically from the bar without AMF at the $p<0.05$ (*) after pdifftest.

It is interesting to highlight that only the genotypes 2 and 10 were able to achieve also at $0 \mathrm{P}$ a high $\mathrm{P}$ inflow. This suggested that these genotypes are capable to increase the available $\mathrm{P}$ on the root surface through the development of physiological adaptation mechanisms in the root (root hair, root exudations, acid phosphatase activity). Although in this trial the soil solution $\mathrm{P}$ concentration was not determined, in chapter 2 was shown that genotype 2 was able to increase remarkably soil solution $\mathrm{P}$ concentration (2-fold) compared to genotypes 1, 4 and 10. That point at possible chemical $\mathrm{P}$ mobilization in the rhizosphere. Several legume crops can mobilise soil and fertiliser $\mathrm{P}$ through the exudation of organic-acid anions from their roots e.g., chickpea (Veneklaas et al. 2003), pigeon pea (Otani et al. 1996) and white lupin (Gardner et al. 1983; 
Keerthisinghe et al. 1998). This mechanism enables some of these species to acquire P from soil sources that are not readily available to non-secreting crops (Hocking et al. 1997). A number of studies have reported improved growth and $\mathrm{P}$ nutrition of less P-efficient crops following organic-anion exuding legumes (e.g., Ae et al. 1990; Kamh et al. 1999; Hocking and Randall 2001).

On average the $\mathrm{P}$ inflow increased at each $\mathrm{P}$ treatment, when the genotypes were grown in symbiosis with AMF (Figure 3.5). At 0P, the P inflow was not increased in some genotypes (2, $1,10,9)$ similarly as it was found for PURL (Table 3.10). The exception was genotype 4, which increased statistically significant its $\mathrm{P}$ inflow in comparison to -AMF and this was likely due to its high colonisation grade at 90 DAT (Table 3.3). The inefficient genotypes $(3,7,5)$ showed a higher effect of AMF on the $\mathrm{P}$ inflow than the efficient ones and thereby explained their remarkable yield (Figure 3.2) and shoot P content (Table 3.5). However, to which extent the overall stimulation of growth by the AMF was important, cannot be elucidated.

When $\mathrm{P}$ was supplied, on average the $\mathrm{P}$ inflow increased, but especially at 20PR. It is worthy to mention that an increased $\mathrm{P}$ inflow by AMF means that the P taken up by AMF hyphae was added to the acquired $\mathrm{P}$ per unit of root length. The genotypes displayed different effect on the $\mathrm{P}$ inflow by AMF within and among the $\mathrm{P}$ treatments.

As Figure 3.3 shows, some of the inefficient genotypes $(4,5)$ at each $\mathrm{P}$ treatment increased remarkable the $\mathrm{P}$ inflow by its relative high AMF colonization (Table 3.3), i.e. the AMF was a very important $\mathrm{P}$ efficiency mechanism.

Enhanced P uptake in AM-infected plants seems to be facilitated by: (i) the fungal hyphae exploring a greater volume of soil for $\mathrm{P}$ and also intercepting a greater number of point sources of P; ii) the fungi dissolving sparingly soluble P minerals (e.g. PR); and (iii) the infected roots increasing the rate of $\mathrm{P}$ uptake, by increasing the diffusion gradient by depleting $\mathrm{P}$ to a lower concentrations than non-mycorrhizal roots and by enhancing the transfer of $\mathrm{P}$ between living roots and from dying roots to living roots (Karunaratne et al. 1986; Bolan and Robson, 1987; Faquin et al. 1990; Sylvia, 1992; Frossard et al., 1995; Lange Ness and Vlek, 2000; Brundrett, 2002). In addition the AM fungi themselves have also been shown to have an impact on the composition of bacterial communities (Artursson et al., 2005). This impact may be relayed through the plant root because mycorrhizal establishment has been shown to change the chemical composition of root exudates and these are often a source of nutrients to associated bacteria in the zone of soil surrounding the roots and fungal hyphae "mycorrhizosphere" (Harley and Smith, 1983; Linderman, 1992; Azcón-Aguilar and Bago, 1994; Smith et al., 1994; Barea, 1997; 2000; Gryndler, 2000; Linderman, 2000). 
Taking into account that the organic $\mathrm{P}$ concentration in the soil solution was higher than the inorganic $\mathrm{P}$, the mineralization of organic $\mathrm{P}$ could be a explanation for the high $\mathrm{P}$ inflow by AMF at $0 \mathrm{P}$. Organic P may be mineralized by bacteria that secrete phosphatases whereas inorganic P may be released by bacteria that excrete organic acids (Smith and Read, 1997). Several studies have demonstrated synergistic interactions between phosphate-solubilizing bacteria and AM fungi (Barea et al., 1997; Kim et al., 1998). For example, Toro and colleagues (1997) studied phosphate limited systems containing plants, AM fungi and phosphatesolubilizing bacteria. Their study revealed that the bacteria promoted mycorrhizal establishment whereas the mycorrhizal symbiosis increased the size of the phosphate-solubilizing bacterial population. The treatments inoculated with both AM fungi and bacteria significantly increased plant biomass and $\mathrm{N}$ and $\mathrm{P}$ accumulation in plant tissues, compared with their controls which were not dually inoculated. Using ${ }^{32} \mathrm{P}$ isotopic dilution approaches they found that dually inoculated plants displayed lower specific activities $\left({ }^{32} \mathrm{P} /{ }^{31} \mathrm{P}\right)$ than control plants, indicating that AM fungi and phosphate-solubilizing bacteria interacted to make use of $\mathrm{P}$ sources otherwise unavailable to plants.

All this factors influence the $\mathrm{P}$ inflow rates of mycorrhizal roots, which are calculated to be 2-6 times those of non-mycorrhizal roots (Jones et al., 1998). The ion absorption kinetic parameters are also influenced by several factors in addition to the AMF, and especially by plant age (Edwar and Barber, 1976; Drew et al., 1984), which could be the case of genotypes 6 and 4 (Figure 3.5). Cress et al. (1979) found that, under low P concentrations in the solution, the absorption by the mycorrhizal tomato plant was associated with a lower $\mathrm{K}_{\mathrm{m}}$ value, i.e., with greater affinity of the colonized root carriers and/or the hyphae to P. Silveira and Cardoso (2004), reported that mycorrhizal bean plants showed i) at the flowering stage higher values of maximum ion uptake rate $\left(\mathrm{I}_{\max }\right)$ and net $\mathrm{P}$ influx, ii) at the pod-filling stage, lower minimum ion concentration $\left(\mathrm{C}_{\min }\right)$ and Michaelis constant $\left(\mathrm{K}_{\mathrm{m}}\right)$ values, iii) a higher net $\mathrm{P}$ influx in both stages and iv) the $\mathrm{C}_{\min }$ was the kinetic parameter more intimately related to $\mathrm{P}$ absorption, and a significant correlation was obtained between this parameter and shoot $\mathrm{P}$ content and accumulation in bean plants.

The genotype 6 rated as $\mathrm{P}$ efficient, which had at 90 DAT and at $0 \mathrm{P}$ a high biomass production (Figure 3.1) and a high effect on P inflow by AMF but presented a low AMF colonization grade (Table 3.3). Vilarino et al., (1993) found that increases of plant growth caused by higher P absorption promoted by the presence of mycorrhiza is influenced by the integrity, extension and distribution of the external mycelium, which may not be necessary correlated with the degree of colonization (Kucey and Paul, 1982). Thus, the positive response of Glomus fasciculatum in 
mostly Arachis pintoi genotypes could not necessarily be due to root colonization grade, but perhaps to the external mycelium distribution in the soil.

In contrast, other genotypes $(2,10)$ had not a significant increase of the $\mathrm{P}$ inflow by AMF. This result could be due to: i) a low development of the external mycelium unable to increase the $\mathrm{P}$ acquisition and therefore the symbiosis with AMF results irrelevant for the genotypes, or ii) the P taken up by the AMF was not efficiently translocated and/or not more uptaken for the plant, which could be the case of some efficient genotypes 1 and 6 at 20PR. Menge, et al. (1978) found that an increase in the level of soil phosphate results in a reduction in chlamydospore production by the fungus. These spores are involved in root infection and spread of the fungus through the soil. Additionally, research by Abbott and Robson (1979) concluded that levels of soil phosphorus greater than that required for plant growth eliminated the development of the arbuscles of vesicular-arbuscular types of mycorrhizae. Arbuscles are structures produced within the host plant cells by the AMF. These structures are responsible for the transfer of absorbed nutrients from the fungus to the plant.

A controversial point of view results from the finding of Smith et al. (2003), who investigated structural and functional diversity in arbuscular mycorrhizal (AM) symbioses involving three plant species and three AM fungi and measured contributions of the fungi to $\mathrm{P}$ uptake using compartmented pots and ${ }^{33} \mathrm{P}$. Through the specific activities of ${ }^{33} \mathrm{P}$ in plants and soil, they concluded that AM uptake can make a highly significant contribution to total P uptake (100\% in some symbioses involving $G$. intraradices) implies that the direct uptake pathway via root hairs and root epidermal cells must cease to function in some plant/fungus combinations and that this change in the relative contributions of the two pathways is not related to plant responsiveness or AM colonisation. This extends the earlier findings of Pearson and Jakobsen (1993) and Ravnskov and Jakobsen (1995), who provided results suggesting that direct uptake pathways in flax and cucumber ceased to function in roots colonised by Glomus caledonium.

Besides, Smith et al., (2003) proposed that the calculations of AM contributions to P uptake from total plant $\mathrm{P}$ will often be highly inaccurate. Contributions of the mycorrhizal pathway to total plant P uptake have often been calculated from the difference between total P in AM plants and in non-mycorrhizal control plants, grown in the same soil (Sanders and Tinker, 1971; Smith, 1982; West et al., 1993; Smith et al., 1994; Graham and Abbott, 2000). This calculation assumes that colonisation itself has no effect on uptake via the direct pathway in an AM root. It has been repeatedly suggested that this assumption is too simplistic, partly because plant $\mathrm{P}$ status (which may be increased in AM plants) influences the uptake capacity of roots (Gray and Gerdemann, 
1969; Bowen et al., 1975; Jakobsen, 1995). These results led these authors to suggest that lack of plant responsiveness does not mean that an AM fungus makes no contribution to P uptake.

The positive effect on average of AMF on the P inflow at 20PR was higher than that at 4TSP. That could be due to the AMF hyphae has a better ability to use the P from PR source than from TSP ones. Mycorrhizas are particularly for certain plant species to utilize phosphate rock (Bolan, 1991). This could be caused through dissolution by exuded acids or by a changed chemical equilibrium between fixed and dissolved $\mathrm{P}$, after efficient removal of $\mathrm{P}$ or $\mathrm{Ca}$ from the soil solution. Conversely, Ness and Vlek (2000) reported that the possibility that AMF could increase the $\mathrm{P}$ availability of hydroxy apatite (HA) by taking up $\mathrm{Ca}$ was not supported in their study, as mycelial P uptake from HA-amended root free soil was accompanied by the accumulation of Ca in the soil. They suggested that it is more likely that the large uptake surface of mycorrhizas provides a closer contact to the phosphate rock (PR) particles and thereby maintains a low $\mathrm{P}$ concentration in the soil solution surrounding the particles. This would drive the equilibrium from chemically bound towards dissolved P.

\subsection{Concluding discussions}

1. The high differences in $\mathrm{P}$ efficiency recorded among the Arachis pintoi genotypes under low $\mathrm{P}$ supply decreased remarkable due to a high positive influence of AM fungi on plant growth of the genotypes rated as inefficient.

2. Without AMF, the Arachis pintoi genotypes had differing P efficiency under low P supply and the $\mathrm{P}$ efficiency order obtained in the present study match with those found in chapter 2. Genotype 2 was the most efficient due to a high $\mathrm{P}$ inflow, and genotype 4 the least efficient because of a low $\mathrm{P}$ use efficiency and root length-shoot weight ratio in addition to a low $\mathrm{P}$ inflow. The high P efficiency was caused either by high $\mathrm{P}$ use efficiency and high root lengthshoot weight ratio (genotypes 1, 6, 10) and/or high P inflow (genotypes 2,1,10). An increase of the $\mathrm{P}$ availability by $\mathrm{P}$ supply decreased the $\mathrm{P}$ inflow (genotype 2 ) probably due to a inhibition of root exudation.

3. The AMF evened out the P efficiency of the genotypes by finesse and harmonise varying of the root length-shoot weight ratio and the $\mathrm{P}$ inflow or enhancing the root growth. The AMF decreased the root length-shoot weight ratio both efficient $(1,6,10)$ and inefficient $(8,5)$ genotypes but increased its $\mathrm{P}$ inflow probably because of more carbon compounds were used to increase the hyphae network in the soil. 
4. The efficiency of the symbiosis genotypes-fungi to increase the P inflow differed from each other depending not only on the availability of $\mathrm{P}$ in the soil but also on the source of $\mathrm{P}$ added. An increase of the available P in the soil by low amount of a high water soluble fertilizer (TSP) may have decreased more the AMF effectiveness of the genotypes on the $\mathrm{P}$ inflow than by a higher amount of a low water soluble fertilizer (PR). This different effect may be related to an inhibition of the hyphae formation to enhance the exploitation of P.

5. Differences in $\mathrm{P}$ inflow among the genotypes may be caused by differences in the ability to increase i) the number of point source of $\mathrm{P}$ (root hair and/or hyphae of AMF) or ii) the concentration at the root surface by chemical $\mathrm{P}$ mobilisation (root exudate and/or APase activity), which seem to be the case of genotype 2 .

6. The high yield and shoot $\mathrm{P}$ content of some genotypes $(2,1,10,9,8)$ was not related with an increase on the $\mathrm{P}$ acquisition efficiency i.e. the AMF enhance plant growth by the other factors.

7. The genotypes changed its P efficiency with time due to changes in its ability to acquire the P. 


\section{The development of $P$ efficiency mechanisms with plant age of perennial peanut (Arachis pintoi) genotypes and of one groundnut (Arachis hypogea) genotype}

\subsection{Introduction}

The response to low P supply of plant species and cultivars differs greatly and it seems to be also regulated by the $\mathrm{P}$ demand during ontogenesis. The faster a plant grows the higher its $\mathrm{P}$ demand and therefore the more $\mathrm{P}$ that has to be absorbed by the root system (Engels, 1993).

Under P deficient growth conditions, some plants achieve a good growth, because they develop mechanisms which enable them to take up enough $\mathrm{P}$ for optimum growth. As was described in chapters 2 and 3, that was the case of some Arachis pintoi genotypes $(1,2,6,10)$ which were rated as $\mathrm{P}$ efficient.

The high $\mathrm{P}$ acquisition efficiency of genotype 6 was attributed solely to a high root length-shoot ratio (RSR) as Föhse et al. (1988) reported for ryegrass and wheat. A high RSR allows the exploration of a greater volume of soil to feed the plant, by expanding their root system (length or surface area). This may occur because of the changing of morphological root properties such as root radius, root hair, proteoid root and symbiosis with mycorrhizal fungi (Clarkson, 1985; Marschner, 1995). Genotype 1 and especially genotype 10 based their high $\mathrm{P}$ acquisition efficiency on the combination of a relative high RSR and a high P inflow i.e. a high P uptake per unit root and time. And genotype 2, which had always had the highest P acquisition efficiency (see chapters 2 and 3) based it on a high P inflow as Föhse et al., 1988 found for spinach and oilseed rape, and Bhadoria et al. (2001) reported for groundnut.

There are several reasons to account for a high $\mathrm{P}$ inflow at low soil $\mathrm{P}$ availability. These include i) an adapted $P$ uptake kinetics to the $P$ status of the plants, especially by an increased $I_{\max }$ at moderately low P supply (Jungk, 1974; Jungk et al. 1990; Buhse, 1992) and/or ii) an increase in the $\mathrm{P}$ concentration in the soil solution, as it was observed for genotype 2 in the pot trial (see chapter 2). This can be achieved by mobilising soil P by excreting organic compounds (e.g. citrate or cell wall components) capable of solubilizing inorganic soil-bound P (Gardner et al., 1983; Ae et al., 1990; Ae et al., 2001) or by mineralization of organically bound P by secreting free phosphatase (Dalal, 1977).

Moreover, the $\mathrm{P}$ efficiency of the Arachis pintoi changes with time i.e. genotypes with a high growth at the second harvest might have a low growth at the first one or vice-verse (see chapter 3). For instance, at the first harvest genotype 6 had a higher growth than that of genotype 1, 
whereas at the second harvest the growth of genotype 1 was higher. These changes on the $\mathrm{P}$ efficiency could be related to the ability of the genotypes to develop and regulate the above mentioned $\mathrm{P}$ efficiency mechanisms with time under low availability of $\mathrm{P}$.

It is well known that with age, plants present changes in the root growth, being exponential for young plants and later linear. There are also changes in P demand, which is normally highest at flowering and fruit or grain production. Several experiments have been conducted to identify and understand how $\mathrm{P}$ efficient plants or genotypes achieve optimal growth under $\mathrm{P}$ deficient conditions. Despite that, few studies have been conducted to investigate whether plants are able to change its $\mathrm{P}$ efficiency with age and whether it is possible to find differences among genotypes in this respect.

Bhadoria et al. (2001) working with groundnut and maize under field conditions, observed that at early growth stages groundnut was very P efficient; mainly because of a high P inflow (6.8 - 10.3 $\mathrm{x} 10^{-14} \mathrm{~mol} \mathrm{~cm}^{-1} \mathrm{~s}^{-1}$ ), which declined as the plant continued to grow with a concomitant decrease in P efficiency. On the other hand, maize had a low $\mathrm{P}$ inflow at the beginning of the season and grew poorly; in the middle of the season the $\mathrm{P}$ inflow increased by a factor of 6 , and became almost enough to sustain maximum growth. These results show that $\mathrm{P}$ inflow differed greatly between species as well as with the stage of growth of a particular species. However, in a nutrient solution experiment with the same plant species under controlled growth conditions, where four harvests were taken to calculate the $\mathrm{P}$ inflow and study changes in plant growth and $\mathrm{P}$ uptake in relation to plant age, Bhadoria et al. (2004) found that the average P inflow decreased with plant age for both species at 0.2 and $1 \mu \mathrm{M}$ P concentration. Taking into account the low $\mathrm{P}$ concentration in soil solution in the field $(<1 \mu \mathrm{M})$, it was surprising to find that at $0.2 \mu \mathrm{M}$, the $\mathrm{P}$ inflow was almost nil for groundnut but clearly positive for maize. With a 5-fold increase in the $\mathrm{P}$ concentration, the $\mathrm{P}$ inflow of groundnut rose in the first period $\left(1 \times 10^{-14} \mathrm{~mol} \mathrm{~cm}^{-1} \mathrm{~s}^{-1}\right)$ and declined later even reaching negative values between the $3^{\text {rd }}$ and $4^{\text {th }}$ harvest $(28$ and 35 days after transplanting - DAT). Maize started with a three times higher inflow as compared to groundnut, but also declined gradually and in the last phase (24 and 34 DAT) was close to $1 \times 10^{-14} \mathrm{~mol} \mathrm{~cm}^{-1}$ $\mathrm{s}^{-1}$. This shows that maize roots were much more efficient than groundnut roots in absorbing $\mathrm{P}$ from solution in contrast to what happened in the soil. This may indicate that P uptake kinetics is not decisive for P uptake from soil.

The $\mathrm{P}$ inflow may be increased by an increased $\mathrm{I}_{\max }$ at moderately low $\mathrm{P}$ supply. The ion absorption kinetic parameters are also influenced by several factors in addition to the AMF, and especially by plant age (Edwards and Barber, 1976; Drew et al., 1984). Silveira et al. (2004) 
reported that mycorrhizal bean plants showed higher $\mathrm{I}_{\max }$ and net $\mathrm{P}$ inflow at the flowering stage and lower $\mathrm{C}_{\min }$ and $\mathrm{K}_{\mathrm{m}}$ values at the pod-filling stage. However, since groundnut was incapable of obtaining a high inflow in nutrient solution at low $\mathrm{P}$ concentration, this would indicate that groundnut is able to increase chemically the $\mathrm{P}$ availability in soil.

The purpose of this study was to investigate whether the development of $\mathrm{P}$ efficiency mechanisms observed in three perennial peanut (Arachis pintoi) genotypes (see chapter 2 and 3 ) and of one P efficient groundnut (Arachis hypogea) genotype are influenced with time and by the ontogenesis.

\section{Hypotheses}

The following hypotheses were tested:

1. The Arachis pintoi genotypes differ from the Arachis hypogea genotype in their ability to growth under low plant $\mathrm{P}$ availability and these differences are related with the ontogenesis.

2. Changes in the $P$ efficiency of the genotypes during the ontogenesis are due to changes in the P uptake efficiency.

\subsection{Materials and Methods}

The plants were grown in a growth chamber, which conditions were set to a 16/8 hours light/dark regime, $30 / 20^{\circ} \mathrm{C}$ and a constant relative humidity of $75 \%$. The photosynthetic photon flux density during daylight was $250 \mu \mathrm{E} \mathrm{m}^{-2} \mathrm{~s}^{-1}$.

\section{Plant material and growth conditions}

Three from the ten genotypes of Arachis pintoi (1,2 and 10) assessed in chapter 2 and 3 were chosen due to their differences in P uptake attributes. One Arachis hypogea (cv. AK - 12/24) genotype from India, which showed changes in its $\mathrm{P}$ acquisition efficiency with age (Bhadoria et al., 2001; 2004), was included as control. The plants were grown in the same fossil Oxisol used in chapter 2. Plant establishment procedures were performed in the same way as described in chapter 2.

The three rates of $\mathrm{P}$ used were 0,50 and $1000 \mathrm{mg} \mathrm{kg}^{-1}$ soil supplied as $\mathrm{Ca}\left(\mathrm{H}_{2} \mathrm{PO}_{4}\right)_{2} \cdot \mathrm{H}_{2} \mathrm{O}$ and incorporated by thoroughly mixing them with the soil. A basal fertilization was applied as 
described for the pot trial in chapter 2, except for a higher addition of nitrogen $\left(300 \mathrm{mg} \mathrm{kg}^{-1}\right)$ as $\mathrm{Ca}\left(\mathrm{NO}_{3}\right)_{2}$ split in three applications (0,30 and 60 days). The experimental design and the soil moisture content were performed as in chapter 2 for the pot experiment.

\section{Measurements and analysis}

\section{Shoot sampling}

After 30, 60 and 90 days of growth, plants were harvested by cutting them at soil surface, and plant material for chemical analysis was performed as in chapter 2 .

\section{Root sampling, root length $(\mathrm{RL})$ and root radius $\left(\mathrm{r}_{\mathbf{0}}, \mathrm{cm}\right)$}

Root length was measured using the line intersection method of Tennant (1975). For more details refer to the pot trial in chapter 2 . Assuming that the specific weight of roots is $1 \mathrm{~g} \mathrm{~cm}^{-3}$, the mean root radius, $\mathrm{r}_{0}$ in $\mathrm{cm}$, was calculated using the following equation:

$$
\mathrm{r}_{0}=\sqrt{\frac{\mathrm{RF}}{\pi \mathrm{RL}}}
$$

where, $\quad \begin{array}{ll}\mathrm{RF} & =\operatorname{root} \text { fresh weight in } \mathrm{g}\left(\text { equal } \mathrm{cm}^{3}\right) \\ \mathrm{RL} & =\text { root length in } \mathrm{cm}\end{array}$

\section{Root length density $\left(\mathrm{RL}_{\mathrm{v}}, \mathrm{cm} \mathrm{cm}^{-3}\right)$}

It gives the root length per unit soil volume. It was calculated by dividing the total root length (RL) in $\mathrm{cm}$ by the soil volume (SV) in $\mathrm{cm}^{3}$ of the pot.

\section{Average half distance between neighbouring roots $\left(r_{1}, \mathbf{c m}\right)$}

Assuming that the roots are regularly distributed in the soil, the average half distance between neighbouring roots was calculated using the root length density $\mathrm{RL}_{\mathrm{v}}$,

$$
\mathrm{r}_{1}=\sqrt{\frac{1}{\pi \mathrm{RL}_{\mathrm{v}}}}
$$




\section{Phosphorus concentration in plants}

The phosphorus was measured using the molybdate-vanadate method of Kitson and Mellon (1944). For more details see the pot trial in chapter 2.

\section{Absolute shoot growth rate $\left(\mathrm{GR}_{\mathrm{s}}, \mathrm{g} \mathrm{s}^{-1}\right)$}

It shows the new growth of the plant between two periods. It was calculated using the following equation,

$$
\mathrm{GR}_{\mathrm{s}}=\frac{\mathrm{SW}_{2}-\mathrm{SW}_{1}}{\mathrm{t}_{2}-\mathrm{t}_{1}}
$$

where,

$$
\begin{aligned}
& \mathrm{SW}=\text { shoot dry weight in } \mathrm{g} \\
& \mathrm{t} \quad=\text { time in days } \\
& \text { indices } 1 \text { and } 2 \text { mean } 1^{\text {st }} \text { and } 2^{\text {nd }} \text { harvest }
\end{aligned}
$$

\section{$\operatorname{Inflow}\left(\mathbf{I}_{\mathbf{n}}\right)$}

The average $\mathrm{P}$ inflow was calculated as described in chapter 3.

$$
I_{n}=\frac{\left(U_{2}-U_{1}\right)}{\left(t_{2}-t_{1}\right)} \times \frac{2}{\left(R L_{2}+R L_{1}\right)}
$$

where,

$$
\begin{aligned}
& \mathrm{U}=\text { nutrient element content in the shoot in mol } \\
& \mathrm{RL} \quad=\text { root length in } \mathrm{cm} \\
& \mathrm{t} \quad=\text { time in } \mathrm{s} \\
& \text { indices } 1 \text { and } 2 \text { means } 1^{\text {st }} \text { and } 2^{\text {nd }} \text { harvest }
\end{aligned}
$$

\section{Soil Analysis}

\section{Available $P$ in the soil and $P$ concentration in the soil solution}

It was determined in the soil using the Bray II extraction (Bray and Kurtz, 1945) and the CAL (calcium-acetate-lactate) (Schüller, 1969). The soil solution was obtained using the modified column displacement technique (Adams 1974). For more details see chapter 2. 


\section{Concentration difference between bulk soil and root surface $\left(\Delta C_{L}\right)$}

This is the difference in $\mathrm{P}$ concentration between bulk soil solution and concentration at the root surface needed to drive a flux by diffusion equal to the inflow $\left(\mathrm{I}_{\mathrm{n}}\right) . \Delta \mathrm{C}_{\mathrm{L}}$ was calculated as follows, (Barraclough, 1986):

$$
\Delta \mathrm{C}_{\mathrm{L}}=\frac{\mathrm{In}}{4 \pi \mathrm{D}_{\mathrm{L}} \theta \mathrm{f}}\left(1-\frac{1}{1-\pi \mathrm{r}_{0}^{2} \mathrm{RL}_{\mathrm{v}}} \ln \frac{1}{\pi \mathrm{r}_{0}^{2} \mathrm{RL}_{\mathrm{v}}}\right)
$$

where, $\quad \mathrm{D}_{\mathrm{L}}=$ diffusion coefficient of $\mathrm{P}$ in water in $\mathrm{cm}^{2} \mathrm{~s}^{-1}$

$\theta=$ volumetric water content in $\mathrm{cm}^{3} \mathrm{~cm}^{-3}$

$\mathrm{f}=$ impedance factor

$\mathrm{r}_{0}=$ root radius in $\mathrm{cm}$

$\mathrm{RL}_{\mathrm{v}}=$ root length density in $\mathrm{cm} \mathrm{cm}^{-3}$

\subsection{Results and Discussion}

\subsubsection{Shoot biomass production and the shoot growth rate}

At each growth stage, the overall mean of the genotypes in shoot biomass production (leaf, stem, and fruit) increased when $\mathrm{P}$ was added compared to $0 \mathrm{P}$ (Figure 4.1). The increase varied strongly depending on the amount of $\mathrm{P}$ added and with age. At 1000P, the genotypes tended to have a similar yield at 30 and 60 days after establishment (DAE), while at 90 DAE no statistical significant differences were found among the yield of them. Consequently, the genotypes growing under ample $\mathrm{P}$ availability had a similar growth potential.

In contrast, at $0 \mathrm{P}$ and $50 \mathrm{P}$ the genotypes were $\mathrm{P}$ deficient and the yield differences among the genotypes, which were stronger at early growth stage, were because the genotypes differed in their P efficiency. Applying the concept that $\mathrm{P}$ efficient genotypes are those capable of producing high biomass under low P availability (0P) at 90 DAE (Figure 4.1), genotype 1 was the less $\mathrm{P}$ efficient among the Arachis pintoi genotypes, yielding at OP and 90 DAE 60 to $70 \%$ of the others. The Arachis hypogea, which achieved $79 \%$ of its maximum yield had the highest yield at each growth stage but at 90 DAE did not differ statistically from genotype 2 . This results of Arachis hypogea agree with the finding of Bhadoria et al., (2001) who observed that under field conditions groundnut was not limited by low $\mathrm{P}$ in the early growth stage (30-50 days after sowing) producing $75 \%$ of its maximum yield (at $400 \mathrm{mg} \mathrm{P} \mathrm{kg}^{-1}$ soil). Moreover, this $\mathrm{P}$ efficient order was not affected with age i.e. at 30 and 60 DAE the genotypes showed the same P efficiency order. 


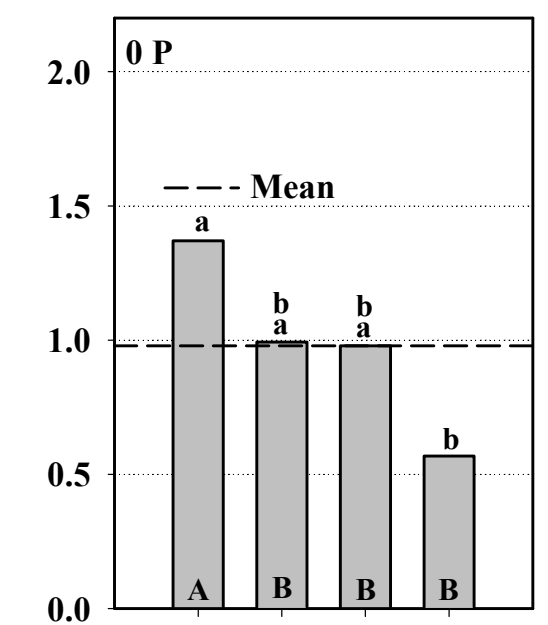

\section{$50 \mathrm{P}$}

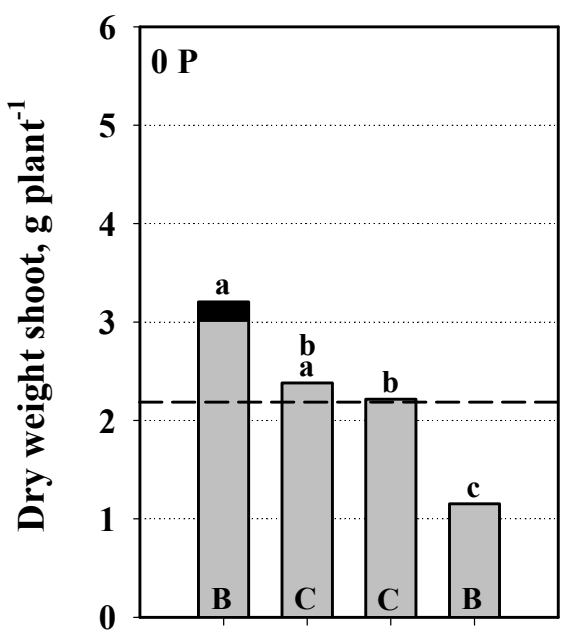

$50 \mathrm{P}$
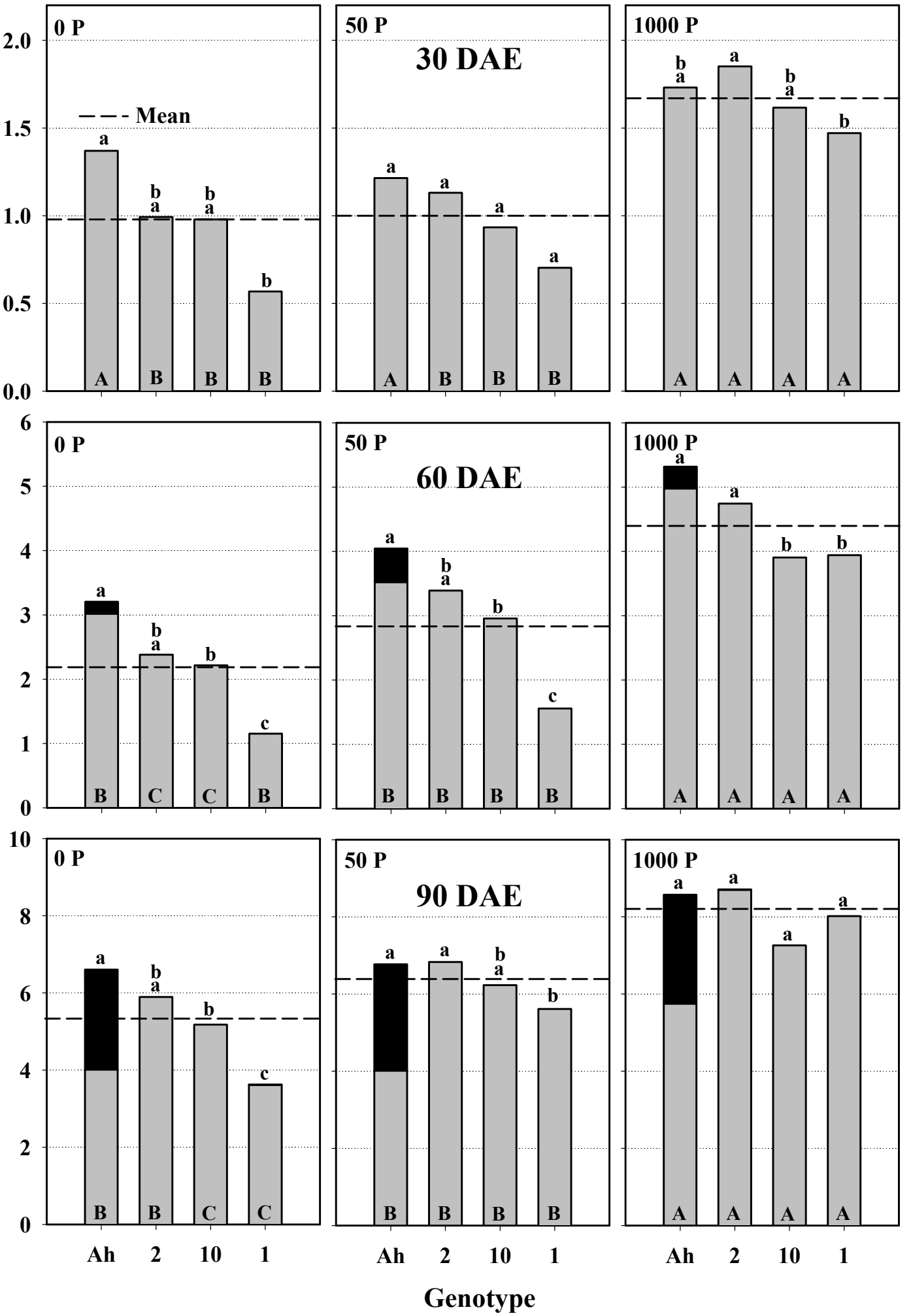

Figure 4.1 Influence of varying P supply on shoot biomass production of three genotypes of Arachis pintoi and one of Arachis hypogea $(A h)$ at 30, 60 and 90 days after establishment (DAE). Within a treatment, bars marked with the same letter are not significantly different after Tukey-test $(p<0.05)$. Among the treatments, bars of the same genotype marked with the same capital letter are not significantly different after Tukey-test $(\mathrm{p}<0.05)$. The black part of the bars of $A h$ is the dry weight of fruits. 
In contrast, as it was observed in chapter 3, the P efficiency of genotype 1 and 10 was changed positively with time in comparison to the other genotypes (see Figure 3.2). At $50 \mathrm{P}$ the $A p$ genotypes showed a similar pattern as at $0 \mathrm{P}$ but at 90 DAE genotype 1 reduced clearly the yield difference (80 to $90 \%$ ).

The dry matter measured at each harvest does not necessarily show the effect of age on the plant ability or growth rate. Table 4.1 shows the absolute shoot growth rate $\left(\mathrm{GR}_{\mathrm{s}}\right)$ of the genotypes between two periods of time.

In the first period (30-60 DAE) the $\mathrm{GR}_{\mathrm{s}}$ increased as response of the $\mathrm{P}$ supply. However, solely the $\mathrm{GR}_{\mathrm{S}}$ of the genotypes at $0 \mathrm{P}$ differed statistically from $1000 \mathrm{P}$, except for genotype 1 at $50 \mathrm{P}$, whose GRs differed also statistically from 1000P (Table 4.1). Furthermore, the $\mathrm{GR}_{\mathrm{s}}$ of the genotypes differed within each P treatment showing the same pattern as observed in the shoot biomass production at 30 and 60 DAE (Figure 4.1).

Interesting is that while the $\mathrm{GR}_{\mathrm{s}}$ of $A h$ and $A p$ genotypes 2 and 10 at $0 \mathrm{P}$ and $50 \mathrm{P}$ were already by $50 \%$ and $80 \%$ of that recorded at $1000 \mathrm{P}$, the $\mathrm{GR}_{\mathrm{s}}$ of genotype 1 at $0 \mathrm{P}$ and $50 \mathrm{P}$ was only by 20 and $30 \%$. Consequently, these results confirmed not only that in the first growth period (30-60 $\mathrm{DAE}$ ) at $\mathrm{OP}$ the genotypes were $\mathrm{P}$ inefficient but also that the genotypes at this time differed in their ability to cover the $\mathrm{P}$ demand imposed by the growth.

Table 4.1 Influence of varying $P$ supply on the shoot growth rate $\left(\mathrm{GR}_{\mathrm{s}}\right)$ of three genotypes of Arachis pintoi and one of Arachis hypogea (Ah) between 30-60 and 60-90 days after establishment (DAE)

\begin{tabular}{|c|c|c|c|c|c|c|}
\hline \multirow[t]{3}{*}{ Genotype } & \multicolumn{6}{|c|}{ Shoot growth rate, $10^{-7} \mathrm{~g} \mathrm{~s}^{-1}$} \\
\hline & \multicolumn{3}{|c|}{30 - 60 days } & \multicolumn{3}{|c|}{60 - 90 days } \\
\hline & $0 \mathrm{P}$ & $50 \mathrm{P}$ & $1000 \mathrm{P}$ & $0 \mathrm{P}$ & $50 \mathrm{P}$ & $1000 \mathrm{P}$ \\
\hline$A h$ & $7.08 \mathrm{a}^{\mathrm{B}}$ & $10.91 \mathrm{a}^{\mathrm{AB}}$ & $13.84 \mathrm{a}^{\mathrm{A}}$ & $13.11 \mathrm{a}^{\mathrm{A}}$ & $10.52 b^{\mathrm{A}}$ & $12.56 \mathrm{a}^{\mathrm{A}}$ \\
\hline 2 & $5.35 \mathrm{ab}^{\mathrm{B}}$ & $8.72 \mathrm{a}^{\mathrm{A}}$ & $11.16 \mathrm{ab}^{\mathrm{A}}$ & $13.57 \mathrm{a}^{\mathrm{A}}$ & $13.27 \mathrm{ab}^{\mathrm{A}}$ & $15.30 \mathrm{a}^{\mathrm{A}}$ \\
\hline 10 & $4.77 \mathrm{ab}^{\mathrm{B}}$ & $7.81 \mathrm{a}^{\mathrm{A}}$ & $8.83 b^{\mathrm{A}}$ & $11.44 \mathrm{a}^{\mathrm{A}}$ & $12.62 \mathrm{ab}^{\mathrm{A}}$ & $12.94 \mathrm{a}^{\mathrm{A}}$ \\
\hline 1 & $2.25 b^{\mathrm{B}}$ & $3.30 b^{\mathrm{B}}$ & $9.53 b^{\mathrm{A}}$ & $9.55 \mathrm{a}^{\mathrm{B}}$ & $15.65 \mathrm{a}^{\mathrm{A}}$ & $15.72 \mathrm{a}^{\mathrm{A}}$ \\
\hline
\end{tabular}

Within a treatment, values that are followed by the same letter are not significantly different after Tukey-test $(p<0.05)$. Among the treatments, values of one genotype marked with the same capital letter are not significantly different after Tukey-test $(\mathrm{p}<0.05)$.

In the second growth period (60-90 DAE) most of the genotypes increased the $\mathrm{GR}_{\mathrm{s}}$ at each $\mathrm{P}$ treatment but in different proportion and thus the statistical differences among the $\mathrm{P}$ treatments and within each $\mathrm{P}$ treatment tended to disappear (Table 4.1). The exception was genotype 1, whose $\mathrm{GR}_{\mathrm{s}}$ at $0 \mathrm{P}$ was statistically inferior $(40 \%)$ than that at $1000 \mathrm{P}$ as well as within the $0 \mathrm{P}$ 
treatment was still lower (at least 20\%) than that observed in the other genotypes (Table 4.1). That indicates that at $0 \mathrm{P}$ genotype 1 was the only one which had still not achieved its maximum $\mathrm{GR}_{\mathrm{s}}$. In contrast, genotype 1 had not only the highest $\mathrm{GR}_{\mathrm{s}}$ at both $\mathrm{P}$ fertilisations whereas $A h$ the lowest one, but also at 50P genotype 1 achieved the same $\mathrm{GR}_{\mathrm{s}}$ as at $1000 \mathrm{P}$.

It is also important to remark the effect of age on the $\mathrm{GR}_{\mathrm{s}}$ of each genotype at each $\mathrm{P}$ treatment i.e. between both growth periods, which was most pronounced at low P availability. For instance, at $\mathrm{OP}$ the $\mathrm{GR}_{\mathrm{S}}$ of genotype 1 increased 4.2-fold followed by genotypes 2 (2.5-fold), 10 (2.4-fold) and $A h$ (1.9-fold). When $\mathrm{P}$ was added, the $A p$ genotypes increased the $\mathrm{GR}_{\mathrm{s}}$, especially the genotype 1 at $50 \mathrm{P}$, whereas $A h$ tended to reduce it. That could be related to an effect of genotypes' ability to cover the P demand on the physiological development i.e. although the genotypes had the same age (DAE), some genotypes had a younger physiological development than the others as observed among the $A p$ genotypes.

Additionally, noteworthy is the clear differences in the ontogenesis between Arachis hypogea and the perennial Arachis pintoi genotypes. While no fruits were produced by the Arachis pintoi genotypes, Arachis hypogea had already produced fruit at $60 \mathrm{DAE}$ at each P treatment. The fruit percentage of the total $A h$ yield at $90 \mathrm{DAE}$ was $39 \%$ at $0 \mathrm{P}, 41 \%$ at $50 \mathrm{P}$ and $33 \%$ at $1000 \mathrm{P}$. Duke, (1981) reported that the flowering of Arachis hypogea commences around 30 days after germination and 80-150 days are required for fruit maturity. Consequently, it is possible that the high biomass production and shoot $\mathrm{P}$ concentration was influenced by the fast development of Ah i.e. high $\mathrm{P}$ demand at each growth stage compared to the Arachis pintoi genotypes. That indicates that a comparison between the Arachis pintoi genotypes and the Arachis hypogea may only be possible at $30 \mathrm{DAE}$ where the plants were still producing only shoot.

\subsubsection{Shoot $P$ concentration and $P$ content}

At each growth stage, the shoot $P$ concentration (Table 4.2) increased as effect of the addition of $\mathrm{P}$ but varied among them at each $\mathrm{P}$ treatment showing the same pattern observed for shoot biomass production (Figure 4.1) and shoot growth rate $\left(\mathrm{GR}_{\mathrm{s}}\right)$ (Table 4.1). At 1000P and each growth stage the Arachis pintoi (Ap) genotypes achieved a $\mathrm{P}$ status in the shoot at least 2-fold higher than that reported as sufficient in the leaves $\left(2 \mathrm{mg} \mathrm{g}^{-1}\right)$ by Rao and Kerridge, (1994) and the Arachis hypogea $(A h)$ near to the maximum value considered as sufficient $\left(2.5-5 \mathrm{mg} \mathrm{g}^{-1}\right)$ by Bergmann, (1993). That means, that the genotypes growing under ample P condition were able to cover totally the $\mathrm{P}$ demand imposed by the plant growth potential. 
On the contrary, the deficient $\mathrm{P}$ status of the genotypes in the early growth stages when grown under low $\mathrm{P}$ condition explained clearly the low yield and $\mathrm{GR}_{\mathrm{s}}$ as well as the differences among the genotypes. At $30 \mathrm{DAE}$ the shoot $\mathrm{P}$ concentration of the genotypes ranged between 0.9 and $1.1 \mathrm{mg} \mathrm{g}^{-1}$ at $0 \mathrm{P}$ and 50P and therefore $\mathrm{P}$ deficient. With time (60 DAE) the genotypes achieved a shoot $\mathrm{P}$ concentration around $2 \mathrm{mg} \mathrm{g}^{-1}$ at $0 \mathrm{P}$, which seem to be the critical concentration because the $\mathrm{GR}_{\mathrm{s}}$ at $\mathrm{OP}$ in the second growth period did not differ statistically from 50P and 1000P (Table 4.1). The exception was genotype 1, which at $60 \mathrm{DAE}$ had still a shoot $\mathrm{P}$ concentration of $1 \mathrm{mg} \mathrm{g}^{-1}$ and thereby genotype 1 had still not achieved its maximum $\mathrm{GR}_{\mathrm{s}}$.

Table 4.2 Influence of varying $\mathrm{P}$ supply on shoot $\mathrm{P}$ concentration of three genotypes of Arachis pintoi and one Arachis hypogea $(A h)$ at 30,60 and 90 days after establishment (DAE).

\begin{tabular}{|c|c|c|c|c|c|c|c|c|c|}
\hline \multirow[t]{3}{*}{ Genotype } & \multicolumn{9}{|c|}{ Shoot $\mathrm{P}$ concentration, $\mathrm{mg} \mathrm{g}^{-1}$} \\
\hline & \multicolumn{3}{|c|}{$30 \mathrm{DAE}$} & \multicolumn{3}{|c|}{$60 \mathrm{DAE}$} & \multicolumn{3}{|c|}{$90 \mathrm{DAE}$} \\
\hline & $0 \mathrm{P}$ & $50 \mathrm{P}$ & $1000 \mathrm{P}$ & $0 \mathrm{P}$ & $50 \mathrm{P}$ & $1000 \mathrm{P}$ & OP & $50 \mathrm{P}$ & $1000 \mathrm{P}$ \\
\hline$A h$ & $1.0 \mathrm{a}^{\mathrm{B}}$ & $1.1 \mathrm{ab}^{\mathrm{B}}$ & $5.3 \mathrm{a}^{\mathrm{A}}$ & $2.2 \mathrm{a}^{\mathrm{B}}$ & $2.0 \mathrm{a}^{\mathrm{B}}$ & $3.4 \mathrm{c}^{\mathrm{A}}$ & $1.6 \mathrm{a}^{\mathrm{C}}$ & $2.1 \mathrm{a}^{\mathrm{B}}$ & $4.1 b^{\mathrm{A}}$ \\
\hline 2 & $1.1 \mathrm{a}^{\mathrm{B}}$ & $1.1 \mathrm{a}^{\mathrm{B}}$ & $5.7 \mathrm{a}^{\mathrm{A}}$ & $2.0 a b^{\mathrm{B}}$ & $2.3 \mathrm{a}^{\mathrm{B}}$ & $5.7 \mathrm{ab}^{\mathrm{A}}$ & $1.3 \mathrm{~b}^{\mathrm{B}}$ & $1.5 b^{\mathrm{B}}$ & $4.7 \mathrm{ab}^{\mathrm{A}}$ \\
\hline 10 & $1.0 \mathrm{a}^{\mathrm{B}}$ & $1.0 \mathrm{bc}^{\mathrm{B}}$ & $5.5 \mathrm{a}^{\mathrm{A}}$ & $1.9 a b^{B}$ & $2.4 \mathrm{a}^{\mathrm{B}}$ & $5.1 \mathrm{~b}^{\mathrm{A}}$ & $1.3 b^{B}$ & $1.7 b^{B}$ & $4.5 \mathrm{~b}^{\mathrm{A}}$ \\
\hline 1 & $0.9 \mathrm{a}^{\mathrm{B}}$ & $0.9 c^{\mathrm{B}}$ & $6.0 \mathrm{a}^{\mathrm{A}}$ & $1.0 \mathrm{~b}^{\mathrm{B}}$ & $1.7 \mathrm{a}^{\mathrm{B}}$ & $6.3 \mathrm{a}^{\mathrm{A}}$ & $1.4 \mathrm{ab}^{\mathrm{B}}$ & $1.5 b^{\mathrm{B}}$ & $5.2 \mathrm{a}^{\mathrm{A}}$ \\
\hline
\end{tabular}

Within a treatment, values that are followed by the same letter are not significantly different after Tukey-test $(p<0.05)$. Among the treatments, values of one genotype marked with the same capital letter are not significantly different after Tukey-test $(\mathrm{p}<0.05)$.

Consequently, the growth for $A h$ and $A p$ genotypes 2 and 10 at $0 \mathrm{P}$ and $50 \mathrm{P}$ was already optimum. This could not be recognized by total biomass (Figure 4.1) because of the stunted growth in the first growth stages.

The content of $\mathrm{P}$ in the shoot, which is the product of dry matter and the $\mathrm{P}$ concentration in dry matter, displays the ability of genotypes to acquire $\mathrm{P}$ from the soil. Table 4.3 shows the shoot $\mathrm{P}$ content as affected by $\mathrm{P}$ fertilization at each harvest.

Since the differences in the shoot $\mathrm{P}$ concentration among the genotypes at each $\mathrm{P}$ treatment were small but already at 60 DAE achieved an optimal P status (Table 4.2), the genotypes showed the same pattern for the shoot $\mathrm{P}$ content as those described for the shoot $\mathrm{P}$ concentration at each $\mathrm{P}$ treatment and at each growth stage (Table 4.2). 
Table 4.3 Influence of varying $\mathrm{P}$ supply on shoot $\mathrm{P}$ content of three genotypes of Arachis pintoi and one Arachis hypogea (Ah) at 30,60 and 90 days after establishment (DAE).

\begin{tabular}{|c|c|c|c|c|c|c|c|c|c|}
\hline \multirow[t]{3}{*}{ Genotype } & \multicolumn{9}{|c|}{ Shoot $\mathrm{P}$ content, mg plant ${ }^{-1}$} \\
\hline & \multicolumn{3}{|c|}{$30 \mathrm{DAE}$} & \multicolumn{3}{|c|}{$60 \mathrm{DAE}$} & \multicolumn{3}{|c|}{$90 \mathrm{DAE}$} \\
\hline & $0 \mathrm{P}$ & $50 \mathrm{P}$ & $1000 \mathrm{P}$ & $\mathrm{OP}$ & $50 \mathrm{P}$ & $1000 \mathrm{P}$ & $0 \mathrm{P}$ & $50 \mathrm{P}$ & $1000 \mathrm{P}$ \\
\hline$A h$ & $1.4 \mathrm{a}^{\mathrm{B}}$ & $1.3 \mathrm{a}^{\mathrm{B}}$ & $9.1 \mathrm{a}^{\mathrm{A}}$ & $6.7 \mathrm{a}^{\mathrm{B}}$ & $8.0 \mathrm{a}^{\mathrm{B}}$ & $18.2 b^{\mathrm{A}}$ & $10.2 \mathrm{a}^{\mathrm{C}}$ & $14.0 \mathrm{a}^{\mathrm{B}}$ & $35.0 \mathrm{ab}^{\mathrm{A}}$ \\
\hline 2 & $1.1 \mathrm{a}^{\mathrm{B}}$ & $1.3 \mathrm{ab}^{\mathrm{B}}$ & $11.0 \mathrm{a}^{\mathrm{A}}$ & $4.7 b^{C}$ & $7.7 \mathrm{a}^{\mathrm{B}}$ & $27.0 \mathrm{a}^{\mathrm{A}}$ & $7.5 b^{B}$ & $10.5 b^{B}$ & $40.7 \mathrm{a}^{\mathrm{A}}$ \\
\hline 10 & $1.0 \mathrm{ab}^{\mathrm{B}}$ & $0.9 \mathrm{ab}^{\mathrm{B}}$ & $9.0 \mathrm{a}^{\mathrm{A}}$ & $4.2 b^{C}$ & $7.0 \mathrm{a}^{\mathrm{B}}$ & $20.0 b^{\mathrm{A}}$ & $6.7 b^{B}$ & $10.3 b^{B}$ & $32.4 b^{\mathrm{A}}$ \\
\hline 1 & $0.5 b^{\mathrm{B}}$ & $0.6 b^{\mathrm{B}}$ & $8.8 \mathrm{a}^{\mathrm{A}}$ & $1.2 \mathrm{c}^{\mathrm{B}}$ & $2.8 \mathrm{~b}^{\mathrm{B}}$ & $24.9 \mathrm{a}^{\mathrm{A}}$ & $5.0 \mathrm{c}^{\mathrm{B}}$ & $8.6 c^{B}$ & $42.0 \mathrm{a}^{\mathrm{A}}$ \\
\hline
\end{tabular}

Within a treatment, values that are followed by the same letter are not significantly different after Tukey-test $(p<0.05)$. Among the treatments, values of one genotype marked with the same capital letter are not significantly different after Tukey-test $(\mathrm{p}<0.05)$.

Therefore, the variation of shoot $\mathrm{P}$ content of the genotypes at $\mathrm{OP}$ and 50P point out that i) differences among the genotypes were due to different ability to acquire $\mathrm{P}$ and ii) the genotypes at $60 \mathrm{DAE}$ were able to adapt to this low P conditions (e.g. due to more root, P inflow) in order to achieve a higher concentration than that at 30 DAE (Table 4.2).

\subsubsection{Root length shoot ratio and the $P$ inflow $\left(I_{n}\right)$}

The amount of $\mathrm{P}$ taken up by a plant will depend on the root size and the $\mathrm{P}$ inflow. At 30 and 60 DAE, the Arachis pintoi $(A p)$ genotypes had all a similar root length at $0 \mathrm{P}$ and differed statistically from Arachis hypogea $(A h)$ (see Appendix). Noteworthy is that the root system of $A h$ at $0 \mathrm{P}$ and at $30 \mathrm{DAE}$ had already developed $81 \%$ of its total root length (90 DAE) contrasting with genotype $10(58 \%), 2(38 \%)$ and $1(30 \%)$. The $A p$ genotypes 1 and 2 enlarged the root system above $70 \%$ at each growth period, while genotype 10 by $40 \%$ at the first growth period and by $20 \%$ in the second one. However, the large root length of genotype 1 at 60 DAE was not able to increase its shoot $\mathrm{P}$ content (Table 4.3) i.e. it was not able to cover the $\mathrm{P}$ demand at this time.

The effect of the root growth on the plant feeding may provide a better understand about the development of adaptation mechanisms under low P availability. As Table 4.4 shows, the root length-shoot ratio (RSR) of the genotypes decreased at each growth stage by increasing P supply, which was mostly pronounced at 1000P in the early growth stage. Moreover, the RSR differed among the genotypes at each $\mathrm{P}$ treatment and with time. 
At $0 \mathrm{P}$ and 30 DAE RSR of $A h$ and genotypes 2 and 10 was 2.3 -fold higher than that at 1000P, whereas the RSR of genotype 1 was 3 -fold higher. Therefore, the variation of this relation may reflect the $\mathrm{P}$ nutritional status of the genotypes. At 60 DAE while the difference of RSR of genotype 1 from 1000P to 0P still increased (3.5-fold), the other genotypes tended to decrease. At 90 DAE the RSR of genotype 1 also decreased. These results would be another sign that at 60 DAE, genotype 1 was still not able to develop efficient adaptation mechanisms for improving $\mathrm{P}$ supply under this low $\mathrm{P}$ conditions but at 90 DAE it came closer. Consequently, differences on $\mathrm{P}$ efficiency among the genotypes recorded at each growth stage were not because the RSR of genotype 1 was lower than that of the others but likely because of differences in their ability taking up $\mathrm{P}$ per unit root and time (P inflow).

Table 4.4 Influence of varying P supply on root length-shoot ratio of three genotypes of Arachis pintoi and one Arachis hypogea $(A h)$ at 30,60 and 90 days after establishment (DAE).

\begin{tabular}{|c|c|c|c|c|c|c|c|c|c|}
\hline \multirow[t]{3}{*}{ Genotype } & \multicolumn{9}{|c|}{ Root-shoot ratio, $\mathrm{m} \mathrm{g}^{-1}$} \\
\hline & \multicolumn{3}{|c|}{$30 \mathrm{DAE}$} & \multicolumn{3}{|c|}{$60 \mathrm{DAE}$} & \multicolumn{3}{|c|}{$90 \mathrm{DAE}$} \\
\hline & $0 \mathrm{P}$ & $50 \mathrm{P}$ & $1000 \mathrm{P}$ & OP & $50 \mathrm{P}$ & $1000 \mathrm{P}$ & $\mathrm{OP}$ & $50 \mathrm{P}$ & $1000 \mathrm{P}$ \\
\hline$A h$ & $91 \mathrm{a}^{\mathrm{A}}$ & $81 \mathrm{a}^{\mathrm{A}}$ & $40 a^{B}$ & $44 b^{A}$ & $29 b^{B}$ & $20 \mathrm{a}^{\mathrm{B}}$ & $23 b^{A}$ & $20 a b^{A B}$ & $15 \mathrm{ab}^{\mathrm{B}}$ \\
\hline 2 & $50 c^{\mathrm{A}}$ & $41 b^{A}$ & $22 b^{B}$ & $35 b^{A}$ & $28 b^{B}$ & $20 \mathrm{a}^{\mathrm{C}}$ & $22 b^{A}$ & $21 a b^{A}$ & $12 b c^{B}$ \\
\hline 10 & $56 b c^{A}$ & $46 b^{\mathrm{A}}$ & $22 b^{B}$ & $35 b^{A}$ & $27 b^{B}$ & $17 \mathrm{a}^{\mathrm{C}}$ & $18 b^{\mathrm{A}}$ & $15 b^{\mathrm{AB}}$ & $11 c^{\mathrm{B}}$ \\
\hline 1 & $72 b^{A}$ & $58 b^{B}$ & $24 a b^{C}$ & $62 a^{A}$ & $56 \mathrm{a}^{\mathrm{A}}$ & $18 \mathrm{a}^{\mathrm{B}}$ & $37 a^{A}$ & $27 \mathrm{a}^{\mathrm{A}}$ & $16 \mathrm{a}^{\mathrm{B}}$ \\
\hline
\end{tabular}

Within a treatment, values that are followed by the same letter are not significantly different after Tukey-test $(p<0.05)$. Among the treatments, values of one genotype marked with the same capital letter are not significantly different after Tukey-test $(\mathrm{p}<0.05)$.

The differences between both Arachis species seem to be related to the different kind of ontogenesis. Arachis hypogea has a defined growth period of 90 to 115 days and in this time the plant needs to develop sequential plant stages such as growth, flowering and pod filling (Figure 4.1) which have different $\mathrm{P}$ demand. On the contrary the growth of Arachis pintoi is perennial i.e. the growth period is undefined and continuously and therefore the growth may be slower than that of defined growth period as it was observed in Figure 4.1.

The $\mathrm{P}$ inflow i.e. the amount of $\mathrm{P}$ taken up per unit root and time, can be a measure of the available $\mathrm{P}$ in the soil for the plant, and at limiting soil $\mathrm{P}$ availability, it can be a measure of the physiological capability of the roots to acquire $\mathrm{P}$ from the soil. Figures 4.3 show the $\mathrm{P}$ inflow in the first (30-60 DAE) and second (60-90 DAE) growth period. 
The treatment 1000P reflects the inflow, which the plants intend to reach i.e. the required $\mathrm{P}$ inflow for maximum growth. In the first growth period (30-60 DAE), Arachis hypogea (Ah) growing under ample $\mathrm{P}$ conditions had the lowest $\mathrm{P}$ inflow because of its large root length shoot ratio (Table 4.3 in the caption). In contrast, the Arachis pintoi $(A p)$ genotypes had a high $\mathrm{P}$ inflow and statistically were superior to $A h$ (Figure 4.3).

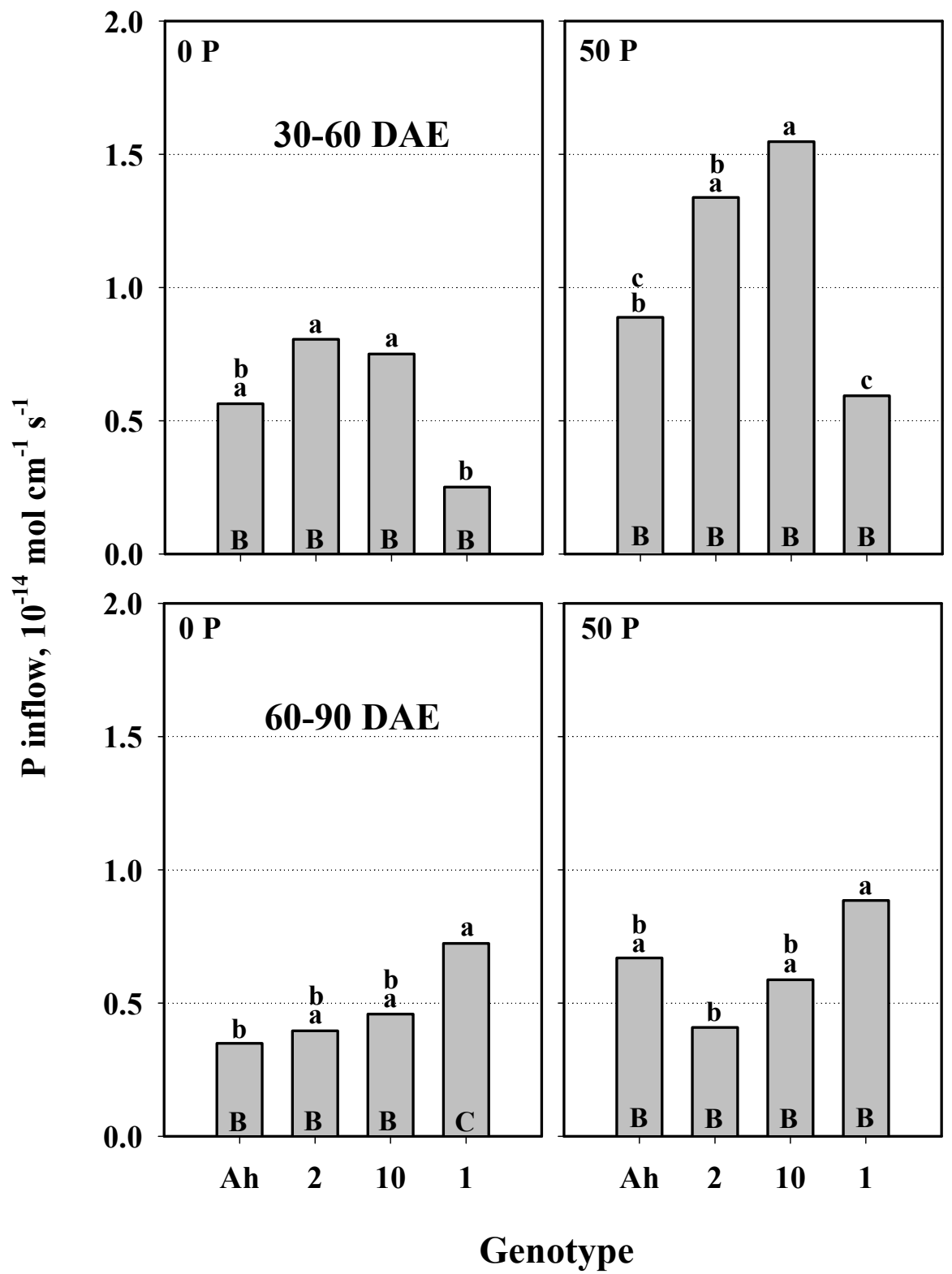

Figure 4.2 Influence of varying P supply on phosphorus inflow of three genotypes of Arachis pintoi and one Arachis hypogea (Ah) between 30-60 and 60-90 days after establishment (DAE). Within a treatment, bars marked with the same letter are not significantly different after Tukeytest $(p<0.05)$. Among the treatments, bars of the same genotype marked with the same capital letter are not significantly different after Tukey-test $(p<0.05)$.

The $\mathrm{P}$ inflow $\left(10^{-14} \mathrm{~mol} \mathrm{~cm}^{-1} \mathrm{~s}^{-1}\right)$ at 1000P between 30-60 DAE and 60-90 DAE were 1.48 and 1.71 for $A h, 3.46$ and 1.62 for genotype 2, 3.00 and 2.18 for genotype 10 and 4.31 and 2.10 for genotype 1 respectively. The $\mathrm{P}$ inflow of the genotypes at $1000 \mathrm{P}$ was statistically superior to $50 \mathrm{P}$ and $0 \mathrm{P}$. 
Despite their small root system, the $\mathrm{P}$ demand was covered likely due to a high $\mathrm{P}$ concentration in the soil solution. In the second growth period (60-90 DAE) while $\mathrm{P}$ inflow of $A h$ was not changed that of $A p$ genotypes decreased, probably because a reduction of its $\mathrm{P}$ demand i.e. its shoot $\mathrm{P}$ concentration decreased from 60 to 90 DAE although $\mathrm{P}$ was not limiting. This high $\mathrm{P}$ inflow at $1000 \mathrm{P}$ was by far not achieved by the genotypes growing under low available $\mathrm{P}$ conditions (OP). In the first growth period the genotypes had only between 6 and $38 \%$ whereas in the second growth period they achieved between 20 and $34 \%$ of the maximum P inflow.

The $A h$ reduced its $\mathrm{P}$ inflow at $0 \mathrm{P}$ but because of its low $\mathrm{P}$ inflow at 1000P the differences were not too large. Taking into account that $A h$ had a high RSR at OP (Table 4.2) and a relative low $\mathrm{P}$ inflow, the reason for the high P efficiency of Arachis hypogea $(A h)$ in the present study seems to be more related to its ability to enlarge the root system. In contrast, Bhadoria et al. (2001), working with the same plant material, conclude that the high P efficiency of $A h$ at early growth stage on the field was mainly due to a high $\mathrm{P}$ inflow, which declined in the following growth stage with a concomitant decrease in P efficiency.

The very low $\mathrm{P}$ inflow of genotype 1 at $0 \mathrm{P}$, which reached only $6 \%$ of the maximum in the first growth period, explained its low $\mathrm{GR}_{\mathrm{s}}$ despite its high RSR (Table 4.4). The inflow of genotypes 2 and 10 was statistically superior to genotype 1 (Figure 4.3) and therefore despite its lower RSR in the first growth period were able to achieve a high $\mathrm{GR}_{\mathrm{s}}$. In chapter 3, the same pattern of $\mathrm{P}$ inflow (see Figure 3.5) and RSR (see Table 3.7) was observed as in the current study.

In the second growth period (60-90 DAE) at OP while the P inflow of genotypes 2 and 10 decreased slightly, genotype 1 increase 2.9-fold its $\mathrm{P}$ inflow and thus changed the $\mathrm{P}$ uptake efficiency in comparison to the first period. Statistically genotype 1 differed only from $A h$. The decrease of $\mathrm{P}$ inflow with time of $A h$ and genotypes 2 and 10 could be because even so they were able to achieve a growth close to maximum. The combination of a relative high root shoot ratio (RSR) with a high P inflow was the reason for the increase by 4.5-fold of the shoot growth rate $\left(\mathrm{GR}_{\mathrm{s}}\right)$ of genotype 1 between the first and second growth period (Table 4.1). The higher $\mathrm{P}$ inflows in this low $\mathrm{P}$ soil are probably only possible by chemical mobilisation by root exudates. This property was already present of $A h$ and $A p$ genotypes 2 and 10 but genotype 1 only developed this mechanism with age i.e. in the second growth period.

\subsubsection{Phosphorus concentration and $\mathrm{pH}$ in the soil solution and the extractable $\mathrm{P}$ in the soil}

Table 4.5 shows the $\mathrm{pH}$ and the $\mathrm{P}$ concentration of the soil solution at each growth stage as affected by the fertilisation and plant growth. The addition of $1000 \mathrm{P}$ increased from the 
beginning (at 30 DAE) remarkably the concentration of $\mathrm{P}$ in the soil solution of planted soils (between 25.7 and $21.7 \mu \mathrm{M}$ ) and at $90 \mathrm{DAE}$ ranged between 14 and $18 \mu \mathrm{M}$. Consequently, the genotypes were grown under ample P conditions explaining the high yield (Figure 4.1), shoot $\mathrm{P}$ concentration (Table 4.2) and P inflow (Figure 4.3) of the genotypes at 1000P.

Table 4.5 Inorganic $\mathrm{P}\left(\mathrm{P}_{\mathrm{i}}\right)$ concentration and $\mathrm{pH}$ in the soil solution at 30,60 and 90 days after establishment (DAE)

\begin{tabular}{|c|c|c|c|c|c|c|}
\hline \multirow[t]{2}{*}{ Genotype } & \multicolumn{3}{|c|}{$\mathrm{pH}$} & \multicolumn{3}{|c|}{$\mathrm{Pi}, \mu \mathrm{M}$} \\
\hline & $0 \mathrm{P}$ & $50 \mathrm{P}$ & $1000 \mathrm{P}$ & $\mathrm{OP}$ & $50 \mathrm{P}$ & $1000 \mathrm{P}$ \\
\hline & \multicolumn{6}{|c|}{$30 \mathrm{DAE}$} \\
\hline$A h$ & $4.9 \mathrm{~b}$ & $4.9 \mathrm{~b}$ & $5.1 b$ & $0.08 \mathrm{a}$ & $0.07 \mathrm{c}$ & $25.7 \mathrm{a}$ \\
\hline 2 & $5.3 \mathrm{a}$ & $5.2 \mathrm{a}$ & $5.3 \mathrm{a}$ & $0.08 \mathrm{a}$ & $0.08 \mathrm{c}$ & $21.7 b$ \\
\hline 10 & $5.2 \mathrm{a}$ & $5.2 \mathrm{a}$ & $5.2 \mathrm{a}$ & $0.08 \mathrm{a}$ & $0.13 \mathrm{ab}$ & $23.5 \mathrm{ab}$ \\
\hline 1 & $5.1 \mathrm{a}$ & $5.1 \mathrm{a}$ & $5.2 \mathrm{a}$ & $0.07 a$ & $0.10 b c$ & $21.9 b$ \\
\hline \multirow[t]{2}{*}{ unplanted } & $5.0 \mathrm{ab}$ & $5.0 \mathrm{~b}$ & $5.1 \mathrm{ab}$ & $0.09 a$ & $0.14 \mathrm{a}$ & $19.0 \mathrm{~b}$ \\
\hline & \multicolumn{6}{|c|}{$60 \mathrm{DAE}$} \\
\hline$A h$ & $4.7 b$ & $4.6 b$ & $4.9 \mathrm{a}$ & $0.09 \mathrm{bc}$ & $0.08 \mathrm{a}$ & $26.0 \mathrm{a}$ \\
\hline 2 & $5.0 \mathrm{a}$ & $4.9 \mathrm{ab}$ & $5.1 \mathrm{a}$ & $0.18 \mathrm{a}$ & $0.12 \mathrm{a}$ & $20.7 b c$ \\
\hline 10 & $5.0 \mathrm{a}$ & $5.0 \mathrm{a}$ & $5.0 \mathrm{a}$ & $0.15 \mathrm{ab}$ & $0.13 \mathrm{a}$ & $24.6 \mathrm{ab}$ \\
\hline 1 & $4.8 \mathrm{ab}$ & $5.0 \mathrm{a}$ & $5.0 \mathrm{a}$ & $0.07 \mathrm{c}$ & $0.06 \mathrm{a}$ & $20.2 c$ \\
\hline \multirow[t]{2}{*}{ unplanted } & $4.9 \mathrm{ab}$ & $4.9 \mathrm{ab}$ & $5.0 \mathrm{a}$ & $0.09 b c$ & $0.10 \mathrm{a}$ & $19.7 d$ \\
\hline & \multicolumn{6}{|c|}{$90 \mathrm{DAE}$} \\
\hline$A h$ & $4.6 \mathrm{c}$ & $4.6 b$ & $4.8 b$ & $0.11 b c$ & $0.36 \mathrm{ab}$ & $18.0 \mathrm{a}$ \\
\hline 2 & $4.7 b c$ & $4.6 \mathrm{~b}$ & $4.9 b$ & $0.59 a$ & $0.51 \mathrm{a}$ & $17.9 \mathrm{a}$ \\
\hline 10 & $4.8 b$ & $4.7 b$ & $4.9 b$ & $0.24 \mathrm{ab}$ & $0.25 b$ & $15.5 b$ \\
\hline 1 & $4.8 b$ & $4.8 b$ & $4.9 b$ & $0.20 \mathrm{~b}$ & $0.22 b$ & $14.0 \mathrm{~b}$ \\
\hline unplanted & $5.0 \mathrm{a}$ & $5.1 \mathrm{a}$ & $5.1 \mathrm{a}$ & $0.08 \mathrm{c}$ & $0.09 \mathrm{c}$ & $18.7 \mathrm{a}$ \\
\hline
\end{tabular}

Within a treatment, values that are followed by the same letter are not significantly different after Tukey-test $(\mathrm{p}<0.05)$. Ah $=$ Arachis hypogea.

The limit of determination (LOD) of $\mathrm{Pi}=0.065 \mu \mathrm{M} \pm 0.016 \mu \mathrm{M}$ (after Eurachem methodology)

In contrast, the soil solution $\mathrm{P}$ concentration was not increased when $50 \mathrm{P}$ was added at $30 \mathrm{DAE}$ in comparison to $0 \mathrm{P}$, which was around $0.1 \mu \mathrm{M}$ for all planted soils. Oxisols and Ultisols, with a moderate to high P "fixation" capacity, required between 110 to $450 \mathrm{mg} \mathrm{P} \mathrm{kg}{ }^{-1}$ soil to obtain 3 $\mu \mathrm{M}$ in equilibrium soil solution in these soils (Le Mare, 1982), a level considered adequate for 
crop growth (Smith and Sanchez, 1982). Between 30 and 60 DAE at OP the P concentration in the soil solution of the genotypes 2 and 10 increased about 1.9 times. In the second growth period (60-90 DAE) the $\mathrm{P}$ concentration in the soil solution increased for all planted soils with Arachis pintoi at $0 \mathrm{P}$ and 50P. Genotypes 2 had the highest increase (3.2-fold at 0P and 4.3-fold at 50P) followed by genotypes 1 (2.8-fold at $\mathrm{OP}$ and 3.7-fold at 50P) and 10 (1.6-fold at $\mathrm{OP}$ and 1.9-fold at 50P). Statistically differences were confirmed among planted soils as well as in comparison to the unplanted soil (Table 4.5). These results would indicate that these genotypes had developed mechanisms to release $\mathrm{P}$ from the solid phase, e.g. by solubilization through root exudates.

The fact that even plant species well adapted to extreme low $\mathrm{P}$ conditions are not able to grow in nutrient solution lower than $0.2 \mu \mathrm{M}\left(\mathrm{C}_{\mathrm{Lmin}}\right)$ due to a low P inflow such as groundnut (Bhadoria et al., 2004), and the cyperaceae Schoenus unispiculatus (Shane et al., 2005), would indicate that the $A p$ genotypes in order to achieve the measured $\mathrm{P}$ inflow must have higher $\mathrm{P}$ concentration at the root surface $\left(\mathrm{C}_{\mathrm{L} 0}\right)$ than those measured in the soil solution without plants $\left(\mathrm{C}_{\mathrm{Li}}\right)$ at each growth stage (Table 4.5).

Ion diffusion to the roots is driven by the concentration gradient. The $\mathrm{P}$ concentration difference $\left(\Delta \mathrm{C}_{\mathrm{L}}\right)$ between the bulk soil $\left(\mathrm{C}_{\mathrm{Li}}\right)$ and the root surface $\left(\mathrm{C}_{\mathrm{L} 0}\right)$ needed to drive a diffusive flux equal to the inflow was calculated after Barraclough, (1986). The calculated $\Delta \mathrm{C}_{\mathrm{L}}$ values for the genotypes were by far greater than the $\mathrm{C}_{\mathrm{Li}}$ of the bulk soil at both growth stage (Table 4.6). This would result in calculated negative values of $\mathrm{C}_{\mathrm{L} 0}$. However, this is physically not possible.

Moreover, the former findings could be proved by the calculation of $\mathrm{C}_{\mathrm{L} 0}$ from the equation $\mathrm{I}_{\mathrm{n}}=$ $\left[\left(\left(\mathrm{I}_{\max } * \mathrm{C}_{\mathrm{L} 0}\right)-\left(\mathrm{I}_{\max } * \mathrm{C}_{\mathrm{Lmin}}\right)\right) /\left(\mathrm{K}_{\mathrm{m}}+\mathrm{C}_{\mathrm{L} 0}-\mathrm{C}_{\mathrm{Lmin}}\right)\right]$. Since the $\mathrm{P}$ uptake kinetics of the Arachis pintoi genotypes have still not been studied, this verification is not possible. But for $A h$ using the P uptake kinetics reported by Bhadoria et al., (2004) for the same $A h$ genotype of this study ( $\mathrm{I}_{\max }$ $\left.=4.8 \times 10^{-14} \mathrm{~mol} \mathrm{~cm}^{-1} \mathrm{~s}^{-1}, \mathrm{C}_{\mathrm{Lmin}}=0.6 \mu \mathrm{M}, \mathrm{K}_{\mathrm{m}}=9 \mu \mathrm{M}\right)$ the $\mathrm{C}_{\mathrm{L} 0}$ for the measured $\mathrm{P}$ inflow in this trial at $0 \mathrm{P}$ between $30-60 \mathrm{DAE}\left(0.56 \times 10^{-14} \mathrm{~mol} \mathrm{~cm}^{-1} \mathrm{~s}^{-1}\right)$ and between 60-90 DAE $\left(0.35 \times 10^{-14}\right.$ mol cm $\mathrm{c}^{-1} \mathrm{~s}^{-1}$ ) was 2.0 and $1.4 \mu \mathrm{M}$ respectively. Taking into account that the effect of root hair and/or $\mathrm{AM}$ hyphae on $\Delta \mathrm{C}_{\mathrm{L}}$ was not considered in the equation of Barraclough (1986), the $\mathrm{P}$ concentration in the bulk soil solution at the root surface $\left(\mathrm{C}_{\mathrm{L} 0}+\Delta \mathrm{C}_{\mathrm{L}}\right)$ should be $4 \mu \mathrm{M}$ between 30-60 DAE and 2.7 $\mu \mathrm{M}$ between 60-90 DAE. Although these high P concentrations were not measured in the soil solution of $A h$ at $0 \mathrm{P}$, an increase was recorded at 50P between 60 and 90 $\mathrm{DAE}$ as it was observed for the Arachis pintoi (Ap) genotype 2 but also at 0P. Assuming root exudates mobilise $\mathrm{P}$, only the $\mathrm{P}$ concentration near to the root surface had to be increased (4 and 
$2.7 \mu \mathrm{M}$ for $A h$ ), but a few millimetres far from the root surface the $\mathrm{P}$ concentration would decrease because the root exudates cannot affect up to this soil far from the root surface. Therefore, the P concentration of planted soils was higher than without plant (Table 4.6). Summarizing, soil solution P concentration of 4 and $2.7 \mu \mathrm{M}$ had to occur at the root surface but this was not measured because only the average (rhizosphere + bulk soil) was determined. Moreover, the genotypes do not need to achieve the maximum gradient for $\mathrm{P}$ transport calculated by Barraclough (1986) but a P concentration within the slope of this maximum gradient.

Table 4.6 The P inflow $\left(\mathrm{I}_{\mathrm{n}}\right)$, the initial $\mathrm{P}$ soil solution concentration of the "bulk soil" $\left(\mathrm{C}_{\mathrm{Li}}\right)$, and the concentration difference in soil solution $\left(\Delta \mathrm{C}_{\mathrm{L}}\right)$ needed between bulk soil and the root surface to drive the flux by diffusion equal to the measured $\mathrm{P}$ inflow of three genotypes of Arachis pintoi and one of Arachis hypogea (Ah) between 30-60 and 60-90 days after establishment (DAE) at 0P

\begin{tabular}{cccc}
\hline Genotype & $\begin{array}{c}\mathrm{I}_{\mathrm{n}} \\
10^{-14} \mathrm{~mol} \mathrm{~cm} \mathrm{~s}^{-1}\end{array}$ & $\begin{array}{c}\mathrm{C}_{\mathrm{Li}} \\
\mu \mathrm{M} \mathrm{P}\end{array}$ & $\begin{array}{c}\Delta \mathrm{C}_{\mathrm{L}} \\
\mu \mathrm{M} \mathrm{P}\end{array}$ \\
\cline { 2 - 4 }$A h$ & $0.56 \mathrm{ab}$ & $0.07 \mathrm{a}$ & $2.0 \mathrm{~b}$ \\
2 & $0.81 \mathrm{a}$ & $0.13 \mathrm{ab}$ & $3.5 \mathrm{ab}$ \\
10 & $0.75 \mathrm{a}$ & $0.12 \mathrm{ab}$ & $3.2 \mathrm{ab}$ \\
1 & $0.25 \mathrm{~b}$ & $0.09 \mathrm{~b}$ & $1.1 \mathrm{a}$ \\
& & & \\
\cline { 2 - 2 }$A h$ & & $60-90 \mathrm{DAE}$ & \\
2 & $0.35 \mathrm{~b}$ & $0.14 \mathrm{a}$ & $1.3 \mathrm{~b}$ \\
10 & $0.40 \mathrm{ab}$ & $0.39 \mathrm{a}$ & $1.6 \mathrm{~b}$ \\
1 & $0.46 \mathrm{ab}$ & $0.20 \mathrm{a}$ & $1.9 \mathrm{~b}$ \\
\hline
\end{tabular}

For calculating $\Delta \mathrm{C}_{\mathrm{L}}$ by Barraclough (1986) the following parameters were used:

$\mathrm{D}_{\mathrm{L}}=8.9 \times 10^{-6} \mathrm{~cm}^{2} \mathrm{~s}^{-1}, \theta=0.44 \mathrm{~cm}^{3} \mathrm{~cm}^{-3}, \mathrm{f}=0.99 \theta-0.17$ and the measured $\mathrm{P}$ inflow (see Figure 4.3). The $\mathrm{C}_{\mathrm{Li}}$ is the average of Pi between the growth periods.

Within a parameter, values that are followed by the same letter are not significantly different after Tukey-test $(\mathrm{p}<0.05)$.

Between 30 and 60 DAE the root radius $\left(r_{0}\right)$ ranged between 1.3 and $1.5 \times 10^{-2} \mathrm{~cm}$, the root length density $\left(R L_{v}\right)$ between 1.9 and $4.3 \mathrm{~cm} \mathrm{~cm}^{-3}$ and the average half distance between neighbouring roots $\left(r_{1}\right)$ between 0.27 and $0.43 \mathrm{~cm}$.

Between 60 and 90 DAE the $\mathrm{r}_{0}$ ranged between 1.2 and $1.3 \times 10^{-2} \mathrm{~cm}$, the $\mathrm{RL}_{\mathrm{v}}$ between 2.9 and $4.8 \mathrm{~cm} \mathrm{~cm}^{-3}$ and $\mathrm{r}_{1}$ between 0.26 and $0.33 \mathrm{~cm}$.

The very low $\mathrm{P}$ concentration measured especially at 30 and 60 DAE, would not necessarily mean that the plant at this age were not able to mobilise $\mathrm{P}$ i.e. the roots had not got exudates at 
the beginning. The $\mathrm{P}$ concentration in the soil solution was measured from a mix of bulk and rhizosphere soil. Taking into account the extreme high P buffer capacity of this Oxisol, likely the $\mathrm{P}$ released into the soil solution of the rhizosphere was adsorbed when diffusing away from the root. The influence of the buffer capacity on the $\mathrm{P}$ sorbed may be related to the ratio between bulk and rhizosphere soil per pot for each genotype as well as to the ability of the root system to release $\mathrm{P}$ bound to the soil solid phase.

After Jones (1998), the zone of soil immediately surrounding the root system, where ions can diffuse to the root or influence by root exudation, vary between 0.2 and $1 \mathrm{~mm}$ and even more than $5 \mathrm{~mm}$. Assuming a distance of $0.75 \mathrm{~mm}$ from the root surface as the zone of soil influenced by the root, the rhizosphere soil (RS) in $\mathrm{g} \mathrm{pot}^{-1}$ can be calculated using the equation:

$$
\mathrm{RS}=\left(\mathrm{V}_{2}-\mathrm{V}_{1}\right) \times \text { bulk density }=\left[\left(\mathrm{r}_{2}^{2} \times \pi \times \mathrm{RL}\right)-\left(\mathrm{r}_{1}^{2} \times \pi \times \mathrm{RL}\right)\right] \times \text { bulk density }
$$

where $r_{1}$ is the root radius $(0.13-0.15 \mathrm{~mm}),, r_{2}$ is the root radius plus the soil distance influenced by the root $(1 \mathrm{~mm})$ and $\mathrm{RL}$ is the total root length per pot and a bulk density of $1.25 \mathrm{~g} \mathrm{~cm}^{-3}$. From $3500 \mathrm{~g}$ of soil per pot, at $30 \mathrm{DAE}$ and at OP the Arachis pintoi genotypes had only between 18 and $24 \%$ as rhizosphere soil, whereas the Arachis hypogea $(A h)$ had $40 \%$. At 90 DAE, the genotypes 1 and 2 had 59\% followed by genotypes 10 (41\%), whereas $A h$ had $67 \%$.

Since the amount of rhizosphere soil affected by exudate i.e. increasing the P concentration, is smaller than the bulk soil, the $\mathrm{P}$ concentration in the soil solution decreased to a value similar to the bulk soil. The increase on the P concentration necessary at the root surface was no measured because only a small portion of soil near to the root surface, likely $1 \mathrm{~mm}$ or less, it would be enough to get a $\mathrm{P}$ transport by diffusion.

The $\mathrm{pH}$ in the soil solution did not vary among the genotypes at each $\mathrm{P}$ treatment, but with time tended slightly to decrease. In this soil with mainly $\mathrm{P}$ bound to $\mathrm{Fe}$ and $\mathrm{Al}$ a decrease of $\mathrm{pH}$ would result in a decreased $\mathrm{P}$ concentration in soil solution as was actually observed in this soil by Hoffmann et al. (1994). Therefore the increase of $P C_{L i}$ in planted soils is not because of the effect of plant on soil $\mathrm{pH}$.

Both, within and among the $\mathrm{P}$ levels at each growth stage the $\mathrm{pH}$ in the soil showed slight changes (Table 4.6), but these were not confirmed statistically in most of the case. However, the $\mathrm{pH}$ decreased in the planted soil with age, especially at 90 DAE as it was also observed in the soil solution (Table 4.5), and hence it was statistically inferior to the unplanted soil.

At $0 \mathrm{P}$, the extractable P was very low by both methods (CAL and Bray II) and statistically equal among the planted soils at each growth stage (Table 4.6), except Bray II at 30 DAE. The 
extractable $\mathrm{P}$ of the unplanted soil tended to be higher than that of the planted soils but was statistically confirmed only by the extractable P-Bray II.

The addition of 50P showed a slight increase in the extractable $\mathrm{P}$ at each growth stage. In contrast, the addition of $1000 \mathrm{P}$ increase the extractable $\mathrm{P}$ at least 20 -fold compared to $0 \mathrm{P}$ at each growth stage and with age.

Table 4.7 Extractable $P$ in the soil at 30, 60 and 90 days after establishment (DAE)

\begin{tabular}{|c|c|c|c|c|c|c|}
\hline \multirow[t]{2}{*}{ Genotype } & \multicolumn{3}{|c|}{ P-CAL, mg kg ${ }^{-1}$} & \multicolumn{3}{|c|}{ P-Bray II mg kg-1 } \\
\hline & OP & $50 \mathrm{P}$ & $1000 \mathrm{P}$ & OP & $50 \mathrm{P}$ & $1000 \mathrm{P}$ \\
\hline & \multicolumn{6}{|c|}{$30 \mathrm{DAE}$} \\
\hline$A h$ & $4.1 \mathrm{a}$ & $4.7 b$ & $93.7 \mathrm{a}$ & $7.1 \mathrm{c}$ & $13.2 \mathrm{a}$ & $240.8 \mathrm{a}$ \\
\hline 2 & $4.1 \mathrm{a}$ & $5.4 \mathrm{a}$ & $96.5 \mathrm{a}$ & $6.9 c$ & $11.8 \mathrm{a}$ & $245.7 \mathrm{a}$ \\
\hline 10 & $4.1 \mathrm{a}$ & $4.7 b$ & $104.8 \mathrm{a}$ & $7.6 \mathrm{bc}$ & $12.2 \mathrm{a}$ & $259.1 \mathrm{a}$ \\
\hline 1 & $4.1 \mathrm{a}$ & $4.6 b$ & $97.7 \mathrm{a}$ & $8.0 \mathrm{~b}$ & $11.7 \mathrm{a}$ & $255.5 \mathrm{a}$ \\
\hline \multirow[t]{2}{*}{ unplanted } & $4.1 \mathrm{a}$ & $5.1 \mathrm{a}$ & $90.2 \mathrm{a}$ & $8.8 \mathrm{a}$ & $13.2 \mathrm{a}$ & $252.7 \mathrm{a}$ \\
\hline & \multicolumn{6}{|c|}{$60 \mathrm{DAE}$} \\
\hline$A h$ & $3.9 \mathrm{a}$ & $4.4 \mathrm{ab}$ & $74.4 b$ & $7.1 \mathrm{~b}$ & $10.9 b$ & $231.1 \mathrm{a}$ \\
\hline 2 & $4.0 \mathrm{a}$ & $3.9 b$ & $92.6 \mathrm{ab}$ & $6.7 b$ & $9.9 b$ & $228.9 a$ \\
\hline 10 & $3.9 \mathrm{a}$ & $4.1 b$ & $95.9 \mathrm{a}$ & $6.8 b$ & $11.2 \mathrm{ab}$ & $255.3 \mathrm{a}$ \\
\hline 1 & $4.0 \mathrm{a}$ & $4.3 \mathrm{ab}$ & $88.6 \mathrm{ab}$ & $6.6 \mathrm{~b}$ & $11.7 \mathrm{ab}$ & $229.1 \mathrm{a}$ \\
\hline \multirow[t]{2}{*}{ unplanted } & $4.0 \mathrm{a}$ & $4.8 \mathrm{a}$ & $74.5 b$ & $8.5 \mathrm{a}$ & $13.3 \mathrm{a}$ & $250.6 \mathrm{a}$ \\
\hline & \multicolumn{6}{|c|}{$90 \mathrm{DAE}$} \\
\hline$A h$ & $3.2 b$ & $3.3 b$ & $71.4 \mathrm{a}$ & $7.6 b$ & $9.6 \mathrm{~b}$ & $217.6 \mathrm{a}$ \\
\hline 2 & $3.3 b$ & $3.4 \mathrm{~b}$ & $67.1 \mathrm{a}$ & $6.8 \mathrm{~b}$ & $9.9 b$ & $232.6 \mathrm{a}$ \\
\hline 10 & $3.2 b$ & $3.8 \mathrm{~b}$ & $71.0 \mathrm{a}$ & $8.0 \mathrm{~b}$ & $9.8 \mathrm{~b}$ & $232.5 \mathrm{a}$ \\
\hline 1 & $3.5 b$ & $3.7 b$ & $68.6 \mathrm{a}$ & $7.4 b$ & $11.0 \mathrm{~b}$ & $223.8 \mathrm{a}$ \\
\hline unplanted & $3.9 \mathrm{a}$ & $5.0 \mathrm{a}$ & $75.2 \mathrm{a}$ & $8.6 \mathrm{a}$ & $12.9 \mathrm{a}$ & $250.7 \mathrm{a}$ \\
\hline
\end{tabular}

Within a treatment, values that are followed by the same letter are not significantly different after Tukey-test $(\mathrm{p}<0.05)$. Ah $=$ Arachis hypogea

Interesting to note that because of plant growth the amount of available P (CAL-P, BrayII-P) decreased (Table 4.7), as might be expected, but $\mathrm{P}$ in soil solution increased (Table 4.5). This shows that plants did not increase the amount of "available P" but they are able to increase its solubility and thereby its availability to the plant. 


\subsection{Conclusions}

The ontogenesis of both Arachis species influenced their ability to grow under low P availability. Arachis hypogea covered the $\mathrm{P}$ demand at scarce $\mathrm{P}$ conditions by a strong enlargement of its root system i.e. high root-shoot ratio (RSR) and an efficient $\mathrm{P}$ uptake per unit root length (P inflow) at the first growth stages.

The ability to grow under scarce P conditions varied among the Arachis pintoi genotypes and changed during their ontogenesis. Genotype 1 was $\mathrm{P}$ inefficient at start because even thought it had similar RSR as the genotypes 2 and 10, it had a P inflow of only $1 / 3$ of that of the others. Later (60-90 DAE) it became P efficient because of a high P inflow. The genotypes 2 and 10 were $\mathrm{P}$ efficient not because of many roots but due to a high $\mathrm{P}$ inflow from the beginning (at $\mathrm{OP}$ and 50P).

Due to this high P inflow, the Arachis pintoi genotypes 2 and 10 achieved a sufficient P status (2 $\mathrm{mg} \mathrm{g}^{-1}$ ) at $60 \mathrm{DAE}$ in order to cover the P demand imposed by the high $\mathrm{GR}_{\mathrm{S}}$. Taking into account the calculated high concentration difference in soil solution $\left(\Delta \mathrm{C}_{\mathrm{L}}\right)$ necessary to achieve the measured P inflow, the Arachis pintoi genotypes must have a higher P concentration at the root surface $\left(\mathrm{C}_{\mathrm{L} 0}\right)$, than those measured in the soil solution without plants $\left(\mathrm{C}_{\mathrm{Li}}\right)$. This suggests that chemical P mobilisation occurred at the root surface. 


\section{Root exudation of organic acids and acid phosphatase of two different $P$ efficient Arachis pintoi genotypes and their influence on $P$ acquisition efficiency}

\subsection{Introduction}

As it was observed in previous chapters, the Arachis pintoi genotypes differed in their abilities to reach optimum yield in soils with low $\mathrm{P}$ availability, which also changed with age of the plant. Differences in $\mathrm{P}$ efficiency were mainly based on varied ability to take up $\mathrm{P}$ from plant unavailable $\mathrm{P}$ in the soil as it was observed for genotypes 2 and 1 (see chapter 4). The P acquisition strategies were i) the enlargement of root surface to feed the plant (root length shoot ratio) through root elongation as well as extraradical network of mycorrhizal hyphae to increase the exploration of soil volume from which $\mathrm{P}$ is taken up, ii) a high $\mathrm{P}$ uptake per unit root and time ( $\mathrm{P}$ inflow) by an increase of soil solution $\mathrm{P}$ concentration at the root surface probably through the exudation of phosphatases to release organically bound soil $\mathrm{P}$ and/or of organic acids and $\mathrm{H}^{+}$to solubilise inorganic P (Marschner, 1995; Uren and Reisenauer, 1988; Raghothama, 1999).

The importance of the enlargement of the root surface in crops (e.g. wheat, maize, thale cress) and grasses (e.g. rye grass and Brachiaria) as well as the release of protons from roots (e.g. rape, bean, white clover) under $\mathrm{P}$ deficient conditions for improving the $\mathrm{P}$ supply of plants is well documented (Römer et al., 1988; Brück et al., 1992; Sattelmacher et al., 1990;. Krannitz et al., 1991; Gahoonia and Nielsen, 1998; Rao et al., 1996; Friesen et al., 1997; Grinsted et al., 1982; Moorby et al., 1988; Trolove et al., 1996; Yan et al., 1996).

Comparative studies have strongly suggested that also the release of organic compounds from plant roots play an important functional role in many plants in response to phosphorus stress. However, the composition of root exudates vary highly depending on plant species and cultivars, nutritional P status, plant age and physiochemical environment (Curl and Truelove, 1986).

Organic bound phosphorus is hydrolyzed by ectoenzymes like root-borne acid phosphatase (APase). The APase secretion to the rhizosphere is usually enhanced under low P availability in many plant species, including maize (Clark, 1975), tomato (Goldstein et al., 1988a, 1988b), lupin, rice and soybean (Tadano et al., 1993). Tarafdar and Jungk (1987) suggested that the activity of APase in the rhizosphere of wheat and clover under P stress led to a depletion of organic phosphates due to hydrolysis and to a release of orthophosphate. Helal, (1990) working with bean and Asmar et al., (1995) with barley reported a positive relation between root APase 
and phosphorus uptake from inositol hexaphosphate. However, McLachlan (1980) found a negative relationship between root APase and phosphorus uptake by wheat under low P stress. A comparative study between white clover genotypes with contrasting $\mathrm{P}$ efficiency did not show significant difference in root surface APase activity (Hunter and McManus, 1999). Therefore, the role of secreted APase in plant adaptation to low phosphorus availability is unclear.

Organic acid (OA) anions released from roots are able to mobilize inorganic phosphate from soil minerals (Nagarajah et al., 1970; Fox and Comerford, 1990; Staunton and Leprince, 1996) by i) the competition for similar $\mathrm{P}$ adsorption sites, where $\mathrm{P}$ is directly replaced by OA on crystalline Al- and Fe-oxides by ligand exchange (Earl et al., 1979; Parfitt, 1979; Gerke, 1992; Hue, 1991; Staunton and Leprince, 1996) and ii) the complexation of metal ions in the exchange matrix holding the $\mathrm{P}$ such as $\mathrm{Fe}^{3+}$ and $\mathrm{Al}^{3+}$ in Fe- and Al-oxides (Zhang et al., 1985; Otani et al., 1996). However, as OA can carry varying negative charges depending on the dissociation properties and number of carboxylic groups, their efficiency to extract $\mathrm{P}$ from iron oxide and clay minerals or to prevent the sorption of new added P, generally decreases in the following order: citrate, oxalate, malate, sulphate and acetate (Nagarajah et al., 1970; Hue, 1991; Jones and Darrah, 1994). Moreover, since root exudates act not only on P-fixed minerals, but also on other ion components without $\mathrm{P}$, a negative effect has also been observed on the $\mathrm{P}$ availability in the soil solution to the plant. For example, Traina et al., (1986) showed that citrate, tartrate and formate can extract metallic ions from mineral surfaces creating new P sorption sites.

It has been demonstrated that some dicots plant roots, in particular legumes, can increase the synthesis of $\mathrm{OA}$ in roots under low $\mathrm{P}$ conditions. They are capable of releasing large amounts of these OA into the rhizosphere (Dinkelaker et al., 1989; Otani et al., 1996; Zhang et al., 1997). However, high concentrations of organic acids $(>100 \mu \mathrm{M}$ for citrate, $>1 \mathrm{mM}$ for oxalate, malate and tartrate) are required to mobilise significant quantities of $\mathrm{P}$ into the soil and its effect is extremely soil-dependent (Earl et al., 1979; Lopez-Hernandez et al., 1986; Jones and Darrah, 1994; Lan et al., 1995). These concentration can be reached in the rhizosphere of proteoid roots (or "cluster" roots) of white lupin (Lupinus albus) and other species with cluster roots (e.g., Banksia), due to high root density in the root cluster and thus a 13-40-fold increase in the citrate and malate excretion of the cluster roots (Dinkelaker et al., 1989; Gardner et al., 1983; Grierson, 1992; Johnson et al., 1996a, 1996b). Compared to the proteoid roots, concentration of $\mathrm{OA}$ in the rhizosphere of non-proteoid roots are much less because of a lower excretion rate and the fast microbial degradation of the organic acids. Therefore, the importance of OA to solubilise fixed P and to increase P availability in the rhizosphere is still unclear (Jones et al., 1996). 
The objective of this study was to examine whether the release of OA and/or the APase activity on the root surface are influenced by $\mathrm{P}$ availability conditions in the soil solution (deficient and sufficient $\mathrm{P}$ supply) and to investigate their effect on the $\mathrm{P}$ acquisition efficiency at different plant age, using as unit measure the $\mathrm{P}$ inflow $\left(\mathrm{mol} \mathrm{cm}^{-1} \mathrm{~s}^{-1}\right)$. In order to reach this goal, the Arachis pintoi genotypes 1 and 2, which differed in their P efficiency (see chapters 3 and 4) were grown under controlled environmental conditions using a split-root design, where half of the roots were in soil and the remaining in sand. This setup allows i) to measure P inflow, APase activity and $\mathrm{pH}$ at the root surface in soil and ii) to gain and assess qualitatively and quantitatively the released root exudates from the sand and soil compartments of the same plant.

\subsection{Materials and Methods}

The plants were grown in a growth chamber with a light/dark regime of 16/8 hours, temperature of $20 / 30{ }^{\circ} \mathrm{C}$ and relative humidity of $70 \%$. The photosynthetic active radiation during the day was $250 \mu \mathrm{E} \mathrm{m}^{-2} \mathrm{~s}^{-1}$.

\section{Plant material and growth conditions}

Genotypes 1 (CIAT 17434) and 2 (CIAT 18744) were chosen due to their different P acquisition attributes in relation to their growth stage, as shown in chapter 4. After raising the seedlings in sand (seen chapter 2), these were pre-cultured in a $\mathrm{P}$ free nutrient solution. Its composition (M) was: $\mathrm{Ca}\left(\mathrm{NO}_{3}\right)_{2} 5.0 \times 10^{-3}, \mathrm{KCl} 5.0 \times 10^{-4}, \mathrm{~K}_{2} \mathrm{SO}_{4} 3.5 \times 10^{-3}, \mathrm{MgSO}_{4} 2.5 \times 10^{-3}, \mathrm{H}_{3} \mathrm{BO}_{3} 5.0 \times 10^{-5}$, $\mathrm{MnSO}_{4} 5.0 \times 10^{-6}, \mathrm{ZnSO}_{4} 2.5 \times 10^{-6}, \mathrm{CuSO}_{4} 1.0 \times 10^{-6},\left(\mathrm{NH}_{4}\right)_{6} \mathrm{Mo}_{7} \mathrm{O}_{24} 5.0 \times 10^{-8}$, and FeEDTA $1.0 \times 10^{-4}$. After 5 days the taproot was excised to develop lateral roots for an additional 15 days until the lateral roots had reached a length of about $5 \mathrm{~cm}$.

Eight seedlings were transplanted into special pots divided in three compartments (Figure 5.1) and placed on the dividing walls with their roots $50 \%$ in soil and $50 \%$ in sand. Each one of the outer compartments was filled with $2 \mathrm{~kg}$ of air dry fossil Oxisol, with the same physical and chemical soil characteristic as described in chapter 2 . The middle compartment was filled with 3 $\mathrm{kg}$ of air dry sand (size 3-5 mm). The $\mathrm{P}$ was removed using $5 \% \mathrm{HCl}$ solution and the acid washed with bi-distilled water until the same $\mathrm{pH}$ as pure bi-distilled water was reached. 

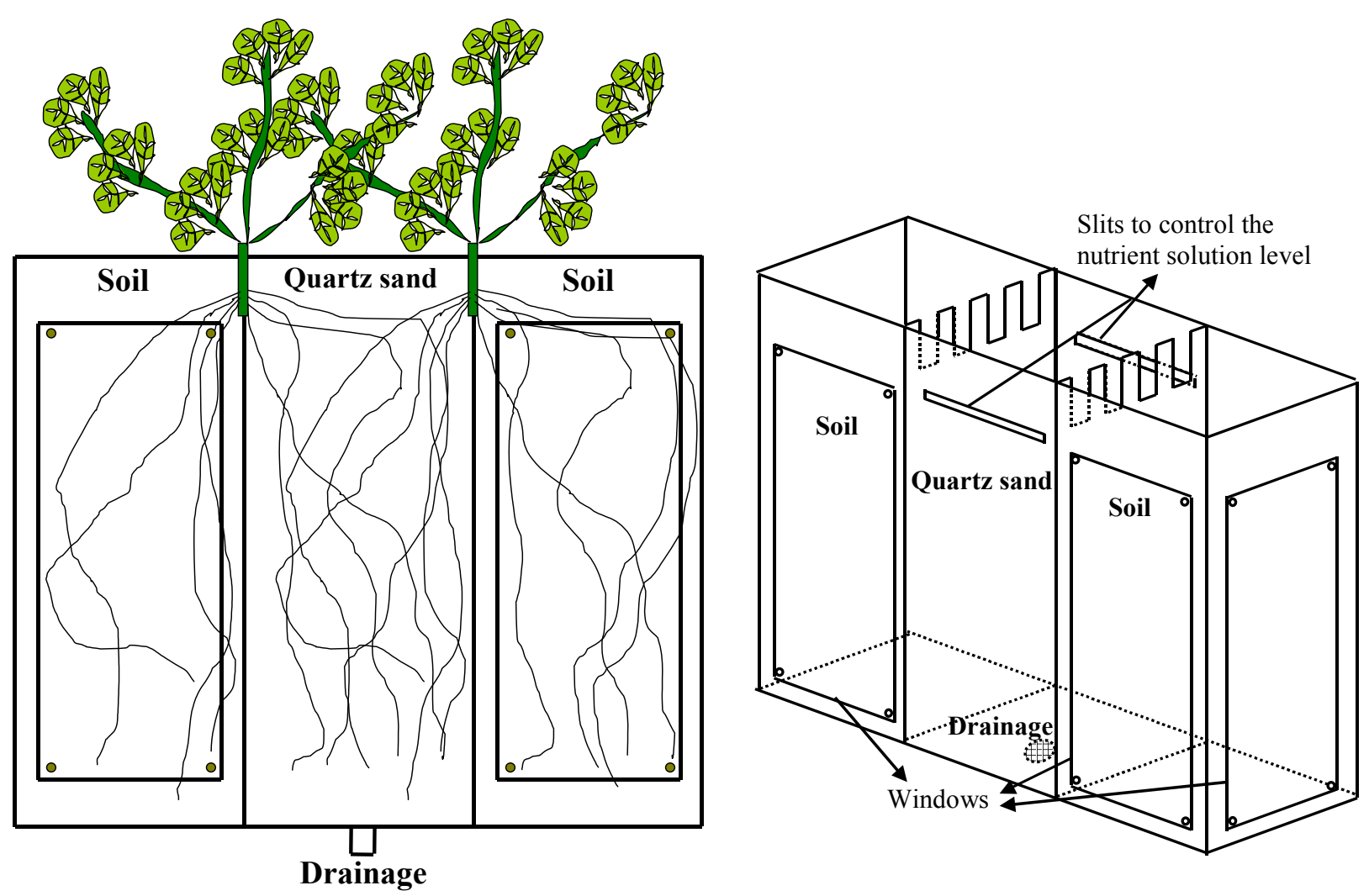

Figure 5.1 Design of the experimental split-root pot developed to allow different morphological and physiological root determination at the same time while the plant is alive.

Two P levels 0 and $1000 \mathrm{mg} \mathrm{kg}^{-1}$ as $\mathrm{Ca}\left(\mathrm{H}_{2} \mathrm{PO}_{4}\right)_{2}$ were applied to the soil compartments. Before transplanting, these fertilization levels resulted in a soil solution $\mathrm{P}$ concentration of $0.13 \mu \mathrm{M}(0 \mathrm{P})$ and $26.9 \mu \mathrm{M}(1000 \mathrm{P})$, respectively.

A basal fertilization was applied as described in chapter 4 . The moisture content of the soil compartments was adjusted to $65 \%$ of the maximum water holding capacity and monitored daily by weight.

The sand compartment was watered three times per day with the same $\mathrm{P}$ free nutrient solution used for the pre-culture afore described. The drainage, located at the bottom of the sand compartment, was kept open to allow the percolation of the nutrient solution warranting the root aeration. One pot from each $\mathrm{P}$ treatment was left unplanted to measure soil moisture evaporation losses and as control of $\mathrm{P}$ dynamic under unplanted conditions. There were four replicates for each treatment. The pot experiment was arranged as described in chapter 4 . 


\section{Measurements and analysis}

Three harvests (30, 60 and 100 day after transplanting - DAT) were performed to enable the calculation of shoot and root growth rates and $\mathrm{P}$ influx. Before harvesting, the following methods were conducted:

\section{Collection of root exudates}

Two methods for collecting root exudates were used:

\section{a. Localized collection using chromatography paper}

After opening the lateral window from each soil compartment (see Figure 5.1), five young roots per each soil compartment were chosen and small sheets of polyethylene foil were placed under the roots. Afterwards, at the root tip segment of $1 \mathrm{~cm}$ in length, two moist filter paper discs were laid on $\left(\varnothing=0.5 \mathrm{~cm}\right.$ with $60 \mu \mathrm{L} \mathrm{cm}{ }^{-2}$ water uptake capacity of Schleicher and Schüll 1992, Dassel, Germany), which had been previously washed with methanol and distilled water. After darkening the windows with aluminium foil to avoid the degradation of root exudates due to light, the collection was carried out in the growth chamber where the plants were grown. The filter paper discs used for the exudation sampling were occasionally remoistened with $10 \mu \mathrm{L}$ of distilled water and after 2 hrs collected in $1.5 \mathrm{~mL}$ Eppendorf reaction vials.

The root exudates collected were extracted by addition of $300 \mu \mathrm{L}$ of distilled water and then shaken on trembler three-times for 30 seconds each time to improve the extraction of carboxylates. The extracted solution was centrifuged at $2000 \mathrm{~g}$ for $10 \mathrm{~min}$. The supernatant was collected by a micropipette and stored at $-20^{\circ} \mathrm{C}$ for analysis of organic acid anions with High Pressure Liquid Chromatography (HPLC).

\section{b. Percolation system}

Prior to collection of root exudates, the sand compartment was thoroughly washed with distilled water until all the nutrient ions had been removed, especially $\mathrm{NO}_{3}$, which disables the accurate determination of organic acid by HPLC. The sand compartment drainage was closed and then filled with bi-distilled water for 1 hour. After that, the leached root exudates were collected in order to avoid $\mathrm{O}_{2}$ stress in the roots and immediately the sand compartment was once again filled with the collected root exudation for another hour. Finally, the collected root exudates were once again added to the sand with a pressure bottle in order to leach as much root exudates from the sand as possible. 
The collected root exudates were lyophilized to concentrate them. Later, the dried root exudates were diluted in $1 \mathrm{~mL}$ bi-distilled water and put into $1.5 \mathrm{~mL}$ Eppendorf reaction vials. Thereafter, they were shaken on a trembler three times (30 seconds each time) to extract the carboxylates. The aliquot was centrifuged at $2000 \mathrm{~g}$ for $10 \mathrm{~min}$. The supernatant was collected with a micropipette and stored at $-20^{\circ} \mathrm{C}$ for analysis of organic acid anions using a HPLC.

\section{Analysis of carboxylates}

The organic acid anions in the root exudate samples were analyzed with a HPLC reversed phase in the ion suppression mode. Separation was conducted on a $250 \times 4 \mathrm{~mm}$ reversed phase column (LiChrospher $100 \mathrm{RP}-18,5 \mu \mathrm{m}$ particle size) equipped with a $4 \times 4 \mathrm{~mm}$ LiChrospher $100 \mathrm{RP}-18$ guard column (Merck, Darmstadt, Germany). Sample solutions $(100 \mu \mathrm{L})$ were injected into the column and an $18 \mathrm{mM} \mathrm{KH}_{2} \mathrm{PO}_{4}$ solution adjusted to $\mathrm{pH} 2.2$ with $\mathrm{H}_{3} \mathrm{PO}_{4}$, for isocratic elution was used, with a flow rate of $0.25 \mathrm{~mL} \mathrm{~min}^{-1}$ at $24^{\circ} \mathrm{C}$ and $\mathrm{UV}$ detection at $210 \mathrm{~nm}$. Identification of organic acids was performed by comparing retention times and absorption spectra with those of known standards.

\section{Determination of root surface acid phosphatase activity (APase)}

Excised segments (2-3 root tips at $1.5-2 \mathrm{~cm}$ from the root tip) were harvested in the soil compartments and transferred to $1.5 \mathrm{~mL}$ Eppendorf reaction vials. The root segments were washed 2 times with distilled water for 5 min to remove contaminating wounded cells, then 0.5 $\mathrm{mL}$ water, $0.4-\mathrm{mL} \mathrm{Na}-\mathrm{Ac}$ buffer and $0.1 \mathrm{~mL} p \mathrm{NPP}$ substrate was added. After a reaction time of $10 \mathrm{~min}$ at $25-30^{\circ} \mathrm{C}$, an aliquot of $0.8 \mathrm{~mL}$ of the reaction medium was taken out and mixed with $0.4 \mathrm{~mL}$ of $0.5 \mathrm{M} \mathrm{NaOH}$ to terminate the reaction. The absorption of reaction solution was measured at $405 \mathrm{~nm}$. The fresh weight of excised segments of root tips was recorded after determination of APase activity.

\section{Quantitative determination of the $\mathrm{pH}$ values on the root surface with the antimony electrode}

In the soil compartments, the $\mathrm{pH}$ values on the root surfaces of young and old roots were measured potentiometrically with an antimony electrode. Before starting the measurement, the electrode was calibrated in $\mathrm{pH}$ buffer solutions and a calibration curve was calculated for the 
potential range of -200 to $-400 \mathrm{mV}$. The potentials were measured with a $\mathrm{pH}$ meter, which is connected to the antimony electrode and to the reference electrode (kalomel-electrode). According to the calibration curve, the potentials measured $(\mathrm{mV})$ were calculated into $\mathrm{pH}$ values.

\section{Shoot sampling}

The plants were harvested by cutting them at soil surface as separate roots and shoot at 30,60 and 100 days after transplanting (DAT) them into the split-root pots. Plant material for chemical analysis was performed as in chapter 2 .

\section{Root sampling and root length}

Root length was separately determined for each compartment using the line intersection method of Tennant (1975). Please refer to chapter 2 for more details.

\section{Phosphorus concentration in plants}

The Phosphorus was measured using the molybdate-vanadium method of Kitson and Mellon (1944). For more details see chapter 2.

\section{Absolute shoot growth rate $\left(\mathrm{GR}_{\mathrm{s}}, \mathrm{g} \mathrm{s}^{-1}\right)$}

It shows the new growth of the plant between two periods. It was calculated as described in chapter 4 .

\section{Phosphorus net inflow $\left(I_{n}\right)$}

The average $\mathrm{P}$ net inflow was calculated as described in chapter 3.

\section{Soil Analysis}

\section{Available phosphorus}

It was determined in the soil using the Bray II extraction (Bray and Kurtz, 1945) and the CAL (calcium acetate lactate) (Schüller, 1969). The soil solution was obtained using the modified column displacement technique (Adams 1974). For more details see chapter 2. 


\subsection{Results}

\subsubsection{Dry shoot matter production and shoot growth rate $\left(G_{R}\right)$}

Figure 5.2 shows the shoot biomass production of genotypes 1 and 2 when grown at $0 \mathrm{P}$ and $1000 \mathrm{P}$ at 30, 60 and 100 days after transplanting (DAT). As it was observed in chapter 4, both genotypes increased statistically significant the yield at $1000 \mathrm{P}$ in comparison to $0 \mathrm{P}$ at each growth stage, but in similar proportion and thus at 1000P no significant statistical differences were found between them at each growth stage. These results confirmed the findings in chapter 4 that both genotypes had a similar growth potential when grown under sufficient P conditions, although in this study the genotypes took P up using only half of their root system.

When not P fertilised (0P), the shoot biomass of genotype 2 was 1.6-fold, 1.8-fold and 4.2-fold higher and statistically superior to that of genotype 1 at 30,60 and 100 DAT, respectively. Despite of the fact that the yield of genotype 2 differed also statistically from genotype 1 at each growth stage in chapter 4 , the strong yield difference at 100 DAT could be in part related to the experimental setup, where after visual observation the growth of genotype 1 was more depressed by the split root system at early growth stage than genotype 2 .

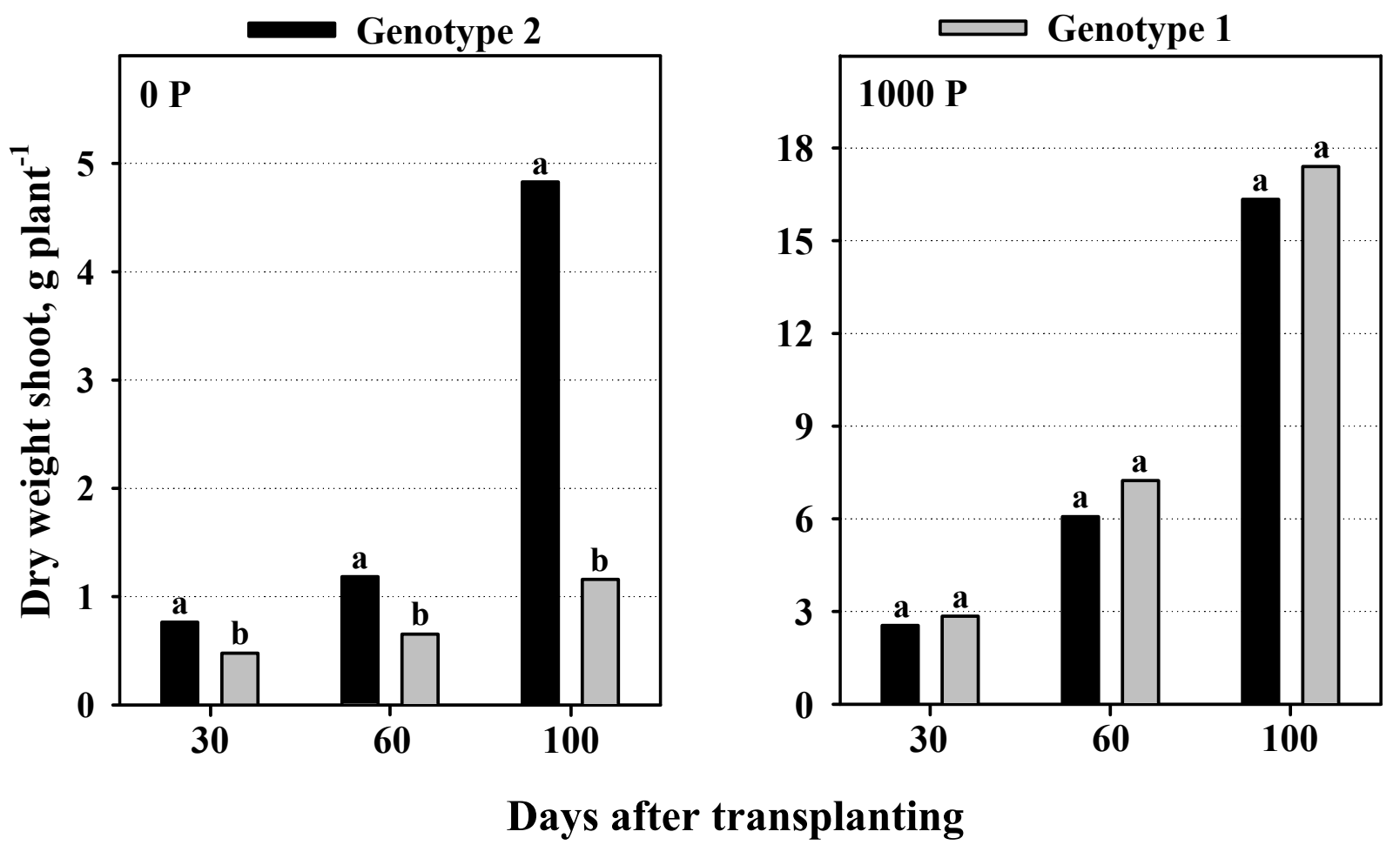

Figure 5.2 Influence of different $\mathrm{P}$ supply on shoot biomass production of two Arachis pintoi genotypes at 30,60 and 100 days after transplanting (DAT). Within a treatment, bars marked with the same letter are not statistically significant according to the Tukey-test $(p<0.05)$. 
The plant's ability to produce quickly or slowly new shoot growth can be a measure of the physiological P requirement during a growth period, as well as of the plant's efficiency to cover the $\mathrm{P}$ demand put on the root system. As Table 5.1 shows, the addition of 1000P increased statistically significant the shoot growth rate $\left(\mathrm{GR}_{\mathrm{s}}\right)$ of both genotypes at both growth periods, but the differences decreased with age. For instance, the $\mathrm{GR}_{\mathrm{s}}$ of the genotypes 1 and 2 at $1000 \mathrm{P}$ was 24-fold and 8.5-fold higher than that at 0P respectively, whereas with age (60-100 DAT) was 20fold and 2.8-fold respectively.

Table 5.1 Influence of different $P$ supply on shoot growth rate, $\left(\mathrm{GR}_{\mathrm{s}}\right)$ of two Arachis pintoi genotypes between 30-60 and 60-100 days after transplantation (DAT).

\begin{tabular}{|c|c|c|c|c|}
\hline \multirow[t]{3}{*}{ Genotype } & \multicolumn{4}{|c|}{ Shoot growth rate, $10^{-7} \mathrm{~g} \mathrm{~s}^{-1}$} \\
\hline & \multicolumn{2}{|c|}{$30-60 \mathrm{DAT}$} & \multicolumn{2}{|c|}{$60-100 \mathrm{DAT}$} \\
\hline & OP & $1000 \mathrm{P}$ & OP & $1000 \mathrm{P}$ \\
\hline 2 & $1.6 \mathrm{a}^{\mathrm{B}}$ & $13.6 b^{A}$ & $10.6 \mathrm{a}^{\mathrm{B}}$ & $29.7 \mathrm{a}^{\mathrm{A}}$ \\
\hline 1 & $0.7 b^{B}$ & $17.0 \mathrm{a}^{\mathrm{A}}$ & $1.5 b^{\mathrm{B}}$ & $29.4 \mathrm{a}^{\mathrm{A}}$ \\
\hline
\end{tabular}

Within a treatment, values that are followed by the same letter are not statistically significant according to the Tukey-test $(\mathrm{p}<0.05)$. Among the treatments, values of one genotype marked with the same capital letter are not significantly different after Tukey-test $(p<0.05)$.

Moreover, at $\mathrm{OP}$ the $\mathrm{GR}_{\mathrm{s}}$ of genotype 2 was statistically superior to genotype 1 at each growth period but the differences increased with time from 2.3-fold to 7.1-fold. The large $\mathrm{GR}_{\mathrm{s}}$ differences between the genotypes could likely be related to the effect of the experimental setup on the growth of genotype 1 at the early growth stages. Moreover, when $\mathrm{GR}_{\mathrm{s}}$ of the genotypes at each growth period is compared, at $0 \mathrm{P}$ the $\mathrm{GR}_{\mathrm{s}}$ increased 2.1-fold and 6.6-fold for genotype 1 and genotype 2, respectively, whereas at 1000P the increase was 1.7-fold for genotype 1 and 2.2fold for genotype 2. Consequently, these results indicate that at $0 \mathrm{P}$ the genotypes differed in their ability to cover the $\mathrm{P}$ demand imposed by the growth at each growth stage i.e. genotype 2 was more $\mathrm{P}$ efficient than genotype 1 .

\subsubsection{Shoot $P$ concentration and $P$ content}

When $\mathrm{P}$ was added, the shoot $\mathrm{P}$ concentration of the genotypes increased in the same proportion above the level considered as sufficient (Rao and Kerridge, 1994) at each growth stage (Table 5.2 ) as it was also observed in chapter 4. For example, on average the P status at 30 DAT was 2.7-fold higher than that considered as sufficient $\left(2 \mathrm{mg} \mathrm{g}^{-1}\right)$ and 1.5-fold at 100 DAT. That 
indicates that both genotypes grown at 1000P had the same growth potential i.e. yield (Figure 5.2) and shoot growth rate (Table 5.1), because they were able to cover totally the P demand.

Table 5.2 Influence of different $\mathrm{P}$ supply on $\mathrm{P}$ concentration in shoot of two Arachis pintoi genotypes at 30, 60 and 100 days after transplanting (DAT).

\begin{tabular}{|c|c|c|c|c|c|c|}
\hline \multirow[t]{3}{*}{ Genotype } & \multicolumn{6}{|c|}{ Shoot $\mathrm{P}$ concentration, $\mathrm{mg} \mathrm{g}^{-1}$} \\
\hline & \multicolumn{2}{|c|}{$30 \mathrm{DAT}$} & \multicolumn{2}{|c|}{$60 \mathrm{DAT}$} & \multicolumn{2}{|c|}{$100 \mathrm{DAT}$} \\
\hline & $0 \mathrm{P}$ & $1000 \mathrm{P}$ & $0 \mathrm{P}$ & $1000 \mathrm{P}$ & $0 \mathrm{P}$ & $1000 \mathrm{P}$ \\
\hline 2 & $1.06 \mathrm{a}^{\mathrm{B}}$ & $5.82 \mathrm{a}^{\mathrm{A}}$ & $1.07 \mathrm{a}^{\mathrm{B}}$ & $4.25 \mathrm{a}^{\mathrm{A}}$ & $1.40 \mathrm{a}^{\mathrm{B}}$ & $2.96 \mathrm{a}^{\mathrm{A}}$ \\
\hline 1 & $0.89 b^{\mathrm{B}}$ & $5.26 \mathrm{a}^{\mathrm{A}}$ & $0.94 b^{\mathrm{B}}$ & $4.43 \mathrm{a}^{\mathrm{A}}$ & $1.32 b^{\mathrm{B}}$ & $2.95 \mathrm{a}^{\mathrm{A}}$ \\
\hline
\end{tabular}

Within a treatment, values that are followed by the same letter are not statistically significant according to the Tukey-test $(p<0.05)$. Among the treatments, values of one genotype marked with the same capital letter are not significantly different after Tukey-test $(p<0.05)$.

At 0P the genotypes had a deficient nutritional $\mathrm{P}$ status $\left(<2 \mathrm{mg} \mathrm{g}^{-1}\right)$ at each growth stage and even thought the shoot $\mathrm{P}$ concentration increased with time (Table 5.2), this was not enough to achieve optimum growth i.e. yield (Figure 5.2) and $\mathrm{GR}_{\mathrm{s}}$ (Table 5.1). However, differences in yield and $\mathrm{GR}_{\mathrm{s}}$ agreed with a higher and statistically superior shoot $\mathrm{P}$ concentration of genotype 2 compared to genotype 1 at each growth stage (Table 5.2). It is interesting to note that with age the shoot $\mathrm{P}$ concentration of genotype 1 increased more than that of genotype 2 . The differences in shoot $\mathrm{P}$ concentration between genotypes 1 and 2 decreased from $20 \%$ at 30 DAT to $6 \%$ at 100 DAT (Table 5.2), indicating that the genotypes achieved with age the same nutritional $\mathrm{P}$ status i.e. genotype 1 improved the P supply with time. Since differences in the ability of both genotypes to produce biomass per mg of total P uptake (shoot + root) i.e. P use efficiency, were small (see Appendix), differences in P efficiency between the genotypes must be related to the ability of the genotypes to take up P from the soil, which can be assessed by the P content in the shoot biomass.

As Table 5.3 shows, the shoot $\mathrm{P}$ content of the genotypes had the same pattern as described for their shoot biomass production at each growth stage (Figure 5.1), due to their relative similar shoot $\mathrm{P}$ concentration (Table 5.2). For example, at OP the shoot $\mathrm{P}$ content of genotype 2 was higher than that of genotype 1 and statistical significant differences were also detected over time. Consequently, these results point out that at 0P genotype 2 was able to acquire over the time a higher percentage of the $\mathrm{P}$ demand required for a maximum growth at both growth periods (e.g. due to the enlargement of the root and/or high $\mathrm{P}$ inflow) than genotype 1, i.e. differences in yield 
between both genotypes occurred because they had different $\mathrm{P}$ acquisition efficiency, as it was also observed in chapters 3 and 4.

Table 5.3 Influence of different P supply on P content in shoot of two Arachis pintoi genotypes at 30, 60 and 100 days after transplanting (DAT).

\begin{tabular}{|c|c|c|c|c|c|c|}
\hline \multirow[t]{3}{*}{ Genotype } & \multicolumn{6}{|c|}{ Shoot $\mathrm{P}$ content, mg plant ${ }^{-1}$} \\
\hline & \multicolumn{2}{|c|}{$30 \mathrm{DAT}$} & \multicolumn{2}{|c|}{$60 \mathrm{DAT}$} & \multicolumn{2}{|c|}{$100 \mathrm{DAT}$} \\
\hline & $0 \mathrm{P}$ & $1000 \mathrm{P}$ & $0 \mathrm{P}$ & $1000 \mathrm{P}$ & $0 \mathrm{P}$ & $1000 \mathrm{P}$ \\
\hline 2 & $0.81 \mathrm{a}^{\mathrm{B}}$ & $14.78 \mathrm{a}^{\mathrm{A}}$ & $1.27 \mathrm{a}^{\mathrm{B}}$ & $25.71 b^{A}$ & $6.77 \mathrm{a}^{\mathrm{B}}$ & $48.28 \mathrm{a}^{\mathrm{A}}$ \\
\hline 1 & $0.43 b^{B}$ & $14.90 \mathrm{a}^{\mathrm{A}}$ & $0.62 b^{B}$ & $32.08 \mathrm{a}^{\mathrm{A}}$ & $1.52 \mathrm{~b}^{\mathrm{B}}$ & $51.33 \mathrm{a}^{\mathrm{A}}$ \\
\hline
\end{tabular}

Within a treatment, values that are followed by the same letter are not statistically significant according to the Tukey-test $(p<0.05)$. Among the treatments, values of one genotype marked with the same capital letter are not significantly different after Tukey-test $(p<0.05)$.

\subsubsection{Root length shoot ratio and $P$ inflow}

The amount of $\mathrm{P}$ taken up by a plant is related to its ability to enlarge the root system (root surface) to exploit larger volumes of soil and/or its ability to regulate the enlargement of the root system in relationship to the shoot production i.e. the root length-shoot ratio (RSR). Since the genotypes were fed only by roots grown in the soil compartment i.e. half of the total root system, the calculation of RSR and P inflow was done using the root length from the soil compartment.

As a response to the large $\mathrm{P}$ addition (1000P), the RSR of both genotypes decreased similarly at each growth stage in comparison to $0 \mathrm{P}$, which was most pronounced with time for genotype 1 (Table 5.4). For example, at 1000P the RSR of genotype 2 was $35 \%$ at 30 DAT and $56 \%$ at 100 DAT lower than that at $0 \mathrm{P}$, whereas the RSR of genotype 1 was $66 \%$ and $80 \%$ respectively.

Table 5.4 Influence of different $\mathrm{P}$ supply on root length shoot ratio of two Arachis pintoi genotypes at 30,60 and 100 days after transplanting (DAT).

\begin{tabular}{|c|c|c|c|c|c|c|}
\hline \multirow[t]{3}{*}{ Genotype } & \multicolumn{6}{|c|}{ Root-shoot ratio, $\mathrm{m} \mathrm{g}^{-1}$} \\
\hline & \multicolumn{2}{|c|}{$30 \mathrm{DAT}$} & \multicolumn{2}{|c|}{$60 \mathrm{DAT}$} & \multicolumn{2}{|c|}{$100 \mathrm{DAT}$} \\
\hline & $0 \mathrm{P}$ & $1000 \mathrm{P}$ & $0 \mathrm{P}$ & $1000 \mathrm{P}$ & $0 \mathrm{P}$ & $1000 \mathrm{P}$ \\
\hline 2 & $35.7 b^{A}$ & $23.2 \mathrm{a}^{\mathrm{B}}$ & $30.6 b^{\mathrm{A}}$ & $10.8 \mathrm{a}^{\mathrm{B}}$ & $13.4 b^{A}$ & $5.9 \mathrm{a}^{\mathrm{B}}$ \\
\hline 1 & $51.9 \mathrm{a}^{\mathrm{A}}$ & $17.8 \mathrm{a}^{\mathrm{B}}$ & $51.7 \mathrm{a}^{\mathrm{A}}$ & $8.1 \mathrm{a}^{\mathrm{B}}$ & $29.5 \mathrm{a}^{\mathrm{A}}$ & $5.9 \mathrm{a}^{\mathrm{B}}$ \\
\hline
\end{tabular}

Within a treatment, values that are followed by the same letter are not statistically significant according to the Tukey-test $(\mathrm{p}<0.05)$. Among the treatments, values of one genotype marked with the same capital letter are not significantly different after Tukey-test $(p<0.05)$. 
That indicates that at 100 DAT genotype 2 but especially genotype 1 were still developing adaptation mechanisms to improve $\mathrm{P}$ uptake under scarce $\mathrm{P}$ availability.

Since the shoot $\mathrm{P}$ content of genotype 2 was higher than that of genotype 1 at each growth stage (Table 5.3), these results indicate that while genotype 2 was from the beginning more efficient in taking up P per unit root length in order to cover the P demand imposed by the growth (Table 5.1), genotype 1 tried to cover this inefficiency by enlarging its root system in the first two growth stages and it seems to be that with age it became more efficient in taking up P per unit root length, explaining its $43 \%$ reduction in the root-shoot ratio.

As the $\mathrm{P}$ inflow is the amount of $\mathrm{P}$ taken up per unit root and time, it is a measure of the ability of root to extract $\mathrm{P}$ from the soil. Figure 5.3 shows the $\mathrm{P}$ inflow in two different growth periods (30-60 and 60-100 DAT), as affected by different P fertilisations.
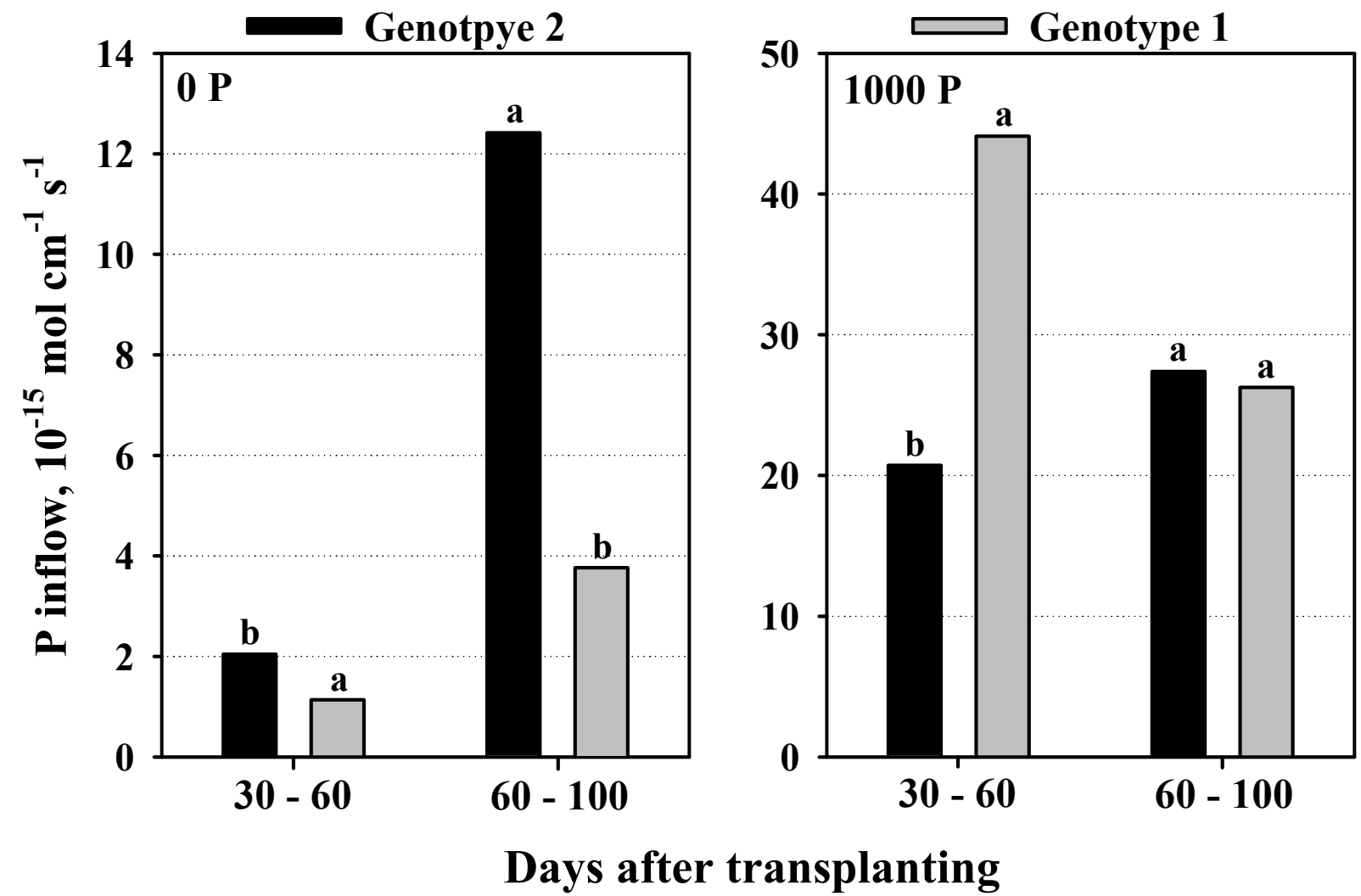

Figure 5.3 Influence of different $\mathrm{P}$ supply on $\mathrm{P}$ inflow of two Arachis pintoi genotypes between 30-60 and 60-100 days after transplanting (DAT). Within a treatment, bars marked with the same letter are not statistically significant according to the Tukey-test $(\mathrm{p}<0.05)$.

In agreement with the shoot growth rate (Table 5.1) and the yield (Figure 5.2), the genotypes differed statistically in its $\mathrm{P}$ inflow at both $\mathrm{P}$ treatments which were remarkably high at $\mathrm{OP}$ at the second growth period (Figure 5.3). 
As it was observed in chapter 4 , at 1000P both genotypes were able to achieve maximum growth i.e. high yield and shoot growth rate $\left(\mathrm{GR}_{\mathrm{s}}\right)$ in both growth periods, in concomitant of a high $\mathrm{P}$ inflow (Figure 5.3). Moreover, the low root length-shoot ratio of both genotypes and their decreasing over time (Table 5.4) signified that the high P demand imposed by the growth had to be covered by an increase of the soil solution P concentration surrounding the root surface as a result of the high $\mathrm{P}$ addition.

At $0 \mathrm{P}$ in the first growth period the genotypes 2 and 1 achieved only $10 \%$ and $2.6 \%$ of the maximum $\mathrm{P}$ inflow respectively. Whereas with time (60-100 DAT), achieved $43 \%$ and 14\% respectively. Furthermore, the $\mathrm{P}$ inflow differed statistically between the genotypes at each growth period and with time in agreement to the $\mathrm{GR}_{\mathrm{s}}$ (Table 5.1). For instance, at $0 \mathrm{P}$ the $\mathrm{P}$ inflow of the $\mathrm{P}$ efficient genotype 2 was 1.8-fold and 3.3-fold higher than that of the $\mathrm{P}$ inefficient genotype 1 in the first and second growth periods, respectively. However, comparing the $\mathrm{P}$ inflow of each genotype between the growth periods, it is interesting to note that although the increase of genotype 2 was 6.6-fold, the inefficient genotype 1 also achieved a relative high increase of 3.3-fold in its $\mathrm{P}$ inflow (Figure 5.3). This increase on P uptake efficiency of single roots of genotype 1 was in agreement with the notable decrease $(43 \%)$ on the root length-shoot ratio showed at $100 \mathrm{DAT}$.

\subsubsection{Phosphorus concentration and $\mathrm{pH}$ in the soil solution and the extractable $\mathrm{P}$ in the soil}

Table 5.5 shows the $\mathrm{pH}$ and the soil solution $\mathrm{P}$ concentration at each growth stage as affected by the fertilisation. Although at $\mathrm{OP}$ and at each growth stage the $\mathrm{pH}$ in the soil solution of planted and unplanted soils did not differ statistically, with time the $\mathrm{pH}$ of planted soils tended to decrease slightly compared to the unplanted (Table 5.5). The addition of $\mathrm{P}$ increased the $\mathrm{pH}$ in the soil solution of planted soil, especially in genotype 2 .

As Table 5.5 also shows, the $\mathrm{P}$ fertilisation increased remarkably the soil solution $\mathrm{P}$ concentration, which at 100 DAT ranged still between 22.9 and $21.1 \mu \mathrm{M}$, allowing the genotypes to achieve their maximum growth at each growth period i.e. maximum yield (Figure 5.2) and shoot growth rate (Table 5.1).

At $0 \mathrm{P}$, the soil solution $\mathrm{P}$ concentration of planted and unplanted was extremely low (about 0.1 $\mu \mathrm{M}$ ) at $30 \mathrm{DAT}$ and increased at $60 \mathrm{DAT}$, but with time (at $100 \mathrm{DAT}$ ) significant statistical differences were found (Table 5.5). Similar results were observed in chapter 4. For instance, differences were observed only from 60 DAT on, where the soil solution P concentration of 
genotype 2 was 1.6-fold and 1.5-fold higher than that of genotype 1 and the unplanted soil, respectively.

Table 5.5 Influence of different $\mathrm{P}$ supply on $\mathrm{P}$ concentration $\left(\mathrm{C}_{\mathrm{Li}}\right)$ and $\mathrm{pH}$ in the soil solution of two Arachis pintoi genotypes at 30,60 and 100 days after transplanting (DAT).

\begin{tabular}{|c|c|c|c|c|}
\hline \multirow[t]{2}{*}{ Genotype } & \multicolumn{2}{|c|}{$\mathrm{pH}$} & \multicolumn{2}{|c|}{$\mathrm{C}_{\mathrm{Li}}, \mu \mathrm{M}$} \\
\hline & OP & $1000 \mathrm{P}$ & $0 \mathrm{P}$ & $1000 \mathrm{P}$ \\
\hline & \multicolumn{4}{|c|}{$30 \mathrm{DAT}$} \\
\hline 2 & $5.3 \mathrm{a}$ & $5.5 \mathrm{a}$ & $0.07 \mathrm{a}$ & $30.9 \mathrm{a}$ \\
\hline 1 & $5.2 \mathrm{a}$ & $5.4 \mathrm{ab}$ & $0.08 \mathrm{a}$ & $28.5 \mathrm{a}$ \\
\hline \multirow[t]{2}{*}{ unplanted } & $5.1 \mathrm{a}$ & $5.2 b$ & $0.07 \mathrm{a}$ & $26.9 a$ \\
\hline & \multicolumn{4}{|c|}{$60 \mathrm{DAT}$} \\
\hline 2 & $5.0 \mathrm{a}$ & $5.4 \mathrm{a}$ & $0.19 \mathrm{a}$ & $29.7 \mathrm{a}$ \\
\hline 1 & $4.9 \mathrm{a}$ & $5.2 \mathrm{ab}$ & $0.12 \mathrm{a}$ & $27.0 \mathrm{a}$ \\
\hline \multirow[t]{2}{*}{ unplanted } & $4.9 \mathrm{a}$ & $5.1 \mathrm{~b}$ & $0.13 a$ & $27.7 \mathrm{a}$ \\
\hline & \multicolumn{4}{|c|}{$100 \mathrm{DAT}$} \\
\hline 2 & $5.0 \mathrm{a}$ & $5.4 \mathrm{a}$ & $0.75 a$ & $22.9 \mathrm{a}$ \\
\hline 1 & $5.1 \mathrm{a}$ & $5.1 b$ & $0.19 b$ & $21.1 b$ \\
\hline unplanted & $5.0 \mathrm{a}$ & $5.0 \mathrm{~b}$ & $0.13 b$ & $27.7 \mathrm{a}$ \\
\hline
\end{tabular}

Within a treatment, values that are followed by the same letter are not statistically significant according to the Tukey-test $(\mathrm{p}<0.05)$.

The determination limit of $\mathrm{Pi}=0.065 \mu \mathrm{M} \pm 0.016$ (after Eurachem methodology)

Nevertheless, the soil solution P concentration did not differed statistically. At 100 DAT, the P concentration of genotype 2 was 3.9-fold and 5.8-fold higher than that of genotype 1 and the unplanted soil, respectively. In comparison to 60 DAT, a remarkable increase of 3.9-fold and 1.6-fold on soil solution $\mathrm{P}$ concentration was recorded for genotype 2 and genotype 1 respectively, which was in agreement with the increase in $\mathrm{P}$ inflow at the second growth period (Figure 5.3). Moreover, the genotypes could only attain the measured $\mathrm{P}$ inflow through a higher $\mathrm{P}$ concentration at the root surface $\left(\mathrm{C}_{\mathrm{L} 0}\right)$ than those measured in the soil solution without plants $\left(\mathrm{C}_{\mathrm{Li}}\right)$ at each growth stage (Table 5.5). Since especially in the second growth period the calculated $\Delta \mathrm{C}_{\mathrm{L}}$ values were much larger than the $\mathrm{C}_{\mathrm{Li}}$ of the bulk soil at both growth stage (Table 5.6), the calculated $\left(C_{L 0}\right)$ values would be negative, which is physically not possible. 
Table 5.6 The $P$ inflow $\left(I_{n}\right)$, the initial $P$ soil solution concentration of the "bulk soil" $\left(C_{L i}\right)$, and the concentration difference in soil solution $\left(\Delta \mathrm{C}_{\mathrm{L}}\right)$ needed between bulk soil and the root surface to drive the flux by diffusion equal to the measured $\mathrm{P}$ inflow of two genotypes of Arachis pinto $i$ between 30-60 and 60-100 days after transplanting (DAT) at 0P

\begin{tabular}{cccc}
\hline Genotype & $\begin{array}{c}\mathrm{I}_{\mathrm{n}} \\
10^{-15} \mathrm{~mol} \mathrm{~cm} \mathrm{~s}^{-1}\end{array}$ & $\begin{array}{c}\mathrm{C}_{\mathrm{Li}} \\
\mu \mathrm{M} \mathrm{P}\end{array}$ & $\begin{array}{c}\Delta \mathrm{C}_{\mathrm{L}} \\
\mu \mathrm{M} \mathrm{P}\end{array}$ \\
\cline { 2 - 4 } 2 & $30-60 \mathrm{DAT}$ & \\
1 & $2.1 \mathrm{a}$ & $0.13 \mathrm{a}$ & $0.9 \mathrm{a}$ \\
& $1.2 \mathrm{~b}$ & $0.10 \mathrm{a}$ & $0.5 \mathrm{~b}$ \\
& & & \\
2 & & $60-90 \mathrm{DAT}$ & \\
1 & $12.4 \mathrm{ab}$ & $0.47 \mathrm{a}$ & $4.6 \mathrm{a}$ \\
\hline
\end{tabular}

For calculating $\Delta \mathrm{C}_{\mathrm{L}}$ by Barraclough (1986) the following parameters were used:

$\mathrm{D}_{\mathrm{L}}=8.9 \times 10^{-6} \mathrm{~cm}^{2} \mathrm{~s}^{-1}, \theta=0.44 \mathrm{~cm}^{3} \mathrm{~cm}^{-3}, \mathrm{f}=0.99 \theta-0.17$ and the measured $\mathrm{P}$ inflow (see Figure 5.3). The $\mathrm{C}_{\mathrm{Li}}$ is the average of $\mathrm{Pi}$ between the growth periods.

Within a parameter, values that are followed by the same letter are not significantly different after Tukey-test $(\mathrm{p}<0.05)$.

Between 30 and 60 DAT for genotypes 1 and 2 the root radius $\left(r_{0}\right)$ was 1.4 and $1.3 \times 10^{-2} \mathrm{~cm}$, the root length density $\left(\mathrm{RL}_{\mathrm{v}}\right) 1.6$ and $1.5 \mathrm{~cm} \mathrm{~cm}^{-3}$ and the average half distance between neighbouring roots $\left(\mathrm{r}_{1}\right) 0.45$ and $0.47 \mathrm{~cm}$ respectively

Between 60 and 100 DAT the $\mathrm{r}_{0}$ was 2.3 and $2.2 \times 10^{-2} \mathrm{~cm}$, the $\mathrm{RL}_{\mathrm{v}} 2.5$ and $1.7 \mathrm{~cm} \mathrm{~cm}^{-3}$ and $\mathrm{r}_{1}$ 0.37 and $0.43 \mathrm{~cm}$.

As it was also observed in chapter 4 , the fact that the measured soil solution $\mathrm{P}$ concentration of genotype 2 increased with time and that the $\Delta \mathrm{C}_{\mathrm{L}}$ needed between bulk soil and the root surface to drive a flux by diffusion equal to the $\mathrm{P}$ inflow measured in the genotype 2 increased also with time, implies that genotype 2 had to have mobilised P from the solid phase e.g. by solubilization of $\mathrm{P}$ through exudation of organic acids and/or acid phosphatase.

Concerning the extractable P (P-CAL and P-Bray II) from the soil, the addition of $1000 \mathrm{~kg} \mathrm{P} \mathrm{kg}^{-1}$ soil, increased markedly the $\mathrm{P}$ availability in comparison to OP (see Appendix). Although statistical differences were found at some growth stages at both $\mathrm{P}$ treatments, at $\mathrm{P}$ differences between the genotypes and the unplanted soil were small. 


\subsubsection{Colonisation grade in roots of native arbuscular mycorrhizae fungi (AMF)}

It is well known that the soil contains native mycorrhizae species which are able to establish a symbiosis with a host plant. As arbuscular mycorrhizae fungae (AMF) was able to improve the $\mathrm{P}$ acquisition abilities of the genotypes growing under P deficient conditions (see chapter 3), the colonisation grade of native AMF was determined. Table 5.7 shows the colonisation grade of the native $\mathrm{AMF}$ as affected by the $\mathrm{P}$ fertilisation. At 1000P a low AMF colonisation in both genotypes was only found at 100 DAT.

Table 5.7 Influence of different $P$ supply on the native arbuscular mycorrhizae fungae (AMF) colonisation of two Arachis pintoi genotypes at 30,60 and 100 days after transplanting (DAT).

\begin{tabular}{|c|c|c|c|c|c|c|}
\hline \multirow[t]{3}{*}{ Genotype } & \multicolumn{6}{|c|}{ Colonisation grade, $\%$} \\
\hline & \multicolumn{2}{|c|}{$30 \mathrm{DAT}$} & \multicolumn{2}{|c|}{$60 \mathrm{DAT}$} & \multicolumn{2}{|c|}{$100 \mathrm{DAT}$} \\
\hline & $0 \mathrm{P}$ & $1000 \mathrm{P}$ & $0 \mathrm{P}$ & $1000 \mathrm{P}$ & $0 \mathrm{P}$ & $1000 \mathrm{P}$ \\
\hline 2 & $<1 \mathrm{a}^{\mathrm{A}}$ & $<1 \mathrm{a}^{\mathrm{A}}$ & $<5 \mathrm{a}^{\mathrm{A}}$ & $<1 \mathrm{a}^{\mathrm{A}}$ & $56 \mathrm{a}^{\mathrm{A}}$ & $12 \mathrm{a}^{\mathrm{B}}$ \\
\hline 1 & $<1 \mathrm{a}^{\mathrm{A}}$ & $<1 \mathrm{a}^{\mathrm{A}}$ & $<5 \mathrm{a}^{\mathrm{A}}$ & $<1 \mathrm{a}^{\mathrm{A}}$ & $25 \mathrm{~b}^{\mathrm{A}}$ & $5 \mathrm{a}^{\mathrm{B}}$ \\
\hline
\end{tabular}

Within a treatment, values that are followed by the same letter are not statistically significant according to the Tukey-test $(\mathrm{p}<0.05)$. Among the treatments, values of one genotype marked with the same capital letter are not significantly different after Tukey-test $(p<0.05)$.

At $0 \mathrm{P}$ at $60 \mathrm{DAT}$ the genotypes had a low and similar colonisation, which increased 11-fold for genotype 2 and only 5-fold for genotype 1 (Table 5.7). Therefore, the colonisation grade of genotype 2 was 2.2-fold higher than that of genotype 1 and this difference was statistically confirmed.

\subsubsection{Acid phosphatase activity (APase) and pH on the root surface}

Figure 5.4 displays the enzymatic activity of the acid phosphatase (APase) and the $\mathrm{pH}$ on the surface of young roots as affected by the $\mathrm{P}$ fertilisation. At each growth stage and at both $\mathrm{P}$ treatments, the APase activity of the inefficient genotype 1 was higher than that of the $\mathrm{P}$ efficient genotype 2 and these differences were statistically significant (Figure 5.4). However, the APase activity of the genotypes was negatively affected by the $\mathrm{P}$ fertilisation and with age, the difference between the genotypes had an inverse trend. For example, at $0 \mathrm{P}$ the differences between the genotypes increased with time from 1.1-fold at 30 DAT to 1.9-fold at 100 DAT, whereas at 1000P decreased from 1.3-fold to 1.1-fold respectively. 

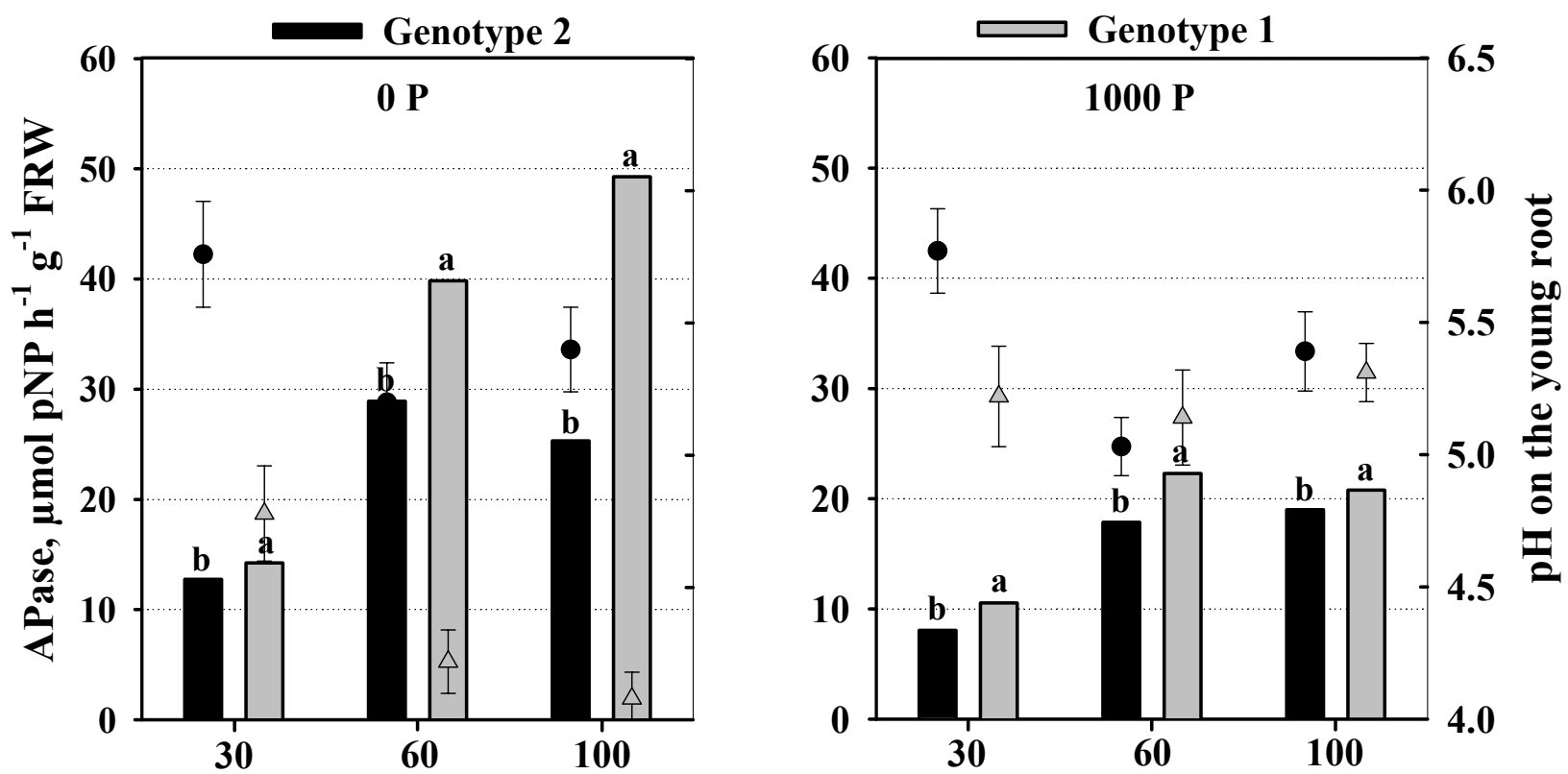

Days after transplanting

Figure 5.4 Influence of different $\mathrm{P}$ supply on acid phosphatase activity (bars) of fresh root weight (FRW) and pH-value (symbols) on the root surface of two Arachis pintoi genotypes at 30, 60 and 100 days after transplanting (DAT). Within a treatment, bars marked with the same letter are not statistically significant according to the Tukey-test $(\mathrm{p}<0.05)$.

At $\mathrm{OP}$ at each growth stage, changes in the $\mathrm{pH}$ on the surface of young roots of both genotypes were inversely related to the changes in the APase activity (Figure 5.4). This relation was most pronounced at the early growth period. For instance, a decrease of $13 \%$ and $10 \%$ on the $\mathrm{pH}$ of genotypes 1 and 2 was related to an increase of 2.8-fold and 2.3-fold on the APase activity respectively. Whereas, between 60 and 100 DAT a low decrease (3\%) on the $\mathrm{pH}$ of genotype 1 was related to an increase of 1.2-fold on the APase activity and the slight increase (4\%) on the $\mathrm{pH}$ of genotype 2 was related to a decrease of $12 \%$ on its APase activity.

\subsubsection{Root exudation of organic acids}

The exudation of organic acids (OA) was determined separately from the roots grown in soil (localized collection by chromatography paper) and from the roots grown in sand (collection by percolation system) using the split root system.

From the OA used as standard (Acetic, c-aconitic, Citric, Formic, Fumaric, Lactic, Malic, Malonic, Oxalic, Succinic, t-aconitic, Tartaric), the roots grown in soil exuded only traces of malic, citric and fumaric at both $\mathrm{P}$ treatments. However, in the roots grown in sand, lactic and 
acetic acids were the main carboxylates detected and traces of citric, malonic, malic, formic, fumaric, c-aconitic and t-aconitic acid were found. Since at each growth stage the exudation rate of both acids were extremely low when P was added (1000P) and did not differ statistically, Figure 5.5 shows the exudation rate at each growth stage of lactic and acetic acids from the proportion of roots grown in sand at $0 \mathrm{P}$.

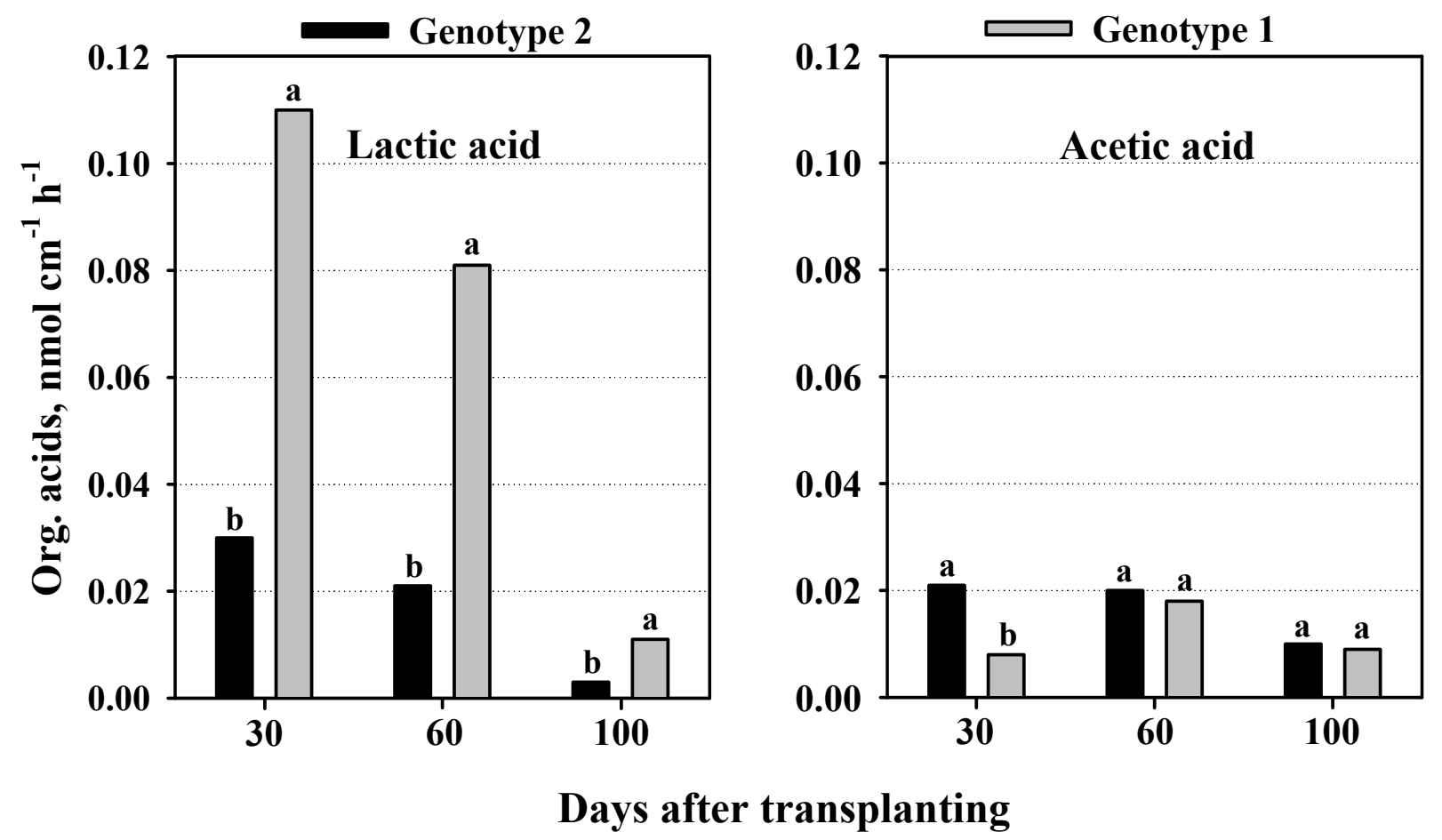

Figure 5.5 Root exudation rate of lactic acid and acetic acid of two Arachis pintoi genotypes at 30, 60 and 100 days after transplanting (DAT) grown at 0P. Within a treatment, bars of the same acid marked with the same letter are not statistically significant according to the Tukey-test $(\mathrm{p}<0.05)$.

At $1000 \mathrm{P}$ the minimum and maximum exudation rate among the growth stages of lactic acid was 0.004 and $0.023 \mathrm{nmol} \mathrm{cm}^{-1} \mathrm{~h}^{-1}$ and of acetic acid was 0.002 and $0.015 \mathrm{nmol} \mathrm{cm}^{-1} \mathrm{~h}^{-1}$.

The root exudation rate $\left(\mathrm{nmol} \mathrm{cm} \mathrm{ch}^{-1}\right)$ of both acids was very low. Although the exudation rate of lactic acid of genotype 1 was statistically superior to genotype 2 at each growth stage, with time decreased remarkable from 0.11 (30 DAT) to 0.01 (100 DAT). The root exudation of acetic acid was even lower in both genotypes than that of lactic acid. The maximum exudation rate of acetic acid (0.02) at each growth stage was achieved by genotype 2. Since the genotypes were not $\mathrm{P}$ efficient at the early growth period, but increased it with time, these results of root exudation rate were not related to the increase on the $\mathrm{P}$ efficiency of the genotypes. 


\subsection{General Discussion}

Widespread adoption of forage cultivars depends on their ability to efficiently acquire nutrients from the soil and using them for growth. This is influenced by their genetic potential, and the environments in which they are grown. From both of them, genetic differences within a species in their ability to absorb, translocate, distribute, accumulate, and use phosphorus are important traits in the process of adapting plants to acid soils that are naturally deficient in P.

This low $\mathrm{P}$ availability is not because of low total $\mathrm{P}$ content but because $\mathrm{P}$ is strongly bound to $\mathrm{Fe}$ and $\mathrm{Al}$ or to $\mathrm{Ca}$ and therefore the $\mathrm{P}$ concentration in soil solution $\left(\mathrm{C}_{\mathrm{Li}}\right)$ is very low, mostly below $1 \mu \mathrm{M}$. At this low $\mathrm{P}$ concentration transport to and uptake into roots is restricted.

It is known that the forage legume Arachis pintoi ( $A p)$, native of the Amazon region, grows well on highly weathered low P soils in comparison to other forage legumes such as Stylosanthes capitata and Centrosema acutifolium (Rao et al., 1996).

The use of a fossil Oxisol and an Ultisol, which had an extremely low soil solution $\mathrm{P}_{\mathrm{i}}$ concentration i.e. $\mathrm{C}_{\mathrm{Li}}$ around $0.2 \mu \mathrm{M}$ (see Figure 2.10, Table 3.2, 4.5 and 5.5), revealed different responses among ten promising Arachis pintoi genotypes, in relation to their ability to produce shoot biomass as observed in chapters 2 and 3. These marked yield differences, which changed with age, were linked more to their capacity to absorb $\mathrm{P}$ rather than to their use of $\mathrm{P}$.

The objective of this study was to investigate the reasons behind the different $\mathrm{P}$ efficiencies of Arachis pintoi genotypes, and mainly whether native AM infection, organic acid root exudates or APase activity could explain the $\mathrm{P}$ efficiency of $A p$.

Based on the previous results, two genotypes with contrasting $\mathrm{P}$ efficiency, that furthermore underwent changes with age, were used and assessed at different growth stages.

At limited P supply, the efficient genotype 2 outyielded the P inefficient genotype 1 by 1.6 -fold, 1.8-fold and 4.2-fold at 30,60 and 100 DAT respectively (Figure 5.2). Based on the selection criteria assumed in this study that $\mathrm{P}$ efficient genotypes are those capable of producing a high yield under low P availability, genotype 2 was more P efficient than genotype 1 at each growth stage (Figure 5.2) and the difference statistically confirmed, as it was also observed in chapters 2 (see figure 2.4), 3 (see Figure 3.1 and 3.2) and 4 (see Figure 4.1).

Differences in P efficiency among genotypes can be related to differences in growth potential. Dinkelaker (1990) reported that P efficiency differences among nine chickpea genotypes were not because of specific adaptation mechanisms to low $\mathrm{P}$ availability, but rely on unspecific differences in growth potential. 
However, this was not the case between genotypes 1 and 2 . Since when both genotypes were grown under ample soil solution P concentrations i.e. $31 \mu \mathrm{M}$ at $30 \mathrm{DAT}$ and $21 \mu \mathrm{M}$ at $100 \mathrm{DAT}$ (Table 5.5), both grew equally well and the differences were not statistically significant at each growth stage (Figure 5.2). Similar results were recorded not only for genotypes 1 and 2 in chapters 2, (see Figure 2.4) and 4 (see Figure 4.1) but also for genotypes 4 and 10.

Besides the absolute differences in $\mathrm{P}$ efficiency at $0 \mathrm{P}$, the genotypes differed in their ability to achieve their maximum growth. In agreement with the results of chapter 4, at 1000P at each growth stage the yield of both genotypes was statistically superior to that at $0 \mathrm{P}$ (Figure 5.2). However, at $0 \mathrm{P}$ at 100 DAT genotype 2 was able to achieve $30 \%$ of its maximum growth while genotype 1 only $10 \%$. Although the genotypes displayed in chapter 4 the same pattern, at 90 days after establishment (DAE), both genotypes achieved a higher percentage of their maximum growth i.e. genotype $270 \%$ and genotype $145 \%$. This large yield difference could be related to differences in the experimental setup, where after visual observation the growth of both genotypes was depressed by the split root system. Moreover, this negative effect was more severe for genotype 1 during the early growth stages, but it overcame it with time.

To which extent the effect of age on the differences in P efficiency of both genotypes affected their growth was observed through their shoot growth rate $\left(\mathrm{GR}_{\mathrm{s}}\right)$. At $0 \mathrm{P}$ genotype 2 had much faster growing shoots at both growth periods (2.3 and 4 times) than genotype 1 (Table 5.1), which was reflected in their yield. Although both genotypes were not able to achieve their maximum $\mathrm{GR}_{\mathrm{s}}$ (at 1000P), the fact that differences in $\mathrm{GR}_{\mathrm{s}}$ of genotype 2 between both $\mathrm{P}$ levels (0P and 1000P) decreased from 8.5 (30-60 DAT) to 2.8 times (60-100 DAT) whereas genotype 1 from 24 to 20 times respectively (Table 5.1), indicate that genotype 2 was more efficient than genotype 1 in covering the $\mathrm{P}$ demand imposed by the growth.

In natural ecosystems, with low availability of nitrogen and phosphorus, species mainly adjust by decreasing growth rate, because this answers best to the aim of species survival in sub-optimal conditions (Chapin, 1980)

A similar trend was observed in chapter 4 (see Table 4.1), and the effect of age on the P efficiency was even more evident. At low $\mathrm{P}$ conditions, the $\mathrm{GR}_{\mathrm{s}}$ of genotype 2 was 2.4 and 1.4 times higher than that of genotype 1 at both growth periods. However, genotypes 1 and 2 attained $24 \%$ and $48 \%$ of their maximum $\mathrm{GR}_{\mathrm{S}}(1000 \mathrm{P})$ in the first growth period, whereas in the second one 61 and $89 \%$ respectively, and thereby the $\mathrm{GR}_{\mathrm{s}}$ of genotype 2 at $0 \mathrm{P}$ was statistically similar to that at 1000P. Although genotype 1 had still not achieved its maximum GRs in the 
second growth period, the remarkable increase of its GRs at 0P, (4.2-fold) between both growth periods, is noteworthy.

Consequently, at $0 \mathrm{P}$ the genotypes were $\mathrm{P}$ deficient in the early growth stages and with time improved their P efficiency in different proportions. Furthermore, these results mean that yield differences between the genotypes grown in a soil solution $\mathrm{P}$ concentration close to $0.2 \mu \mathrm{M}$ (Table 5.5), which is the $\mathrm{C}_{\mathrm{Lmin}}$ found for Arachis hypogea (Bhadoria et al., 2004), occured because the genotypes differed markedly in their P efficiency with age (Figure 5.2).

The high yield and $\mathrm{GR}_{\mathrm{s}}$ of both genotypes grown under ample $\mathrm{P}$ conditions were because of their high nutritional P status in the shoot, which at each growth stage was at least 2-fold higher than that reported as sufficient in the leaves $\left(2 \mathrm{mg} \mathrm{g}^{-1}\right)$ by Rao and Kerridge, (1994) (see Table 4.1 and Table 5.2). This signified that the genotypes growing under ample $\mathrm{P}$ conditions were able to cover totally the $\mathrm{P}$ demand imposed by the plant growth potential.

On the contrary, differences in yield and $\mathrm{GR}_{\mathrm{s}}$ in both growth periods under limited $\mathrm{P}$ conditions were closely related to the shoot $\mathrm{P}$ concentration. Although both genotypes grown in the split root system had a deficient nutritional $\mathrm{P}$ status $\left(<2 \mathrm{mg} \mathrm{g}^{-1}\right)$, over time (Table 5.2), statistical significant differences found between the genotypes explained their low yield and growth.

However, the fact that in spite of the increase with time, at 90 DAE genotype 1 had still a deficient nutritional $\mathrm{P}$ status $\left(1.4 \mathrm{mg} \mathrm{g}^{-1}\right)$ and that already at 60 DAE genotype 2 attained a sufficient nutritional $\mathrm{P}$ status $\left(2 \mathrm{mg} \mathrm{g}^{-1}\right.$ ) (see Table 4.2), explained why genotype 2 at $0 \mathrm{P}$ achieved the maximum $\mathrm{GR}_{\mathrm{s}}$ while genotype 1 had still not done so (see Table 4.1). A similar behavior as described for genotype 2 was also recorded for genotype 10 . This indicates that the growth in the second growth period (60-90 DAE) of genotypes 2 and 10 was already optimum. This could not be recognized by the total biomass (Figure 4.1) because of the stunted growth in the first growth stages.

Genotypical differences in $\mathrm{P}$ efficiency could be due to differences in the ability to acquire $\mathrm{P}$ from the soil or/and to use P for the production of yield within plants (Marschner, 1995). The inverse of the nutritional $\mathrm{P}$ status of the genotypes reflects the ability to produce biomass per mg of total P uptake i.e. the P use efficiency. Therefore, the relative small differences found in shoot $\mathrm{P}$ concentration at $\mathrm{OP}$ between the genotypes (see Figure 2.5, Tables 3.4, 4.2, 5.2), indicate that differences in $\mathrm{P}$ efficiency between the genotypes were because of differences in the ability of the genotypes to take up P from the soil, which was reflected in the statistical significant differences found in shoot $\mathrm{P}$ content at different growth stages (see Figure 2.7, Tables 3.5, 4.3, 5.3). Furthermore, none of the genotypes showed a combination of high $\mathrm{P}$ acquisition efficiency 
and low shoot $\mathrm{P}$ concentration. This combination would further improve $\mathrm{P}$ efficiency, i.e., external P requirement would be reduced (Föhse et al., 1988).

Therefore, the variation of shoot $\mathrm{P}$ content of the genotypes at $\mathrm{OP}$ points out that the genotypes with age were able to adapt to this low $\mathrm{P}$ conditions (e.g. due to more roots, $\mathrm{P}$ inflow) in order to overcome the deficient nutritional P status undergone at the early growth stages.

The amount of $\mathrm{P}$ taken up by a plant depends on the size of the root and the P inflow: i) the enlargement of the root system, i.e. larger root surface to exploit the P in larger volumes of soil, ii) the increase of the root length-shoot ratio (RSR), i.e. the effect of root growth on plant feeding, and iii) the $\mathrm{P}$ uptake rate per unit root length ( $\mathrm{P}$ inflow) have been identified as the adaptive attributes of plant species as well as genotypes within a specie when grown under $\mathrm{P}$ deficient conditions (Marschner, 1995; Jungk and Claassen, 1997; Trolove et al., 2003).

Numerous reports have clearly demonstrated the beneficial effects of the ability of plants to adapt their morphological root characteristics to $\mathrm{P}$ acquisition, when soils deficient in available $\mathrm{P}$ limit plant growth (Jungk, 2001; Egle et al., 1999; Marchner, 1995, Sattelmacher et a., 1994). For instance, spinach enlarged more its root length and had a higher root hair density than that of bean, wheat and oilseed rape (Föhse et al., 1991). The tolerance to low-P conditions in maize cultivars relied on an increase of the root length (Gaume, 2000). Differences in P efficiency between two cabbage varieties (Eticha and Schenk, 2001) and among white clover genotypes was based on the root hair length (Caradus, 1983), whereas among bush beans was due to an above-mean RSR and a good root growth (Whiteaker, et al. 1976; Gabelman, et al. 1986).

However, the root length developed by the Arachis pintoi genotypes and their RSR could not explain the differences in shoot $\mathrm{P}$ content i.e. the $\mathrm{P}$ acquisition efficiency. Under low $\mathrm{P}$ conditions, the root system of genotypes 1 and 2 evolved similarly at different growth stages and therefore statistical significant differences were not found (see Appendix chapters 2, 4 and 5). Moreover, the root length-shoot ratio of the $\mathrm{P}$ efficient genotype 2 was statistically inferior to that of genotype 1 at each growth stage (Table 5.4). Similar results in root length-shoot ratio were also observed in the previous chapters as well as in other genotypes differing in the $\mathrm{P}$ efficiency such as genotypes 10 and 8 (see Figure 2.8, Tables 3.7 and 4.4).

Consequently, since only the inefficient genotype 1 responded through allocation of more carbon to roots as strategy for $\mathrm{P}$ acquisition under low $\mathrm{P}$ conditions, the efficient genotype 2 must cover the high $\mathrm{P}$ demand imposed by its high shoot growth rate through a high $\mathrm{P}$ inflow as was also confirmed in this study. 
Differences in shoot $\mathrm{P}$ content between both genotypes under low P conditions (Table 5.3) were mainly because of the notable differences, statistically significant, in the $\mathrm{P}$ inflow at each growth stage (Figure 5.3) in commitment with the shoot growth rate $\left(\mathrm{GR}_{\mathrm{s}}\right)$ (Table 5.1). The $\mathrm{P}$ inflow of the P efficient genotype 2 was 1.8-fold and 3.3-fold higher than that of the P inefficient genotype 1 in the first and second growth periods, respectively. Similarly Bhadoria et al. (2001) found that older maize plants were more P efficient because their P inflow increased by a factor of around five with respect to younger plants.

Moreover, comparing the $\mathrm{P}$ inflow of each genotype between the growth periods, it is interesting to note that although the $\mathrm{P}$ inflow increase of genotype 2 was 6.6-fold, the inefficient genotype 1 also achieved a relative high increase of 3.3-fold in its $\mathrm{P}$ inflow (Figure 5.3). This increase in $\mathrm{P}$ acquisition efficiency of single roots of genotype 1, was in agreement with the notable decrease (43\%) of the root length-shoot ratio showed at 100 DAT (Table 5.4). Differences in P inflow with time between both genotypes were also the explanation for differences in shoot $\mathrm{P}$ content when grown in other environments (see Figures 2.9, 3.3 and 4.2). A similar relation was observed in genotype 10 i.e. high shoot $\mathrm{P}$ content was the result of a high $\mathrm{P}$ inflow.

Phosphorus acquisition efficiency in oilseed rape and spinach (Föhse et al., 1988) and in groundnut (Bhadoria et al., 2001) relied on a high P uptake per unit root and time (P inflow). In tomatoes, $\mathrm{P}$ efficient genotypes resulted from high root length and high $\mathrm{P}$ inflow (Coltman et al. 1985; Gabelman et al. 1986).

The inflow per unit root length depends on the concentration of the ions on the root surface and on root properties (Jungk and Claassen, 1997). The symbiosis with mycorrhizae is important for $P$ supply to forage grasses and legumes in tropical Oxisols (Arias et al., 1991; Sieverding, 1991). Mycorrhizal hyphae, which with approximately $3 \mu \mathrm{m}$ in diameter are about 10 times thinner than fine roots and therefore have more surface per unit of assimilation, act as extensions of the root to take up P (Marschner and Dell, 1994) and thus could increase the P inflow (mol cm${ }^{-1}$ root s$^{-1}$ ). Various mechanisms have been suggested for the increase in the uptake of P by mycorrhizal plants: i) exploration of a larger soil volume by increasing the surface area of absorption through the external hyphae network (Sanders and Tinker, 1973; Tinker, 1978), ii) faster movement of $\mathrm{P}$ into mycorrhizal hyphae by increasing the affinity for P ions (Cress et al., 1979; Howeler et al., 1982), iii) solubilization of soil $\mathrm{P}$ achieved by the release of organic acids and phosphatases. (Gianinazzi - Pearson and Gianinazzi, 1978; Parfitt, 1979; Moawad, 1986; Vielhauer, 1992). 
Baon et al. (1994) working with rye genotypes, and Caradus (1995) with white clover genotypes, reported that genotypes with short root hairs were more dependent on root-mycorrhizal association for growth in a P-deficient soil than genotypes with long root hairs.

In the current study, a low native AMF infection $(<5 \%)$ was only found at 60 DAT under low P conditions. With time, genotype 2 had a grade of infection of $56 \%$, which was 2.2 -fold higher than that of genotype 1 (Table 5.7). This stronger increase of AMF at 90 DAT could be related to the remarkable increase of $\mathrm{P}$ inflow in the second growth period. But since differences in $\mathrm{P}$ efficiency already were evident before 60 days, AM could not be, at least is not the only explanation for differences in $\mathrm{P}$ efficiency. Moreover, at $0 \mathrm{P}$ and at 90 DAT the $\mathrm{P}$ inflow of genotypes 2, 1 and 10 was not increased (see Figure 3.3), when grown in symbiosis with an AMF colonization grade of 22, 18 and $19 \%$ respectively (see Table 3.3).

Taking into account that i) under non fertilised conditions ( $(\mathrm{P})$ the soil solution $\mathrm{P}$ concentration $\left(\mathrm{C}_{\mathrm{Li}}\right)$ measured in the fossil Oxisol and Ultisol was close to the $\mathrm{C}_{\mathrm{Lmin}}$ value found for Arachis hypogea $(0.2 \mu \mathrm{M})$ (Bhadoria et al., 2004), ii) the measured soil solution $\mathrm{P}$ concentration of genotype 2 increased with time (see Figure 2.10, Tables 4.5 and 5.5) and iii) the $\Delta \mathrm{C}_{\mathrm{L}}$ needed between bulk soil and the root surface to drive a flux by diffusion equal to the $\mathrm{P}$ inflow measured in genotype 2 increased also with time (see Tables 4.6 and 5.6), the high P inflow of genotype 2 had to be because of an increase of the soil solution $\mathrm{P}$ concentration in the zone of soil immediately surrounding the root system through the mobilisation of P from the solid phase e.g. by solubilization of $\mathrm{P}$ through exudation of organic acids and/or acid phosphatase.

Several authors have reported that plant roots respond to $\mathrm{P}$ deficiency through enhanced exudation of constituents (organic acids, acid phosphatases) that increase $\mathrm{P}$ availability (Dinkelaker et al., 1989; Duff et al., 1991; Tadano and Sakai, 1991; Johnson et al., 1994, 1996a; Gilbert et al., 1998; Gilbert et al., 1999; Neumann and Römheld, 1999).

Plants secrete acid phosphatases (APases) into the apoplastic space, which may be important for obtaining $\mathrm{P}_{\mathrm{i}}$ from organic $\mathrm{P}\left(\mathrm{P}_{\mathrm{o}}\right)$ sources by the hydrolysis of organic P-ester-forms into inorganic-P $\left(\mathrm{P}_{\mathrm{i}}\right)$ (Tarafdar and Chhonkar, 1978).

The APase secretion to the rhizosphere is usually enhanced under low $\mathrm{P}$ availability in many plant species, including maize (Clark, 1975, Gaume, 2000), tomato (Goldstein et al., 1988a, 1988b), lupin, rice and soybean (Tadano et al., 1993). However, the relative importance of these enzymes for plant $\mathrm{P}$ nutrition is yet to be determined i.e. it is unclear how high the APase activity has to be in relation to the amount of $\mathrm{P}_{\mathrm{o}}$ in the vicinity of the root, in order to be significant to the plant's $\mathrm{P}$ nutrition under extremely low $\mathrm{P}$ availability. 
Tarafdar and Jungk (1987) suggested that the activity of APase in the rhizosphere of wheat and clover under $\mathrm{P}$ stress led to a depletion of $\mathrm{P}_{\mathrm{o}}$ due to hydrolysis and to a release of orthophosphate. Helal, (1990) working with bean and Asmar et al., (1995) with barley reported a positive relation between root APase and phosphorus uptake from inositol hexaphosphate. Tomscha et al., (2004) demonstrated that the root-associated APase pool is increased in Arabidopsis when $\mathrm{P}_{\mathrm{i}}$ is limited and documented five APase isoforms secreted from Arabidopsis roots. Plants grown in solution culture mobilize a variety of $\mathrm{P}_{\mathrm{o}}$ substrates to fulfill their complete $\mathrm{P}$ nutritional requirements when deprived of $\mathrm{P}_{\mathrm{i}}$, so plant-derived phosphohydrolases have the capacity to provide for P growth demands (Richardson et al., 2001; Abel et al., 2002).

However, McLachlan (1980) found a negative relationship between root APase and phosphorus uptake by wheat under low P stress. A comparative study between white clover genotypes with contrasting $\mathrm{P}$ efficiency did not show significant difference in root surface APase activity (Hunter and McManus, 1999).

In the present study, at 0P in the first growth period (30-60 DAT) both genotypes increased in different proportions the APase activity, but in the second growth period (60-100 DAT) only the inefficient genotype 1 increased its APase activity (Figure 5.4). This indicates that this property was not responsible for the higher $\mathrm{P}$ inflow nor for the increased $\mathrm{P}$ inflow with age in genotype 2. In contrast, the remarkable increase (3.5-fold) of the APase activity of genotype 1 with time (30-100 DAT) could be in part responsible for the increase (3.3-fold) of its P inflow between both growth periods (Figure 5.3).

Moreover, even though the fossil Oxisol had extremely low organic matter $(0.3 \%)$, this relation could be plausible if it is considered the high $\mathrm{P}$ fixing capacity and high buffering capacity of inorganic $\mathrm{P}\left(\mathrm{P}_{\mathrm{i}}\right)$, as compared to $\mathrm{P}_{\mathrm{o}}$ (Tarafdar and Claassen, 2003), which resulted in a negligible change in $\mathrm{Pi}$ concentration due to fertilization $\left(50 \mathrm{mg} \mathrm{P} \mathrm{kg}^{-1}\right.$ soil) after equilibrium in soil solution (see Table 4.5).

While microbes secrete phosphatases that liberate $P_{i}$ for plants, they also compete with plants for that resource. Mycorrhizal fungi are also a significant source of soil phosphatases, and they can be major providers of $\mathrm{P}_{\mathrm{i}}$ to plants when available $\mathrm{P}$ is limited (Miyasaka and Habte, 2001).

However, Tarafdar and Claassen (2003), assessing the role of $\mathrm{P}_{\mathrm{o}}$ in soil solution in the nutrition of wheat under sterile conditions, concluded that the higher yields by wheat in the $\mathrm{P}_{\mathrm{i}}+\mathrm{P}_{\mathrm{o}}$ than in the $\mathrm{P}_{\mathrm{i}}$ treatment depends on the higher $\mathrm{P}$ uptake due to the higher APase activity found in $\mathrm{P}_{\mathrm{o}}$ treatments, which was 5-11 times higher than in the respective $\mathrm{P}_{\mathrm{i}}$ treatments. Therefore, they 
hypothesized that plants secrete phosphatases in response to the presence of $\mathrm{P}_{\mathrm{o}}$ in soil solution and $\mathrm{P}_{\mathrm{o}}$ might be responsible for the increase in $\mathrm{P}$ inflow to wheat.

Moreover, Rao et al., (1999) reported that genotype 1 was able to acquire $\mathrm{P}$ from different sources applied to an Oxisol, where $\mathrm{Ca}-\mathrm{P}=100 \%$, was $43 \%$ for Al-P 20, 33\% for organic-P, and $54 \%$ for dung-P. The high amount of $\mathrm{P}$ acquired from organic-P was associated with a higher activity of the enzyme phosphatase in the roots.

The other well documented factor, which is capable of increasing the soil solution $\mathrm{P}$ concentration, is the exudation of organic acids (OA). It has been demonstrated that some dicots plant roots, in particular legumes, can increase the synthesis of OA in roots under low $\mathrm{P}$ conditions. They are capable of releasing large amounts of these OA into the rhizosphere (Dinkelaker et al., 1989; Otani et al., 1996; Zhang et al., 1997). However, these high concentrations of organic acids needed $(>100 \mu \mathrm{M}$ for citrate, $>1 \mathrm{mM}$ for oxalate, malate and tartrate) to mobilise significant quantities of $\mathrm{P}$ into the soil can be reached in the rhizosphere proteoid roots (or "cluster" roots) and other species with cluster roots (e.g., Banksia), due to high root density in the root cluster and thus a 13-40-fold increase in the citrate and malate excretion of the cluster roots (Dinkelaker et al., 1989; Gardner et al., 1983; Grierson, 1992; Johnson et al., 1996a, 1996b). Compared to the proteoid roots, concentration of OA in the rhizosphere of non-proteoid roots is much less because of a lower excretion rate and the fast microbial degradation of the organic acids. Therefore, the importance of OA to solubilise fixed P and to increase P availability in the rhizosphere is still unclear (Jones et al., 1996).

Several plant species such as tomato, sugar beet, chickpea, oilseed rape and alfalfa, increase the exudation rate of citric acid when grown under low P conditions (Imas et al., 1997; Beissner, 1995, Ohwaki and Hirata, 1990; Hoffland et al., 1989; Lipton et al., 1989). P-deficient potato, radish and oilseed rape increased the exudation rate of succinate acid. However, differences between maize genotypes in the organic acids content of roots and phloem were not related to their low-P tolerance (Gaume, 2000).

Two methods were used in order to assess whether the exudation of organic acids explained the different $\mathrm{P}$ inflow between both genotypes and the changes with time. The exudation of organic acids (OA) was determined separately from the roots grown in soil (localized collection by chromatography paper) and from the roots grown in sand (collection by percolation system) using the split root system. 
From the standard used for the detection, only traces of malic, citric and fumaric acids were found at both $\mathrm{P}$ treatments in the chromatography paper put on the roots grown in soil. Taking into consideration factors such as dilution, time and the sensitivity of the HPLC used for the determination, this results indicate that the exudation rate of citric, malic and fumaric acids was lower than $0.078,0.112$ and $0.001 \mathrm{nmol} \mathrm{cm}^{-1} \mathrm{~h}^{-1}$ respectively.

Moreover, the portion of roots grown in sand exuded only measurable amounts of lactic and acetic acid, while only traces of citric, malonic, malic, formic, fumaric, c-aconitic and t-aconitic acid were found. Oxalic, tartaric and succinic acid were not detected.

The root exudation rate $\left(\mathrm{nmol} \mathrm{cm}^{-1} \mathrm{~h}^{-1}\right)$ of both acids was very low and decreased with time (Figure 5.5). The lactic acid of genotype 1 decreased remarkably from 0.11 (30 DAT) to 0.01 (100 DAT). The exudation rate of acetic acid was even lower in both genotypes than that of lactic acid $(<0.02)$. Moreover, exudation of lactic acid has been also related to microbial activity (Gransee, 2002)

From a collaborative project where root exudates were also collected using chromatography paper, similar results were found in both genotypes grown in nutrition solution without P. Malic and citric acids were the main carboxylates detected in exudates from tip roots but the exudation rates were low i.e. at $0 \mathrm{P}$ and after 38 days of sowing, the exudation rate of malic and citric acids was 0.49 and $0.22 \mathrm{nmol} \mathrm{cm} \mathrm{h}^{-1}$ for genotype 1 and 0.11 and $0.05 \mathrm{nmol} \mathrm{cm} \mathrm{h}^{-1} 1$ for genotype 2 . (G. Neumann, personal communication).

It is noteworthy that the exudation rates detected were extremely low in comparison to many other plant species (Neumann and Römheld, 2002) and that the efficiency of lactic and acetic acids to extract $\mathrm{P}$ from iron oxide and clay minerals or to prevent the sorption of new added $\mathrm{P}$ is one of the lowest because their dissociation properties and number of carboxylic groups are also the lowest (Nagarajah et al., 1970; Hue, 1991; Jones and Darrah, 1994).

Otani et al. (1996) also found for Arachis hypogea that OA would not explain its P efficiency and in a later paper Ae and Otani (1997) proposed cell wall components as related to the P efficiency of plants. However, this relationship is not very conclusive yet.

Consequently, these results indicate that adaptation mechanisms as organic acids and acid phosphatase, well known as responsible for improving $\mathrm{P}$ efficiency in several plants species grown under low $\mathrm{P}$ conditions, were neither responsible for the high $\mathrm{P}$ inflow recorded by genotype 2 at each growth stage nor for the improvement of the $\mathrm{P}$ efficiency observed in genotype 1 with age. Therefore, the Arachis pintoi had other mechanism to adapt to low P supply 
that were not studied in this research, such as the cell wall components, or other still not known ways to acquire P from low P available sources. 


\section{Summary}

In natural tropical ecosystems, $\mathrm{P}$ availability is often too low for optimal plant growth due to their highly weathered soils with strong P buffer capacity. This fact has induced the development of $\mathrm{P}$ efficient plants i.e. plants with the ability to grow well at low $\mathrm{P}$ availability. However, differences in $\mathrm{P}$ efficiency occur between species and cultivars.

The main purpose of the study was to assess Arachis pintoi (Ap) genotypes in relation to their $\mathrm{P}$ efficiency and to investigate the reasons behind their different $\mathrm{P}$ efficiencies i.e. the morphological and physiological root characteristics. For this, ten Ap genotypes were investigated, which did not differ in their growth potential as was observed by growing them at a high $\mathrm{P}$ supply of $1000 \mathrm{mg} \mathrm{P} \mathrm{kg}^{-1}$ but differed in their growth at low $\mathrm{P}$ supply.

To assess $\mathrm{P}$ efficiency mechanisms, the $A p$ genotypes were grown in field, greenhouse and growth chamber experiments. A fossil Oxisol and an Ultisol were used, which had an extremely low soil solution $\mathrm{P}$ concentration i.e. $\mathrm{C}_{\mathrm{Li}}$ about $0.2 \mu \mathrm{M}$.

Shoot and root biomass production and $\mathrm{P}$ concentration as well as root length data were obtained in batches to calculate the $\mathrm{P}$ inflow. The effect of the symbiosis with arbuscular mycorrhiza fungi (AMF) on the $\mathrm{P}$ use efficiency, in relation to the acid phosphatase activity (APase) in the leaf, and on the $\mathrm{P}$ acquisition efficiency i.e. $\mathrm{P}$ inflow, was assessed. To investigate physiological root properties affecting $\mathrm{P}$ acquisition efficiency at different age, APase activity on the root surface and root exudation of organic acids was studied by growing plants in a split root system (soil and sand) with and without $\mathrm{P}$ supply.

As classification criteria in this study, $\mathrm{P}$ efficient genotypes were those capable of producing a high yield under low P conditions compared to the average yield of all genotypes. Ranking the genotypes according their efficiency, genotypes 2 (CIAT 18748), 10 (CIAT 22172), 1 (CIAT 17434) and 6 (CIAT 18751) were rated as P efficient, the genotypes 8 (CIAT 22159) and 9 (CIAT 22160) as average $\mathrm{P}$ efficient and the genotypes 3 (CIAT 18745), 4 (CIAT 18747), 5 (CIAT 18748) and 7 (CIAT 22155) as P inefficient. These differences in P efficiency among the genotypes disappeared by the symbiosis with arbuscular mycorrhiza fungi (AMF) (Glomus fasciculatum), which influenced both total $\mathrm{P}$ uptake and use efficiency.

Differences in P efficiency among the genotypes were due to different morphological and physiological root characteristics, as summarised below:

1. Genotype 6 (CIAT 18751) can be highlighted because of its high P use efficiency (PUE) which was complemented by an average ability to acquire $\mathrm{P}$ per unit root and time (P inflow) and 
a relative high root length-shoot ratio (RSR). The high PUE of genotype 6 was related to a relative high APase activity in the leaves and thus compensated its low ability to acquire $\mathrm{P}$ per unit root and time (P inflow).

Arbuscular mycorrhiza fungi increased remarkably the $\mathrm{P}$ inflow (genotype 6), which was reflected in a high yield.

2. The high P efficiency of genotypes 2 (CIAT 18744) and 10 (CIAT 22172) was because of a higher P inflow when compared with the other genotypes. This high inflow was due to an increase in the soil solution $\mathrm{P}$ concentration i.e. the genotypes were able to mobilise P. However, this mobilisation activity could not be linked to root exudation of APase for hydrolyzing organic $\mathrm{P}$ or organic acids.

The P efficiency of genotype 1 (CIAT 17434) resulted from a high RSR at the first growth period and the improvement with time of its $\mathrm{P}$ inflow, which was related to a remarkable increase of the APase activity on the root surface with age.

The AMF enhanced the root growth of the genotypes but not their P inflow.

3. Although genotypes 8 (CIAT 22159) and 9 (CIAT 22160) were rated as average P efficient, their high RSR, allowing them to explore a larger soil volume and an average P inflow, were responsible for their growth under scarce $\mathrm{P}$ availability in the soil. The remarkable high shoot biomass of genotype 8 with AMF was due to an increase on the PUE.

4. The low P efficiency of genotypes 3 (CIAT 18745), 4 (CIAT 18747), 5 (CIAT 18748) and 7 (CIAT 22155) was because of a relative low RSR with a low P inflow and relative low PUE, which in genotypes 4 and 7 was related to low APase activity in the leaves.

The genotypes overcame their P inefficiency by AMF, which increased the P inflow and thus the P demand imposed by the shoot growth rate was covered.

These results show different mechanisms influencing the P efficiency of the genotypes. Among them, the ability to increase the soil solution $\mathrm{P}$ concentration was the most effective and therefore indicates that the $\mathrm{P}$ efficient genotypes are capable to mobilise $\mathrm{P}$. Although the mechanism by which sparingly soluble inorganic $\mathrm{P}$ was solubilized remains unidentified, in further screening and investigation this P mobilisation strategy should be considered. 


\section{References}

Abdou, M. 1989. Genotypische Unterscheide in der Phosphateffizienz von Sommerweizen. Ph.D. Thesis. University of Hohenheim, Stuttgart, Germany.

Abel, S., C.A. Ticconi and C.A. Delatorre. 2002. Phosphate sensing in higher plants. Physiologia Plantarum 115, 1-8.

Abott, L.K. and A.D. Robson. 1982. The role of vesicular-arbuscular mycorrhizal fungi in agriculture and the selection of fungi for inoculation. Australian Journal of Agriculture Research 33, 389-408.

Adu-Gyamfi, J.J., K. Fujika, S. Ogata. 1989. Phosphorus absorption and utilization efficiency of pigeon pea (Cajanus cajan L. Millsp.) in relation to dry matter production, and dinitrogen fixation. Plant and Soil 119, 315-324.

Adu-Gyamfi, J.J., K. Fujita and S. Ogata. 1990. Phosphorus fractions in relation to growth in pigeon pea (Cajanus cajan L. Millsp.) at various levels of P supply. Soil Science and Plant Nutrition 36, 531-543.

Ae, N., J. Arihara, K. Okada, T. Yoshihara and C. Johansen. 1996. Phosphorus uptake by pigeonpea and its role in cropping systems of the Indian subcontinent. Science 248, 477480.

Ae, N., K. Okada, T. Yoshihara, and C. Johansen. 1990. Phosphorus uptake by pigeon pea and its role in cropping systems of the Indian subcontinent. Science 248, 477-480.

Ae, N., R. Shen and T. Otani. 2001. The significance of the root cell wall in phosphorus uptake. In: N. Ae., J. Arihara, K. Okada, A. Srinivasan eds. Plant Nutrient Acquisition. Tokyo: New perspectives, Springer-Verlag, pp 251-275.

Ae, N., T. Otani and J. Tazawa. 1996. Role of cell wall of groundnut roots in solubilizing sparingly soluble phosphorus in soil. Plant and Soil 186, 197-204.

Allen, M.F., J.T.S. Moore and M. Christensen. 1980. Phytohormone changes in Bouteloua gracilis infected by arbuscular-vesicular mycorrhizae: I. Cytokinin increases in the host plant. Canadian Journal of Botany 58, 371-374.

Anghinoni, I and S.A. Barber. 1980. Phosphorus application rate and soil distribution and uptake by corn. Soil Science Society of American Journal 44, 1041-1044.

Arias, I., I. Koomen, J.C. Dodd, R.P. White and D.S. Hayman. 1991. Growth-responses of mycorrhizal and nonmycorrhizal tropical forage species to different levels of soil phosphate. Plant and Soil 132, 253-260.

Arvidsson, J. 1999. Nutrient uptake and growth of barley as affected by soil compaction. Plant and Soil 208, 9-19.

Asher, C. J. 1978. In: M. Rechcigl, Jr, ed. CRC Handbook Series in Nutrition and Food. Vol 3. Boca Rotan, FL: CRC Press, pp 575.

Asher, C.J. and J.F. Loneraga. 1967. Response of plants to phosphate concentration in solution culture. I. Growth and phosphorus content. Soil Science 103, 225-233.

Asmar, F., T.S. Gahoonia and N.E. Nielsen. 1995. Barley genotypes differ in activity of soluble extracellular phosphatase ad depletion of organic phosphorus in the rhizosphere soil. Plant and Soil 172, 117-122. 
Atkinson, D. 1985. Spatial and temporal aspects of root distribution as indicated by the use of a root observation laboratory. In: A.H. Fitter, D. Atkinson, D.J. Read, M.B. Usher eds. Ecological Interactions in Soil. Oxford: Blackwell Scientific, pp 43-66.

Atkinson, D. 1990. Influence of root system morphology and development on the need for fertilizers and the efficiency of use. In: V.C. Baligar, R.R. Duncan eds. Crops as Enhancers of Nutrient Use. San Diego: Academic Press, pp 411-451.

Baon, J.B., S.E. Smith and A.M. Alston. 1994. Growth response and phosphorus uptake of rye with long and short root hairs: Interactions with mycorrhizal infection. Plant and Soil 167, 247-254.

Barber, S.A. 1980. Soil-plant interactions in the phosphorus nutrition of plants. In: E. Khasawneh, E.C. Sample, E.J. Kamprath eds. The Role of Phosphorus in Agriculture. Madison, WI: American Society of Agronomy, pp 591-616.

Barber, S.A. 1984. Phosphorus. In: John Wiley eds. Soil Nutrient Bioavailability: A mechanistic approach. New York: Springer-Verlag, pp 201-228.

Barber, W.D., W.I. Thomas and D.E. Baker. 1967. Inheritance of relative phosphorus accumulation in corn (Zea mays L.). Crop Science 7, 104-107.

Barker, S.J. and D. Tagu. 2000. The role of Auxins and Cytokinins in mycorrhizal symbiosis. Journal of Plant Growth Regulation 19, 144-154.

Barnes, J.S. and E.J. Kamprath. 1975. Availability of North Carolina rock phosphate applied to soils. N. C. Agric. Exp. St. Tech. Bull., 229. Raleigh, USA.

Barrow, N.J. 1975. The response to phosphate of two annual pasture species. II. The specific rate of uptake of phosphate, its distribution and use for growth. Australian Journal for Agricultural Research 26, 145-156.

Barrow, N.J. 1990. Relating chemical processes to management systems. In: Phosphorus Requirements for Sustainable Agriculture in Asia and Oceania. Proceedings of a Symposium. Manila: IRRI, pp 199-209.

Barry, D.A.J. and M.H Miller. 1989. Phosphorus nutritional requirement of maize seedlings for maximum yield. Agronomy Journal 81, 95-99.

Bationo, A., W.E. Baethgen, C.B. Christianson, and A.U. Mokwunye. 1991. Comparison of five soil-testing methods to establish phosphorus sufficiency levels in soil fertilized with water-soluble and sparingly soluble phosphorus sources. Fert. Res. 28, 271-279.

Batjes, N.H. 1997. A world data set of derived soil properties by FAO-UNESCO soil unit for global modelling. Soil Use Mang. 13, 9-16.

Batten, G.D. 1992. A review of phosphorus efficiency in wheat. Plant and Soil 146, 163-168.

Baylis, G.T.S. 1975. The magnolioid mycorrhiza and mycotrophy in root systems derived from it. In: F.E. Sanders, B. Mosse, P.B. Tinker eds. Endomycorrhizas. London: Academic, pp 373-389.

Beadle, N.C.W. 1966. Soil phosphate and its role in molding segments of the Australian flora and vegetation, with special reference to xeromorphy and sclerophylly. Ecology 47, 9921007.

Bergmann, W. 1993. Ernährungstörungen bei Kulturpflanzen. Gustav Fisher Verlag, Jena, 3. Auflage . Stuttgart.

Besford, R.T. 1980. A rapid tissue test for diagnosing phosphorus deficiency in tomato plant. Annals of Botany 45, 225-227. 
Bhadoria, P.S., H. EI Dessougi, H. Liebersbach and N. Claassen. 2004. Phosphorus uptake kinetics, size of root system and growth of maize and groundnut in solution culture. Plant and Soil 262, 327-336.

Bhadoria, P.S., S. Singh and N. Claassen. 2001. Phosphorus efficiency of wheat, maize and groundnut grown in low phosphorus supplying soil. In: W.J. Horst, M.K. Schenk, A. Bürkert, N. Claassen, H. Flessa, W.B. Frommer, H. Goldbach, H.W. Olfs, V. Römheld, B. Sattelmacher, U. Schmidhalter, S. Schubert, N.V. Wirén and L. Wittenmayer eds. Plant Nutrition- Food security and sustainability of Agro-ecosystems. Dordrecht: Kluwer Academic Publishers, pp 530-531.

Bieleski, R.L. 1973. Phosphate pools, phosphate transport, and phosphate availability. Annual Review of Plant Physiology 24, 225-252.

Bieleski, R.L. and I.B. Ferguson. 1983. Physiology and metabolism of phosphate and its compounds. In: A. Läuchli, R.L. Bieleski eds. Encyclopedia of Plant Physiology. Vol 15A. New York: Springer-Verlag, pp 422-449.

Bolan, N.S. 1991. A critical review on the role of mycorrhizal fungi in the uptake of phosphorus by plants. Plant and Soil 134, 189-207.

Bolan, N.S., R.E. White and M.J. Hedley. 1990. A review of the use of phosphate rocks as fertilizers for direct application in Australia and New-Zealand. Australian Journal of Experimental Agriculture 30 (2), 297-313.

Bolland, M.D.A. and R.J. Gilkes. 1989. Reactive rock phosphate fertilizers and soil testing for phosphorus: the effect of particle size of the rock phosphate. Fertilizer Research 20, 7593.

Bolland, M.D.A. and R.J. Gilkes. 1990. Rock phosphates are not effective fertilizers in Western Australian soils: a review of one hundred years research. Fertilizer Research 22, 79-95.

Bolland, M.D.A., D.G. Allen and R.J. Gilkes. 1989. The influence of seasonal conditions, plant species and fertilizer type on the prediction of plant yield using the Colwell bicarbonate soil test for phosphate. Fertilizer Research 22, 79-95.

Bolland, M.D.A., R.J. Gilkes and D.G. Allen. 1988. The residual value of superphosphate and rock phosphates for lateritic soils and its evaluation using three soil phosphate test. Fertilizer Research 15, 523-280.

Bothe, H., A. Klingner, M. Kaldorf, O. Schmitz, H. Esch, B. Hundeshagen and H. Kernebeck. 1994. Biochemical approaches to the study of plant-fungal interactions in arbuscular mycorrhiza. Experientia 50, 919-925.

Bould, C. and R.I. Parfitt. 1973. Leaf analysis as a guide to the nutrition of fruit crops. X. Magnesium and phosphorus sand culture experiments with apple. J Sci Food Agric 24, 175-185.

Bouma, D. 1983. Diagnosis of mineral deficiencies using plant tests. In: A. Läuchli, R.L. Bieleski, eds. Encyclopedia of Plant Physiology, Vol. 15B, Inorganic Plant Nutrition. Berlin, Germany: Springer-Verlag, pp 120-146.

Boyer, J.S. 1982. Plant productivity and environment. Science 218, 443-448.

Brady, N.C. and R.R. Weil. 1996. The nature and properties of soils (11th ed.). Prentice Hall, New York.

Brück, H., H. C. Becker and B. Sattelmacher. 1992. Phosphate efficiency of two maize inbred lines. In: L. Kutschera, E. Hübl, E. Lichtenegger, H. Person, M. Sobotik eds. Root 
Ecology and its practical application 3. ISSR Symp. Klagenfurt: Verein für Wurzelforschung, pp 193-196.

Buhse, J. 1992. Wirkung der Wurzelraumtemperatur auf das Phosphataneinungsvermögen von Pflanzen und die Phosphatverfügbarkeit im Boden. Ph.D. Thesis. University of Göttingen, Germany.

Buso, G.S.C. and F.A. Bliss. 1998. Variability among lettuce cultivars at two levels of available phosphorus. Plant and Soil 111, 67-73.

Cakmak, I. 2002. Plant nutrition research: Priorities to meet human needs for foods in sustainable ways. Plant and Soil 247, 3-24.

Cakmak, I., L. Ozturk, S. Eker, B. Torun, H.I. Kalfa and A. Yilmaz. 1997. Concentration of zinc and activity of cooper/zinc-superoxide dismutase in leaves of rye and wheat cultivars differing in sensitivity to zinc deficiency. Journal of Plant Physiology 151, 91-95.

Caradus, J.R. 1983. Genetic differences in phosphorus absorption among white clover populations. Plant and Soil 72 (2-3), 379-383.

Caradus, J.R. 1990. Mechanisms improving nutrient use by crop and herbage legumes. In: V.C. Baligar, R.R. Duncan eds. Crops as Enhancers of Nutrient Use. San Diego: Academic Press, pp 253-311.

Caradus, J.R. 1994. Selection for improved adaptation of white clover to low phosphorus and acid soil. Euphytica 77, 243-250.

Caradus, J.R. 1995. Genetic control of phosphorus uptake and phosphorus status in plants. In: C. Johansen, K.K. Lee, K.K. Sharma, G.V. Subbarao, E.A. Kuenman eds. Genetic manipulation of crop plants to enhance integrated nutrient management in cropping systems. 1. Phosphorus. Proceedings of an FAO/ICRISAT Expert Consultancy Workshop, March 15-18, 1994, Patancheru, Andhra Pradesh India: Internal Crops Research Institute for the Semi-Arid Tropics, pp 55-74.

Caradus, J.R. and R.W. Snaydon. 1988. Aspects of phosphorus nutrition of white clover populations. I. Inorganic phosphorus content of leaf tissue. Journal of Plant Nutrition 10, 273-285.

Cartwright, B. 1972. The effect of phosphate deficiency on the kinetics of phosphate absorption by sterile excised barley roots, and some factors affecting the ion uptake efficiency of roots. Communication in Soil Science and Plant Analysis 3, 313-322.

Chapin, F.S. and R.L. Bieleski. 1982. Mild phosphorus stress in barley and a related lowphosphorus-adapted barley grass: Phosphorus fractions and phosphate absorption in relation to growth. Physiologia Plantarum 54, 309-317.

Chen, J.J. and W.H. Gabelman. 1995. Isolation of tomato strains varying in potassium acquisition using a sand-zeolite culture system. Plant and Soil 176 (1), 65-70.

Chien, S.H. 1978. Interpretation of Bray I extractable phosphorus from acid soil treated with phosphate rock. Soil Science, 144, 34-39.

Chien, S.H. 1992. Reactions of phosphate rocks with acid soils of the humid tropics. In: A.T. Bachik, A. Bidin, eds. Proceedings of a workshop on phosphate sources for acid soils in the humid tropics of Asia, Kuala Lumpur, Malaysian Society of Soil Science, pp 18-29.

Claassen, N. 1994. Nährstoffafnahme höhere Pflanzen aus dem Boden. Ergebnis von Verfügbarkeit und Aneignugsvermögen. Habilitationsschrift. Severin Verlag, Göttingen. 
Claassen, N. and S.A. Barber. 1976. Simulation model for nutrient uptake from soil by growing plant root system. Agronomy Journal 68, 961-964.

Clark, R.B. 1975. Characterization of phosphatase of intact maize roots. Journal of Agricultural and Food Chemistry 23, 458-460.

Clark, R.B. 1990. Physiology of cereals for mineral nutrient uptake, use, and efficiency. In: V.C. Baligar, R.R. Duncan eds. Crops as Enhancers of Nutrient Use. San Diego: Academic Press, pp 131-209.

Clark, R.B. and R.R. Duncan. 1991. Improvement of plant mineral nutrition through breeding. Field Crops Research 27, 219-240.

Clarkson, D.T. 1985. Factors affecting mineral nutrient acquisition by plants. Annual Review of Plant Physiology 36, 77-115.

Clarkson, D.T. 1991. Root structure and sites of ion uptake. In: Y. Waisel, A. Eshel, U. Kafkafi eds. Plant Roots. The Hidden Half. New York: Marcel Dekker, pp 417-453.

Clarkson, D.T. and C.B. Scattergood. 1982. Growth and phosphate-transport in barley and tomato plants during the development of, and recovery from, phosphate stress. Journal of Experimental Botany 33 (136), 865-875.

Clarkson, D.T. and J. B. Hanson. 1980. The mineral nutrition of higher plants. Annual Review of Plant Physiology 31, 239-298.

Clement, C.R. and J. DeFrank. 1998. The use of ground covers during establishment of heartof-palm plantations in Hawaii. Horticultural Science. 33 (5), 814-815.

Coltman, R.R., G.C. Gerloff and W.H. Gabelman. 1985. Differential tolerance of tomato strains to maintained and deficient levels of phosphorus. Journal of the American Society for Horticultural Science 110 (2), 140-144.

Cook, R.G. 1992. Arachis pintoi Krap. \& Greg., nom. nud. In: L.'t Mannetje, R.M. Jones eds. Plant Resources of South-East Asia No 4 Forages. Wageningen, the Netherlands: PudocDLO, pp 48-50.

Creelman, R.A. and J.E. Mullet. 1997. Biosynthesis and action of jasmonates in plants (Review). Annual Review of Plant Physiology and Plant Molecular Biology 48, 355-381.

Cress, W.A., G.O. Throneberry and D.L. Lindsey. .1979. Kinetics of phosphorus absorption by mycorrhizal and non-mycorrhizal tomato roots. Plant Physiology 64 (3), 484-487.

Curl, E.L. and B. Truelove. 1986. The Rhizosphere. Springer-Verlag, Berlin.

Da Silva, A.E. and W.H. Gabelman. 1992. Screening maize inbred lines for tolerance to low-P stress condition. Plant and Soil 146, 181-187.

Dalal, R.C. 1977. Soil organic phosphorus. Advances in Agronomy 29, 83-113.

Danneberg, G. C. Latus, W. Zimmer, B. Hundeshagen, H. Scheneider-Poatsch and H. Bothe. 1993. Influence of vesicular-arbuscular mycorrhiza on phytohormone balance in maize (Zea maize L.). Journal of Plant Physiology 141, 33-39.

De Datta, S.K., H.U. Neue, D. Senadhira and C. Quijano. 1994. Success in rice improvement for poor soils. In: Proceedings of the Workshop on Adaptation of Plants to Soil Stresses, 1-4 August 1993, University of Nebraska, Lincoln, Nebraska. INTSORMIL Publication No. 94-2. Lincoln, Nebraska (USA): University of Nebraska, pp 248-268. 
Dechassa N., M.K. Schenk, N. Claassen and B. Steingrobe. 2003. Phosphorus efficiency of cabbage (Brassica oleraceae L. var. capitata), carrot (Daucus carota L.), and potato (Solanum tuberosum L.) Plant and Soil 250 (2), 215-224.

Dinkelaker B., V. Römheld and H. Marschner. 1989. Citric-acid excretion and precipitation of calcium citrate in the rhizosphere of white lupin (Lupinus albus L.). Plant Cell Environment 12, 285-292.

Dinkelaker, B. 1990. Genotypische Unterschiede in der Phosphateffizienz von Kichererbse (Cicer arietinum L.). Ph.D. Thesis. University of Hohenheim, Stuttgart, Germany.

Dodd, J., C. Burton, R. Burns and P. Jeffries. 1987. Phosphatase activity associated with the roots and the rhizosphere of plants infected with vesicular-arbuscular mycorrhizal fungi. New Phytologist 107, 163-172.

Duff, S.M., W.C. Plaxton and D.D. Lefebvre. 1991. Phosphate-starvation response in plant cells: de novo synthesis and degradation of acid phosphatases. Proceedings of the National Academy of Sciences, USA 88, 9538-9542.

Duff, S.M.G., G. Sarath and W.C. Plaxton. 1994. The role of acid-phosphatases in plant phosphorus-metabolism. Physiologia Plantarum. 90 (4), 791-800.

Duke, J.A. 1981. Handbook of legumes of world economic importance. Plenum Press. New York.

Duponnois, R., A. Colombet, V. Hien and J. Thioulouse. 2005. The mycorrhizal fungus Glomus intraradices and rock phosphate amendment influence plant growth and microbial activity in the rhizosphere of Acacia holosericea. Soil Biology and Biochemestry 37, 1460-1468.

Earl, K.D., J.K. Syers and J.R. Mclaughlin. 1979. Origin of the effects of citrate, tartrate and acetate on phosphate sorption by soils and synthetic gels. Soil Science Society of American Journal 43, 674-678.

Edwards, J.h, and S.A. Barber. 1976. Phosphorus uptake rate of soybean roots as influenced by plant age, root trimming, and solution p concentration. Agronomy Journal 68 (6), 973 975.

Egle, K., G. Maske, W. Römer and P.L.G. Vlek. 1999. Improve phosphorus efficiency of three new wheat genotypes from CIMMYT in comparison with an older Mexican variety. Journal of Plant Nutrition and Soil Sciences 162, 353-358.

Elliott, G.C. and A. Lauchli. 1986. Evaluation of an acid phosphatase assay for detection of phosphorus deficiency in leaves of maize (Zea mays L.). Journal of Plant Nutrition 9, 1469-1477.

Engels, C. 1993. Differences between maize and wheat in growth-related nutrient demand and uptake of potassium and phosphorus at suboptimal root-zone temperatures. Plant and Soil 150 (1), 129-138.

Esch, H., B. Hundeshagen, H. Scheneider-Poatsch and H. Bothe. 1994. Demonstration of abscisic acid in spores and hyphae of the arbuscular-mycorrhiza fungus Glomus and the N2-fixing cyanobacterium Anabena variabilis. Plant Science 99, 9-16.

Eticha, D. and M.K. Schenk. 2001. Phosphorus efficiency of cabbage varieties. In: W.J. Horst, M.K. Schenk, A. Bürkert, N. Claassen, H. Flessa, W.B. Frommer, H. Goldbach, H.W. Olfs, V. Römheld, B. Sattelmacher, U. Schmidhalter, S. Schubert, N.V. Wirén and L. Wittenmayer eds. Plant Nutrition- Food security and sustainability of Agro-ecosystems. Dordrecht: Kluwer Academic Publishers, pp 542-543. 
Faber, B.A., R.J. Zasoski, R.G. Burau and K. Uriu. 1990. Zinc uptake by corn as affected by vesicular-arbuscular mycorrhizae. Plant and Soil 129, 121-130.

Fageria, N.K. and V.C. Baligar. 1997. Phosphorus-use efficiency by corn genotypes. Journal of Plant Nutrition. 20 (10), 1267-1277.

Farmer, E.E., H. Weber and S. Vollenweider. 1998. Fatty acids signalling in Arabidopsis (Review). Planta 206, 167-174.

Fawole, I., W.H. Gabelman, G.C. Gerloff and E.V. Nordheim. 1982. Heritability of efficiency in phosphorus utilization in beans (Phaseolus vulgaris L.) grown under phosphorus stress. Journal of the American Society for Horticultural Science 107, 98100.

Fernandez, D.S. and J. Ascencio. 1994. Acid phosphatase activity in bean and cowpea plants grown under phosphorus stress. Journal of Plant Nutrition 17, 229-241.

Fitter, A.H. 1991. Characteristics and functions of root systems. In: Y. Waisel, A. Eshel, U. Kafkafi eds. Plant Roots. The Hidden Half. New York: Marcel Dekker, pp 3-25.

Fixen, P.E. and J.H. Grove. 1990. Testing soils for phosphorus. In: R.L. Westerman eds. Soil testing and plant analysis. Book Series No. 3. Madison, WI: ASA, SSSA, pp 141-180.

Föhse, D., N. Claassen, and A. Jungk. 1988. Phosphorus efficiency of plants I. External and internal $\mathrm{P}$ requirement and $\mathrm{P}$ uptake efficiency of different plant species. Plant and Soil 110, 101-109.

Föhse, D., N. Claassen, and A. Jungk. 1991. Phosphorus efficiency of plants II. Significance of root radius, root hair and cation-anion balance for phosphorus influx in seven plants species. Plant and Soil 131, 261-272.

Fontes, P.C.R., S.A. Barber and G.E. Wilcox. 1986. Prediction of phosphorus uptake by 2 tomato cultivars growing under insufficient and sufficient phosphorus soil-conditions using a mechanistic mathematical-model. Plant and Soil 94, 87-97.

Fox, R.L. 1981. External phosphorus requirements of crops. In: R.H. Dowdy, J.A. Ryan, V.V. Volk, D.E. Baker eds. Chemistry in the Soil Environment, ASA Spec Publ No 40. Madison, WI: ASA, SSSA, pp 223-239.

Fox, R.L., and P.G.E. Searle. 1978. Phosphate adsorption by soils of the tropics. In: The Diversity of Soils of the Tropics. ASA Special Publication No. 34. Madison, WI: American Society of Agronomy, pp 97-119.

Fox, T.R. and N.B. Comerford. 1990. Low-molecular weight organic acids in selected forest soils of the south eastern USA. Soil Science Society of American Journal 54, 1139-1144.

Foyer, C. and C. Spencer. 1986. The relationship between phosphate status and photosynthesis in leaves: effects on intracellular orthophosphate distribution, photosynthesis and assimilate partitioning. Planta 167 (3), 369-375.

Fransen, B., J. Blijjenberg, and H. de Kroon. 1999. Root morphological and physiological plasticity of perennial grass species and the exploitation of spatial and temporal heterogeneous nutrient patches. Plant and Soil 211, 179-189.

Friesen, D.K., I.M. Rao, R. J. Thomas, A. Oberson, and J. I. Sanz. 1997. Phosphorus acquisition and cycling in crop and pasture systems in low fertility tropical soils. Plant and Soil 196 (2), 289-294. 
Frossard, E., M. Brossard, M.J. Hedley, and A. Metherell. 1995. Reaction controlling the cycling of $\mathrm{P}$ in the soil. In: $\mathrm{H}$. Tiessen eds. Phosphorus in the global environment. SCOPE, pp 107-137.

Fukuda, T., M. Osaki, T. Shinano and J. Wasaki. 2001. Cloning and characterization of two secreted acid phosphatases from rice calli. In: W.J. Horst, M.K. Schenk, A. Bürkert, N. Claassen, H. Flessa, W.B. Frommer, H. Goldbach, H.W. Olfs, V. Römheld, B. Sattelmacher, U. Schmidhalter, S. Schubert, N.V. Wirén and L. Wittenmayer eds. Plant Nutrition- Food security and sustainability of Agro-ecosystems. Dordrecht: Kluwer Academic Publishers, pp 34-35.

Gabelman, W.H. and G.C. Gerloff. 1983. The search for and interpretation of genetic-controls that enhance plant-growth under deficiency levels of a macronutrient. Plant and Soil $\mathbf{7 2}$ (2-3), 335-350.

Gabelman, W.H., G.C. Gerloff, T. Schettini and R. Coltman. 1986. Genetic-variability in root systems associated with nutrient acquisition and use. Hortscience 21 (4), 971-973.

Gahoonia T.S. and N.E. Nielsen. 1998. Direct evidence on participation of root hairs in phosphorus (32P) uptake from soil. Plant and Soil 198, 147-152.

Gardner, W.K., D.A. Barber and D.G. Parbery. 1983. The acquisition of phosphorus by Lupinus albus L. III. The probable mechanism by which phosphorus movement in the soil/root interface is enhanced. Plant and Soil 70, 107-124.

Geil R.D and F.C. Guinel. 2002. Effects of elevated substrate-ethylene on colonization of leek (Allium porrum) by the arbuscular mycorrhizal fungus Glomus aggregatum. Canadian Jorunal of Botany-Revue Canadienne de Botanique 80, 114-119.

George, E., H. Marschner and I. Jakobsen. 1995. Role of arbuscular mycorrhizal fungi in uptake of phosphorus and nitrogen from soil. Critical Reviews in Biotechnology 15, 257270 .

Gerke, J. 1992. Phosphate, aluminium and iron in the soil solution of three different soils in relation to varying concentrations of citric acid. Zeitschrift für Pflanzenernährung und Bodenkunde 155, 33-343.

Gerloff, G.C. 1987. Intact-plant screening for tolerance of nutrient-deficiency stress. Plant and Soil 99, 3-16.

Gerloff, G.C. and W.H. Gabelman. 1983. Genetic basis of inorganic plant nutrition. In: A. Läuchli, R.L. Bieleski eds. Encyclopedia of plant physiology. Springer Verlag, New series vol. 15B, pp 453-480.

Gianinazzi-Pearson, V. and S. Gianinazzi. 1978. Enzymatic studies on metabolism of vesicular-arbuscular mycorrhiza. 2. Soluble alkaline-phosphatase specific to mycorrhizal infection in onion roots. Physiological Plant Pathology 12, 45-53.

Gilbert, G.A., C.P. Vance and D.L. Allan. 1998. Regulation of white lupin metabolism by phosphorus availability. In: J.P. Lynch, J. Deikman eds. Phosphorus in plant biology: regulatory roles in molecular, cellular, organismic and ecosystem processes. Rockville, MD, USA: American Society of Plant Physiology, pp 157-167.

Gilbert, G.A., J.D. Knight, C.P. Vance and D.L. Allan. 1999. Acid phosphatase activity in phosphorus-deficient white lupin roots. Plant, Cell and Environment 22, 801-810.

Godwin, D.C. and G.J. Blair. 1991. Phosphorus efficiency in pasture species. 5. A comparison of white clover accessions. Australian Journal of Agricultural Research 42 (3), 531-540. 
Gogala, N. 1991. Regulation of mycorrhizal infection by hormonal factors produced by hosts and fungi. Experientia 37, 331-340.

Goldstein, A.H., A. Danon, D. Baertlein and R. McDaniel. 1988b. Phosphate starvation inducible metabolism in Lycopersicon esculentum. II. Characterization of the phosphate starvation inducible-excreted acid phosphatase. Plant Physiology 87, 716-720.

Goldstein, A.H., D. Baertlein and R. McDaniel. 1988a. Phosphate starvation inducible metabolism in Lycopersicon esculentum. I. Excretion of acid phosphatase by tomato plants and suspension-cultured cells. Plant Physiology 87, 711-715.

Gourley, C.J.P., D.L. Allan, and M.P. Russelle. 1994. Plant nutrient efficiency: A comparison of definitions and suggested improvement. Plant and Soil 158, 29-37.

Graham, J.H., R.T. Leonard and J.A. Menge. 1981. Membrane-mediated decrease in root exudation responsible for phosphorus inhibition of vesicular-arbuscular mycorrhiza formation. Plant Physiology 68 (3), 548-552.

Graham, R.D. 1984. Breeding for nutritional characteristics in cereals. Advances in Plant Nutrition 1, 57-102.

Gransee, A. 2002. Whechselwirkung zwischen den Wurzelabscheidungen von Kulturpflanzen und der P-Dynamik in der Rhizosphere - Ansätze zur Verbesserung der Nährstoffeffiezienz -. Habilitationsschrift. Verlagsgesellschaft für Ackerbau GmbH.

Grierson, P.F. 1992. Organic acids in the rhizosphere of Banksia integrifolia L.F. Plant and Soil, 144, 259-265.

Grime, J.P. and R. Hunt. 1975. Relative growth rate: Its range and adaptive significance in a local flora. Journal of Ecology 63 (2), 393-422.

Grinsted, M.J., M.J. Hedley, R.E. White and P.H. Nye. 1982. Plant-induced changes in the rhizosphere of rape (Brassica napus var - Emerald) seedlings. I. pH change and the increase in P concentration in the soil solution. New Phytologist 91 (1), 19-29

Grundwald, U. 2004. Analyse der Genregulation in Medicago truncatula und Pisum sativum während der Entwicklung arbuskulärer Mykorrhiza. Ph.D. Thesis. Philipps University of Margburg, Margburg/Lahn, Germany.

Gunze, C.M.B. and C.M.R. Hennessy. 1980. Effect of host-applied auxin on development of endomycorrhiza in cowpeas. Transactions of the British Mycological Society 74, 247251.

Guthrie, R.E., K.D. Mclachlan and D.G. Demarco. 1991. Acid-phosphatases associated with phosphorus deficiency in wheat - Partial purification and properties. Australian Journal of Plant Physiology 18, 615-626.

Halsted, M. and J.P. Lynch. 1996. Phosphorus responses of C3 and C4 species. Journal of Experimental Botany 47, 497-505.

Harrison, M.J. 1997. The arbuscular mycorrhizal symbiosis: An underground association. Trends Plant Science 2, 54-60.

Hart, A.L. and D.J. Jessop. 1983. Phosphorus fractions in trifoliate leaves of white clover and lotus at various levels of phosphorus supply. New Zealand Journal of Agricultural Research 26 (3), 357-361.

Hause, B., W. Maier, O. Miersch, R. Kramell and D. Strack. 2002. Induction of jasmonate biosynthesis in arbuscular mycorrhiza barley roots. Plant Physiology 130, 1213-1220. 
He, Z.L. and J. Zhu. 1997. Transformation and bioavailability of specifically sorbed phosphate on variable-charge minerals in soils. Biology and Fertility of Soils 25, 175-181.

Hecht-Bucholz, C. 1967. Über die Dunkelfarbung des Blattgruns bei Phosphormangel. Z Pflanzenernährung Bodenkunde 118, 12-22.

Hedley, M.J. P.H. Nye and R.E. White. 1982. Plant induced changes in the rhizosphere of rape (Brassica napus var. Emerald) seedlings II. Origin of the $\mathrm{pH}$ change. New Phytologist 91, 31-44.

Helal, H.M and A. Dressler. 1989. Mobilisation and turnover of soil phosphorus in the rhizosphere. Zeitschrift für Pflanzenernährung und Bodenkunde 152, 175-180.

Helal, H.M. 1990. Varietal differences in root phosphatase activity as related to the utilization of organic phosphates. Plant and Soil, 123, 161-163.

Helal, H.M. and D.R. Sauerbeck. 1984. Influence of plant roots on C and P metabolism in soil. Plant and Soil 76, 175-182.

Hendriks, L., N. Claassen, and A. Jungk. 1981. Phosphatveramung des wurzelnahen Bodens und Phosphataufnahme von Mais and Rape. Zeitschrift für Pflanzenernährung und Bodenkunde 144 (5), 486-499.

Henriksen, G.H., D. Raja Raman, L.P. Walker and R. M. Spanswick. 1992. Measurement of net fluxes of ammonium and nitrate at the surface of barley roots using ion-selective microelectrodes. II. Patterns of uptake along the root axis and evaluation of the microelectrode flux estimation technique. Plant Physiology 99 (2), 734-747.

Hinsinger, P. 2001. Bioavailability of sol inorganic P in the rhizosphere as affected by rootinduced chemical changes: a review. Plant and Soil 237, 173-195.

Hocking, P.J. and P.J. Randall. 2001. Better growth and phosphorus nutrition of sorghum and wheat following organic-acid secreting crops. In: W.J. Horst, M.K. Schenk, A. Bürkert, N. Claassen, H. Flessa, W.B. Frommer, H. Goldbach, H.W. Olfs, V. Römheld, B. Sattelmacher, U. Schmidhalter, S. Schubert, N.V. Wirén and L. Wittenmayer eds. Plant Nutrition- Food security and sustainability of Agro-ecosystems. Dordrecht: Kluwer Academic Publishers, pp 548-549.

Hocking, P.J., G. Keerthisinghe, F.W. Smith and P.J. Randall. 1997. Comparison of the ability of different crop species to access poorly-available soil phosphorus. In: Ando T., et al. eds. Plant Nutrition for Sustainable Food Production and Environment. Dordrecht: Kluwer Academic Publishers, pp 305-308.

Hoffmann, C., E. Ladewig, N. Claassen and A. Jungk. 1994. Phosphorus uptake of maize as affected by ammonium and nitrate-nitrogen - measurements and model-calculations. Zeitschrift für Pflanzenernährung und Bodenkunde 157 (3), 225-232.

Horst, W.J., M. Abdou and F. Wiesler. 1993. Genotypic differences in phosphorus efficiency of wheat. Plant and Soil 156, 293-296.

Horst, W.J., M. Abdou, and F. Wiesler. 1996. Differences between wheat cultivars in acquisition and utilisation of phosphorus. Zeitschrift für Pflanzenernährung und Bodenkunde 159 (2), 155-161.

Howeler, R. H., E. Sieverding and S. Saif. 1987. Practical aspects of mycorrhizal technology in some tropical crops and pastures. Plant and Soil 100, 249-283.

Howeler, R.H., C.J. Asher and D.G. Edwards. 1982. Establishment of an effective endomycorrhizal association on cassava in flowing solution culture and its effects on phosphorus nutrition. New Phytologist 90 (2), 229-238. 
Hue, N.V. 1991. Effects of organic acids/anions on P sorption and phytoavailability in soils with different mineralogies. Soil Science 152 (6), 463-471.

Hunter, D.A. and M.T. McManus. 1999. Comparison of acid phosphatases in two genotypes of white clover with different responses to applied phosphate. Journal of Plant Nutrition 22, 679-692.

Jakobsen, I., L.K Abbott, and A.D. Robson. 1992a. External hyphae of vesicular- arbuscular mycorrhizal fungi associated with Trifolium subterraneum L. 1. Spread of hyphae and phosphorus inflow into roots. New Phytologist 120, 371-380.

Jakobsen, I., L.K Abbott, and A.D. Robson. 1992b. External hyphae of vesicular- arbuscular mycorrhizal fungi associated with Trifolium subterraneum L. 2. Hyphal transport of 32P over defined distances. New Phytologist 120, 509-516.

Johansen, C., G.V. Subbarao, K.K. Lee and K.K. Sharma. 1995. Genetic manipulation of crop plants to enhance integrated nutrient management in cropping systems-the case of phosphorus. In: C. Johansen, K.K. Lee, K.K. Sharma, G.V. Subbarao, E.A. Kueneman eds. Genetic Manipulation of Crop Plants to Enhance Integrated Nutrient Management in Cropping Systems - 1. Phosphorus. Patancheru, India: ICRISAT, pp 9-29.

Johnson, J.F., C.P. Vance and D.L. Allan. 1996b. Phosphorus deficiency in Lupinus albus: altered lateral root development and enhanced expression of phosphoenolpyruvate carboxylase. Plant Physiology 112, 31-41.

Johnson, J.F., D.L. Allan and C.P. Vance. 1994. Phosphorus stress-induced proteoid roots show altered metabolism in Lupinus albus. Plant Physiology 104, 657-665.

Johnson, J.F., D.L. Allan, C.P. Vance and G. Weiblen. 1996a. Root carbon dioxide fixation by phosphorus-deficient Lupinus albus - Contribution to organic acid exudation by proteoid roots. Plant Physiology 112, 19-30.

Jones, D. and J. Farrar. 1999. Phosphorus mobilization by root exudates in the rhizosphere: fact or fiction?. Agroforestry Forum 9 (4), 20-25.

Jones, D.L. and P.R. Darrah. 1994. Role of root derived organic acids in the mobilization of nutrients from the rhizosphere. Plant and Soil 166, 247-257.

Jones, D.L., A.M. Prabowo and L.V. Kochian. 1996. Kinetics of malate transport and decomposition in acid soils and isolated bacterial populations: The effect of microorganisms on root exudation of malate under Al stress. Plant and Soil 182 (2), 239247.

Jones, M.D., D.M. Durall and P.B. Tinker. 1990. Phosphorus relationships and production of extramatrical hyphae by two types of willow ectomycorrhizas at different soilphosphorus levels. New Phytologist 115 (2), 99-106.

Jungk, A. 1974. Phosphate uptake characteristics of intact root systems in nutrient solution as affected by plant species, age and P supply. In: J. Wehrmann eds. Proceedings of the $7^{\text {th }}$ International Colloquium on Plant Analysis and Fertilizer Problems. Hannover, Germany: pp 519-527.

Jungk, A. 1991. Dynamics of nutrient movement at the soil-root interface. In: Y. Waisel, A. Eshel, U. Kafkafi eds. Plant roots: the hidden half. New York, USA: Marcel Dekker, 455481.

Jungk, A. and N. Claassen. 1989. Availability in soil and acquisition by plants as the basis for potassium and phosphorus supply to plants. Zeitschrift für Pflanzenernährung und Bodenke 152, 151-158. 
Jungk, A. and N. Claassen. 1997. Ion diffusion in the soil-root system. Advances in Agronomy 61, 53-110.

Jungk, A., C.J. Asher, D.G. Edwards and D. Meyer. 1990. Influence of phosphate status on phosphate-uptake kinetics of maize and soybean. Plant and Soil 124 (2), 175-182.

Kaldorf, M. and J. Ludwig-Müller. 2000. AM fungi might affect the root morphology of maize by increasing indole-3-butiryc acid biosynthesis. Physiologia Plantarum 109, 5867.

Kamh, M, W.J. Horst, F. Amer, H. Mostafa and P. Maier. 1999. Mobilization of soil and fertilizer phosphate by cover crops. Plant and Soil 211, 19-27.

Kamprath, E.J. and M.E Watson. 1980. Conventional soil and tissue tests for assessing the phosphorus status of soils. In: F.E. Khasawneh, E.C. Sample, E.J. Kamprath eds. The Role of Phosphorus in Agriculture. Madison, WI: ASA, CSSA, SSSA, pp 433-469.

Kanabo, I.A.K. and R.J. Gilkes. 1987a. The role of soil pH in the dissolution of phosphate rock fertilisers. Fertilizer Research 12, 165-174.

Kanabo, I.A.K. and R.J. Gilkes. 1987b. The influence of the addition of goethite to soil on the dissolution of North Carolina phosphate rock. Australian Journal of Agriculture Research 25, 313-22.

Kaya, C., D. Huggs and A. Burton. 2000. Phosphorus and acid phosphatase enzyme activity in leaves of tomato cultivars in relation to zinc supply. Communication in Soil Science and Plant Analysis 31, 3239-3248.

Keerthisinghe, G., P.J. Hocking, P.R. Ryan and E. Delhaize. 1998. Effect of phosphorus supply on the formation and function of proteoid roots of white lupin (Lupinus albus L.). Plant, Cell and Environment 21, 467-478.

Kerridge, P.C. and D. Ratcliff. 1982. Comparative growth of 4 tropical pasture legumes and guinea grass with different phosphorus sources. Tropical Grasslands 16 (1), 33-40.

Kirk, G.J.D. and Nye, P.H. 1986. A simple model for predicting the rates of dissolution of sparingly soluble calcium phosphates in soil II. Applications of the model. Soil Science, 37, 541-554.

Kirk, G.J.D., T. George, B. Courtois and D. Senadhira. 1998. Opportunities to improve phosphorus efficiency and soil fertility in rainfed lowland and upland rice ecosystems. Field Crops Research 56, 73-92.

Koide, R.T. 1991. Nutrient supply, nutrient demand and plant response to mycorrhizal infection. New Phytologist 117 (3), 365-386.

Koide, R.T. and M.G. Li. 1990. On host regulation of the vesicular arbuscular mycorrhizal symbiosis. New Phytologist 114, 59-64.

Krannitz, P.G., L.W. Aarssen and D.D. Lefebvre. 1991. Relationships between physiological and morphological attributes related to phosphate uptake in 25 genotypes of Arabidopsis thaliana. Plant and Soil 133, 169-175.

Krieg, D.R. 1994. Stress tolerance mechanisms in above ground organs. In: Proceedings of the Workshop on Adaptation of Plants to Soil Stresses. INTSORMIL Publ No 94-2, Lincoln, NB: University of Nebraska, pp 65-79.

Kuhlmann, H. and P.B. Barraclough. 1987. Comparison between the seminal and nodal root system of winter wheat in their activity for $\mathrm{N}$ and $\mathrm{K}$ uptake. Zeitschrift für Pflanzenernährung und Bodenkunde 150, 24-30. 
Lan, M., N.B. Comerford and T.R. Fox. 1995. Organic anions effect on phosphorus release from spodic horizons. Soil Science Society of American Journal 59, 1745-1749.

Landwirtschaftskammer Weser Ems. 2003. Richtwerte für die Düngung in Niedersachsen. Landwirtschaftskammern Hannover und Weser-Ems.

Lee, R.B. 1982. Selectivity and kinetics of ion uptake by barley plants following nutrient deficiency. Annals of Botany 50, 429-449.

Lefebvre, D.D. and A.D.M. Glass. 1982. Regulation of phosphate influx in barley roots effects of phosphate deprivation and reduction of influx with provision of orthophosphate. Physiologia Plantarum 54 (2), 199-206.

Li, M.G., T. Shinano and T. Tadano. 1997. Distribution of lupin roots in the rhizosphere under phosphorus deficient conditions. Soil Science and Plant Nutrition 43, 237-245.

Li, X.L., E. George and H. Marschner. 1991. Extension of the phosphorus depletion zone in VA-mycorrhizal white clover in a calcareous soil. Plant and Soil 136, 41-48.

Liu, A., B. Wang and C. Hamel. 2004. Arbuscular mycorrhiza colonization and development at suboptimal root zone temperature. Mycorrhiza 14 (2), 93-101.

Loneraga, J.F. 1978. The physiology of plant tolerance to low phosphorus availability. In: G.A. Jung, ed. Crop Tolerance to Suboptimal Land Conditions. Madison, WI: ASA, pp 329343.

Loneraga, J.F. and C.J. Asher. 1967. Response of plants to phosphate concentration in solution culture .2. rate of phosphate absorption and its relation to growth. Soil Science 103 (5), 311-318.

Lopez-Hernandez, D., G. Siegert and J.V. Rodriguez. 1986. Competitive adsoption of phosphate with malate and oxalate by tropical soils. Soil Science Society of American Journal 50, 1460-1462.

Ludwig-Müller, J., M. Kaldorf, E.G. Sutter and E. Epstein. 1997. Indole-3-butiryc acid (IBA) is enhanced in young maize (Zea maize L.) roots colonized with the arbuscular mycorrhizal fungus Glomus intraradices. Plant Science 125, 153-162.

Lynch, J.P. 1998. The role of nutrient-efficient crops in modern agriculture. In: H. Tiessen eds. Phosphorus in the global environment: Transfers, Cycles and Management. New York: John Wiley and Sons, pp 241-264.

Lynch, J.P. and K.M. Brown. 2001. Topsoil foraging - an architectural adaptation of plants to low phosphorus availability. Plant and Soil 237 (2), 225-237.

Lynch, J.P. and S.E. Beebe. 1995. Adaptation of Beans (Phaseolus vulgaris L.) to low phosphorus availability. HortScience, 30 (6), 1165-1171.

Machado, C.T. de T. 2000. Caracterização de genótipos de milho (Zea mays L.) quanto aos parâmetros morfológicos, fisiológicos e microbiológicos associados à eficiência na absorção e utilização de fósforo. Seropédica. Ph.D. Thesis. Universidade Federal Rural do Rio de Janeiro (UFRRJ).

Machado, C.T. de T. and A.M.C. Furlani. 2004. Root phosphatase activity, plant growth and phosphorus accumulation of maize genotypes. Scientia Agricola 61, 69-76.

Machado, C.T. de T., A.M.C. Furlani and A.T. Machado. 2001. Índices de eficiência de variedades locais e melhoradas de milho ao fósforo. Bragantia 60, 225-238. 
Malagón, D., C. Pulido, R. Llinas and C. Chamorro. 1995. Suelos de Colombia, origen, evolución, clasificación, distribución y uso. Canal Ramírez Antares Ltda. Santafé de Bogotá. 632 p.

Marschner, H. 1991. Mechanisms of adaptation of plants to acid soils. Plant and Soil 134, 1-20.

Marschner, H. 1995. Mineral nutrition of higher plants. 2nd ed. London: Academic Press, pp 265-277.

Marschner, H. and B. Dell. 1994. Nutrient uptake in mycorrhizal symbiosis. Plant and Soil 159, 89-102.

Marschner, H., E.A. Kirkby and I. Cakmak. 1996. Effect of mineral nutritional status on shoot-root partitioning of photoassimilates and cycling of mineral nutrients. Journal of Experimental Botany 47, 1255-1263.

McLachlan, K.D. 1980. Acid phosphatase activity of intact roots and phosphorus nutrition in plants. II. Variations among wheat roots. Australian Journal of Agriculture Research 31, 441-448.

McLachlan, K.D., D.E. Elliott, D.G. de Marco and J.H. Garran. 1987. Leaf acid phosphatase isozymes in the diagnosis of phosphorus status in field-grown wheat. Australian Journal of Agriculture Research 38, 1-13.

Mengel, K. and E.A. Kirkby. 1982. 'Principles of plant nutrition.' 3rd edn (International Potash Institute: Bern) Miyasaka SC, Buta JG, Howell RK, Foy CD (1991) Mechanism of aluminum tolerance in snapbeans: Root exudation of citric acid. Plant Physiology 96, 737-743.

Miller, M., T. Mcgonigle and H. Addy. 1994. An economic approach to evaluate the role of mycorrhizas in managed ecosystems. Plant and Soil 159, 27-35.

Miyasaka, S.C. and M. Habte. 2001. Plant mechanisms and mycorrhizal symbioses to increase phosphorus uptake efficiency. Communications in Soil Science and Plant Analysis 32, 1101-1147.

Moawad, A.M. 1986. Wie verbessert die VA-Mykorrhiza die Phosphatversorgung der Pflanzen?. In: W. Achtnich, H. Lamprecht eds. Landnutzung, Bodenfruchtbarkeit und Pflanzenproduktion in den Tropen und Subtropen. Göttinger Beiträge zur Land- und Forstwirtschaft in den Tropen u. Subtropen 12, pp 7-20.

Moghimi, A. M.E. Tate and J.M. Oades. 1978. Characterization of rhizosphere products specially 2-ketogluconic acid. Soil Biology and Biochemistry 10, 238-287.

Mokwunye, A.U. and L.L. Hammond. 1992. Myths and science of fertilizer use in the tropics. In: R. Lal, P.A. Sánchez eds. Myths and Science of Soils of the Tropics. SSSA Spec Publ No 29. Madison, WI: SSSA, ASA, pp 121-134.

Mollier, A. and S. Pellerin. 1999. Maize root system growth and development as influenced by phosphorus deficiency. Journal of Experimental Botany 55 (333), 487-497.

Moorby, H., R.E. White and P.H. Nye. 1988. The influence of phosphate nutrition on H ion efflux from the roots of young rape plants. Plant and Soil 105, 247-256.

Moorby, J. and R.T. Besford. 1983. Mineral nutrition and growth. In: A. Läuchli, R.L. Bieleski eds. Encyclopedia of Plant Physiology. Vol 15B. New York: Springer-Verlag, pp 481527.

Murphy, J. and J.P. Riley. 1962. A modified single solution method for the determination of phosphate in natural waters. Analytica Chimica Acta 27, 31-36. 
Nagarajah, S.A., M. Posner and J.P. Quirk. 1970. Competitive adsorption of phosphate with polygalactrurnate and other organic anions on kaolinite and oxide surfaces. Nature 228, 83-85.

Neumann, G. and V. Roemheld. 2002. Root-induced changes in the availability of nutrients in the rhizosphere. In: Y. Waisel, A. Eshel, U. Kafkafi, eds. Plant roots: The hidden half. New York-Basel: Marcel Dekker, pp 617-649.

Neumann, G. and V. Römheld. 1999. Root excretion of carboxylic acids and protons in phosphorus-deficient plants. Plant and Soil 211, 121-130.

Nielsen, N.E. 1979. Is the efficiency of nutrient uptake genetically controlled? (abstr). In: J.L. Harley, R.S. Russel eds. The Soil-Root Interface. New York: Academic Press, pp 429.

Nye, P.H. and P.B. Tinker. 1977. Solute Movement in the Soil-Root System. Studies in Ecology. Oxford: Blackwell Scientific Publications, pp 342.

Oberson, A., D.K. Friesen, H. Tiessen, C. Morel and W. Stahel. 1999. Phosphorus status and cycling in native savanna and improved pastures on an acid low-P Colombian Oxisol. Nutrient Cycling in Agroecosystems 55 (1), 77-88.

Ohwaki, Y. and H. Hirata. 1992. Differences in carboxylic acid exudation among P-starved leguminous crops in relation to carboxylic acid contents in plant tissue and phospholipid level in roots. Soil Science and Plant Nutrition 38, 235-243.

Olsen, S.R. and F.E. Khasawneh. 1980. Use and limitations of physical-chemical criteria for assessing the status of phosphorus in soils. In: F.E. Khasawneh, E.C. Sample, E.J. Kamprath eds. The Role of Phosphorus in Agriculture. Madison, WI: ASA, CSSA, SSSA, pp 361-410.

Ortas, I., Z. Kaya, and I. Çakmak. 2001. Influence of VA-Mycorrhiza inoculation on growth of maize and green pepper plants in phosphorus and zinc deficient soils. In: W.J. Horst, M.K. Schenk, A. Bürkert, N. Claassen, H. Flessa, W.B. Frommer, H. Goldbach, H.W. Olfs, V. Römheld, B. Sattelmacher, U. Schmidhalter, S. Schubert, N.V. Wirén and L. Wittenmayer eds. Plant Nutrition- Food security and sustainability of Agro-ecosystems. Dordrecht: Kluwer Academic Publishers, pp 632-633.

Osborne, L.D. and Z. Rengel. 2002. Genotypic differences in wheat for uptake and utilisation of P from iron phosphate. Australian Journal of Agricultural Research 53 (7), 837-844.

Otani, F., N. Ae, and H. Tanaka. 1996. Uptake mechanisms of crops grown in soils with low P status. II. Significance of organic acids in root exudates of pigeonpea. Soil Science and Plant Nutrition 42, 533-560.

Otani, T. and N. Ae. 1996. Sensitivity of phosphorus uptake to changes in root length and soil volume. Agronomy Journal 88, 371-375.

Otani, T. and N. Ae. 1997. The exudation of organic acids by pigeonpea roots for solubilizing iron- and aluminum-bound phosphorus. In: Ando, T. et al., eds. Plant nutrition for sustainable food and environment. Dordrecht: Kluwer Academic Publisher, pp 325-326.

Otani, T., N. Ae and H. Tanaka. 1996. Phosphorus uptake mechanisms of crop grown in soil with low P status. II. Significance of organic acids in root exudates of pigeonpea. Soil Science and Plant Nutrition 42, 553-560.

Ozawa, K., M. Osaki, H. Matsui, M. Houma and T. Tadano. 1995. Purification and properties of acid phosphatase secreted from lupin roots under phosphorus-deficiency conditions. Soil Science and Plant Nutrition 41, 461-469. 
Parfitt, R.L. 1978. Anion adsorption by soils and soil materials. Advances in Agronomy 30, 150.

Parfitt, R.L. 1979. The availability of $\mathrm{P}$ from phosphate-goethite bridging complexes desorption and uptake by ryegrass. Plant and Soil 53, 55-65.

Parra, C., E. Martinez-Barajas, J. Acosta and P. Coello. 2004. Phosphate deficiency responses of bean genotypes contrasting in their efficiency capacity to grow in lowphosphorus soils. Agrociencia 38 (2), 131-139.

Passioura, J.B. 2002. Soil conditions and plant growth. Plant Cell and Environment 25, 311318.

Pellet, D. and M.A. Elsharkawy. 1993a. Cassava varietal response to phosphorus fertilization. 1. Yield, biomass and gas-exchange. Field Crops Research 35 (1), 1-11.

Pellet, D. and M.A. Elsharkawy. 1993b. Cassava varietal response to phosphorus fertilization. 2. Phosphorus uptake and use efficiency. Field Crops Research 35 (1), 13-20.

Raghothama, K.G. 1999. Phosphate acquisition. Annual Review of Plant Physiology and Plant Molecular Biology 50, 665-693.

Randall, PJ. 1995. Genotypic differences in phosphorus uptake. In: C. Johansen, K.K. Lee, K.K. Sharma, G.V. Subbarao, E.A. Kueneman eds. Genetic Manipulation of Crop Plants to Enhance Integrated Nutrient Management in Cropping Systems - 1. Phosphorus. Patancheru, India: ICRISAT, pp 31-47.

Rao, I.M. 1996. The role of phosphorus in photosynthesis. In: M. Pessarakli, eds. Handbook of Photosynthesis. New York: Marcel Dekker, pp 173-194.

Rao, I.M. and N. Terry. 1989. Leaf phosphate status, photosynthesis and carbon partitioning in sugar beet I. Changes in growth, gas exchange and Calvin cycle enzymes. Plant Physiology 90 (3), 814-819.

Rao, I.M. and N. Terry. 1995. Leaf phosphate status, photosynthesis, and carbon partitioning in sugar beet. IV. Changes with time following increased supply of phosphate to lowphosphate plants. Plant Physiology 107, 1313-1321.

Rao, I.M. and P.C. Kerridge. 1994. Mineral nutrition of forage Arachis. In: P.C. Kerridge, B. Hardy eds. Biology and Agronomy of Forage Arachis. CIAT Publication No. 240, Cali, Colombia: Centro Internacional de Agricultura Tropical, pp 71-83.

Rao, I.M., D.K. Friesen and M. Osaki. 1999c. Plant adaptation to phosphorus-limited tropical soils. In: M. Pessarakli eds. Handbook of plant and crop stress. New York: Marcel Dekker, pp 61-95.

Rao, I.M., D.K. Friesen and W.J. Horst. 1999b. Opportunities for germplasm selection to influence phosphorus acquisition from low-phosphorus soils. Agroforestry Forum, 9 (4), 13-17.

Rao, I.M., M.A. Ayarza and R. Garcia. 1995. Adaptive attributes of tropical forage species to acid soils I. Differences in plant growth, nutrient acquisition and nutrient utilization among $\mathrm{C}_{4}$ and grasses and $\mathrm{C}_{3}$ legumes. Journal of Plant Nutrition 18, 2135-2155.

Rao, I.M., V. Borrero, J. Ricaurte and R. Garcia. 1999a. Adaptive attributes of tropical forage species to acid soils V. Differences in phosphorus acquisition from less available inorganic and organic sources of phosphate. Journal of Plant Nutrition 22, 1175-1196. 
Rao, I.M., V. Borrero, J. Ricaurte, R. Garcia and M.A. Ayarza. 1996. Adaptive attributes of tropical forage species to acid soils II. Differences in shoot and root growth responses to varying phosphorus supply and soil type. Journal of Plant Nutrition 19, 323-352.

Rao, I.M., V. Borrero, J. Ricaurte, R. Garcia and M.A. Ayarza. 1997. Adaptive attributes of tropical forage species to acid soils III. Differences in phosphorus acquisition and utilization as influenced by varying phosphorus supply and soil type. Journal of Plant Nutrition 20, 155-180.

Rao, I.M., V. Borrero, M.A. Ayarza and R. Garcia. 1993. Adaptation of tropical forage species to acid soils: The influence of varying P supply and soil type on P uptake and use. In: N.J. Barrow eds. Plant Nutrition: from genetic engineering to field practice. Dordrecht, the Netherlands: Kluwer Academic Publishers, pp 345-348.

Ratcliffe, R.G. 1994. In vivo NMR-studies of higher-plants and algae. Advances in Botanical Research 20, 43-123.

Ratnayake, M., R.T. Leonard and J.A. Menge. 1978. Root exudation in relation to supply of phosphorus and its possible relevance to mycorrhizal formation. New Phytologist 81, 543-552.

Regvar, M., N. Gogala and P Zalar. 1996. Effects of jasmonic acid on mycorrhizal Allium sativum. New Phytologist 134, 703-707.

Reinhard S., E. Weber, P. Martin and H. Marschner. 1994. Influence of phosphorus supply and light-intensity on mycorrhizal response in Pisum-rhizobium-glomus symbiosis. Experientia 50 (10), 890-896.

Richardson, A.E., P.A. Hadobas and J.E. Hayes. 2001. Extracellular secretion of Aspergillus phytase from Arabidopsis roots enables plants to obtain phosphorus from phytate. Plant Journal 25, 641-649.

Richter, D.D. and L.I. Babbar. 1991. Soil diversity in the tropics. Advances in Ecological Research 21, 316-389.

Ridge, R.W. 1996. Root hairs: Cell biology and development. In: Y. Waisel, A. Eshel, U. Kafkafi eds. Plant roots-the Hidden Half. New York: Marcel Dekker, pp 127-147.

Römer, W., J. Augustin and G. Schilling. 1988. The relationship between phosphate absorption and root-length in nine wheat cultivars. Plant and Soil 111, 199-201.

Rossiter, R.C. 1978. Phosphorus deficiency and flowering in subterranean clover (Tr. subterraneum L.). Annals of Botany 42, 325-329.

Ryan, C.A. 2000. The systemin signaling pathway: Differential activation of plant defensive genes (Review). Biochimica at Biophysica Acta - Protein Structure and Molecular Enzymology 1477, 112-121.

Salinas, J.G. and S.R. Saif. 1990. Nutritional requirements of Andropogon gayanus. In: J.M. Toledo, R. Vera, C. Lascano, J.M. Lenné eds. Andropogon gayanus Kunth: A grass for tropical acid soils. Cali, Colombia: Centro Internacional de Agricultura Tropical (CIAT), pp 99-155.

Salinas, J.G., P.C. Kerridge and R.M. Schunke. 1990. Mineral nutrition of Centrosema. In: R. Schultze-Kraft, R.J. Clements eds. Centrosema: Biology, agronomy and utilization. Cali, Colombia: Centro Internacional de Agricultura Tropical (CIAT), pp 119-149.

Sample, E.C., R.J. Soper and G.J. Racz. 1980. Reactions of phosphate fertilizers in soils. In: Khasawneh, F.E. et al. eds. The Role of Phosphorus in Agriculture. Madison, WI: American Society of Agronomy, pp 263-310. 
Sanchez, P.A. 1976. Properties and management of soils in the tropics. John Wiley and Sons, New York.

Sanchez, P.A. and G. Uehara. 1980. Management considerations for acid soils with high phosphorus fixation capacity. In: F.E. Khasawneh, E.C. Sample, E.J. Kamprath eds. The Role of Phosphorus in Agriculture. Madison, WI: ASA CSSA, SSSA, pp 471-514.

Sanchez, P.A., C.A. Palm and S.W. Buol. 2003. Fertility capability soil classification: a tool to help assess soil quality in the tropics. Geoderma 114 (3-4), 157-185.

Sanchez, P.A., R. Buresh and R. Leakey. 1997. Trees soil, and food security. Phil. Trans. R. Soc. London, UK. B. 352, 949-961.

Sanders, F.E. and B.P. Tinker. 1973. Phosphate flow into mycorrhizal roots. Pesticide Science 4, 385-395.

Sattelmacher, B., H.C. Becker and H. Bruck. 1990. Genotypische Unterschiede in der PEffizienz von Mais (Zea mays L.). Tagungsbericht der 41. Tagung der Vereinigung österreichischer Pflanzenzüchter, pp 139-144.

Sattelmacher, B., W.J. Horst and H.C. Becker. 1994. Factors that contribute to genetic variation for nutrient efficiency of crop plants. Zeitschrift für Pflanzenernährung und Bodenkunde 157, 215-224.

Schachtman, D.P., R.J. Reid and S.M. Ayling. 1998. Phosphorus uptake by plants: from soil to cell. Plant Physiology 116, 447-453.

Schjorring, J.K. and P. Jensen. 1984a. Phosphorus nutrition of barley, buckwheat and rape seedlings. 1. Influence of seed-borne P-levels and external P-levels on growth, P-content and P-32/P-31-fractionation in shoots and roots. Physiologia Plantarum 61 (4), 577-583.

Schjorring, J.K. and P. Jensen. 1984b. Phosphorus nutrition of barley, buckwheat and rape seedlings. 2. Influx and efflux of phosphorus by intact roots of different $p$ status. Physiologia Plantarum 61 (4), 584-590.

Schweiger, P. and J. Jakobsen. 2000. Laboratory and field methods for measurement of hyphal uptake of nutrients in soil. Plant and Soil 226, 237-244.

Shane, M.W., K.W. Dixon and H. Lambers. 2005. The occurrence of dauciform roots amongst Western Australian reeds, rushes and sedges, and the impact of phosphorus supply on dauciform-root development in Schoenus unispiculatus (Cyperaceae). New Phytologist 165, 887-898.

Sharpley, A.N. and S.J. Smith. 1983. Distribution of phosphorus forms in virgin and cultivated soils and potential erosion losses. Soil Science Society of American Journal 47, 581-586.

Shaul-Keinan, O., V. Gadkar, I. Ginzberg, J.M. Grunzweig, I. Chet, Y. Elad, S. Wininger, E. Belausov, Y. Eshed, N. Arzmond, Y. Ben-Tal and Y. Kapulnik. 2002. Hormone concentrations in tobacco roots change during arbuscular mycorrhiza colonization with Glomus intraradices. New Phytologist 154, 501-507.

Sieverding, E. 1991. Vesicular-arbuscular mycorrhiza management in tropical agroecosystems. Deutsche Gesellschaft für Technische Zusammenarbeit (GTZ) GmbH, Germany.

Smith, F.A., I. Jakobsen, and S.E. Smith. 2000. Spatial differences in acquisition of soil phosphate between two arbuscular mycorrhizal fungi in symbiosis with Medicago truncatula. New Phytologist 147, 357-366. 
Smith, F.W., W.A. Jackson and P.J. vanden Berg. 1990. Internal phosphorus flows during development of phosphorus stress in Stylosanthes-hamata. Australian Journal of Plant Physiology 17 (4), 451-464.

Smith, S.E. and D.J. Read. 1997. Mycorrhizal symbiosis. $2^{\text {nd }}$ edn. Cambridge, UK: Academic Press.

Smith, S.E. and V. Gianninazzi-Pearson. 1988. Physiological interactions between symbionts in vesicular-arbuscular mycorrhizal plants. Annual Review of Plant Physiology and Plant Molecular Biology 39, 221-224.

Smyth, T.J. and P.A. Sanchez. 1982. Phosphate rock dissolution and availability in cerrado soils as affected by phosphorus sorption capacity. Soil Science Society of American Journal 46, 339-45.

Snapp, S.S. and J.P. Lynch. 1996. Phosphorus distribution and remobilization in bean plants as influenced by phosphorus nutrition. Crop Science 36 (4), 929-935.

Specht, R.L. and R.H. Groves. 1966. A comparison of the phosphorus nutrition of Australian heath plants and introduced economic plants. Australian Journal of Botany 14 (2), 201221.

Staunton, S. and F. Leprince. 1996. Effect of $\mathrm{pH}$ and some organic anions on the solubility of soil phosphate: Implications for P bioavailability. European Journal of Soil Science 47 (2), 231-239.

Steingrobe, B. and N. Claassen. 2000. Mechanistic simulation models for a better understanding of nutrient uptake from soil. In: Z. Rengel eds. Mineral Nutrition of Crops: Fundamental mechanisms and implications. N. Y. Binghamton: The Haworth Press, Inc., pp 327-367.

Stevenson, F.J. 1986. Cycles of Soil: Carbon, Nitrogen, Phosphorus, Sulfur, Micronutrients. John Wiley \& Sons Inc., New York.

Sylvia, D.M. and S.E. Williams. 1992. Vesicular-arbuscular mycorrhizae and environmental stress. In: Mycorrhizae in sustainable agriculture. ASA Special Publication No. 54. Madison, WI: ASA, CSSA, SSSA, pp 101-124.

Tadano, T. and H. Sakai. 1991. Secretion of acid phosphatase by roots of several crop species under phosphorus-deficient conditions. Soil Science and Plant Nutrition 37, 129-140.

Tadano, T., K. Ozawa, H. Sakai, M. Osaki and H. Matsui. 1993. Secretion of acid phosphatase by roots of crop plants under phosphorus-deficient conditions and some properties of the enzyme secreted by lupin roots. Plant and Soil 156, 95-98.

Tanaka, H., N. Adachi and T. Isoi. 1995. Secretion of formate in phosphorus-deficient nutrient solution from peanut seedlings (Arachis hypogea L.). Soil Science and Plant Nutrition 41 (2), 389-392.

Tarafdar, J.C. and A. Jungk. 1987. Phosphatase-activity in the rhizosphere and its relation to the depletion of soil organic phosphorus. Biology and Fertility of Soils 3, 199-204.

Tarafdar, J.C. and H. Marschner. 1994. Phosphorus activity in the rhizosphere of VAmycorrhizal wheat supplied with inorganic and organic phosphorus. Soil Biology and Biochemistry 26, 387-395.

Tarafdar, J.C. and N. Claassen. 1988. Organic phosphorus compounds as phosphorus source for higher plants through the activity of phosphatase produced by plant root and microorganisms. Biology and Fertility of Soils 5, 308-312. 
Tarafdar, J.C. and N. Claassen. 2003. Organic phosphorus utilization by wheat plants under sterile conditions. Biology and Fertility of Soils 39 (1), 25-29.

Tarafdar, J.C. and P.K. Chhonkar. 1978. Thermal sensitivity and michaelis constants of acid, neutral and alkaline-phosphatases in different soils and root exudates. Zeitschrift Für Pflanzenernährung und Bodenkunde 141, 753-759.

Tate, K.R. 1984. The biological transformation of phosphorus in soil. Plant and Soil 76, 245256.

Temple-Smith, M.G. and R.C. Menary. 1977. Growth and phosphate absorption in lettuce and cabbage plants in dilute-solution culture. Australian Journal Of Plant Physiology 4 (4), 505-513.

Tennant, D. 1975. A test of a modified line intersect method of estimating root length. Journal of Ecology 63, 995-1001.

Tiessen, H., I.H. Salcedo and E.V.S.B. Sampaio. 1992. Nutrient and soil organic matter dynamics under shifting cultivation in semi-arid northeastern Brazil. Agriculture Ecosystems and Environment 38, 139-151.

Tinker, P.B. 1975. Effects of vesicular-arbuscular mycorrhizas on higher plants. In: Symbiosis, Symp. Soc. Exp. Biol. 29. Cambridge: University Press, pp 325-349.

Tinker, P.B. 1978. Effects of vesicular-arbuscular mycorrhizae on plant nutrition and plant growth. Physiologie Vegetale 16, 743-751.

Tinker, P.B., M.D. Jones and D.M. Durall. 1992. A functional comparison of ecto- and endomycorrhizas. In: D.J. Read, D.H. Lewis, A.H. Fitter, I.J. Alexander eds. Mycorrhizas in Ecosystems, pp 303-310.

Tomscha, J.L., M. C. Trull, J. Deikman,3 J.P. Lynch and M.J. Guiltinan. 2004. Phosphatase under-producer mutants have altered phosphorus relations. Plant Physiology 135, 334345.

Torrent, J. 1997. Interaction between phosphate and iron oxide. Advances in Geoecology 30, 321-344.

Traina, S.J., G. Sposito, D. Hesterberg and U. Kafkafi. 1986. Effects of pH and organic acids on orthophosphate solubility in an acidic, montmorillonitic soil. Soil Science Society of American Journal 50, 45-52.

Trehan, S.P. and N. Claassen. 1998. External K requirement of young plants of potato, sugar beet and wheat in flowing solution culture resulting from different internal requirements and uptake efficiency. Potato Research 41 (3), 229-237.

Trolove, S.N., M.J. Hedely, J.R. Caradus and A.D. Mackay. 1996. Uptake of phosphorus from different sources by Lotus pedunculatus and three genotypes of Trifolium repens. 1. Plant and yield and phosphate efficiency. Australian Journal of Soil Research 34 (6), 1015-1026.

Trolove, S.N., M.J. Hedley, G.J.D. Kirk, N.S. Bolan and P. Loganathan. 2003. Progress in selected areas of rhizosphere research on $\mathrm{P}$ acquisition. Australian Journal of Soil Research 41 (3), 471-499.

Unger, P.W. and T. Kaspar. 1994. Soil compaction and root growth: A review. Agronomy Journal 86, 759-766.

Uren, N.C. and H. M. Reisenauer. 1988. The role of root exudates in nutrient acquisition. Advances in Plant Nutrition. 3, 79-114. 
Van Wambeke, A. 1991. Soils of the Tropics: Properties and Appraisal. New York: McGrawHill, Inc.

Vance, C.P., C. Uhde-Stone and D.L. Allan. 2003. Phosphorus acquisition and use: critical adaptations by plants for securing a nonrenewable resource. New Phytologist 157, 423447.

Veneklaas E.J., J. Stevens, G.R. Cawthray, S. Turner, A.M. Grigg and H. Lambers. 2003. Chickpea and white lupin rhizosphere carboxylates vary with soil properties and enhance phosphorus uptake. Plant and Soil 248, 187-197.

Viebrock, H. 1988. Ursachen der Erhöhung des Phophat-Aneignungsvermögens von Pflanzen durch VA-Mykorrhiza. Ph.D. Thesis. Georg August University of Göttingen, Germany.

Vielhauer, K. 1992. Investigation on the role of phosphatases in the P uptake mechanism of VA-mycorrhizal roots. Ph.D. Thesis. In: Göttinger Beiträge zur Land- und Forstwirtschaft in den Tropen und Subtropen, Heft 74, pp 175.

Vincent, J.B., M.W. Crowder and B.A. Averill. 1992. Hydrolysis of phosphate monoesters: a biological problem with multiple chemical solutions. Trends in Biochemical Science 17 (3), 105-110.

Vincent, J.M. 1982. Nitrogen fixation in legumes. Academic Press, Australia.

Vlek, P.L.G. and H. Koch. 1992. "The Soil Resource Base and Food Production in the Developing World: Special Focus on Africa". In: Göttinger Beiträge zur Land- und Forstwirtschaft in den Tropen und Subtropen, Heft 71, pp 139-160.

Von Uexküll, H.R. and E. Mutert. 1995. Global extent, development and economic impact of acid soils. Plant and Soil 171, 1-15.

Walker, T.W. and J.K. Syers. 1976. The fate of phosphorus during pedogenesis. Geoderma 15 (1), 1-19.

Wang, Q.R., J.Y. Li, Z.S. Li and P. Christie. 2005. Screening Chinese wheat germplasm for phosphorus efficiency in calcareous soils. Journal of Plant Nutrition, 28, 489-505.

Wasternack, C. and B. Hause. 2002. Jasmonates and octadecanoids: Signals in plant stress responses and development. Progress in Nucleic Acids Research and Molecular Biology 72, 165-221.

Welbank, P.J., M.J. Gibb, P.J. Taylor and E.D. Williams. 1973. Root growth of cereal crops. Rep Rothamsted Exp Stn 2, 26-66.

Whiteaker, G., G.C. Gerloff, W.H. Gabelman and D. Lindgren. 1976. Intraspecific differences in growth of beans at stress levels of phosphorus. Journal of the American Society for Horticultural Science 101 (4), 472-475.

Wilcox, H.E. 1991. Mycorrhizae. In: M.Y. Waisel, A. Eshel, U. Kafkafi eds. Plant roots: the hidden half. New York: Marcel Dekker, pp 731-755.

Wild, A. 1988. Plant nutrients in soil: phosphate. In: A. Wild ed. Russell's Soil Conditions and Plant Growth. $11^{\text {th }}$ ed. Essex, England: Longman Scientific and Technical, pp 695-742.

Williams, R.F. 1946. The physiology of plant growth with special reference to the concept of net assimilation rate. Annals of Botany 10 (37), 41-72.

World Bank. 1994. Role of phosphorus in agriculture. In: Feasibility of phosphate rock as a capital investment in sub-Saharan Africa. Issues and opportunities. World Bank/IFA/MIGA, pp 9-37. 
Yan, X.L., J.P. Lynch and S.E. Beebe. 1996. Utilization of phosphorus substrates by contrasting common bean genotypes. Crop Science 36, 936-941.

Yost, R.S., G.C. Naderman, E.J. Kamprath and E. Lobata. 1982. Availability of rock phosphate as measured by an acid-tolerant pasture grass and extractable phosphorus. Agronomy Journal 74 (3), 462-468.

Zeigler, H. 1990. Role of plant physiology in assessing productivity potential under stress environment. In: S.K. Sinha, P.V. Sane, S.C. Bhargava, P.K. Agrawal eds. Proceedings of the International Congress of Plant Physiology. Vol. 1. New Dehli, India: pp 10-17.

Zhang, F.S., J. Ma and Y.P. Cao. 1997. Phosphorus deficiency enhances root exudation of low-molecular weight organic acids and utilization of sparingly soluble inorganic phosphates by radish (Raghanus sativus L.) and rape (Brassica napus L.) plants. Plant and Soil 196, 261-264.

Zhang, Y., N. Kallay and E. Matijevic. 1985. Interaction of metal hydrous oxides with chelating agents. VII. Hematite-oxalic and hematite-citric acid systems. Langmuir 1 (2), 201-206. 


\section{Appendix}

\section{Chapter 2}

Influence of $\mathrm{P}$ fertilisation $\left(\mathrm{mg} \mathrm{kg}^{-1}\right)$ on $\mathrm{P}$ concentration and $\mathrm{P}$ content in shoot 75 days after establishment (DAE).

\begin{tabular}{|c|c|c|c|c|c|c|c|c|}
\hline \multirow[t]{3}{*}{ Genotype } & \multicolumn{4}{|c|}{$\mathrm{P}$ concentration, $\mathrm{mg} \mathrm{g}^{-1}$} & \multicolumn{4}{|c|}{$\mathrm{P}$ content, mg plant ${ }^{-1}$} \\
\hline & \multicolumn{2}{|c|}{ Shoot } & \multicolumn{2}{|c|}{ Root } & \multicolumn{2}{|c|}{ Shoot } & \multicolumn{2}{|c|}{ Root } \\
\hline & $10 \mathrm{P}$ & $400 \mathrm{P}$ & $10 \mathrm{P}$ & $400 \mathrm{P}$ & $10 \mathrm{P}$ & $400 \mathrm{P}$ & $10 \mathrm{P}$ & $400 \mathrm{P}$ \\
\hline 2 & $1.5 \mathrm{a}$ & $2.6 \mathrm{a}$ & $1.4 \mathrm{abc}$ & $2.4 \mathrm{a}$ & $5.1 \mathrm{a}$ & $10.7 \mathrm{a}$ & $1.3 \mathrm{bcd}$ & $2.4 \mathrm{a}$ \\
\hline 6 & $1.0 \mathrm{~b}$ & & $1.6 \mathrm{ab}$ & & $2.7 \mathrm{~d}$ & & $1.4 \mathrm{abc}$ & \\
\hline 1 & $1.6 \mathrm{a}$ & $1.9 \mathrm{~b}$ & $1.5 \mathrm{ab}$ & $2.3 \mathrm{a}$ & $4.0 \mathrm{abcd}$ & $8.7 \mathrm{~b}$ & $1.7 \mathrm{ab}$ & $3.1 \mathrm{a}$ \\
\hline 10 & $1.3 \mathrm{ab}$ & $1.7 \mathrm{~b}$ & $1.3 \mathrm{abc}$ & $2.1 \mathrm{a}$ & $4.2 \mathrm{abc}$ & $7.2 \mathrm{~b}$ & $1.4 \mathrm{abc}$ & $2.3 \mathrm{a}$ \\
\hline 4 & $1.3 \mathrm{ab}$ & $2.0 \mathrm{~b}$ & $1.3 \mathrm{abc}$ & $2.0 \mathrm{a}$ & $3.3 \mathrm{~cd}$ & $8.0 \mathrm{~b}$ & $0.9 \mathrm{~d}$ & $2.1 \mathrm{a}$ \\
\hline 8 & $1.4 \mathrm{ab}$ & & $1.4 \mathrm{abc}$ & & $4.6 \mathrm{abc}$ & & $1.9 \mathrm{a}$ & \\
\hline 9 & $1.1 \mathrm{~b}$ & & $1.1 \mathrm{c}$ & & $3.3 \mathrm{~cd}$ & & $0.9 \mathrm{~d}$ & \\
\hline 3 & $1.4 \mathrm{ab}$ & & $1.3 \mathrm{abc}$ & & $4.7 \mathrm{ab}$ & & $1.1 \mathrm{dc}$ & \\
\hline 5 & $1.2 \mathrm{ab}$ & & $1.6 \mathrm{a}$ & & $3.7 \mathrm{bcd}$ & & $1.5 \mathrm{abc}$ & \\
\hline 7 & $1.3 \mathrm{ab}$ & & $1.2 \mathrm{bc}$ & & $3.5 \mathrm{bcd}$ & & $1.2 \mathrm{dc}$ & \\
\hline $\bar{X}$ & 1.3 & 2.1 & 1.4 & 2.2 & 3.9 & 8.6 & 1.3 & 2.5 \\
\hline
\end{tabular}

Within a treatment, values followed by the same letters are not statistically different according to the Tukey mean test $(\mathrm{p}<0.05)$.

Influence of $\mathrm{P}$ fertilisation ( $\mathrm{mg} \mathrm{kg}^{-1}$ ) on root length 75 days after establishment (DAE).

\begin{tabular}{cccc}
\hline Genotype & \multicolumn{3}{c}{ Root length, m plant ${ }^{-1}$} \\
\cline { 2 - 4 } & $0 \mathrm{P}$ & $10 \mathrm{P}$ & $400 \mathrm{P}$ \\
\hline 2 & $58.4 \mathrm{bc}$ & $62.5 \mathrm{c}$ & $84.2 \mathrm{c}$ \\
6 & $90.1 \mathrm{a}$ & $78.0 \mathrm{bc}$ & \\
1 & $55.4 \mathrm{c}$ & $88.5 \mathrm{ab}$ & $120.7 \mathrm{ab}$ \\
10 & $76.5 \mathrm{abc}$ & $73.0 \mathrm{bc}$ & $102.4 \mathrm{bc}$ \\
4 & $83.2 \mathrm{ab}$ & $77.6 \mathrm{bc}$ & $134.6 \mathrm{a}$ \\
8 & $102.6 \mathrm{a}$ & $98.2 \mathrm{a}$ & \\
9 & $80.6 \mathrm{abc}$ & $77.8 \mathrm{bc}$ & \\
3 & $99.2 \mathrm{a}$ & $87.5 \mathrm{ab}$ & \\
5 & $75.8 \mathrm{abc}$ & $74.6 \mathrm{bc}$ & \\
7 & $92.6 \mathrm{a}$ & $92.1 \mathrm{ab}$ & \\
$\bar{X}$ & 81.4 & 81.0 & 110.5 \\
\hline
\end{tabular}

Within a treatment, values followed by the same letters are not statistically different according to the Tukey mean test $(\mathrm{p}<0.05)$. 


\section{Chapter 3}

Influence of varying $\mathrm{P}$ supply of phosphate rock (PR) and triple superphosphate (TSP) and AMF on the overall mean of extractable P-Bray II from planted and unplanted soils and $\mathrm{PH}_{(\mathrm{H} 2 \mathrm{O})}$ in soil at 45 and 90 days after transplanting (DAT).

\begin{tabular}{|c|c|c|c|c|c|}
\hline \multirow{2}{*}{$\begin{array}{c}\text { P level } \\
\mathrm{mg} \mathrm{P} \mathrm{kg}^{-1}\end{array}$} & \multirow[t]{2}{*}{ Soil } & \multicolumn{2}{|c|}{$\mathrm{PH}_{(\mathrm{H} 2 \mathrm{O})}$} & \multicolumn{2}{|c|}{ P-Bray II, mg P kg-1 } \\
\hline & & $-\mathrm{AMF}$ & $+\mathrm{AMF}$ & $-\mathrm{AMF}$ & $+\mathrm{AMF}$ \\
\hline & & & - & 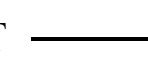 & \\
\hline \multirow[t]{2}{*}{$0 \mathrm{P}$} & planted & $4.0 \mathrm{ab}$ & $3.9 \mathrm{a}$ & $7.9 c$ & $10.2 b$ \\
\hline & unplanted & $3.9 b$ & & $7.5 \mathrm{c}$ & \\
\hline \multirow[t]{2}{*}{$20 \mathrm{PR}$} & planted & $3.9 b$ & $3.9 \mathrm{a}$ & $13.9 \mathrm{a}$ & $13.2 \mathrm{a}$ \\
\hline & unplanted & $4.3 \mathrm{a}$ & & $14.9 \mathrm{a}$ & \\
\hline \multirow[t]{2}{*}{4 TSP } & planted & $4.0 \mathrm{~b}$ & $3.9 \mathrm{a}$ & $9.2 \mathrm{~b}$ & $8.6 \mathrm{c}$ \\
\hline & unplanted & $4.0 \mathrm{ab}$ & & $10.3 b$ & \\
\hline \multirow[t]{2}{*}{$0 \mathrm{P}$} & planted & $4.2 \mathrm{ab}$ & $4.1 \mathrm{~b}$ & $6.4 \mathrm{c}$ & $6.4 b$ \\
\hline & unplanted & $4.3 \mathrm{a}$ & & $6.9 \mathrm{bc}$ & \\
\hline \multirow[t]{2}{*}{$20 \mathrm{PR}$} & planted & $4.2 \mathrm{ab}$ & $4.2 \mathrm{~b}$ & $10.1 \mathrm{a}$ & $8.6 \mathrm{a}$ \\
\hline & unplanted & $4.3 \mathrm{a}$ & & $10.7 \mathrm{a}$ & \\
\hline \multirow[t]{2}{*}{4 TSP } & planted & $4.3 \mathrm{a}$ & $4.2 \mathrm{a}$ & $7.2 \mathrm{~b}$ & $6.6 b$ \\
\hline & unplanted & $4.1 \mathrm{~b}$ & & $7.5 b$ & \\
\hline
\end{tabular}

Among P treatments of planted and unplanted soil within a AMF level, values followed by the same letters are not significantly different after pdiff-test $(p<0.05)$. 
Influence of varying P supply of phosphate rock (PR) and triple superphosphate (TSP) and AMF on the internal APase activity in root after 45 and 90 days of transplanting (DAT).

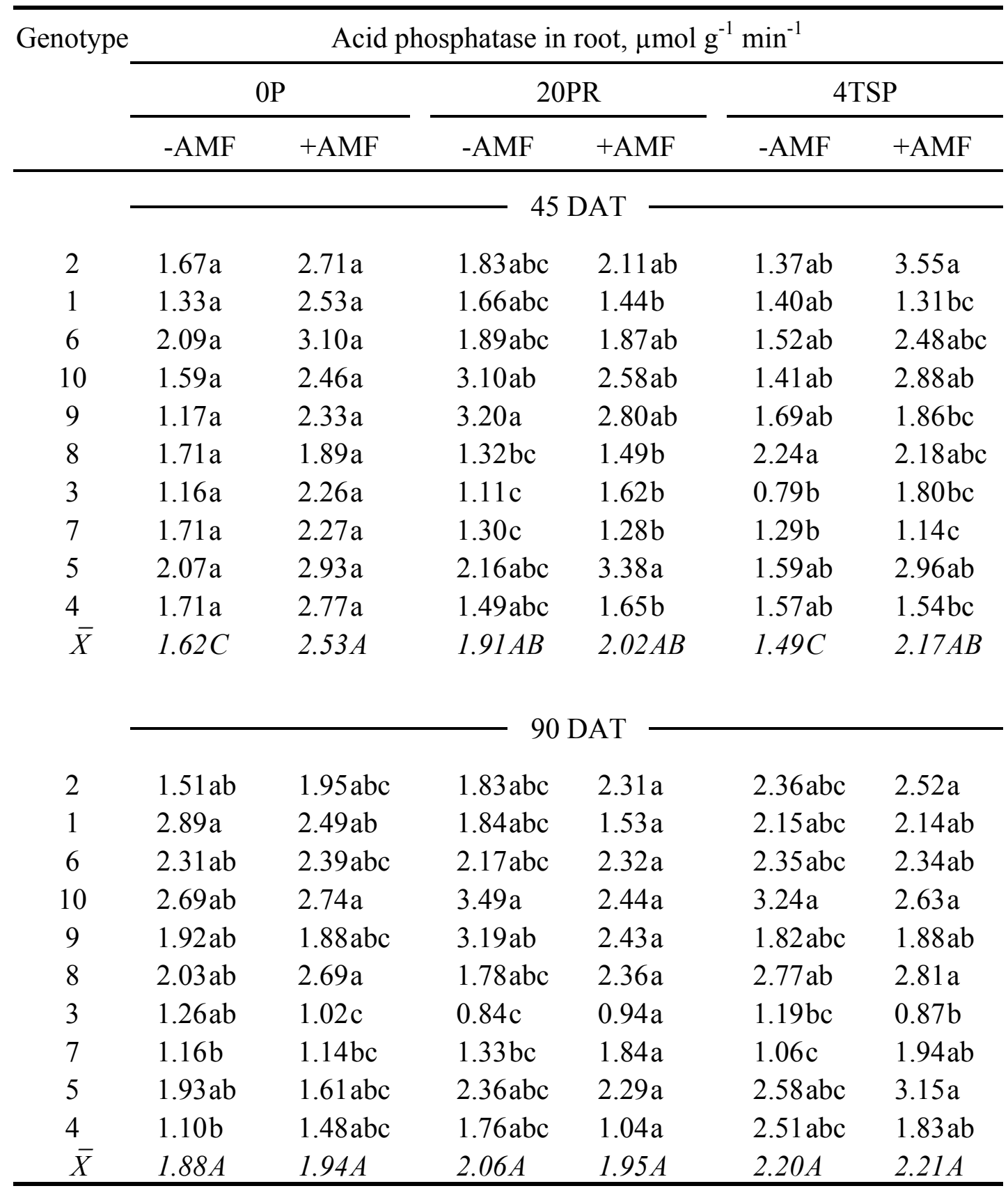

Within a treatment, values that are followed by the same letter are not significantly different according the pdiff-test $(\mathrm{p}<0.05)$.

* No significant differences between $-\mathrm{AMF}$ and $+\mathrm{AMF}$ by treatment after pdiff-test $(\mathrm{p}<0.05)$. 


\section{Chapter 4}

Influence of varying $\mathrm{P}$ supply on root length of three genotypes of Arachis pintoi and one Arachis hypogea $(A h)$ at 30,60 and 90 days after establishment (DAE).

\begin{tabular}{|c|c|c|c|c|c|c|c|c|c|}
\hline \multirow[t]{3}{*}{ Genotype } & \multicolumn{9}{|c|}{ Root length, m plant ${ }^{-1}$} \\
\hline & \multicolumn{3}{|c|}{$30 \mathrm{DAE}$} & \multicolumn{3}{|c|}{$60 \mathrm{DAE}$} & \multicolumn{3}{|c|}{$90 \mathrm{DAE}$} \\
\hline & OP & $50 \mathrm{P}$ & 1000P & $0 \mathrm{P}$ & $50 \mathrm{P}$ & $1000 \mathrm{P}$ & $0 \mathrm{P}$ & $50 \mathrm{P}$ & $1000 \mathrm{P}$ \\
\hline$A h$ & $123 \mathrm{a}^{\mathrm{A}}$ & $95 \mathrm{a}^{\mathrm{AB}}$ & $69 a^{B}$ & $138 \mathrm{a}^{\mathrm{A}}$ & $115 \mathrm{a}^{\mathrm{AB}}$ & $105 \mathrm{a}^{\mathrm{B}}$ & $152 \mathrm{a}^{\mathrm{A}}$ & $138 a^{A}$ & $132 \mathrm{a}^{\mathrm{A}}$ \\
\hline 2 & $50 b^{A}$ & $46 b^{A}$ & $40 b^{A}$ & $84 b^{A}$ & $94 a b^{A}$ & $93 a b^{A}$ & $131 \mathrm{ab}^{\mathrm{A}}$ & $142 a^{A}$ & $103 \mathrm{cb}^{\mathrm{B}}$ \\
\hline 10 & $54 b^{\mathrm{A}}$ & $43 b^{\mathrm{AB}}$ & $36 b^{\mathrm{B}}$ & $79 b^{A}$ & $78 b^{A}$ & $66 c^{A}$ & $94 b^{A}$ & $95 \mathrm{a}^{\mathrm{A}}$ & $78 c^{A}$ \\
\hline 1 & $41 b^{A}$ & $41 b^{A}$ & $36 b^{A}$ & $71 b^{A}$ & $88 \mathrm{ab}^{\mathrm{A}}$ & $71 \mathrm{cb}^{\mathrm{A}}$ & $134 \mathrm{a}^{\mathrm{A}}$ & $154 a^{A}$ & $130 a b^{A}$ \\
\hline
\end{tabular}

Within a treatment, values that are followed by the same letter are not significantly different after Tukey-test $(p<0.05)$. Among the treatments, values of one genotype marked with the same capital letter are not significantly different after Tukey-test $(\mathrm{p}<0.05)$.

Influence of varying $\mathrm{P}$ supply on the root growth rate (GRr) and the relative (RGRr) of three genotypes of Arachis pintoi and one of Arachis hypogea (Ah) between 30-60 and 60-90 days after establishment (DAE)

\begin{tabular}{|c|c|c|c|c|c|c|}
\hline \multirow[t]{2}{*}{ Genotype } & \multicolumn{3}{|c|}{30 - 60 days } & \multicolumn{3}{|c|}{60 - 90 days } \\
\hline & $0 \mathrm{P}$ & $50 \mathrm{P}$ & $1000 \mathrm{P}$ & $0 \mathrm{P}$ & $50 \mathrm{P}$ & $1000 \mathrm{P}$ \\
\hline$A h$ & $0.6 \mathrm{a}^{\mathrm{B}}$ & $0.8 \mathrm{a}^{\mathrm{AB}}$ & $1.4 \mathrm{a}^{\mathrm{A}}$ & $0.6 b^{A}$ & $0.9 \mathrm{a}^{\mathrm{A}}$ & $1.1 \mathrm{~b}^{\mathrm{A}}$ \\
\hline 2 & $1.3 \mathrm{a}^{\mathrm{B}}$ & $1.9 \mathrm{a}^{\mathrm{A}}$ & $2.0 \mathrm{a}^{\mathrm{A}}$ & $1.8 \mathrm{ab}^{\mathrm{A}}$ & $1.9 \mathrm{a}^{\mathrm{A}}$ & $0.4 b^{\mathrm{A}}$ \\
\hline 10 & $0.9 \mathrm{a}^{\mathrm{B}}$ & $1.4 \mathrm{a}^{\mathrm{A}}$ & $1.2 \mathrm{a}^{\mathrm{A}}$ & $0.6 b^{A}$ & $0.6 \mathrm{a}^{\mathrm{A}}$ & $0.5 b^{\mathrm{A}}$ \\
\hline 1 & $1.2 \mathrm{a}^{\mathrm{B}}$ & $1.8 \mathrm{a}^{\mathrm{B}}$ & $1.4 \mathrm{a}^{\mathrm{A}}$ & $2.4 \mathrm{a}^{\mathrm{B}}$ & $2.6 \mathrm{a}^{\mathrm{A}}$ & $2.3 \mathrm{a}^{\mathrm{A}}$ \\
\hline
\end{tabular}

Within a treatment, values that are followed by the same letter are not significantly different after Tukey-test $(\mathrm{p}<0.05)$. Among the treatments, values of one genotype marked with the same capital letter are not significantly different after Tukey-test $(\mathrm{p}<0.05)$. 


\section{Chapter 5}

Influence of different $\mathrm{P}$ supply on total $\mathrm{P}$ use efficiency (shoot and root) of two Arachis pintoi genotypes at 30,60 and 100 days after transplanting (DAT).

\begin{tabular}{|c|c|c|c|c|c|c|}
\hline \multirow[t]{3}{*}{ Genotype } & \multicolumn{6}{|c|}{$\mathrm{P}$ use efficiency, $\mathrm{g} \mathrm{mg}^{-1}$} \\
\hline & \multicolumn{2}{|c|}{$30 \mathrm{DAT}$} & \multicolumn{2}{|c|}{$60 \mathrm{DAT}$} & \multicolumn{2}{|c|}{$100 \mathrm{DAT}$} \\
\hline & OP & $1000 \mathrm{P}$ & $0 \mathrm{P}$ & $1000 \mathrm{P}$ & $\mathrm{OP}$ & $1000 \mathrm{P}$ \\
\hline 2 & $0.56 b^{A}$ & $0.12 \mathrm{a}^{\mathrm{B}}$ & $0.62 \mathrm{a}^{\mathrm{A}}$ & $0.19 \mathrm{a}^{\mathrm{B}}$ & $0.56 \mathrm{a}^{\mathrm{A}}$ & $0.29 \mathrm{a}^{\mathrm{B}}$ \\
\hline 1 & $0.65 \mathrm{a}^{\mathrm{A}}$ & $0.13 \mathrm{a}^{\mathrm{B}}$ & $0.65 \mathrm{a}^{\mathrm{A}}$ & $0.18 \mathrm{a}^{\mathrm{B}}$ & $0.49 b^{\mathrm{A}}$ & $0.27 \mathrm{a}^{\mathrm{B}}$ \\
\hline
\end{tabular}

Within a treatment, values that are followed by the same letter are not statistically significant according to the Tukey-test $(\mathrm{p}<0.05)$. Among the treatments, values of one genotype marked with the same capital letter are not significantly different after Tukey-test $(p<0.05)$.

Influence of different P supply on the root length of two Arachis pintoi genotypes at 30,60 and 100 days after transplanting (DAT).

\begin{tabular}{|c|c|c|c|c|c|c|}
\hline \multirow[t]{3}{*}{ Genotype } & \multicolumn{6}{|c|}{ Root length, m } \\
\hline & \multicolumn{2}{|c|}{$30 \mathrm{DAT}$} & \multicolumn{2}{|c|}{$60 \mathrm{DAT}$} & \multicolumn{2}{|c|}{$100 \mathrm{DAT}$} \\
\hline & OP & $1000 \mathrm{P}$ & OP & $1000 \mathrm{P}$ & OP & $1000 \mathrm{P}$ \\
\hline 2 & $27.2 \mathrm{a}^{\mathrm{B}}$ & $58.6 \mathrm{a}^{\mathrm{A}}$ & $36.3 \mathrm{a}^{\mathrm{B}}$ & $64.9 \mathrm{a}^{\mathrm{A}}$ & $64.8 \mathrm{a}^{\mathrm{B}}$ & $96.1 \mathrm{a}^{\mathrm{A}}$ \\
\hline 1 & $24.7 \mathrm{a}^{\mathrm{B}}$ & $49.8 b^{A}$ & $33.9 \mathrm{a}^{\mathrm{B}}$ & $58.4 \mathrm{a}^{\mathrm{A}}$ & $34.3 b^{\mathrm{B}}$ & $102.3 \mathrm{a}^{\mathrm{A}}$ \\
\hline
\end{tabular}

Within a treatment, values that are followed by the same letter are not statistically significant according to the Tukey-test $(\mathrm{p}<0.05)$. Among the treatments, values of one genotype marked with the same capital letter are not significantly different after Tukey-test $(p<0.05)$. 
Influence of different $\mathrm{P}$ supply on $\mathrm{pH}$ and extractable $\mathrm{P}$ of the soil of two Arachis pintoi genotypes at 30, 60 and 100 days after transplanting (DAT).

\begin{tabular}{|c|c|c|c|c|}
\hline \multirow[t]{2}{*}{ Genotype } & \multicolumn{2}{|c|}{ P-CAL, mg kg-1 } & \multicolumn{2}{|c|}{ P-Bray II, mg kg ${ }^{-1}$} \\
\hline & $\mathrm{OP}$ & $1000 \mathrm{P}$ & $0 \mathrm{P}$ & $1000 \mathrm{P}$ \\
\hline & \multicolumn{4}{|c|}{$30 \mathrm{DAT}$} \\
\hline 2 & $2.9 b$ & $103 b$ & $5.0 \mathrm{a}$ & $176 b$ \\
\hline 1 & $3.0 \mathrm{a}$ & $118 \mathrm{a}$ & $5.1 \mathrm{a}$ & $193 a$ \\
\hline \multirow[t]{2}{*}{ unplanted } & $3.0 \mathrm{a}$ & $120 \mathrm{a}$ & $4.9 \mathrm{a}$ & $196 a$ \\
\hline & \multicolumn{4}{|c|}{$60 \mathrm{DAT}$} \\
\hline 2 & $2.7 \mathrm{a}$ & $95 a$ & $4.7 b$ & $158 b$ \\
\hline 1 & $3.0 \mathrm{a}$ & $87 b$ & $4.9 b$ & $162 b$ \\
\hline \multirow[t]{2}{*}{ unplanted } & $2.9 \mathrm{a}$ & $88 \mathrm{ab}$ & $4.9 \mathrm{a}$ & $203 a$ \\
\hline & \multicolumn{4}{|c|}{$100 \mathrm{DAT}$} \\
\hline 2 & $2.4 \mathrm{~b}$ & $81 b$ & $4.1 b$ & $135 b$ \\
\hline 1 & $2.6 \mathrm{a}$ & $81 b$ & $4.6 \mathrm{ab}$ & $140 \mathrm{~b}$ \\
\hline unplanted & $2.9 \mathrm{~b}$ & $90 \mathrm{a}$ & $4.8 \mathrm{a}$ & $182 \mathrm{a}$ \\
\hline
\end{tabular}

Within a treatment, values that are followed by the same letter are not statistically significant according to the Tukey-test $(\mathrm{p}<0.05)$. 


\section{Acknowledgments}

I wish to express my gratitude to the German Academic Exchange Service (DAAD), the International Center for Tropical Agriculture (CIAT) and the Institute of Agricultural Chemistry in Göttingen for the financial support for this research.

I am especially indebted to my supervisor Prof. Dr. Norbert Claassen and I am extremely grateful to Dr. Bernd Steingrobe. I would like to thank you for your guidance and scientific support on this work as well as for entrusting me to develop this research on my own. I also want to thank Prof. Dr. Heiko C. Becker for kindly accepting to be the co-supervisor of my thesis. My gratitude is extended to Prof. Dr. Achim Spiller and Prof. Dr. Teja Tscharntke for their willingness to be a member of the examination board.

I am grateful to all the staff of the Institute of Agricultural Chemistry. Specially thanks to Prof. Dr. Wilhelm Römer, Marlies Niebuhr, Susanne Koch, Birgit Eichenberg, Reinhard Hilmer, Jürgen Kobbe and Martina Noltkämper. I also want to thank all my colleagues in the institute for their friendship, particularly to Dr. Alexander zu Dreele, for his feedback and time invested in reading my work.

I would like to thank Dr. Idupulapati Rao for his scientific support and also the technical staff at CIAT for their kind cooperation, with special thanks to Ramiro Garcia, Jaumer Ricaurte, Jenny Quintero, Claudia Rojas, Isled Hernández, Jarden Molina, Martín Otero and Luis A. López.

I am also extremely grateful to my friend Richard Varela for his unconditional support with the English correction. Thanks are extended to my brother Leonel Castañeda Ortiz for his productive discussion and feedback as well as to my brothers Edgar and Reinel Castañeda Ortiz for their collaboration with several tasks in the laboratory.

During the research as well as with the subsequent work, my wife Viviane and later on my sons Daniel and Raphael had to spend a lot of time on their own. Their absence and their humble patience in waiting for me during these years have made me realize more than ever how much they mean to me. They have given me the power and determination to carry out my work and it is to them that I dedicate this dissertation.

This dissertation marks the end of a phase in my life, which began in a small and unknown town located in a valley between the mountain ranges that cross Colombia. There, my parents made tremendous sacrifices to ensure that I received a good education. For this and much more, I am forever in their debt. 


\section{Curriculum Vitae}

Personal Data $\quad$ Nelson Castañeda Ortiz

Born September $23^{\text {th }}, 1967$ in Palermo - Colombia

Married with two children

\section{$\underline{\text { Education }}$}

Since 2001

$1993-1996$

$\mathrm{PhD}$ study in plant nutrition, Georg August University of Göttingen Germany - Institute of Agricultural Chemestry, Prof. Dr. N. Claassen.

Magister Scientiarum Agrariarum (M.Sc.agr.) study, Georg August University of Göttingen - Germany.

Specialization: Plant nutrition and Rural socio economy.

$1978-1983$

Agricultural Engineer study, Surcolombiana University of Neiva Colombia.

Specialization: Soil sciences and Rural construction.

$1978-1983$

Secondary school, "Colégio INEM - Julian Motta Salas“, Neiva Colombia.

\section{Work Experience}

2000

$1998-1999$

Research assistant, Institut for Agriculture Technique Bornim e.V., Potsdam, Germany.

Guest researcher, International Center for Tropical Agriculture (CIAT), Colombia.

Guest researcher, International Center for Tropical Agriculture (CIAT), Colombia.

$1992-1993$

Public Works Head, Municipality of Palermo, Colombia.

$1991-1992$

Assistant researcher, Faculty of Engineering - Surcolombiana University, Colombia.

$1989-1989 \quad$ Laboratory assistant, Faculty of Engineering - Surcolombiana University, Colombia.

$1988-1989 \quad$ Laboratory assistant, Faculty of Engineering - Surcolombiana University, Colombia.

\section{Advanced Training}

$2004-2005$

Training at Agricultural Advisory Department, $\mathrm{K}+\mathrm{S}$ Kali GmbH company.

$2002-2003$

Business English, Economics Technical Language, Universität Göttingen. 